\title{
Technology I, II, and III: Criteria for Understanding and Improving the Practice of Instructional Technology
}

Jason K. McDonald

Brigham Young University - Provo

Follow this and additional works at: https://scholarsarchive.byu.edu/etd

Part of the Educational Psychology Commons

\section{BYU ScholarsArchive Citation}

McDonald, Jason K., "Technology I, II, and III: Criteria for Understanding and Improving the Practice of Instructional Technology" (2006). Theses and Dissertations. 1092.

https://scholarsarchive.byu.edu/etd/1092

This Dissertation is brought to you for free and open access by BYU ScholarsArchive. It has been accepted for inclusion in Theses and Dissertations by an authorized administrator of BYU ScholarsArchive. For more information, please contact scholarsarchive@byu.edu, ellen_amatangelo@byu.edu. 
TECHNOLOGY I, II, AND III: CRITERIA FOR UNDERSTANDING AND IMPROVING THE PRACTICE OF INSTRUCTIONAL TECHNOLOGY

by

Jason K. McDonald

\begin{abstract}
A dissertation submitted to the faculty of
Brigham Young University

in partial fulfillment of the requirements for the degree of
\end{abstract}

Doctor of Philosophy

Department of Instructional Psychology and Technology

Brigham Young University

December 2006 
Copyright (C) 2006 Jason K. McDonald

All Rights Reserved 


\section{BRIGHAM YOUNG UNIVERSITY}

\section{GRADUATE COMMITTEE APPROVAL}

of a dissertation submitted by

Jason K. McDonald

This dissertation has been read by each member of the following graduate committee and by majority vote has been found to be satisfactory.

Date

Date

Date

Date

Date
Andrew S. Gibbons, Chair

Charles R. Graham

David D. Williams

Brent G. Wilson

Stephen C. Yanchar 


\section{BRIGHAM YOUNG UNIVERSITY}

As chair of the candidate's graduate committee, I have read the dissertation of Jason K. McDonald in its final form and have found that (1) its format, citations, and bibliographical style are consistent and acceptable and fulfill university and department style requirements; (2) its illustrative materials including figures, tables, and charts are in place; and (3) the final manuscript is satisfactory to the graduate committee and is ready for submission to the university library.

Date

Andrew S. Gibbons

Chair, Graduate Committee

Accepted for the Department

Andrew S. Gibbons

Department Chair

Accepted for the College

K. Richard Young

Dean, David O. McKay School of Education 


\begin{abstract}
TECHNOLOGY I, II, AND III: CRITERIA FOR UNDERSTANDING AND IMPROVING THE PRACTICE OF INSTRUCTIONAL TECHNOLOGY
\end{abstract}

\author{
Jason K. McDonald \\ Department of Instructional Psychology and Technology \\ Doctor of Philosophy
}

In an earlier era of instructional technology, researchers proposed a set of criteria to help practitioners understand what assumptions about their work could help them develop well-designed instruction, as well as what assumptions could lead them to develop rigid instruction that did not characterize the goals they had for their practice. They named these criteria Technology I, II, and III. Technology I presupposed that using physical hardware improved instruction. Technology II presupposed that using formulas or strategies improved instruction. Technology III was the belief that good instruction could consist of many different product or process technologies, but that technology use alone did not define good instruction. Rather, good instruction was the realization of improved systems in which learning could take place.

I used a historical case study method to analyze the major themes of Technology I, II, and III, as well as reasons why some practitioners might limit themselves to only 
Technology I or II. My purpose was to discover how to help instructional technologists better accomplish more of the goals they want to achieve. I compared the original goals of two instructional technologies (programmed instruction and problem-based learning), along with twelve case study reports of actual practice of these technologies, against the criteria for Technology I, II, and III. I found that Technology I, II, and III can describe the goals and practices of instructional technologists. Additionally, I discovered four reasons why instructional technologists may limit themselves to Technology I or II, and therefore might not achieve all the important goals for their practice: (a) distracted focus (or compromised integrity); (b) status quo adherence; (c) solidification; and (d) deliberately chosen Technology I or II. I also discovered three methods to help instructional technologists to avoid limiting themselves and more consistently practice Technology III: (a) legitimate evaluation; (b) adopting guiding principles for practice; and (c) using opinion leaders to disseminate the value of Technology III. This study also provides recommendations to help instructional technologists use Technology III to help them better develop flexible instructional technology that better characterizes their goals for their practice. 


\section{ACKNOWLEDGMENTS}

My study built upon the work of many talented researchers, whose contribution to the field I acknowledge and appreciate. Despite my critique of some of their work, I recognize that this study would not have been possible without their efforts to advance the theory and practice of instructional technology.

I want to thank my colleagues at the Center for Instructional Design, who encouraged me and who also provided many resources to help me complete this study. In particular, I thank Michael Johnson, Larry Seawright, and Greg Waddoups for their feedback, and Jessica Draper, for editing the final document.

I also wish to thank Dr. Cindy Hmelo-Silver, who also offered valuable feedback on my analysis of problem-based learning.

I thank my dissertation committee, who all helped shape this manuscript into its final form. I also appreciate their positive encouragement, and timely responses, when I asked them for help. I make special note of the contributions of Dr. Andy Gibbons. I appreciate his support and friendship as he has guided me through this process.

My family also deserves special mention. I thank my mother and father for giving me a love of learning. I thank my children, Emily and Jason Jr., for supporting me as I did my homework along with them. And I thank my wife, Jennifer, for being willing to lose a spouse for six years so I could complete my graduate degrees. 
Table of Contents

Table of Contents ........................................................................................................ vii

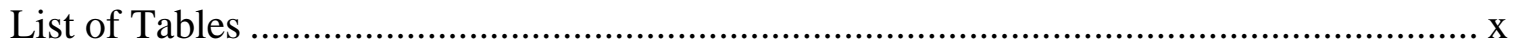

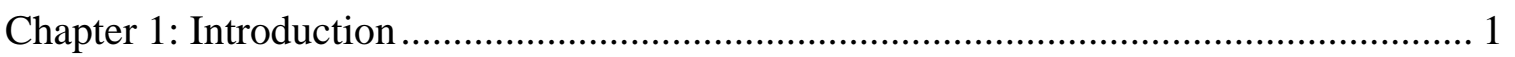

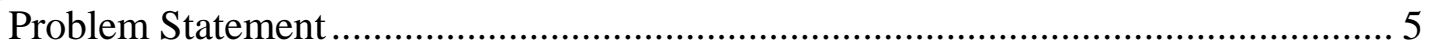

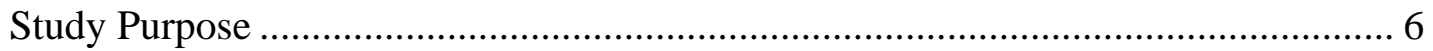

Research Questions ........................................................................................... 6

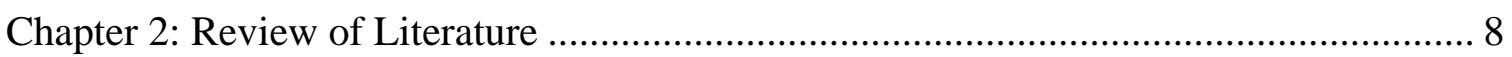

The History of Instructional Technology ……………............................................ 9

Foundational Assumptions.............................................................................. 19

Communities of Practice.................................................................................. 26

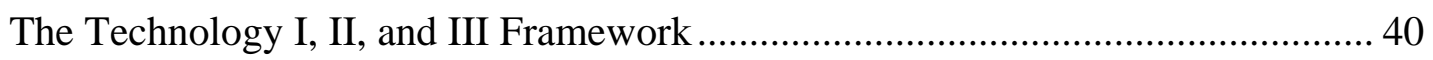

Technology I ...................................................................................................... 43

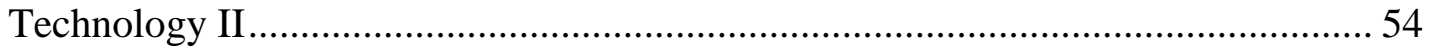

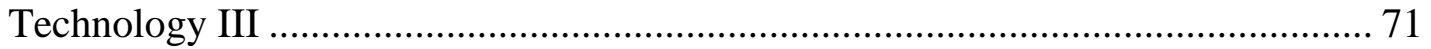

Reasons for Technology I, II, or III ...................................................................... 89

Conclusions from the Review of Literature................................................................ 93

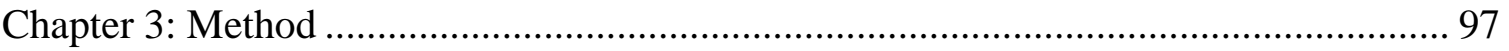

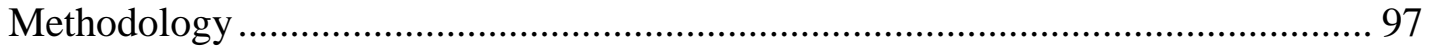

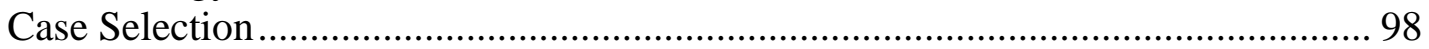

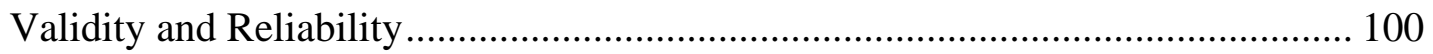

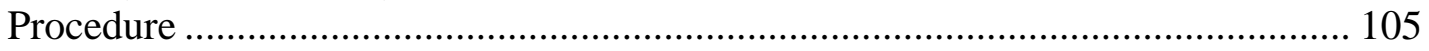

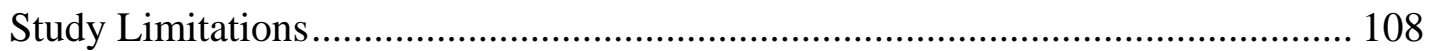

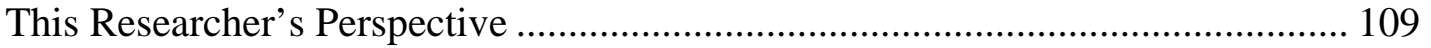

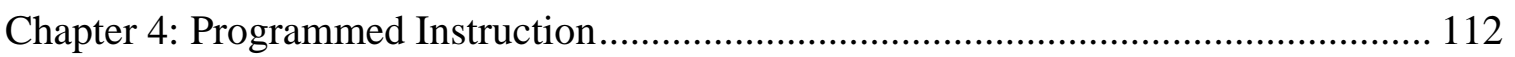

Skinner's Programmed Instruction .......................................................................... 113

Skinner's Programmed Instruction as an Example of Technology II...................... 126

Modifications to Programmed Instruction ............................................................... 135

Example one - Skinner's own practice............................................................. 136

Example two - A second PI exemplar............................................................... 143

Example three - Less successful PI. .................................................................. 149

Example four - Intrinsic PI...................................................................... 155

Example five - Televised PI. The fifth example, ............................................... 160

Example six - PI in a larger system................................................................. 167

Representativeness of these studies .................................................................... 173

Conclusions from Programmed Instruction ............................................................... 177

Chapter 5: Problem-Based Learning.......................................................................... 180 
Barrows’ Problem-Based Learning.................................................................... 180

Barrows’ Problem-Based Learning as an Example of Technology III.................... 195

Modifications to Problem-Based Learning ............................................................... 204

Example one - Barrows’ own practice. ........................................................... 205

Example two - A second PBL exemplar. ..................................................... 212

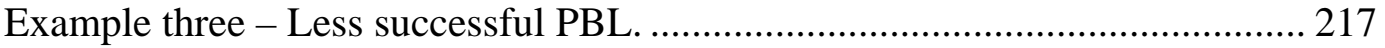

Example four - Hybrid PBL. ........................................................................... 224

Example five - Philosophical opposition to PBL............................................ 228

Example six - Solidifying PBL. ................................................................... 233

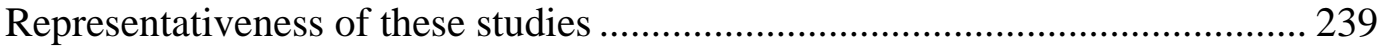

Conclusions from Problem-Based Learning ........................................................ 243

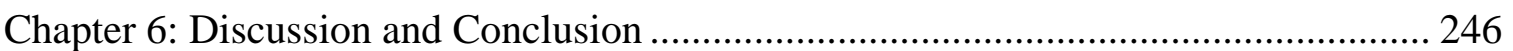

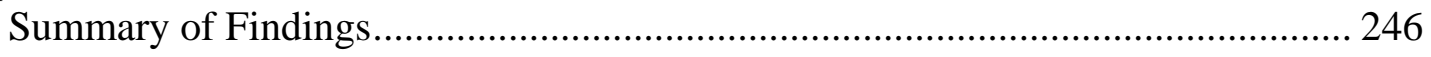

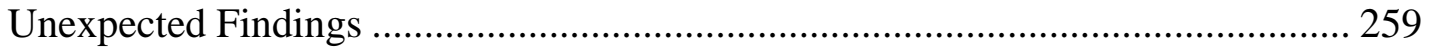

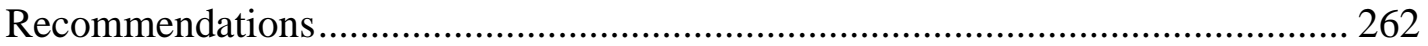

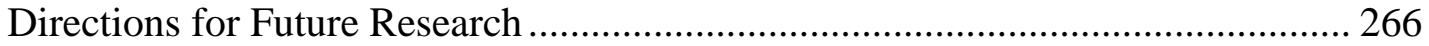

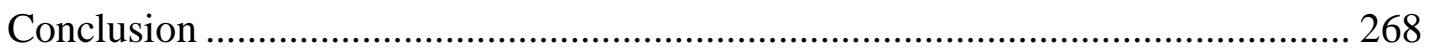

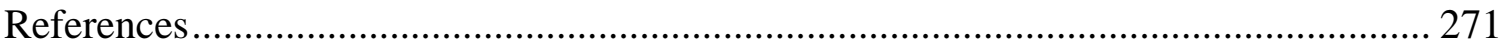


List of Tables

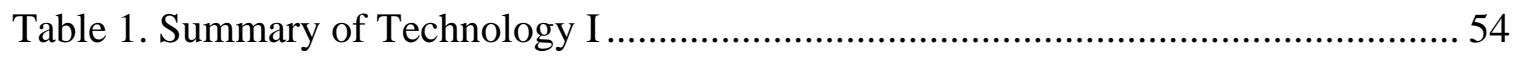

Table 2. Comparing Technology I with Technology II ........................................... 71

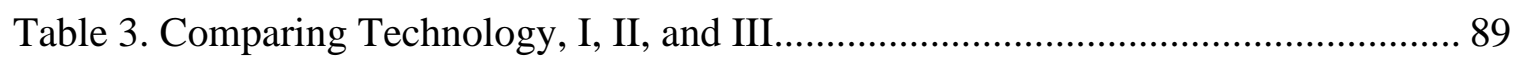

Table 4. What Limits Instructional Technologists to Technology I or II ...................... 251

Table 5. Methods to Sustain Technology III ............................................................. 255 


\section{Chapter 1: Introduction}

The writings of many early instructional technologists reflect a deep sense of idealism. In their theorizing and in the reports of their research, one can find detailed and specific descriptions of what they considered to be well-designed instruction. For example, many early instructional technologists worked towards the ideal of adapting instruction to the individual needs of diverse groups of students (Glaser, 1970, 1977; Hough, 1973; Mitzel, 1974/1970; Weimer, 1960/1958). Others attempted to develop instruction that was generative, or that was produced at the moment of need so that students could make unplanned inquiries and in return receive appropriate and helpful responses (Atkinson \& Wilson, 1969; Lysaught \& Williams, 1963; Pask, 1960; Suppes, 1969/1968). And still others described instruction that was scalable to large numbers of students, not only for economic reasons but also to extend educational opportunities to students who had never previously been served (Blyth, 1960; Finn, 1960b; Gerard, 1969; Suppes, 1969/1968). These examples, together with many others, described instructional technology as a very flexible component of educational systems, able to facilitate a broad range of learning outcomes. And this vision for the field, along with attending methods for creating well-designed instruction, is an important goal for instructional technologists even today (Gibbons, Nelson, \& Richards, 2000).

Yet there is a difference between describing an ideal and actually achieving it. Many early instructional technologists found it very difficult to actually develop instruction of the quality they intended, despite their efforts to do so (Saettler, 1990; Tyler, 1975). The same is still true in the present day. Even with more advanced technology, to a great extent today’s instruction is still not of the quality early researchers 
in the field described. Continuing with the previous example, rather than being adaptive, some instructional products have been criticized for being inflexible and not tailored towards individual learners’ needs (Tennyson, 2000; Zemke \& Rossett, 2002). Rather than being generative, some instructional products have been criticized for completely pre-specifying and over-standardizing instructional components (McDonald, Yanchar, \& Osguthorpe, 2005; Ross \& Schulz, 1999). And although many instructional products are scaled to large numbers of learners, some researchers have asked important questions about how effective those products are once they are scaled beyond a relatively small number (Hill, Wiley, Nelson, \& Han, 2004). And these are only representative of a general concern among some researchers and practitioners, who have wondered why so many instructional technology products or processes do not achieve the results originally promised, and instead often become alternative approaches for developing inflexible or look-alike instruction (e.g. Beckwith, 1988; Reeves, Herrington, \& Oliver, 2004; Reigeluth, 2001).

Some researchers have responded to this concern about instructional technology by encouraging instructional technologists to examine the foundational assumptions they hold about the nature of the field and its practice (e.g. McDonald et al., 2005; Osguthorpe \& Osguthorpe, 2002; Spector, 2000). The assumptions people hold about a discipline influence the way they understand problems in the discipline as well as possible solutions to those problems (Yanchar \& Hill, 2003). At least one researcher has gone on record stating his belief that the assumptions instructional technologists hold about instruction, learning, and design can lead to them creating instruction that is not as helpful in achieving important goals as it could be, because those assumptions reflect an inflexible 
or even inaccurate view about what makes for effective learning (Wilson, 1997). This observation reflects a broader concern in related disciplines. Many researchers are concluding that unexamined assumptions can negatively influence the theory and practice of a field, often because they encourage practices that are rigid or overly narrow, as well as blind practitioners to alternative approaches potentially more appropriate for the situations in which they are working (e.g. Danziger, 1985; Kirschner, 2005; Slife, 1998; Slife \& Williams, 1995). Some have even proposed that inflexible assumptions can become integrated into the structure of the groups in which people work, and so influence them to adopt rigid behaviors while at the same time discouraging them from seriously examining alternatives that may better help them accomplish the work of their group (Wenger, 2000).

In an earlier era of instructional technology, some prominent researchers seemed to agree on a set of assumptions which they proposed as criteria to help practitioners understand what influenced them to act rigidly and inflexibly, or that influenced them to be more reflective about how to accomplish the goals of their practice. They labeled these criteria Technology I, Technology II, and Technology III, with each set of criteria proposing a major idea around which instructional technology practice was organized (Beckwith, 1988; Davies, 1973, 1978; Lumsdaine, 1964). As they proposed these ideas, Technology I presupposed that using mechanical or electrical devices would improve instruction. Technology II presupposed that use of formulas or strategies would improve instruction. Technology III proposed that good instruction could include many different devices, formulas, and strategies, but only using those technologies did not define good 
instruction. Rather, good instruction was the actual realization of improved systems in which learning could take place.

Those researchers proposing Technology I, II, and III predicted that instructional technologists would be more likely to develop inflexible or overly narrow instruction, which could not meet all the goals they originally desired, if they limited their ultimate measure of quality only to the use of certain types of technology. In other words, when practitioners of Technology I or Technology II placed the measure of quality in either the presence or absence of a particular device or formula, they limited the overall effectiveness of their practice precisely because they tied the quality of their instruction to those technologies. If practitioners presupposed that they would find a solution in the technology, they would not consider carefully enough whether or not the technology was actually an appropriate means for accomplishing all the goals they were working towards. As an alternative, proponents of Technology III believed that appropriate use of technology could facilitate quality instruction, but it was not defined by those technologies. Good instruction was defined by the positive changes that took place with both students and broader systems, changes facilitated by the technology. While technologies (both hard and soft) could be powerful tools, proponents of Technology III did not believe their instruction was inherently better only because they had adopted a certain technology. Additionally, at least one of the proponents of Technology III believed that this type of practice could be very difficult to sustain. Even among practitioners who understood the catalytic nature of technology in instruction, various environmental factors could influence them to adopt assumptions that led to the more inflexible practices of Technology I and II (Beckwith, 1988). 


\section{Problem Statement}

It appears that the purpose of the researchers who proposed Technology I, II, and III was similar to the purpose of researchers who have recently encouraged instructional technologists to examine whether or not their assumptions are affecting their practice. Technology I, II, and III, then, may help instructional technologists better understand why they develop instruction that either is or is not rigid and inflexible, or that does or does not achieve their original goals for their practice. Yet despite some discussion of Technology I, II, and III in the era in which they were introduced (e.g. Hamblin, 1974; Hlynka \& Nelson, 1985), Technology I, II, and III has not received any real mention in the literature for nearly twenty years. This observation leads to a problem worthy of investigation. If it is important for instructional technologists to better understand how their foundational assumptions are affecting the quality of their practice, could revisiting Technology I, II, and III help them to do so? In other words, can studying the criteria of Technology I, II, and III help instructional technologists better understand what assumptions affect their own practice, as well as help them learn alternatives for accomplishing their goals of which they had previously not been aware? Additionally, if Beckwith’s (1988) observation was correct—-that instructional technologists might sometimes be pulled away from flexible practices into more rigid and reductive practices—could understanding Technology I, II, and III also help instructional technologists learn how to avoid common traps that can get in the way of the practices they desire? 


\section{Study Purpose}

The purposes of this study are to (a) describe Technology I, II, and III, and whether or not the criteria for each is evident in the practice of real-world instructional technologists; (b) to discover what influences instructional technologists to adopt Technology I, Technology II, or Technology III; and (c) to recommend how instructional technologists can use the criteria of Technology I, II, and III to avoid any traps that might get in the way of the types of practice they desire. This study will help instructional technologists better understand how their own assumptions may be influencing their work. It will also help them understand what assumptions about instructional technology may be most appropriate to help them accomplish their ideal practice. Additionally, this study will contribute to the growing body of knowledge concerning the connection between foundational assumptions and actual practice, as well as the body of knowledge concerning how to develop effective instructional technology.

\section{Research Questions}

The purposes of this study fall into four research questions, the answers to which will organize and summarize my findings:

1. Do the criteria for Technology I, II, and III accurately describe the goals and practice of real-world instructional technologists?

2. Does anything lead instructional technologists to limit themselves to only Technology I or Technology II?

3. Does anything help instructional technologists avoid limiting themselves to only Technology I or II, and sustain practices consistent with Technology III? 
4. Can instructional technologists use this knowledge to help them avoid rigid practices, and more consistently work in flexible ways that are appropriate to help them achieve the goals they have for their work? 


\section{Chapter 2: Review of Literature}

My purpose in this chapter is to review literature that provides a rationale for studying instructional technology practice using the criteria of Technology I, II, and III. A review of literature will demonstrate that many other intellectual fields have historically influenced instructional technologists, and because of this many legitimate, yet sometimes conflicting, types of instructional technology practice exist. This is important to help demonstrate that criteria describing different types of common practice can be valid. Additionally, the literature shows how the foundational assumptions people hold about their work can either help or hinder them in adopting flexible practices, especially if they leave their assumptions unexamined. The concept of the community of practice is also reviewed, along with the observation that communities of instructional technologists exhibit many of the qualities of communities of practice. The communities in which people learn and work can influence them to either sustain flexible practices or to develop rigid and inflexible practices that may lose some of the essential qualities originally important to the work of the community. I will describe the specific framework of Technology I, II, and III in detail, as well as results likely to lead from the practice of each. Finally, I review Beckwith’s (1988) reasons why instructional technologists might limit themselves only to the practices of Technology I or II, along with how each reason might pull one’s practice away from Technology III back into Technology I or II.

It will be helpful to note that while some of the literature I review in this chapter does take a critical tone towards some of the historical events in instructional technology, my intent is not to attack the motives of those who have influenced the direction of the field. Januszewski and Koetting (1998) warned that readers of history must be careful not 
to unduly ascribe negative intentions to actors of the past, for example by assuming that people have been able to anticipate all of the possible consequences (including the negative ones) of their decisions. While instructional technology has been shaped for both good and bad by the actions of instructional technologists throughout its history, there is no reason to suggest that the influential thinkers of the field ever intentionally caused negative results.

\section{The History of Instructional Technology}

Instructional technology is not a single, static, academic and professional field. Instructional technology, as a field, is made up of many groups of researchers and practitioners, loosely bound together by a very general set of ideas and goals which they have adopted from a wide variety of intellectual sources. Shrock (1995) introduced her history of instructional technology by observing that

Rather than a linear progression of well-documented events, the history of instructional development is the story of a gradual confluence of ideas, which took place over several decades. Many of the composite ideas have been legitimately attributed to several different sources, and many of these ideas have and still do overlap with other concepts and procedures that are not instructional development. (p. 11)

Additionally, the scope of instructional technology has not always been clear, even among some members of the field. Braden (1984) stated that, "the edges of the ID concept are fuzzy. That is, there is no consensus - and there may never be-concerning the limits of the process or the boundaries of the profession” (p. 29). The names commonly used to describe the field, some of which include instructional technology, educational technology, instructional design, or instructional systems development, illustrate this lack of clarity. Some, such as Saettler (1990), see distinctions between these labels and use them to describe different, yet related, activities. Others, such as 
Reiser and Ely (1997) have been more willing to view these and related terms as loose synonyms. For reasons that should become clear as this chapter unfolds, in this study I will follow those who group these terms together as synonyms. Unless I need to make a specific distinction by using another term, I will use the generic term instructional technology to describe the practices of those who use physical technologies, systematic processes, or other rigorous methods for the improvement of education.

My purpose in this section is to review literature from the history of instructional technology that describes these historical influences on the field, and how those influences have resulted in many different, yet still legitimate, types of instructional technology practice. While in this section I describe some of the foundational influences on instructional technology, this is not meant to be a history of instructional technology in the sense of comprehensively describing and cataloging historical events. A number of sources have already well documented the history of instructional technology. Some of the more well-known histories of the field include those of Dick (1987), Reiser (1987; 2001a; 2001b), Saettler (1990), and Shrock (1995). Despite some confusion as to the intellectual roots of instructional technology, there are certain influences that are seen more clearly than others. Some of the most important influences on instructional technology have included psychology, engineering, the systems approach and systems theory, and the practices of audiovisual instruction. Yet other influences have also left their mark on the field. The following discussion, then, describes not only these influences, but also other sources that have provided some intellectual guidance for the theory and practice of instructional technology. 
One early and important influence on instructional technology has been the academic discipline of psychology, particularly the behavioral psychology prominent in the early-to-middle part of the $20^{\text {th }}$ century. Early researchers in psychology, such as Thorndike, Hull, Spence, and Skinner, contributed to a base of psychological knowledge that was used to make intentional improvements to the practice of education (R. M. Morgan, 1978; Osguthorpe \& Zhou, 1989). One well-known, early form of instructional technology which drew heavily on behavioral psychology was programmed instruction. While behavioral psychology was not the only influence on programmed instruction, undoubtedly programmed instruction does represent one of the earliest attempts to intentionally apply psychological theories to instructional situations (Jonassen, 1991). Additionally, while the originators of programmed instruction did not invent all of the traditionally popular techniques of instructional technology, such as behavioral objectives, the programmed instruction movement did help popularize those techniques for later generations of instructional technologists (Reiser, 2001b).

Programmed instruction eventually fell out of favor among instructional technologists, but the influence of psychology did not disappear. Cognitive psychology gradually replaced the influence of behavioral theories in instructional technology (Saettler, 1990), which trend mirrored a more general move away from behaviorism in education and psychology as a whole (Di Vista, 1987). Instructional techniques which previously had been based primarily on behaviorism were updated to keep pace with new ideas in psychology (Tennyson, 2005). Wilson (2005a) recently noted, somewhat critically, that although instructional technologists have continually broadened their 
intellectual base over the past thirty years, some instructional technologists continue to look to psychological theory as the primary intellectual guide for their work.

The dominance of psychology in instructional technology has not gone unchallenged, however. Some have claimed that the field of engineering has exerted a greater influence. Molenda (1997), while not downplaying other historical influences on instructional technology, also stated that "the dominant genes for instructional design come from systems engineering” (p. 42). More specifically, Molenda identified engineering's effect on instructional technology as a strong focus on process, detailed procedures for data gathering and analysis, and an adoption of engineering terminology, “e.g. feedback, input, output, channel, entropy, redundancy, lead time” (p. 43). Januszewski (2001) also presented a compelling case that those drawn to instructional technology have also been those interested in applying the principles of engineering to education. Januszewski not only pointed to some of the same indicators as Molenda, but also observed other influences from engineering, such as instructional technology's focus on solving practical problems. Finally, Januszewski identified many early, influential thinkers in instructional technology who were either trained as engineers or who were heavily influenced by the discipline of engineering. Some of these individuals included Franklin Bobbitt, W. W. Charters, and James D. Finn.

Another influence that has left a lasting impression on instructional technology comes from the systems approach and systems theory. However, as I will discuss, systems theory has perhaps been the most misunderstood and contradictory idea in instructional technology. Briefly, systems theory is an approach to science originating the in early $20^{\text {th }}$ century that attempts to explain phenomena using a general set of principles 
that cut across all disciplines (Bertalanffy, 1968). The organizing concepts in systems theory describe the "models, principles, and laws that can be generalized across various systems, their components, and the relationships among [the components]” (Banathy \& Jenlink, 2004, pp. 37-38). Systems thinking discourages investigators from studying phenomena in isolation. Systems theorists work from the assumption that by viewing objects of study as part of one or more systems, they can better understand both the inner working of the object and its relationships to the objects around it than if they used a method of analysis that studied the object alone.

Systems theory was applied to education during the middle of the $20^{\text {th }}$ century, as it was applied to many other fields (e.g. Churchman, 1996/1965; Hoban, 1996/1977). One of the aspects of systems theory that quickly took hold in instructional technology was the systems methodology, or systems approach, to problem solving (Banathy, 1987). Trimby and Gentry (1984) have described the systems approach as "a management tool that organizes decision-making systematically” (p. 81) to define a problem that may exist in a system, identify goals to improve or eliminate the problem, and in a logical way create an intervention that will improve the system. Yet some instructional technologists began to equate the systems approach not so much with a general type of problemsolving strategy, but more often with specific, step-by-step formulas that they often used to implement the strategy (Januszewski, 2001). Critics have charged that instructional technologists have not properly applied the principles of systems theory as envisioned by early thinkers such as Bertalanffy, and that "there is frequently little visible evidence as to the extent that instructional design models . . . relate to the basic concepts of General Systems Theory” (Hug \& King, 1984, p. 18; see also Lee, 2002). In recent years, some 
researchers have attempted to revive the use of systems theory in instructional technology. This trend is visible in research that discusses how the most current concepts of systems theory, such as systems complexity and the emergence of complex patterns from a small set of rules, can enrich the traditional understanding of systems in instructional technology (e.g. Goldstone, 2006; Jacobson \& Wilensky, 2006).

A fourth important influence on instructional technology has been the audiovisual, or instructional media, movement. As with the other influences, some have specifically identified audiovisual instruction as the direct predecessor of instructional technology (De Vaney \& Butler, 1996). But, perhaps because of the visibility of the audiovisual and media tools used in instructional technology, this influence has sometimes been easier to recognize. Reiser (2001a) noted that

Most individuals outside of the profession, as well as many inside it, when asked to define the term instructional technology mention computers, videos, CDROMs, overhead and slide projectors, and other types of hardware and software typically associated with the term instructional media. In other words, most individuals equate the term instructional technology with the term instructional media. (p. 54)

Media and media devices have been used to improve instruction since at least the end of the $19^{\text {th }}$ century, if not earlier. Photography, film, radio, television, computers, and other audiovisual devices, each in their turn, have enjoyed periods of surprising prominence in instructional technology (Saettler, 1990). All of these media devices, especially the computer and its related Internet technology, are still considered important today (Reiser, 2001a).

While these four influences have had broad influence on the direction of the field, they are not the only intellectual foundations for instructional technology. Saettler (1990), for example, has also identified as important the influence of communications and 
communications theory. Additionally, new perspectives that encourage instructional technologists to consider "social and cultural learning. ... values. ... [and] aesthetics" (Wilson, 2005b, p. 246) have also been recently incorporated into instructional technology. The practice of instructional technologists will, in the future, most likely continue to be influenced by diverse fields. Fields which seem likely to make a lasting impact include "human-computer interface and human-factors design; . . . the information sciences; architecture and planning; industrial design; . . . and technical communications” (Wilson, 2005a, p. 11).

In addition to these theoretical and philosophical influences, broader historical events have helped shape other divisions within the field. One of the most important historical influences came from United States military investigations into learning and instruction during World War II. During the war, the military assigned psychologists to find efficient methods to train large numbers of soldiers, many of whom had received a poor education earlier in life. Their efforts helped to develop some of the processes still familiar to instructional technologists, as well as leading to a renewed interest in using media for instructional purposes (Reiser, 1987; Saettler, 1990). Another important influence was the American public school system's adoption of audiovisual devices and other instructional technologies, particularly after the launch of the Soviet Sputnik satellite in the 1950s (Dick, 1987). Although the overall response from the school system has sometimes been less than enthusiastic, some instructional technologists continue to view their purpose as finding better ways of addressing the needs and concerns of the school system, for example how to allow the same number of teachers to effectively teach larger numbers of students (Dick, 1987; Tyler, 1975). Finally, the concerns of the 
distance education movement have influenced the thinking of many other instructional technologists, especially in defining how to best individualize and personalize instruction for each student (Beaudoin, 1990; McIsaac \& Gunawardena, 1996).

Although this great diversity of thought has undoubtedly provided a rich set of practices, beliefs, traditions, and metaphors for the field that instructional technologists might not otherwise have had, this diversity has not come without costs. One consequence is that it is not always clear what it means to be an instructional technologist. The definition of instructional technology has concerned instructional technologists for at least fifty years (Torkelson, 1998). Schwier, Campbell, and Kenny (2004) recently noted that instructional technology seems to be "an area struggling for identity.” Winn (1986) noted that instructional technologists “are at a particular disadvantage . . . because their field lacks clear definition” (p. 346). At another time, Winn (1988) also reflected on the problems instructional technologists encounter because their field "has tried to be all things to all people” (p. 801). One way this struggle for identity appears is in the words and terms instructional technologists use to describe their work. With a language base drawn from so many disciplines, many terms instructional technologists use simply do not have clear meanings. In Gentry and Csete's (1995) critique of this imprecision, they stated, "even so basic a task as standardizing terminology across the field has been haphazard and inadequate” (p. 21). Romiszowski (1981) agreed, stating that the terminology of instructional technology "is so unstandardized that it is not easy to see whether any really important changes in the basic premises underlying learning and instructional theories have taken place” (p. 165). A striking example of this is even noticeable in the name of the field itself. As has been 
mentioned, some people use terms such as instructional technology, educational technology, instructional design, and instructional systems as synonyms, while others make subtle and sometimes difficult-to-understand distinctions between these and other terms (Gentry, 1995/1987; Gustafson \& Branch, 1997; Reiser \& Ely, 1997; Saettler, 1990).

Because of this lack of definition, it appears that instructional technologists are sometimes unsure of their fundamental goals and purposes, or how to best accomplish them. When instructional technologists are unsure of their fundamental goals, it leads to a problem Wilson labeled as “competing paradigms” (Merrill \& Wilson, 2007, p. 342). Although all who identify themselves as instructional technologists would likely accept the general goal of educational improvement, beyond this very broad statement many of the sub-groups within the field define their specific goals in different, and sometimes conflicting, ways (Heinich, 1995/1984). Unfortunately, rather than looking for common ground between their orientations and finding areas of agreement, researchers and practitioners have sometimes “accentuate[d] one or the other extreme” (Rowland, 1993, p. 88) between their positions, further alienating those with perspectives different than their own (see also Snelbecker, 1999). At times, in fact, this has led to intellectual battles between those with different perspectives, each side claiming that they represent a more legitimate approach for effective educational improvement (Braden, 1984). One important example of these “competing paradigms” (Merrill \& Wilson, 2007, p. 342) has been between instructional technologists who primarily pursue goals of cost-reduction and instructional efficiency and those who pursue the goal of increasing the overall learning effectiveness of instruction (Davies, 1984). While instructional technologists 
with differing goals could potentially find ways to work together, in actuality over time they have become more and more isolated from one another (Gibbons \& Fairweather, 2000; Wiley, 2003). Other examples include whether instructional technologists should use primarily quantitative or qualitative research methods, or whether or not instructional technology is a field based on scientific processes or methods more akin to the arts or humanities (Merrill \& Wilson, 2007).

As the different groups in the field of instructional technology have become more isolated from each other, there has been a corresponding tendency for instructional technologists not to learn from those who hold other perspectives. Reiser (2001b), for example, noted that "most of the practices related to instructional media have occurred independent of developments associated with instructional design” (p. 58). Reiser seemed to be pointing out the isolation which these two orientations have experienced throughout the history of the field, as well as the sense that instructional technologists who are interested in instructional media are a different group from instructional technologists interested in instructional design. As another example, the similar groups of learning scientists and instructional technologists have recently began to notice that despite their common concerns and the considerable potential to learn from each other, there has historically been little dialog between, or sometimes even little awareness of, the other group (Hoadley, 2004; Kirby, Hoadley, \& Carr-Chellman, 2005). Of course, the problem with this is that instructional technologists are cut off from those who may have the information, skills, or other forms of help they need to solve the problems they face. If groups become too insular, they can lose the intellectual diversity necessary to find better alternatives for pursuing their goals (Surowiecki, 2004). As Schuller (1986) stated, "if 
you are not changing and adapting to new conditions and needs as time goes on, you're merely perfecting your old bad habits—and congealing the ideas that go with them” (p. 3).

\section{Foundational Assumptions}

My purpose in this section is to review literature that describes how the practice of instructional technology could improve if instructional technologists were more aware of the foundational assumptions underlying their work. To overcome some of the challenges that instructional technologists face in their practice, some thinkers in the field recently proposed that practitioners reflect more on their fundamental assumptions. Gibbons (2003) specifically hoped that instructional technologists would "become aware of the foundations and principles of their practice” (p. 11) so that they can better develop strong professional communities that continually advance the theory and practice of the field. Although this topic has not been widely studied in instructional technology, there is a growing literature within the field that addresses the issue. Additionally, instructional technologists can also draw on a relevant literature about foundational assumptions, and their role in one's practice, from related fields. This literature demonstrates that the practice of any field, including instructional technology, is not as well developed as it could be if practitioners do not understand and question their own assumptions. This literature also provides important suggestions to help practitioners question, and improve, their assumptions if they desire to do so.

In the context of this literature, the word assumption means "the implicit propositions that are taken for granted as a basis for argument or action” (Ennis, 1982, p. 62). Yanchar and Slife (2004) proposed that "assumptions in general are centrally 
important because they provide the foundation of thought, action, and arguments” (p. 85). As they become aware of their assumptions, people are engaging in the personal scholarship of developing their own guiding philosophy. Speaking to instructional technologists in particular, Ely (1970) stated that in developing a philosophy of instructional technology that describes the "beliefs, concepts, and attitudes" they think are important, instructional technologists create an intellectual guide "from which personal purpose and direction [can be] derived” (p. 81). And Solomon (2000) claimed that if instructional technologists had a strong philosophy built on well-understood assumptions, they could better make the professional decisions involved in the everyday practice of instructional technology (see also Davies, 1991/1981).

Despite the importance of foundational assumptions in guiding one’s practice, however, most people are unaware that their assumptions have any effect upon them at all (Osguthorpe \& Osguthorpe, 2002). One reason for this is that many people get so caught up in the habits of their practice that they become blind to how the subtleties of their assumptions influence them. Solomon (2000) stated this possibility when he said, “occasionally ... we become victims of our own routine, replicating steps over and over again, rarely pausing to think about what it all means or to reflect on our values and beliefs as instructional technologists” (p. 2). Reeves (1995) was a little more bold in labeling this as “mindlessness,” which can infect people’s practice when they simply pursue the same courses they have pursued in the past, without thought as to why. As time goes on, these routines can become the unexamined “tradition” (Wingo, as cited in Koetting \& Malisa, 2004, p. 1011) of a field, which passes down to new generations of practitioners. Alvesson (2002) recognized the power of tradition as "often 
lead[ing] to the absence of questioning, or at any rate of serious questioning, of existing social conditions. . . . Basic conditions tend to be taken for granted and the social world [is] regarded as natural, neutral and legitimate” (p. 119). Koetting and Malisa concluded that these traditions “may go unnoticed, may be unconscious, [and] may be unquestioned” (p. 1011) as practitioners give their time and attention to the more visible and immediate aspects of their discipline. As the traditions of a field become more entrenched, the process of “ordering” (Kendall \& Wickham, 2001, p. 27) can take place; in other words, the process of a practice becoming more stable often by becoming more routine, more systematic, and more technical.

In addition, Kirschner (2005) speculated that the process of uncritically adopting these traditions is actually magnified as one becomes more enculturated into a group. Although her example comes specifically from the discipline of psychology, it is interesting to consider the implications for her example on the field of instructional technology:

Indeed, part of becoming well socialized as a psychology student, and then as a psychologist, is to learn to suppress such questions and doubts [about the practices of the field], so that in the end one comes not to think in such terms at all. This is ironic, because it means that our very enculturation as psychologists entails the suppression of crucial elements of what it means to be a critical thinker. (p. 268)

Garner (1966) stated this tendency even more bluntly. In his discussion of how the assumptions of some instructional technologists have led to them blindly follow traditions in their practice, he stated that, "in an enthusiasm to express elaborations of [a] theory, dogmas appear. Absurdities usually follow, in the typical cyclical pattern toward decadence that many movements exhibit as their concepts congeal” (p. 2). 
So, for example, as instructional technologists become more enculturated into a specific group, they may become tightly bound to the particular practices of that group and not seriously compare their practices to other alternatives. This may contribute to some of the problems examined earlier, such as groups of instructional technologists with different orientations becoming more isolated from one another, or using similar terminology in different ways than is used by other groups.

The tendency of practitioners to uncritically adopt traditions based on unexamined assumptions is not without consequence. Kirschner (2005) stated that "assumptions necessarily structure all human inquiry—the questions we ask, the methods we use, and how we interpret what we find” (p. 268). Burgess-Limerick, Abernethy, and Limerick (1994) concluded that peoples' "conceptual framework ... determines what questions are legitimate, how answers may be obtained, what are counted as facts and what significance is attached to those facts” (p. 139). In other words, people will conduct the practice of their field in ways consistent with their assumptions. If these assumptions are narrow and limiting, then the questions, methods, and findings of the practice are also likely to be limiting. As a specific example, Danziger (1985) warned that leaving assumptions unexamined has serious implications for those who use methods based on those assumptions:

The possibility of a methodological circle [exists] where methods based on assumptions about the nature of the subject matter only produce observations which must confirm these assumptions. ... The methods used to test a theory may presuppose the truth (or falsity) of the theory to be tested. Investigators commonly play with loaded dice. Not all kinds of outcomes have an equal chance of appearing in their research situations. (p. 1)

To summarize, practitioners, if they uncritically adopt a method, may increase the likelihood of coming to certain types of conclusions while decreasing the likelihood of 
others. This is not necessarily an attack on any particular method or the use of method in general. Rather, Danzinger appears to be warning that people cannot conclude that they have found the only acceptable answer just because they used a certain method of inquiry. In fact, the choice of method may preclude the discovery of certain types of answers, which may also be acceptable or perhaps even superior.

Slife and Williams (1995) extended the danger of leaving assumptions unexamined beyond the effects those assumptions might have on intellectual tools of a discipline (such as method). They also saw the danger that unexamined assumptions can affect the future directions of a field by limiting the types of inquiries of investigators within the field. They stated that when an assumption becomes one of the foundational cornerstones of a field, it takes on almost a sacred quality, cutting off future questions about the legitimacy of that assumption. Theory begins to take on an unquestionable status. The field can then become stuck in a spiral pattern, never really moving ahead because investigations restrict themselves to the range of phenomena that flow logically from already accepted assumptions.

This is not only a concern for the research in a field, but for its practice as well. For example, Schwen, Leitzman, Misanchuch, Foshay, and Heitland (1984) pointed out the perhaps obvious fact that instructional technologists, when they encounter an educational problem, most often respond by creating some type of instructional technology. Schwen et al. discussed that it is instructional technologists' foundational beliefs about the nature of educational problems and the value of instructional technology that predispose them to these types of solutions. Simply put, instructional technologists make instructional technology. Because of this assumption, many instructional 
technologists rarely consider other possible solutions, especially the heretical solution that in some cases perhaps "eliminating instruction is ... the best way to improve instruction” (p. 40). In effect, their assumptions lead them into a "self-fulfilling prophecy” (pp. 40-41), because when they believe they will find the best solution in an application of instructional technology, that is exactly what they do find.

Since the problem with unexamined assumptions is that it can lead to unreflective practice, a possible solution is that instructional technologists should become more reflective about their assumptions and the connection between their assumptions and their practice. Solomon (2000) stated this position when he encouraged instructional technologists to examine "the things that we so often take for granted during our daily routines" (p. 3), because "the more we know about our beliefs and values, the more reflective we become in our work as instructional technologists” (p. 4).

Slife, Yanchar, and Reber (2005) differentiated this type of reflection (what they call “critical thinking”) from the more commonly discussed concept of "rigorous thinking” (pp. 3-4). Rigorous thinking consists of paying careful attention to detail, appropriately applying chosen methodologies, and analyzing data or conclusions completely. But Slife et al. pointed out that this does not necessarily lead one to ask the helpful questions about assumptions often missing from professional discourse. They described critical thinking as intentionally questioning the foundations on which one's details, methodologies, or data analysis rest. Additionally, Spector (2001), added that to really question the assumptions they hold, instructional technologists must possess a certain intellectual humility that lets them accept that although instructional technology has produced many commendable results, those "conclusions . . . should be tentative and 
treated with the uncertainty they are due” (p. 311). Merrill also seemed to encourage a similar attitude when he concluded that instructional theories did not represent truth so much as they represented a useful system for studying the world until an even more useful system is discovered (Merrill \& Twitchell, 1994).

Some researchers have recommended that professionals undertake certain activities to better understand their own assumptions. Bruning, Schraw, and Ronning (1999) described a process through which people can become more aware of their assumptions by finding environments in which make their assumptions explicit, observing how those assumptions may not be the best explanation for what they find, and then taking the opportunity to reformulate new assumptions that are more consistent with the available evidence (see also Torff, 1999). Yanchar and Slife (2004) proposed another, more detailed approach to help people begin to think critically about their foundational assumptions:

1. Begin with the desire to look at one's assumptions more critically;

2. Create a general set of questions that may be helpful in uncovering assumptions and discussing their implications;

3. Ask those questions about a specific approach within a field to discover the assumptions of that approach;

4. "Identify the practical implications ... that follow from the assumptions" (p. 85); and

5. Come to a conclusion about how useful the approach is, based on what one learns about its assumptions and implications. 
This is what Osguthorpe and Osguthorpe (2002) described as developing "prudential knowledge” (p. 4). Prudential knowledge can act as a "conscience” (p. 4) for instructional technologists, not only helping them develop a practice well grounded in the best theory the field of instructional technology has to offer, but also continually looking for other, flexible, ways of improving that practice. Developing prudential knowledge requires instructional technologists to do more than just align practice with theory. They must also critically evaluate that theory against what they discover through their practice, as well as their personal beliefs about learning, learners, or the nature of instruction. Osguthorpe and Osguthorpe were quick to point out that they were not asking instructional technologists to engage in lazy thinking or to uncritically reject a theory just because they do not understand it. Developing prudential knowledge first requires an indepth understanding of the foundations of a field. Only when instructional technologists can speak knowledgably about the theories, beliefs, and practices within instructional technology are they prepared to critically evaluate those theories, beliefs, and practices and appropriately apply (or reject them. In developing prudential knowledge, instructional technologists may discover that the theorist was suggesting a wise approach, and so modify their practice to align with the theory more fully. In developing prudential knowledge, and critically reflecting on their practice, Osguthorpe and Osguthorpe believed that instructional technologists could respond appropriately to the unique challenges they encounter in any professional setting.

\section{Communities of Practice}

A third perspective on what may lead instructional technologists to adopt either rigid or more flexible beliefs and behaviors comes from the research literature on the 
community of practice. Communities of practice, according to Wenger (1998), are the context in which all professional activities take place. Lave and Wenger (1991) defined a community of practice as "an activity system about which participants share understandings concerning what they are doing and what that means in their lives” (p. 98). More recently, Wegner (2000) described communities of practice as “communities that share cultural practices reflecting their collective learning” (p. 229). Barab, MaKinster, and Scheckler (2004) defined the community of practice as "a persistent, sustained social network of individuals who share and develop an overlapping knowledge base, set of beliefs, values, history, and experiences focused on a common practice and/or mutual enterprise” (p. 56). My purpose in this section is to review literature that defines the concept of a community of practice, and that describes why members of some communities act rigidly and inflexibly while others act more flexibly as they work towards accomplishing the goals of the community. This section also shows that communities of instructional technologists exhibit many of the characteristics of communities of practice, helping to demonstrate that this literature is relevant for the study of instructional technology.

The concept of the community of practice originated from research into the social aspects of learning and performance. During the past two decades, researchers began to pay more attention to evidence that strongly suggested that people do not learn or perform in isolation. As Hutchins (1996) said, "the properties of groups of minds in interaction with each other, or the properties of the interaction between individual minds and artifacts in the world, are frequently at the heart of intelligent human performance” (p. 62). Lave and Wenger (1991) coined the term community of practice to draw attention 
to how peoples' activities in context of their relationships with others naturally lead to them learning what is expected for their work, and how to best accomplish their work. Wenger (1998) proposed three critical features common to communities of practice:

1. A mutual engagement, meaning that "people are engaged in actions whose meaning they negotiate with one another” (p. 73);

2. A joint enterprise, meaning that the negotiated engagement of community members leads to some collective understanding of an important, shared work;

3. A shared repertoire, meaning that the community develops common “activities, symbols, [and] artifacts” (p. 82) that help them accomplish their work in the enterprise.

Comparing the concept of the community of practice with other, related, concepts also helps develop a more complete definition. One related concept is that of the discourse community, a term for the "norms and shared knowledge that influence ‘composing’ practices in a discipline” (Burroughs, Schwartz, \& Hendricks-Lee, 2000, p. 347), or in other words, the way in which words, language, and writing define the boundaries of disciplines or groups. The concept of discourse communities appears similar to that of communities of practice, in that members of both communicate with each other to negotiate their understanding of common outcomes, as well as rely on a shared set of tools or artifacts to help community members communicate and work with each other (Gee, 2003; Swales, 1990). Pogner (2005) specifically compared the literature on communities of practice with that of discourse communities and found much in common, with the valuable addition from the discourse community literature of the 
important role that common languages and texts have for community members' work. The two concepts appear to differ primarily on the focus of analysis. In communities of practice the focus is on the practice, while in discourse communities the focus is on the discourse.

Another related concept is the network of practice. Brown and Duguid (2000) coined the term to describe differences between the close relationships of people whose practice brings them in direct and frequent contact with each other, and the more distant relationships of people who are engaged in similar practices yet whose common work mainly consists of activities such as sharing information of mutual interest. These looser networks have also been labeled “crossroads ... of communities” (Schlager \& Fusco, 2004, p. 121) as well as “constellations of practice” (Wenger, 1998, p. 126). In essence, networks of practice are made up of smaller communities of practice. The larger networks influence the communities that belong to them, and at a higher level also “facilitate learning and knowledge sharing between individuals conducting practicerelated tasks. . . . Networks of practice promote knowledge flow along lines of practice through informal social networks” (Wasko, Faraj, \& Teigland, 2004, p. 497). It appears that communities of practice and networks of practice can be analyzed in similar ways, with the understanding that, in general, as the community or network grows larger the connections between individuals within the community grows weaker. While recognizing that there are some differences between all of these related concepts, for ease in analysis in this chapter I will continue to use the generic term community of practice when discussing the inter-connected relationships between people, their practices, and the ways in which they communicate their practices to others. 
The literature of instructional technology indicates that groups of instructional technologists do exhibit common characteristics of communities of practice. Schwier et al. (2004) have particularly noted the variety of ways in which communities of instructional technologists work together, and how those work patterns correspond to the community of practice concept. For example, they described in detail different types of mutual engagement evident among communities of instructional technologists, such as participation in professional organizations, or through close work with local contacts. Schwier et al. described how instructional technologists not only had relationships with local individuals with whom they worked closely and which bound them together into a sense of joint enterprise, but also had relationships within the broader field of instructional technology that they looked to for advice about how to conduct instructional development activities. Schwier et al.'s descriptions of the looser relationships between members of the field of instructional technology appears consistent with a view of the field as multiple networks of practice, each made up of smaller communities of practice working in or across organizations.

Others have also described the practice of instructional technology in terms that connect instructional technologists to Wenger's (1998) defining characteristics of a community of practice. For example, Wilson's descriptions of instructional technologists sharing different types of “common goals” (Merrill \& Wilson, 2007, p. 342) about why they are engaged in instructional technology practice sounds similar to Wenger's characteristic of communities of practice sharing a joint enterprise which gives direction and focus to the work of community members. Also similar to the concept of joint enterprise was Davies’ (1997) comment that the differing beliefs about instructional 
technology that groups of practitioners hold act as a set of "shared values . . . which bind [them] together into a common community” (p. 35), and that provide a rationale for conducting their work in different ways. As another example, Gibbons and Brewer's (2005) discussion of emerging design languages and notation systems that help instructional technologists communicate details about their work seems to be an indication that there is a growing shared repertoire among some groups of instructional technologists to help them conduct their practice.

Descriptions of communities of practice lead to a sense that they are more than just work groups or work teams (although work groups and teams may exhibit the characteristics of a community of practice). In their richest manifestations, communities of practice are best described as unique work cultures. Brown, Collins, and Duguid (1989) have stated that "the activities of many communities are unfathomable, unless they are viewed from within [a] culture” (p. 33). And Hara (2000) concluded that, "by means of everyday practices and interactions with colleagues, [communities of practice] share, construct, and learn cultural knowledge” (p. 234). Levine and Moreland (1991) offered one definition of culture which provides some interesting insights into the concept of a community of practice:

Culture is often viewed as a set of thoughts that are shared among group members. These thoughts guide group members' actions and provide a common interpretive framework for their experiences. Second, culture is often viewed as a set of customs that embody the thoughts that group members share. These customs serve to remind group members that their experiences can (and should) be interpreted in common ways. (p. 258)

Some of the thoughts community members adopt include the values, beliefs, and norms of the community (Hara, 2000; Teigland, 2003). Shared customs include the language, writing, speaking, and conversation patterns of the community (Fairclough, 2003; Gee, 
2005; Keating \& Egbert, 2004; M. Morgan, 2004). Community members not only learn what to say within the community, but also the when and how of proper community discourse (Gee, 1996). They also share stories and metaphors to help capture and transmit both what it means to be part of the community and how to accomplish the practice of the community (Brown \& Duguid, 1991). They learn ways to identify insiders and outsiders of the community (Bucholtz \& Hall, 2004), as well as ways to sanction those who violate the community norms (Teigland, 2003).

Wenger (1998), however, was quick to point out that communities of practice are more than just a culture, in the sense of people sharing a set of common ideas. They chose the term communities of practice to draw attention to the fact that these communities are unique both because of the group within which members work and because of the practice in which they engage (see also Baek, 2002). In fact, Brown and Duguid (2001) described that the most important knowledge shared among community members is that of "know[ing] how" (p. 204) to properly carry out the specific activities the group performs. Communities of practice, and the unique cultures within these communities, would not exist if they consisted of people who shared only common ideas. They must also share a common work.

Additionally, members of a community of practice do not just absorb a static body of knowledge regarding how to do their work. Community members also share their values, languages, stories, and practices with the rest of the community. They change their communities as their communities change them (Baek, 2002). As community members interact with each other in all of their varied, rich ways, they share with each other knowledge about their work they cannot fully put into words (Hara, 2000; Wilson, 
2005b). This type of knowledge has been called tacit knowledge, or in other words the "implicit beliefs and personal epistemologies (the way and how of knowing) brought to interpret any situation” (Hung, 1999, p. 197).

Most often, people learn tacit knowledge without being consciously aware that they are even learning at all (Horvath, 1999), but this does not mean that a person can never be aware of, or talk about, their tacit knowledge. Reber (1989) clarified, “it is misleading to argue that implicitly acquired knowledge is completely unconscious”; however, "it is not misleading to argue that the implicitly acquired epistemic contents of mind are always richer and more sophisticated that what can be explicated” (p. 229). As Brown and Duguid (2000) pointed out, there are fundamental differences between tacit and explicit knowledge, or the knowledge that one can fully think about and articulate. They stated, "no amount of explicit knowledge provides you with the implicit. They are two different dimensions of knowledge, and trying to reduce one to the other is a little like trying to reduce a two-dimensional drawing to one dimension” (p. 134).

Sternberg, Wagner, Williams, and Horvath (1995) concluded that the process of becoming an expert can contribute to peoples’ inability to consciously think about their tacit knowledge, even though that knowledge is still a powerful influence on their actual practice. And sometimes, even if people conclude that their tacit knowledge is logical and appropriate, it may be more because they “desperately want it to be” (Sternberg, 1999, p. 235) rather than because it actually is. Torff (1999) specifically investigated this phenomenon in education. Torff studied how teachers sometimes held on to their unsophisticated beliefs about teaching even after rigorous professional training that questioned the validity of those beliefs. He concluded that, especially when the beliefs 
underlying one’s educational practice are “oversimplified, misleading, or inaccurate” (p. 197), educational practitioners are prone to overlook any strategy or practice that their intuition does not legitimize. Torff attributed this tendency to the fact that teachers often compartmentalize their professional training from their practice, and in the process of making everyday decisions are more likely to fall back on their original beliefs than to make conscious decisions based on their professional training. He further stated that Folk ... pedagogy is pervasive-it is infused into out thinking about education and professional training. After all, people remain members of their culture, even after training that counters certain beliefs held by laypersons in that culture. Folk pedagogy is strongly enculturated before teacher training begins, and its logic and practices remain in the background, even among the most educated and experienced teachers. As such, folk conceptions function as a largely tacit “default mode” for teachers' reasoning about education. (p. 205)

As people learn the tacit knowledge about the thoughts, customs, and practices of their communities, they also begin to develop a new sense of personal identity that is more consistent with the community work. Barab and Plucker (2002) stated that after becoming a member of a new community of practice, an "individual is no longer the same individual with new skills, but is a new person who has become more enculturated into the practice of [the community]” (p. 173). Community members negotiate their identities through their work with other community members (Wardle, 2004). This is an essential step of communities of practice because individuals too loosely bound together cannot do the work of the community (Brown \& Duguid, 2000; Lesser \& Storck, 2001). They must consider themselves part of something larger than themselves to properly coordinate the complex activities that make up a community’s practice (Barab \& Duffy, 2000; S. D. N. Cook \& Yanow, 1993). Stamps (1997) described the importance of identity formation in the practice of the community: 
As people work together ... they develop a shared sense of what has to happen to get the job done. They develop a common way of thinking and talking about their work. Eventually they come to share a sort of mutual identity—a single understanding of who they are and what their relationship to the larger organization is. (p. 36)

The process of developing a new identity and becoming a member of a community has been called legitimate peripheral participation. In their defining work on the subject, Lave and Wenger (1991) stated that legitimate peripheral participation "provides a way to speak about the relations between newcomers and old-timers, and about activities, identities, artifacts, and communities of knowledge and practice” (p. 29). Although somewhat awkward, the phrase accurately and precisely describes how outsiders of a community of practice develop the identity of community members, and by so doing become full members. First, newcomers must actually participate in the work of the community. Simply observing, or learning about, the practice of a community may play an important role but does not substitute for actual engagement in the community's practice (Lave, 1991). Second, that participation must be legitimate. Newcomers’ participation is most beneficial when it is authentic or in some way important to the ongoing work of the community. Newcomers suffer if their contribution to the community is simply busy work (Johnson, 2001). And third, newcomers’ initial participation should be peripheral. Novices cannot be expected to be able to perform in the same way as do experts (Bransford, Brown, \& Cocking, 2000; Fuhrer, 1993), and over time must be initiated into ever-increasing roles of centrality in a community as they learn the norms, beliefs, and practices of that community. As Morrell (2003) stated, as people "become more active and engaged within the culture [of a community, they also] assume the role of expert or old-timer” (p. 90) within the community. 
An additional insight from Lave and Wenger's (1991) work is their discussion of the breakdowns that occur in communities of practice if something interferes with the process of legitimate peripheral participation. They did not suggest that a particular community of practice would cease to exist without the socializing effects of legitimate peripheral participation. Rather, communities of practice will exist as long as members maintain their commitment to the community's work. However, those communities cannot be fully functional if newcomers cannot actually participate in the practice of the community, if their practice is not legitimate and authentic, or if newcomers cannot move from the periphery to centrality within the community (see also Gee, 2003).

Despite the high level of acceptance the idea of communities of practice has gained in the literature of learning and performance, there is sometimes disagreement as to whether or not the formation of communities of practice is always a healthy development. For example, Barab et al. (2004) believed that it was critical for a community of practice to include "respect for diverse perspectives and minority views" (p. 54). Characteristics such as this could lead one to assume that, by their nature, communities of practice are positive and progressive systems, and members of these communities are open to new viewpoints and ideas because those ideas will help them develop the richest practice possible. Given the large amount of research on the benefits of structuring learning environments around communities of practice (Johnson, 2001), it appears that many have also reached this conclusion.

On the other hand, Brown and Duguid (1996) wondered if the "warm persuasiveness” (p. 53) of the term community has led people to overly optimistic beliefs about the dynamics that happen in real-world communities of practice. In a later report 
they stated more explicitly that "communities of practice are, in fact, as likely to be cold as warm, may sometimes be coercive rather than persuasive, and are occasionally explosive” (Brown \& Duguid, 2001, p. 203). Similarly, Wenger (2000) cautioned that “witch-hunts were also community practices” (p. 230), and that while one can talk about communities that are more healthy than others, restricting the picture of communities of practice to purely positive endeavors prevents one from understanding all of the consequences that follow from their organization.

As vibrant social organizations, a number of both internal and external dynamics influence the working of communities of practice. For example, communities of practice seem to work best when they are free from external mandates regarding how to best accomplish their practice, but rather have "a core of participants whose passion for the topic energizes the community and who provide intellectual and social leadership” (Wenger \& Snyder, 2000, p. 141). As another example, experienced and established members of a community often receive great personal and professional satisfaction from their participation in the community (Hara, 2000; Schwen \& Hara, 2004). Yet Lave (1991) pointed out that there can be an inherent tension within communities, because older members realize that the ongoing success of the community depends on the replacement of the old members with the new. Often, community members experience other tensions as they encounter a culture within one community that conflicts with the cultures of other communities to which they belong (Hodges, 1998; Levine \& Moreland, 1991; Wardle, 2004). And, as Brown \& Duguid (2000) mentioned, some communities are close and personal while others are more distant. Observers have noticed differences in the levels of mutual engagement, the nature of the joint enterprise, and the types of 
shared repertoires as communities move along the spectrum of close to distant (see also Wenger, 1998).

Additionally, some of the dynamics within communities of practice can lead to community members either being more flexible or more rigid in how they conduct their practice. Wenger (2000) suggested several reasons why some communities remain flexible in their practice, while other communities become more reductive or inflexible. To retain flexibility, first, the nature of the community’s mutual engagement must encourage community members to trust the rest of the community. Since the practice of the community is larger than any one person, community members must be able to rely on each other to accomplish the practice at all, let alone accomplish it well (see also S. D. N. Cook \& Yanow, 1993; Lesser \& Storck, 2001). Second, the joint enterprise of the community must have continual improvement and a "spirit of inquiry" (p. 230) as a recognized and central aspect of the community’s practice. A passion for learning and improvement is critical to a community's ability to learn things of lasting value (see also Polanyi, 1962). And third, community members must be able to question and change the shared repertoire of the community, to facilitate the community's forward momentum.

This last point deserves more attention. As was discussed in an earlier section, sometimes one's practice become so routine and mechanical that certain behaviors become rote traditions, uncritically applied in situations in which they may not be appropriate. Pfeffer and Sutton (2000) labeled the tendency of communities to focus too much on their history as "using memory as a substitute for thinking” (p. 92). Lave and Wenger (1991) seemed to agree when they stated, while discussing the role of learning in communities of practice, that "the status quo [of a community] needs as much 
explanation as change” (p. 57). Brown and Duguid (1996) concluded that traditions in a community often arise when a practice becomes disconnected from its original reasons. And Wenger (2000) warned that unless they were careful, members of communities could "become hostage to their own history, insular, defensive, closed in, and oriented to their own focus” (p. 233). These conclusions seem similar of the conclusions reviewed earlier, concerning how unexamined assumptions about one's practice can lead to those practices becoming rigid traditions that have lost some of the essential qualities important to the original practice.

As mentioned, this literature does have application to the field of instructional technology. To summarize, instructional technology practice takes place in local communities which are influenced by larger networks of practice. Local communities of instructional technology practice may consist of groups working together on common problems. The influencing network of practice might consist of all of those communities which adopt the same general approach to instructional technology practice, and that act according to a general set of commonly accepted values, beliefs, and behaviors about that practice. The cultures of different communities tacitly teach participating instructional technologists about what is and is not an acceptable approach to their practice. Even if exposed to formal training regarding other types of practice, instructional technologists' cultural knowledge may continue to be more important when they make decisions in their day-to-day work. Instructional technologists' identities are that they are practitioners of a certain type of instructional technology, and they have been enculturated into that type of practice through powerful social-learning mechanisms. Finally, some communities of instructional technology practice may adopt rigid traditions, because they do not 
encourage a healthy type of organizational or community learning. Other communities adopt more flexible practices because they do encourage a reflective approach to organizational and community learning.

\section{The Technology I, II, and III Framework}

The literature reviewed to this point has all seemed to converge on the conclusion that instructional technologists can become trapped in a rigid and inflexible practice if they do not take steps to better understand their own assumptions and the assumptions of the communities in which they work. To help instructional technologists better understand their assumptions, Davies (1984) proposed grouping similar approaches, values, beliefs, and behaviors into categories that can focus instructional technologists on recurring patterns evident in professional thought, as well as give a general set of guiding principles to help practitioners make decisions about their work. As I discussed in Chapter One, researchers such as Beckwith (1988), Davies (1978), and Lumsdaine (1964) have described an interesting set of assumptions. While at various times they gave these assumptions different labels, a common set of labels that I will adopt for this study are Technology I, Technology II, and Technology III. Technology I was the presupposition that using mechanical or electrical devices improves instruction. Technology II was the presupposition that using formulas or strategies improves instruction. Technology III was the belief that good instruction could include many different devices, formulas, and strategies, but those technologies did not define good instruction. Rather, good instruction was the actual realization of improved systems in which learning could take place.

Historically, researchers have used Technology I, II, and III to describe the beliefs and behaviors of some instructional technologists who have fallen into inflexible and 
reductive practices, and the beliefs and behaviors of others who have remained flexible and achieved a wider variety of goals in their practice. The ideas of Technology I, II, and III appear to correlate with much of the literature already reviewed in this chapter. First, some of the researchers describing Technology I, II, and III have stated that one of their purposes is to better understand the results of many of the historical influences on the field. Additionally, Technology I, II, and III show the consequences that can follow when instructional technologists become too bound to the traditions of their practice, as well as the potential positive results that can follow if they become more reflective about their assumptions and open to unfamiliar ideas in their practice. For instructional technologists who are interested in exploring their foundational assumptions, Technology I, II, and III may make the exploration more convenient. And finally, some who have described Technology I, II, and III have also described reasons why instructional technologists may abandon a flexible type of practice for a more rigid one. Because these reasons often relate to the environmental context in which instructional technologists work, many of these reasons appear to align well with descriptions of how healthy or unhealthy communities of practice may develop.

Although no one report provides a complete definition of Technology I, II, or III, a number of researchers (e.g. Beckwith, 1988; Davies, 1973; Lumsdaine, 1964) have described many of the basic concepts involved. While many of the reports that specifically mention Technology I, II, and III are dated, other researchers in the field have paid attention to the fundamental concepts, even though they have not specifically adopted the terms Technology I, II, and III. To describe Technology I, II, and III in a way helpful to readers, I will organize my discussion of each of them around three themes that 
are identifiable in the literature. Taking the suggestion of Yanchar and Slife (2004), that one should ask questions in order to uncover one's fundamental assumptions, I will discuss these themes through three questions: First, what do practitioners of each level of Technology I, II, and III believe is the basic problem they are trying to solve through their practice? As Davies (1978) said, "the way in which an educational problem is stated, the principles and concepts that are used, all provide a starting point” (p. 15) that leads logically to the solutions. Second, what do practitioners at each level of Technology I, II, and III believe about the definition of learning and the nature of learners? Third, what do practitioners at each level of Technology I, II, and III believe about the nature and benefit of technology as it applies to instruction? Yanchar and Slife also suggested that after articulating the foundational assumptions of an approach, one should explore the consequences and implications of those assumptions. This can help practitioners understand whether or not their assumptions are leading to results they desire. A discussion of consequences and results leads to a fourth question which I will answer along with each of the definitions of Technology I, II, and III. This question is, what results can follow from the adoption of practices consistent with Technology I, II, or III? In exploring each of these issues, I recognize that the answers to each question are most likely interrelated and do not easily separate into isolated, self-contained discussions. Nevertheless, for ease of analysis, I will separate each discussion of Technology I, II, and III, and within each discussion I will answer each question separately and in order. While the following discussion will potentially be very helpful to instructional technologists, it is not the only way of describing Technology I, II, and III. I recognize the interrelated nature of each theme, and I intend no oversimplification. I 
additionally recognize that Technology I, II, and III are only one way of organizing a discussion about instructional technology practice. The researchers who have described Technology I, II, and III did not intend the framework to describe all aspects of an instructional technologist's work. As this chapter will discuss, fundamental to Technology I, II, and III is the belief that good instructional technology practice reflects a wide variety of perspectives and intellectual tools. Presumably, then, those who have historically described Technology I, II, and III would also agree with the conclusion that instructional technologists should use other interpretive frameworks as necessary to develop the richest possible understanding of their practice.

\section{Technology I}

The basic definition of Technology I is the "mechanical or electro-mechanical tools, instrumentation, or 'hardware' which can be used for instructional purposes” (1964, p. 372). Beckwith (1988) stated the definition in a slightly different way when he said Technology I was "the tools approach ... [or] the application of audio-visual devices to the improvement of teaching” (p. 4). Yet Technology I is not simply using technological devices for instructional purposes. Rather, the practice of Technology I occurs when technological devices are viewed as the critical feature of an instructional situation, or when the ultimate measure of quality for an instructional product is viewed as the use of a technological device. An important intellectual heritage for Technology I has been the influence of audiovisual instruction (Davies, 1978), which has often promoted study of the effects of media and technological hardware on instruction. In fact, Januszewski (2001) believed that a view of instructional technology that placed emphasis on the physical devices of instruction has been one of the most prevalent historical views 
of the field, as well as the view that has characterized much of the research that members of the field have conducted.

The practice of Technology I results from assumptions that make this understanding of instructional technology appear to be logical, rational, and correct. My purpose in this section is to describe assumptions that can lead to the practice of Technology I, through an analysis of research literature that either mentions Technology I, II, and III, or that describes similar assumptions but does not mention Technology I, II, or III specifically. My description of Technology I will be organized around the major themes proposed earlier, of instructional technologists' beliefs about the purpose of instructional technology, the nature of learning and learners, and the nature of technology as it applies to instruction. I will also point out that practitioners of Technology I can neglect important characteristics of instructional problems and solutions that the instructional hardware they use to develop instruction cannot easily express. This can result in rigid practice, with instructional technologists creating inflexible instruction that cannot adequately meet some students’ learning needs because they view only certain types of instruction as legitimate. This section concludes with a discussion of what types of rigidity the literature predicts can result from the practice of Technology I.

Before beginning a more detailed discussion of Technology I, however, I wish to emphasize that this section is not an attack on the general idea of using instructional hardware or instructional media, nor is it an attempt to revisit the classic media-versusmethod debate (R. E. Clark, 1994b; Kozma, 1994). As I will discuss more fully, the literature describing the assumptions of Technology I is, in actuality, criticizing the thoughtless acceptance of those assumptions. And, again, this can potentially lead to rigid 
traditions of practice which practitioners adopt not necessarily because they are the most appropriate choice for a situation, but because they have become familiar and routine. I hope that readers of this section will not interpret my comments as being more critical of the physical devices used for instructional purposes than they are meant to be.

The first theme in Technology I is that instructional technologists believe the primary problem they are trying to solve is how to make teaching a more efficient and scalable activity. Although Davies (1997) did recognize practitioners of Technology I might also see value in using instructional technology for other purposes, such as creating more entertaining or more effective instructional experiences, the dominant view in Technology I is that traditional teaching is a highly inefficient activity that we can and must make more efficient. Davies (1973) stated this theme succinctly when he said, "the aim of [Technology I] has been to increase the impact that teaching makes, without substantially increasing the cost of each student taught” (p. 5).

One example of this theme has been the traditional push to increase the number of students that each individual teacher can instruct. While this has been an important topic in education for many years (Saettler, 1990), it became a driving concern for many instructional technologists during World War II, when large numbers of untrained soldiers had to be prepared for war (Reiser, 2001a), and during the 1950s when an increasing number of children began entering the school system without a corresponding increase in the number of qualified teachers (Tyler, 1975). Another example of this theme has been the attempt to decrease the costs of some instructional experiences that are otherwise too impractical to consider (Lumsdaine, 1964). Other examples of how this theme has affected instructional technologists also include the desire to provide 
instructional modes that present information more quickly than possible through live teaching alone, to more cheaply produce and distribute instructional materials, to create aids for instructing students at a distance, or to find time savings when conducting other educational activities such as testing (Davies, 1997; Lumsdaine, 1964). While these are important problems and are not unique to practitioners of Technology I alone, it is important to note that practitioners of Technology I rarely move beyond this understanding of their purpose (Davies, 1978). As I will discuss in more detail later, in viewing the purpose of instructional technology only in this way, instructional technologists sometimes limit their view and may misunderstand the problems they encounter in many instructional development situations (Beckwith, 1988; Gilbert, 1960).

The second theme in Technology I is the critical requirement of good learning is that information be transmitted to learners in the most efficient manner possible. A corollary to this is the belief that learners are vessels which receive whatever information has been sent (Davies, 1978). In other words, the practitioner of Technology I believes that learning is what is done to students, and not what students do in return (Davies, 1973; Januszewski, 2001). Lumsdaine’s (1964) analysis of this view is highly relevant. Although on the surface his comments reflect the tradition of behavioral psychology which was prevalent when he wrote, his underlying observation is still applicable for Technology I today. Lumsdaine stated that in some situations, instructional media was "almost exclusively used as vehicles for presenting stimulus materials, with little explicit attention to the response aspect of the stimulus-response paradigm of learning” (p. 377). Perhaps a more current way of stating Lumsdaine's message would be that sometimes instructional media is "almost exclusively used as vehicles for presenting [information], 
with little explicit attention to [what students do with that information in return].” Such a claim is consistent with Jonassen's (1994) statement that “our field . . . is founded on the premise that communicating content to students will result in learning.”

Davies (1978) later echoed the Technology I focus on information presentation when he said that the goal in Technology I was to "mechaniz[e] or automat[e] the process of teaching” so that it would be easier to "transmit, amplify, distribute, record, and reproduce stimuli materials” (p. 13). This view of learning is very closely connected with a view of the learner as a "passive instrument to be manipulated and acted upon” (Davies, 1973, p. 10). Davies (1973) described the Technology I view of learners as a group that must be constantly controlled or else they could not (or perhaps would not) learn what had been taught (see also Nichols, 1991/1987). The Technology I view of learning and of learners, then, may encourage a view of students that does not see them as capable of making their own learning decisions without the supervision of some type of instructor or instructional guide.

The third theme of Technology I is the nature and benefit of technology as it applies to instruction is that the physical devices used for instruction have an intrinsic ability to solve educational problems. This theme, perhaps the most recognizable of Technology I, has received very heavy criticism in the field of instructional technology for at least fifty years (Beckwith, 1988), yet interestingly it continues to find those who will still advocate for it. The observation Davies (1973) made over thirty years ago, "that a technology of machines is intimately related to a technology of teaching, and progressive views, are, accordingly, often associated with the possession of the latest [machine]” (p. 5) still sounds current to some instructional technologists. For example, du 
Boulay (2000) recently observed how advocates for a particular tool still frequently describe the "wonderful educational results [that follow] simply by virtue of that technology” (p. 10). Salomon (2002) added the comment that

It appears that many [advocates of technology] entertain the expectation that computers, all on their own, will bring about a change. All you need is to equip schools with computers and with access to the Internet and voilá - a revolution will start. (p. 72).

This view of the innate power of technological devices seems to spring from a more fundamental belief that teaching activities somehow cause learning to take place. Hlynka and Nelson (1985) stated this argument succinctly when they said, “[if] the teacher is perceived as a potter at the wheel, moulding and shaping the thinking of the students. ... [then] to improve upon the tools should obviously improve upon the product” (p. 12). Also, instructional technologists have sometimes expressed the belief that technological hardware had power to improve instruction because the capabilities of the hardware drove innovation in other areas. In other words, as the physical tools of instruction became more capable, they would force a change in theories of instruction, making them more capable as well (Finn, 1963).

These assumptions of Technology I can result in instructional technologists producing instruction that is not flexible enough to adapt to real-life diversity in students' educational needs, because the languages and tools those instructional technologists use to develop instruction limit the types of instruction they view as legitimate. As I mentioned, this observation is not an attack on the idea of using instructional media or instructional hardware in general. Many of the benefits of instructional technology described by practitioners of Technology I do, in fact, exist. For example, technological hardware or audio-visual devices can help teachers show things to students they would 
otherwise not be able to show. The problem, then, has occurred when instructional technologists see the practices and products of Technology I as the only, or even the primary, solutions. In effect, instructional technologists' reliance on the ideas of Technology I are traditions that they adopt without reflection as to whether or not there might exist more appropriate alternatives for the situation in which they are working. As I will show, some researchers have predicted that practitioners of Technology I sometimes redefine all aspects of their practice into instructional technologies that aligns with their existing Technology I perspective.

The first way in which this result of Technology I is visible is when practitioners of Technology I inappropriately apply instructional media or other hardware when solving an instructional problem. The observation that instructional technologists encounter difficulty when they focus solely on the physical tools of instruction has a long history in the field. As early as 1960, Gilbert stated, “if you begin with a device of any kind, you will try to develop the teaching program to fit the device” (p. 478). Beckwith (1988) also criticized this tendency when he stated that there was a "temptation [for instructional technologists] to define learning and instructional problems in terms of the latest innovative 'solutions' rather than to create appropriate solutions to pre-addressed problems.” (p. 8). He also believed that instructional technology was in constant danger of being “defined by its most visible and tangible parts” (p. 9), or the concrete technological devices it uses for instructional purposes.

More recently, Januszewski (2001) and Gibbons (2003b) have echoed similar criticism. Gibbons, in particular, analyzed the practice of what he labeled "media-centric designers” (p. 22), and concluded that they did tend to describe instructional problems 
and solutions in the only language and terminology they knew, which centered on the physical medium of transmission. This is problematic, Gibbons concluded, because the language of media alone is inadequate to fully represent the range of possible solutions to instructional problems. In Gibbons’ words, these instructional technologists “struggle ... to apply inadequate thought tools to complex design problems” (p. 22).

The end result of this particular mindset is that as new tools for instruction appear, practitioners often use them to reproduce the same instructional experiences common to the field. Davies (1978) observed, “instead of viewing educational technology as an opportunity for renewing educational practice, it has, too often, been conceived as a means of doing what has always been done-only more efficiently” (p. 12). More recently, both Häkkinen (2002) and Reigeluth (2001) have also come to a similar conclusion. And Häkkinen stated, "hardware technology has too often been harnessed merely to accommodate ... traditional conceptions of learning” (p. 464). And Reigeluth appeared to concur when he said that

In most educational and training settings, hard technology is not typically used in a way that entails changing how things have traditionally been done. . . . One could say that technology's role typically has been to do the wrong thing better, rather than to do the right thing. (p. 13)

Another way in which the result of Technology I appears is in how products of Technology I sometimes only superficially meet the needs of students, because the instructional technologist's view of learning and of learners is too limited. In Technology I there is such a strong emphasis on how to improve teaching activities that sometimes little or no attention is given to whether or not those activities actually have any influence on student learning (Davies, 1973). For example, Lumsdaine (1964) observed that often instructional media produced from a Technology I viewpoint is used to provide consistent 
presentations to every student "without explicit regard to individual differences in learning ability” (p. 376). And according to Yeaman, the situation has not improved much since Lumsdaine's time, with some instructional technologists still focusing on one-size-fits-all instruction for students regardless of ability (Januszewski, 2001).

Dick (1987) blamed this tendency on the fact that the capabilities of instructional tools were advancing at a tremendous rate, but without a corresponding increase in understanding among instructional technologists about how to use them appropriately for instruction. Ironically, this result is the opposite of what Finn (1963) earlier predicted. Also, both Lumsdaine (1964) and Davies (1973) noted that nearly all of the devices instructional technologists in Technology I adopted were originally developed for purposes other than instruction (see also Reiser, 2001b). In fact, Lumsdaine went so far to suggest that much of the research from a Technology I perspective had been conducted more to justify already existing uses of an instructional tool, rather than to understand or improve the use of that tool. This was problematic, Lumsdaine continued, because instructional technologists were simply unaware of the effect their tools were really having on their students. And when this tendency is combined with the Technology I view of learners as vessels to absorb information transmitted by instruction, it appears that this type of instructional technology may actually result in instructional experiences that are boring and uninspiring. As Davies (1973) summarized, "there is a marked tendency ... [in Technology I] to emphasize the importance of rote-learning. ... There is little ‘discovery’ or challenge” (p. 10) for students. And, according to Hockings (2004), this approach is evident in the practice of some teachers today, even among those who may claim to appreciate more flexible ideas about how to help students learn. 
A final way in which the result of Technology I appears is that practitioners of Technology I sometimes do not consider other possible educational goals that may lead to a wider range of educational outcomes, because they define all educational problems in terms of efficiency and scalability. Januszewski (2001), in reviewing the history of instructional technology, lamented the tendency to make standards like "efficiency ... the de facto ends of education rather than well-thought-out goals grounded in a sound educational philosophy” (p. 86). In assuming that efficiency and scalability, as important as they may be, are the only legitimate educational goals worth pursuing, practitioners of Technology I are sometimes tempted to redefine other problems they face into the language and terminology of efficiency and scalability. This may happen even if the original problem had little to do with these goals. When instructional technologists focused their work only on one goal or one type of purpose, Davies (1997) felt they were being "myopic" (p. 32) in their views, and warned that they may not be able to make the positive changes the instructional innovations they champion promise. Unfortunately, if instructional technologists redefine their instructional goals into other goals, the new goals may only marginally resemble the goals they started with. They actually investigate only those parts of their goals which they can describe in the language of their new goals. This can potentially leave out many critical aspects of the problems they are trying to solve, because they no longer consider those aspects a legitimate part of the goal they are pursuing (see Slife, 1998).

Many of these criticisms are well known in the literature of instructional technology. It may be that current readers will review Technology I and find this type of practice to be obsolete or out of touch with today's concerns (for a summary of 
Technology I, see Table 1). And, in fact, Beckwith (1988) claimed that the field of instructional technology as a whole had started to move beyond the practice of Technology I in the mid-1950s. Yet even the most current researchers have been concerned that some Technology I practices may still influence today’s instructional technologist (or user of instructional technology). Additionally, it may be that some of the common reactions to Technology I have also been overly rigid in the alternatives they provide. For example, a common reaction to ideas consistent with Technology I has been that it is not the instructional hardware or media that makes a difference in student learning, but the instructional method (e.g. R. E. Clark, 1994a, 1994b). But the question can be asked, how much more successful is this alternative to the practices of Technology I? Turning now to a discussion of Technology II, I will show that while broadening the practice of instructional technology to include more than physical devices may solve some of the problems encountered with Technology I, it is also not enough to avoid all of the rigidity that observable among some instructional technology practitioners. 
Table 1

Summary of Technology I

Theme

Technology I

Purpose of instructional

technology

Making teaching more efficient and scalable.

Beliefs about learning and learners

Good learning is efficient; learners are vessels.

Nature of technology in instruction

Consequences

Neglect of important problems and solutions; inflexible practice; viewing only some instructional types as legitimate.

\section{Technology II}

The basic definition of Technology II is the "development and application of methodological, rule-based processes [used for] the facilitation of learning” (Beckwith, 1988, p. 4). Technology II is not the same as simply using a process, strategy, or technique for instructional purposes. Rather, Technology II results when practitioners view processes, strategies, or techniques as the critical features of an instructional situation, or see the use of certain processes, strategies, or techniques as the ultimate measure of quality for an instructional product. Two of the important intellectual heritages for Technology II have been the influences of psychology (especially behavioral psychology) and the application of an engineering metaphor to instructional technology (Davies, 1978), both of which are consistent with many current views of instructional technology (Januszewski, 2001). Additionally, the definition of Technology II is broader than the definition of Technology I. Technology II encompasses more than 
just the physical devices of instruction to include processes and techniques that, in the spirit of Saettler's (1990) definition of technology, allow for "the systematic use of knowledge for intelligent human action” (p. 3). While practitioners of Technology II do use physical hardware for instructional purposes, they do not believe that hardware is the critical feature of the instruction. Rather, practitioners of Technology II believe the critical features of instruction are the instructional methods that they express through the hardware (Davies, 1978).

As with Technology I, the practice of Technology II results from assumptions that make this understanding of instructional technology appear to be logical, rational, and correct. My purpose in this section is to describe assumptions that can lead to the practice of Technology II, through an analysis of research literature that either mentions Technology I, II, and III, or that describes similar assumptions but does not mention Technology I, II, or III specifically. My description of Technology II will be organized around the same major themes I have used this far, of instructional technologists' beliefs about the purpose of instructional technology, the nature of learning and learners, and the nature of technology as it applies to instruction. As I will also discuss, practitioners of Technology II can neglect important characteristics of instructional problems and solutions that they cannot easily express in the languages and processes they use to develop instruction. As with Technology I, this can also result in a rigid practice, with instructional technologists sometimes creating look-alike instruction that cannot adequately meet real-life diversity in students' learning needs. This section concludes with a discussion of what types of rigidity the literature predicts can result from the practice of Technology II. 
Before beginning a detailed discussion of Technology II, however, I wish to emphasize that this section is not an attack on the techniques or processes used in Technology II to develop instruction, per se. As I noted earlier, the spirit of this study is that all methods of developing instruction can be helpful, depending on the circumstances of the practicing instructional technologist. Some of the critics in this section do speak harshly about Technology II. Yet it will be shown that they are not criticizing the use of instructional processes in and of themselves, but rather are criticizing a type of practice in which practitioners see certain methods as the only legitimate way to develop instruction. As with the definition of Technology I, I urge readers to interpret this section as an argument against narrow views of instruction, learners, and technology, rather than as an argument against any particular instructional form or methodological approach. As Davies (1978) stated, criticisms of a Technology II approach are only a "warning of the limitations that can be expected if enthusiasm and systematic development activities lose sight of the ultimate 'name of the game'” (p. 14).

The first theme in Technology II is that instructional technologists believe that the primary problem they are trying to solve is how to develop instruction that effectively and efficiently helps students reach a predetermined instructional outcome (Davies, 1978). Sims (2006) recently stated this theme succinctly when he said, "Instructional Design focuses on following pre-determined pathways that, if undertaken rigorously, will ensure a transfer of knowledge” (p. 2). To some, this sense of purpose is the defining characteristic for the practice of instructional technology (Merrill, Drake, Lacy, Pratt, \& The $\mathrm{ID}_{2}$ Research Group at Utah State University, 1996). Lumsdaine (1964) reported that this focus became important to instructional technologists in specific reaction against 
what some practitioners saw as the excessive Technology I emphasis on improving methods of information presentation without paying attention to the learning outcome they expected to occur as a result of that presentation.

Since some may wonder why I include such a seemingly universal purpose for instructional technologists here as belonging specifically to Technology II, it is important to comment further. As I have discussed, Technology II does contain many helpful ideas, of which this theme is one. However, the tendency in Technology II is to adopt these ideas as ends in themselves, rather than as a possible means to other ends (see Januszewski, 2001). When instructional technologists adopt a sense of purpose that gives primacy to the development of instruction, they tend to act as if the need for their instruction was a given (Schwen et al., 1984). Yet Davies (1997) pointed out that when instructional technologists begin with the assumption that instruction is the best solution, by definition they are blind to the possibility that sometimes it is not, and that it may be better to address some learning problems through means other than formal instruction. Additionally, this theme of Technology II places the emphasis on preplanned instruction that meets predetermined outcomes. This can be problematic, as Wilson (1997) warned, because it may be that many important learning outcomes simply cannot be predicted in advance, and instruction that ignores this potential may not be sufficient to facilitate students' achievement of those outcomes.

The second theme in Technology II is the critical requirement that leads to learning is for people to experience the appropriate processes and strategies that control the acquisition of the desired learning outcomes (Lumsdaine, 1964). In part, this view of learning was in reaction to the Technology I view of instruction as simply the 
presentation of materials to students without regard to what the students did with those materials in return (Davies, 1973; Lumsdaine, 1964). Some have even represented the Technology II view of learning as a legitimate science of instruction (see Yeaman, 1994). Early advocates of creating a science of instruction believed that in so doing they would be able to modify learning environments in ways that could bring about any type of desired learning outcome (Januszewski, 2001; Merrill, 1971). Lumsdaine (1964) specifically proposed that psychology, especially behavioral psychology, was the foundational science on which to build a separate science of instruction. As he stated

Optimal [instruction], applicable to many students, can often be better determined through psychological analysis of the ... learning task, together with empirical development based on responses of typical students, than by the efforts of any one student to sequence his own activities. (p. 383)

But Lumsdaine also recognized value in using techniques from biology, communications, economics, and statistics in building an instructional science. And as techniques from other fields have application to human learning, they have also been ingredients in the scientific base of instructional technology (Saettler, 1990). The only requirement for inclusion has been that practitioners could empirically show the instructional technique or strategy to be a superior cause of learning than other alternatives (Davies, 1978).

The Technology II view of learning and learners has led to both some similarities to and differences from Technology I in how instructional technologists conduct their practice. Whereas Technology I assumes that learners learn just through exposure to effective instruction, Technology II believes that learners have to make some active response to instruction in order to learn (Lumsdaine, 1964). This difference does promote some practical differences in how instructional technologists treat learners. For example, Dick (1987) noticed that as instructional technologists moved away from views of 
learning-as-information-presentation towards views of learning-as-active-response, they also changed their focus away from specifying only what teachers would do during instruction, and began focusing more on what students themselves would do during instruction (see also Merrill, 1971). And Davies (1973) noted a trend in Technology II that led to instruction that was "so carefully structured and designed that learning [was] enjoyable, rewarding, and successful. Rote learning . . . was minimal, and the importance of the meaningful learning of potentially meaningful tasks ... [was] emphasized” (pp. 11-12).

Yet in addition to these adjustments in how instructional technologists view learners, there is still a strong assumption in Technology II about the power of instruction to control learning. For example, Lumsdaine (1964) stated his belief that the instructional technologist had primary responsibility for whether or not students learn during instruction, because the principles of behavioral psychology on which they relied had power to control whether or not learning took place. Writing from the same era, Merrill (1971) stated that effective instructional events “cause the learner to interact [with the learning environment] in such a way that a specified change occurs in his behavior” (p. 1, emphasis added). And Corey (1971/1967) stated that "the assumption [of the instructional technologist] is that [the student's] reactions will result in the intended modifications of [that student's] behavior” (p. 6).

Although most current instructional technologists believe the field has moved beyond the assumptions of behavioral psychology, Jonassen (1991) noted that some instructional technologists behave as if these assumptions still influenced them. This appears to include the assumption that instructional events ultimately explain and control 
learning, although it is more common to hear appeals to cognitive or social principles, rather than behavioral principles, as the controlling force (e.g. Winn, 2004). Nichols (1991/1987) summarized this still-common Technology II view of learners by observing that among instructional technologists, "human learning is [often] believed to be ultimately explainable and predictable via science and technology” (p. 126). And Wilson (2005a; 2005b) recently noted that some assumptions about the deterministic power of instruction still influence many current approaches to instructional technology, even when advocates of those approaches sometimes claim to believe otherwise.

The third theme in Technology II is the nature and benefit of technology as it applies to instruction is that the processes and methods used to develop instruction have an inherent power to solve educational problems. This understanding of the benefit of technology is broader than the Technology I view, which ascribed power to the technological devices used for instructional purposes. In Technology II, just as science has the power to predict and control learning, engineering-like processes based on that science also have the power to create instruction that controls learning (Gordon \& Zemke, 2000; see also Merrill et al., 1996). Lumsdaine (1964) summarized the believed power of these processes, stating that over time instructional technologists would be able to develop processes that would give them total "control over learning," and let them "realize [the] goal of guaranteed mastery for all qualified students" (p. 387). Although this is not a universally held belief among instructional technologists (Molenda, 1997), many researchers have become more bold in discussing this assumption, as well as in criticizing its validity (Gordon \& Zemke, 2000; Osguthorpe, Osguthorpe, Jacob, \& 
Davies, 2003; Romiszowski, 1996; Zemke \& Rossett, 2002). Davies (1997) summarized

this belief well when he concluded that

A great deal of initial effort [in instructional technology] was expended in comparing the efficiency of one methodology with another. ... In order to find the "one best way," the whole process of instructional development was flowcharted, complete with boxes, arrows, and feedback loops, in an attempt to lay down a systematic step-by-step process. It was prescribed that the ends must always be defined before the means. The systematic approach was emphasized as the only way to go. (p. 36)

Williams' (2005) comments on the role of method in psychology are relevant in

illustrating why practitioners of Technology II rely on methods which they believe will

allow anyone to develop effective instructional materials:

Psychology has found great appeal in the assumption that methods might guarantee to any practitioner real knowledge, given that minimal conditions of training and expertise are met and regardless of the presence of other factors such as the cultural, moral, and philosophical commitments of the practitioner himself or herself. It is assumed that methods as methods are immune from the influence of these things, or that they have built-in guarantees against such influences when properly applied. (p. 240)

Wilson (1997) stated this position similarly when he said, "such a view ... places the expertise or knowledge into the textbook—or the rule-based expert system. ...

Technician-level people can even do it, even if they don't really understand what they're doing” (p. 301). As Gibbons (2001) said, this belief can lead to the conclusion that people can use instructional development processes to "build-in to [instructional] products the wisdom and judgment of the expert instructor” (p. 519), and so give power to that instruction to produce consistently acceptable results (see also Hlynka \& Nelson, 1985; Osguthorpe et al., 2003).

Many of these instructional development processes are commonly referred to by blanket terms such as ISD or ADDIE (Dick, 1987; Molenda, 2003). Often they require instructional technologists to proceed in a step-by-step, methodical fashion, and rely 
heavily on empirically gathered data as the foundation for decisions they make during the instructional development process (Willis, 1995). Davies (1978) described some of the critical aspects of Technology II practice as

Identifying appropriate aims, goals, and objectives; selecting relevant content and subject matter; choosing contrasting learning methodologies, activities, and experiences so as to make for a worthwhile and rewarding course of study; and then evaluating not only the success of the resulting learning experience but also the effectiveness of the very development techniques employed. (p. 13)

As I discussed earlier, often instructional technologists believe these processes are an application of systems theory. But in reality it is more accurate to label them as systematic, because of their procedural natures, rather than as applications of systems theory (Hug \& King, 1984).

These three assumptions of Technology II can result in instructional technology practitioners neglecting important characteristics of instructional problems and solutions that they cannot easily express in the languages and processes they use to develop instruction. Similar to Technology I, this can result in inflexible practice, with instructional technologists creating look-alike instruction that cannot adequately meet real-life diversity in student learning needs. As I mentioned earlier, this critique is not directed as much towards any particular instructional technique or strategy, or instructional development process, as it is directed towards a type of practice which sees only a narrow range of approaches as legitimate. Januszewski (2001) pointed out a difference in the way instructional technologists have described instructional development which is relevant in this discussion of results of Technology II. He observed that in some cases instructional technologists have used instructional development methods as tools to help them focus their attention on important details of their work, and in other cases they have used processes or methodologies in an "assembly-line” (p. 4) 
fashion, requiring a linear, stepwise adherence to the process because it appears scientific or because it has produced results in the past. This same critique extends to Technology II. As Gibbons and McDonald (2005) stated, "having arrived at a set of usable solutions, [Technology II] chooses to stop seeking new solutions and changes from a search for solutions to a service and a craft” (p. 7). As in Technology I, the ideas in Technology II can solidify into traditions that practitioners then unquestionably apply. It is this result that the critics of Technology II have argued against, and that I will describe more fully below.

One way in which the results of Technology II become visible comes from the Technology II theme of practitioners believing that the primary problem they are trying to solve is how to develop instruction for a predetermined set of outcomes. Davies (1989) criticized this statement of purpose as being "too narrow. It limits the scope" (p. 133) of instructional technology practice. While a belief that the purpose of instructional technology is to design formal instruction may seem logical, it can also lead practitioners to redefine any encountered problem into one requiring designed instruction to solve. In another article, Davies (1997) criticized this view because when instructional technologists design instruction for situations in which it was not necessary, the adopters of that instruction may lose trust in instructional technologists' ability to appropriately solve educational problems. While Davies’ primary concern was for business situations in which the ultimate goal was performance and not necessarily abstract learning, his critique is not solely encouraging instructional technologists to find other methods of workplace performance improvement besides formal training. It applies equally well to situations in which learning is obviously valuable, but where a designed instructional 
product may not be the best approach to facilitate that learning (Januszewski, 2001; Wilson, 1995).

The results of this tendency are compounded because of another tendency derived from the Technology II view of the inherent power of instructional methods and processes. Because practitioners of Technology II attribute so much power to their methods, they tend to define all new instructional innovations in terms of what is already familiar and that most easily allows them to apply the techniques of their already used instructional development processes. The problem with this is that the languages and notation systems these processes use to create and explain instruction (see Gibbons \& Brewer, 2005) sometimes cannot adequately account for the new characteristics of an innovation, and so may lose a critical feature of that innovation. Researchers have long recognized this potential problem. Lumsdaine (1964), for example, warned of this in the then-innovative method of programmed instruction. He said that the "tendency [of programmed instruction developers was] to identify some particular kind of program with the term 'program,' or to fasten on some particular feature of current programs as a principle identifying characteristic” (p. 382), and then to reject anything that did not fit into their narrow definition of the technique regardless of whether or not it might have any potential benefit. Mitchell (1989) noted the same problem twenty-five years later, when he criticized instructional technologists for trying to fit all instructional products into certain formats for instructional development, such as always starting with performance objectives, or following certain rules for information display. More recently, Reeves, Herrington, and Oliver (2004) also noted how practitioners still tend to express some of the most recent advances in instruction in traditional language and methods, 
rather than using advances as opportunities to create new alternatives for accomplishing the goals of instructional technology practice.

These two tendencies may in part have to do with what happens when one's assumptions become so ingrained into one's beliefs and behaviors that they cut off questions about those assumptions. Slife (1998) discussed how the assumptions of psychologists often lead them to operationalize complex theoretical ideas into simplified methodologies to more easily work with those ideas. Slife called this a process of “translation” (p. 213), recognizing that operationalizing ideas requires us to express them in a new language which may or may not be fully capable of expressing all the nuance of the original ideas. Slife continued by explaining that once a person began using a process based on a translated idea rather than the original idea itself, "only those aspects or that particular rendition of the original idea [that can be expressed in the new language] is truly investigated. ... Results, therefore, may have little to do with the original ideas before translation” (p. 213). Kirschner (2005) came to a similar conclusion when she stated, “there is often a great deal of distortion and simplification” (p. 269) of complex ideas and theories to translate them into the processes and methods that practitioners actually use to implement those ideas (see also Jonassen et al., 1997).

These ideas of translation appear to be similar to what happens when instructional technologists operationalize ideas about how people learn into an instructional strategy or an instructional development approach. Osguthorpe and Osguthorpe (2002) considered the how the translation of ideas into instructional models might affect the practice of instructional technology:

Those who implement a given model [of instructional development] might observe some benefits of their instruction and unintentionally ignore more 
important negative side effects - all because the model itself, to simplify the design task, has obscured the view of learning in all its richness and variety. (pp. 10-11)

An implication of this statement is that the processes instructional technologists use in some cases might actually prevent them from implementing a flexible instructional approach, because the process itself may preclude them from considering that approach as a viable solution. Sfard (1998) seemed to be expressing this possibility when she warned, "when a theory is translated into an instructional prescription, exclusivity becomes the worst enemy of success. Educational practices have an overpowering propensity for extreme, one-for-all practical recipes” (p. 10). Beckwith (1988) came to a similar conclusion. He felt that many of the original ideas central to good instructional technology had undergone a "cementing [which turned them into] reductionist . . . static, systematic research models” (p. 14) that could not adequately help practitioners develop instructional experiences that could facilitate the widest range of educational goals.

McDonald et al. (2005) concluded that the translation of instructional ideas into rigid processes sometimes "prevented teachers and students [who used instruction created from these processes] from exploring subject matter in ways that may have been more suitable to the particular needs of that group” (p. 89). For example, practitioners of Technology II often state their goal as to create instruction that is highly individualized to the needs of each student. Yet by following some common instructional development practices, the resulting instruction may in fact be more homogenous and less able to adapt to individual needs (Davies, 1997; see also Dick, 1987). Wilson (2005b) wondered if the use of reductionist development processes sometimes led to “an intangible part of instruction —a valued goal, experience, or outcome-[being] lost as things are documented and codified” (p. 242). The counsel of Davies (1984) in this regard seems 
wise: "procedures do not define the field [of instructional technology], any more than sawing, planning, chiseling, shaping, hammering, and finishing define the field of carpentry. The nature and scope of instructional development remains hidden when only techniques are discussed” (p. 9).

Further, as processes and methods in Technology II become more formalized, they also tend to become more rigid. Finn (1960a) proposed that, "the thrust and energy of technology will force a greater organization upon us at every point at which it is applied to instruction" (p. 21). Finn was speaking of technology as more than just the use of physical devices, but also in the spirit of technology as this section defines it, the application of rational processes to aid human activity. Beckwith (1988) described many common Technology II development processes as the "solidification” of helpful ideas into "uniformly applied rules” (p. 13) that instructional technologists attempt to use in any situation without fully understanding whether or not those rules are appropriate for the situation (see also Romiszowski, 1996; Tennyson, 1994; Winn, 1986, 1997). And Wenger (1998), who labeled the process of making of abstract concepts concrete "reification” (p. 58), also described some of the possible consequences of ideas and methods becoming more formalized:

The process of reification can be very powerful.... A procedure can reify a concept so that its application is automatic. A formula can express in a few terms a regularity that pervades the universe. But the power of reification-its succinctness, its portability . . . its focusing effect-is also its danger. ... . Procedures can hide broader meanings in blind sequences of operations. And the knowledge of a formula can lead to the illusion that one fully understands the process it describes. (p. 58)

Davies (1973) also believed that the practices of Technology II could become too standardized, and "introduce a degree of rigidity and lack of flexibility" into instructional technology practice that could make new "changes difficult to introduce or accept" (p. 
16). Gayeski described this as the "clone the best practice and then rigidly follow it" (Gordon \& Zemke, 2000, p. 52) approach to instructional technology, one that focuses more on perfecting existing methods than on seeking out new ideas. Tennyson (2000) recently observed that instructional development processes, as commonly understood, “offer the same solution process regardless of the conditions of the given learning problem or need” (p. 232; see also Brown \& Duguid, 1996). And Zemke and Rossett (2002) speculated that the traditional understanding of how to develop instruction has been “pushed beyond rational utility and made into a lock-step straitjacket” (p. 32) that does not give instructional technologists the help they need to make unanticipated decisions during a development process.

Additionally, there is actually little evidence that instructional technology processes have been subjected to any empirical verification at all, despite that many practitioners of Technology II believe their approaches are based on verified, scientific knowledge. Rowland (1993) said, "the body of literature describing and prescribing ID processes is based primarily on experts' opinions and recollections rather than a systematic investigation” (p. 79). Wilson (2005b) pointed to the lack "of a solid body of research empirically demonstrating [the] advantage [of common instructional technology practices] over other curriculum development methods” (p. 242). Yeaman (1994) concluded that, "models [of instructional development] are not so much empirically based on ... research as they are founded upon agreement about conventional practice” (p. 18). And Murphy provided the ultimate test. Observing that there do exist examples of successful learning where no one adhered to any instructional development process, he concluded that, “if you don’t follow the instructions and people still learn, that raises the 
question of whether there’s a 'technology' there in the first place” (Gordon \& Zemke, 2000, p. 48; see also Reigeluth, 1997).

In a practical sense, this has meant that instructional technologists in Technology II "have evolved a wealth of techniques [for developing instruction] without providing a corresponding richness in their underlying theory [of when and how they should use those techniques]” (Davies, 1984, p. 8; see also Dijkstra, 2005). Dick (1987) stated that, "the instructional designer is charged with the responsibility for developing 'good' instruction, with no more guidelines as to what good instruction is than the basic instructional design principles that have been available for some time” (p. 193). Kayes (2003) recently criticized instructional technologists for ignoring the solid knowledge base that is growing in other, related design and development fields that may help instructional technologists better understand when and how to apply the techniques they develop.

All of this points to perhaps the most notable result of Technology II, that many instructional development processes are not flexible enough to help practitioners create instruction that can meet many, real-world learning needs. The processes common in Technology II may be very good at creating certain types of instruction, but sometimes that instruction tends to be very simple and linear, and does not always reflect the complexity of the domains being taught (Gordon \& Zemke, 2000; Häkkinen, 2002; Jonassen et al., 1997; Mitchell, 1989; Tennyson, 1997, 2000). Minstrell (1999) noted that "teaching is an ill-defined problem” (p. 215) and each teaching and learning situation is so unique that no one process of instructional development can capture everything about it. Minstrell's warning to teachers is also informative for instructional technologists. He 
stated, "attempting to program teachers to perform in a particular way ... is not productive” (p. 216), because it does not prepare them to make decisions on their own during instruction that they could not predict beforehand (see also Winn, 1989). Additionally, Thiagarajan criticized instructional technologists because the instruction they create sometimes "tends to [be] boring, cookie-cutter programs geared to the slowest and most ignorant learners in the audience” (Gordon \& Zemke, 2000, p. 51). And Gayeski said, “we inadvertently may be creating ‘disabled’ learners when we spoon-feed them instruction in an effort to achieve homogenous outcomes: You know, 'Upon completion of course, everyone will have learned to behave in exactly the same way'” (Gordon \& Zemke, 2000, p. 51). As Wilson (1997) warned

If you sterilize and control the learning environment and teach only your targeted objectives, learners will fail to learn how to be the thing you want them to be. They may learn some things you want them to learn, but they will fail at the role you're asking them to play in a real world of practice. (p. 302)

The conclusion, then, seems to be to broaden the practice of instructional technology so that practitioners can more flexibly draw on other ideas, processes, and methodologies beyond the traditions Technology II legitimizes (for a summary of Technology II, see Table 2). Dijkstra (2005), while noting the benefit of having processes for developing instruction, warned that "the use of models and rules, however, does not guarantee that students will acquire knowledge and skills” (p. 190). In fact, as Zemke and Rossett (2002) concluded, “there frequently isn’t one right way for much of the work [of instructional technology]" (p. 31). Davies (1991/1981) stated it more bluntly: "if there is no one best recipe for making tomato soup, it is absurd to argue that there is a best way of teaching” (p. 94). Wilson (1999) added that, despite the apparent belief of some instructional technologists, "instructional quality cannot be determined by adherence to a 
particular method or strategy.” And finally, Gibbons and McDonald (2005) concluded, “if [instructional technologists] have learned today to accept the status quo and to cease looking for superior solutions and new designs, then the technology has ceased to grow, and the original dream [of instructional technology] has little chance of ever being realized” (p. 8). With this introduction, I now turn to a definition of Technology III, which attempts to realize this original dream.

Table 2

Comparing Technology I with Technology II Theme Technology I Technology II

Purpose of instructional technology

Beliefs about learning and learners

Nature of technology in instruction

Consequences
Making teaching more efficient and scalable.

Good learning is efficient; learners are vessels.

Physical devices can solve problems.

Neglect of important problems and solutions; inflexible practice; viewing only some instructional types as legitimate.
Developing instruction for predetermined outcomes.

Processes and strategies control learning; learning processes control learners.

Processes and methods can solve problems.

Languages and processes used cannot express all problems and solutions; inflexible, look-alike instruction.

\section{Technology III}

The basic definition of Technology III is "the creation of unified and dynamic wholes (from previously separated components) to effect the transformation of learning” (Beckwith, 1988, p. 4). The definition of Technology III encompasses both technology- 
as-product and technology-as-process (Davies, 1973). Yet Technology III does not put the measure of quality in the use of any type of technology alone, but rather in the consequences that result with students and with the system as a whole (Beckwith, 1988). Those who have articulated the assumptions of Technology III have also been very broad in their descriptions of what constitutes an effective learning experience, instructional technology's effect on those experiences, and how to develop instruction that facilitates those experiences. The influence of systems thinking on instructional technology has been an important intellectual heritage leading to the assumptions of Technology III, as well as the influence of those who have advocated for a broader base for instructional technology other than just psychological theory and engineering practices. As I discussed earlier, the notions of systems and systems theory have multiple meanings in instructional technology, some of which contradict each other. Hug and King (1984) expressed the systems concept, as it has influenced Technology III, well when they stated that systems theory "emphasizes the study of a whole entity by understanding the functional relationships existing among components of all systems” (p. 19).

As with Technology I and II, the practice of Technology III results from assumptions that make this understanding of instructional technology appear to be logical, rational, and correct. My purpose in this section is to describe assumptions that can lead to the practice of Technology III, through an analysis of research literature that either mentions Technology I, II, and III, or that describes similar assumptions but does not mention Technology I, II, or III specifically. My description of Technology III will be organized around the same major themes I have used this far, of instructional technologists' beliefs about the purpose of instructional technology, the nature of learning 
and learners, and the nature of technology as it applies to instruction. As I will also discuss, in contrast to practitioners of Technology I or II, practitioners of Technology III view more languages and tools for developing instruction as legitimate, and so they can better express and understand important characteristics of instructional problems and solutions. This can result in a more flexible practice, with instructional technologists better able to meet real-life diversity in student learning needs because they accept a wider range of possible goals as well as methods to achieve those goals. This section concludes with examples of the flexible and broad applications of instructional technology that the literature predicts can result from the practice of Technology III.

The first theme in Technology III is that instructional technologists believe the primary problem they are trying to solve is how to facilitate learning wherever or however it may happen. This view of instructional technology's purpose is intentionally more inclusive than the views of purpose in Technology I or II. Davies (1989) was one who contrasted the goal of facilitating learning with the goal of developing instruction (which is characteristic of Technology II). He stated that being concerned with only developing instruction "is too narrow," and that it "limits the scope” (p. 133) of instructional technologists’ potential influence when solving educational problems. Wilson and Ryder (1998), although not using the specific terms of Technology II or Technology III, described well the differences between the two contrasting purposes instructional technologists have in each perspective:

Originally, instructional designers thought they were in the business of designing instructional systems to meet prespecified learning objectives. But. . . . increasingly, people are learning without help from designed instruction! . . . We believe that the situation requires a re-examination of our core roles. Are we in the business of designing instruction or of supporting valuable learning, wherever it may happen? 
Practitioners of Technology III view Technology I and II as potentially leading to people doing routine tasks only because they are familiar, not because those tasks are the best for the specific situation in which they are working. As Davies (1978) put it, instructional technologists in Technology III believe that "technology . . . is not necessarily confined to the means by which educators realize their ends. Technology also raises anew questions about the nature of the ends themselves” (p. 9). The Technology III approach, according to Davies (1978), leads instructional technologists to focus more on acting because they believe their actions will be meaningful and advantageous to the real people they serve, and not just because those actions are a common or accepted practice.

This belief has not only led some instructional technologists to move into fields such as Human Performance Technology with its focus on all methods of improving productivity (Davies, 1997; Rosenberg, Coscarelli, \& Hutchinson, 1999), but has also led to a broader focus among some instructional technologists to examine whether or not the environments in which people learn and work are helping them reach their fullest potential as human beings (Silber, 1972). For example, Hlynka and Nelson (1985) stated that in Technology III, instructional technologists are concerned with "a holistic outcome, evidenced as students becoming expressive human beings, creative thinkers, and compassionate citizens” (p. 13). Torkelson (1989) said that instructional technologists should be engaged in activities that help them "understand and support interaction processes among learners and instructional systems with the hope of establishing learner 'self-hood' and residual behaviors which support inquiry, introspection, adjustment, originality, psychological/philosophical balance, excitement in discovery, self-esteem, and success” (p. 146). And Inouye, Merrill, and Swan (2005) stated that instructional 
technology "is essentially a helping profession whose mission is to foster the growth of individuals in all of the important venues of their lives” (p. 4).

This expanded view of the purpose of instructional technology has also led in Technology III to an expanded view of instruction "as anything that is done to help someone learn” (Reigeluth, 1997, p. 44). The Technology III view of instruction is in contrast to the Technology II view of instruction as a set of preplanned activities designed to help people achieve predetermined outcomes (Davies, 1978). Davies (1997) called on instructional technologists to broaden their perspectives of effective instruction to include more than preplanned learning materials or activities, to also include in their definition of instruction any environmental change helpful for people to experience learning, whether planned or not. In another article, Davies (1991/1981) used the term “experience” to help broaden instructional technologists' understanding of what they were actually developing: “instructional developers don’t make products, they create experiences likely to lead to worthy performance” (p. 100). Wilson’s (2004) description of what instructional technologists do was similar to Davies’ view of instruction-as-experience: "the environment metaphor has gained prominence, suggesting a comfortable base from which learners can venture forth on various learning journeys” (p. 77). Good instruction, then, should be more than just certain types of well-defined activities designed to bring about a change in behavior, but should also include anything that can help people better achieve their potentials (Hlynka \& Nelson, 1985).

The second theme in Technology III is that learners are agents with the ability to control their own learning as well as the purposes that drive their learning. This is in contrast to the Technology II view, which suggests that environmental processes control 
learning, rather than people controlling their environment in support of their own learning. The differences between the Technology II and Technology III views of learning leads to a strong bias in Technology III toward developing instruction that is not as restrictive of learners as is the instruction that comes from Technology II. Davies (1973) said that the practitioner of Technology III "views human beings as natural decision-makers and problem solvers” (p. 12). Lian (2000) described a view of instruction that appears compatible with this view of learning and learners, as an environment which allows for possible discovery and learning beyond that specified in any formal goals accompanying the instruction. To borrow Davies’ (1991/1981) definition of instruction as "experience” (p. 100), it may be accurate to claim that learners in Technology III help create their learning experiences just as much as do their teachers, or instructional technologists.

A possible criticism of this view of instruction is that it provides too much freedom for learners who may not be ready for it. Lian (2000) responded that common instructional activities can be an appropriate aid to learning, but that practitioners should perhaps change their view of their purpose. For example, rather than seeing learning goals as standards against which to judge an objective measure of success or failure of learning, learning goals could rather act as "challenges against which learners negotiate their paths in ways that enable them to build further” (p. 16). This view of instruction reflects a very different view of learners, one which assumes they are capable of making, or of learning how to make, significant learning decisions on their own. Mitchell (1989) described this type of instruction as a "conversational system” (p. 12), where learners and instructors (or an instructional system) negotiate together the best goals and methods of 
instruction. His description of these instructional conversations is insightful for understanding the Technology III view:

If you were asked by someone to explain or teach something to him, what would you do? Would you establish performance objectives, devise a special sequence of statements to make to him, or insist on special audiovisual displays? What would you look for in order to infer that he understands you? . . . I doubt if your conversation would be punctuated by multiple choice questions or monosyllabilic responses. I suspect you would probe for evidence of his grasping related concepts or principles. In short, you would function as a supportive conversational system, building upon this student's strengths, clarifying misconceptions and linking it into a rich, intricately connected conceptual structure. (p. 12)

As I mentioned, the Technology III view states that learners should have an active role in negotiating what happens to them during learning, but Technology III does not encourage instructional technologists to accede to every learner demand uncritically. This point is important. The Technology III view is not that learners' desires should always overrule the desires of those providing the instruction, nor does Technology III state that others cannot have important learning goals for learners as well as important reasons for those goals. The Technology III view simply recognizes that people have their own wills, and that instruction is both a more humane and more effective experience when learners can negotiate their own needs with other stakeholders who may also have important needs. As Mitchell (1989) said, "if we begin to take into account the controlling behaviour of the people previously thought of only as objects to be controlled ... we immediately can see that the learners' ability to control themselves is essential to education” (p. 11). It was in this spirit that Beckwith (1989) suggested that instructional technologists recognize and support peoples’ own “learning, learning how to learn, and learning how to control the learning process. ... [through] interactions within and/or between self and environment” (pp. 127-128). 
Despite the possible criticism of this view that Technology III is advancing an “anything goes” approach to instruction or instructional technology, practitioners of Technology III do not believe that learning is uncontrollable, or there are no processes that facilitate learning or the development of learning environments. Practitioners of Technology III do accept the existence of instructional strategies that are beneficial for learning, but do not accept that there is a single, causal relationship between an instructional method and a type of learning (see Wilson, 1995). They also do not attempt to take the responsibility for learning away from those learners whom they are serving. The critical requirement for learning, then, becomes the learner's own agency and desire to learn. Gibbons (2001) described a use of instruction and instructional strategies consistent with this view in Technology III:

Events of instruction, which are the structures we design, serve ongoing human learning processes and interact with them in a way hoped to support new learning. But learning is still principally within the control of the individual. Instruction, therefore, does not cause learning but supports those learning intentions to which the learner commits. (p. 513)

The third theme in Technology III is the nature and benefit of technology as it applies to instruction is that the products and processes of instructional technology can facilitate the creation of good learning experiences, but those experiences cannot be fully reduced to, nor controlled by, the technology. In other words, technology can be a catalyst to improve a learning environment or system, but a technology alone is not solely responsible for those improvements. The Technology III view of instructional technology is much more in line with Gibbons' (2003) definition of technology as "the structuring of time and/or space in order to achieve specified purposes within the bounds of given problem constraints and to the level of given problem criteria” (p. 13). According to Gibbons, a developed technology creates “structures” which "channel the actions of 
forces” (p. 13) to use the power of those forces to bring about some end that the technologist and the learner agree are desirable. Yet while technologists do rely on causeand-effect relationships to direct, influence, or move relevant forces towards the desirable goal, they have available to them theories, techniques, and processes beyond those derived from science alone. Additionally, it is more correct to speak of instructional technologists controlling the creation of their technology rather than the technology controlling a person’s learning. As I have discussed, instructional technology can influence an individual's learning processes rather than control those processes, which remain under the learner's control (e. g. Nichols, 1991/1987).

This belief about the nature of instructional technology helps explain the Technology III view of the benefits of using technology in instruction. Instructional technologists in Technology III do use processes and technology devices to help solve educational problems, but their use is very different than in Technology I or Technology II. In Technology III, instructional technologists do not use technology (process or product) because some instructional development theory or model specifies it, but because the technology has a very practical, positive influence in helping to solve a defined and specific problem (see Wilson, 1999). Both Davies and Beckwith have proposed metaphors for understanding the use of technology, and the role of the instructional technologist, in Technology III:

[Technology III is like] a chess game, in which players engage in an intellectual activity for which there is no one set of appropriate moves. . . . The order, and manner, in which [instructional systems are created] depends upon the character of the problem, and the aim in mind. There is no one best way, and no one way of proceeding. Neither is there one optimal solution. Everything depends upon the situation, and the skills available. (Davies, 1978, pp. 22-23)

Just as a master coach can transform individual teenagers into an Olympic medalist team; just as a master architect can stretch the capabilities of each 
construction team; just as a master film director can transform almost any assortment of people, things, and processes into a vibrant and scintillating whole—-so too can a master educational technologist systemically structure [instructional] environments. (Beckwith, 1988, p. 4)

To summarize, when they encounter a learning problem, practitioners of Technology III draw on many types of technological products and processes to create a specific solution that is more than the sum of its parts. The benefit of what they develop is not that it has any causal power in itself, but that it can be a meaningful learning aid to those individuals who choose to use it in their learning (Davies, 1991/1981). Additionally, an individual instructional technology fits into the broader educational context or environment. It can affect other parts of the system as well as be acted on by other components in the system, sometimes in unanticipated ways. This can then lead to unanticipated consequences, both positive and negative, that were beyond the predictive power of the instructional technologist. This use of technology is very much in line with the idea of systems theory, more than the application of systematic processes. This view of systems is one which sees systems as cumulative wholes, made up of many individual parts, as well as the combined total of the relationships between those parts (e.g. HmeloSilver \& Azevedo, 2006).

An important aspect of this view of technology is the acceptance among instructional technologists that there is often more than one suitable solution for any given learning problem (Davies, 1978). Instructional technologists in Technology III reject the notion that there is only one right approach to improve learning or instruction. In addition, they continue to search for new and better solutions even though they or others may have successfully applied one or more acceptable solutions in the past (Beckwith, 1988; Davies, 1997). Yet the bias in Technology III is also towards making 
incremental improvements to an instructional system rather than attempting to make every possible improvement at once. In Technology III, instructional technologists recognize that there may be constraints in a given problem situation which prevent them from implementing their most optimal solution, and so they are willing to accept other solutions that provide a still-acceptable benefit with a minimum cost (Davies, 1973, 1978; Gibbons, 2003a). Practitioners of Technology III are willing to live with the realities of the situation without abandoning their ideals. Because of the constraints of a situation, the solution an instructional technologist offers may, on the surface and without analysis, look very much like one provided by Technology I or Technology II. But the instructional technologist goes through a very different process to come to that solution. The solution is, in a sense, a living solution that can continue to change and adapt as circumstances also change (see Hlynka \& Nelson, 1985).

At this point an example of the use of technology in Technology III may be helpful. Roschelle (1992) described one application of instructional technology as “a tool that enables individuals to jointly engage in active production of shared knowledge” (p. 40). As an example of this type of technology, Roschelle used the film storyboard, which allows "script writers, set designers, and directors to construct a shared understanding of the film they aim to produce” (p. 40). The storyboard itself does not have any power to produce a good film, nor is there only one acceptable way to produce a storyboard. Rather, the storyboard is a common artifact to which all of the participants can refer to “communicate designs, plans, and intentions to each other” (Gibbons \& Brewer, 2005, p. 113). As long as the storyboard helps the participants accomplish this goal, it is an effective use of technology. The knowledge about the film resides in and among those 
making the film, but the storyboard is an anchor point to help the filmmakers refer to tacit knowledge that they cannot explicitly share. As Bucciarelli (1994) stated

'Shared vision' is the key phrase: The design is the shared vision, and the shared vision is the design. ... The shared vision, as some synthetic representation of the artifact as a whole, is not in documents or written plans. To the extent that it exists as a whole, it is a social construction-dynamic, plastic, given nuance and new meaning at each informal gathering of two and three in a hallway or at formal meetings such as scheduled design reviews. (p. 159)

Similarly, among instructional technologists an artifact created during an instructional development process can serve as an anchor to help members of the instructional development team communicate with each other details of their plans that they cannot always share explicitly. The technology in this case is not a causal agent that creates good instruction. But because of the context in which it is embedded, the technology facilitates knowledge creation among those (including students) who actually have the ability to create and share knowledge in a specific learning situation.

The role of instructional technology processes, then, takes on a very different meaning in Technology III than it does in Technology II. Gibbons and McDonald (2005) stated

Those with a Technology III view assume that instruction can be improved through many means. It refuses to solidify its position simply because one successful solution has been found. It does not try to make the successful solution fit all problems, but it continues its search for new solutions, new principles, [and] new designs. In the process, the technologist learns, and the standard by which technological solutions [are] judged continues to evolve. (p. 7)

Practitioners of Technology III do not limit themselves to certain theoretical views or certain sources of knowledge to develop or refine their methods. Practitioner knowledge about how to develop instructional technology is valued as much as academic knowledge. This is because, as unscientific as the former sometimes seems to be, the bias is on 
solving local, individual problems more than on trying to find a solution which can generalize to every situation (see Wilson, 2004). As Schön (1987) stated

[Sometimes a] case falls outside the categories of existing theory and technique, [so] the practitioner cannot treat it as an instrumental problem to be solved by applying one of the rules in her store of professional knowledge. The case is not "in the book." If she is to deal with it competently, she must do so by a kind of improvisation, inventing and testing in the situation strategies of her own devising. (p. 5)

Before discussing the results of Technology III, I must note that these ideas have not been without their critics. For example, Hamblin (1974) made an extended critique of Technology III, and while it appears that at least some of his criticism resulted from his confusing some elements of Technology II and Technology III, one of his points should receive attention. Hamblin stated that, “[Technology III] is an all-embracing concept and difficult to pin down” (p. 185). In response, Technology III is certainly a very inclusive concept, yet some advocates of Technology III see its inclusion of alternative approaches as one of its major strengths (e.g. Beckwith, 1988). There certainly is a balance between being so bound to tradition that one cannot advance the practice of a field, and being so open to new ideas that one loses the field's unique focus. Advocates of Technology III attempt to find that balance, and believe that the advantages of being more open outweigh the disadvantages. Additionally, while it is true that many advocates of Technology III have not been completely clear in their descriptions, it is my express purpose in this study to richly define Technology III so that it can be a more helpful guide to practitioners of instructional technology.

A related critique is that because Technology III rejects science as the only means of conducting instructional development, then practitioners of Technology III do not have a reliable base of knowledge on which to develop sound instruction. Merrill et al. (1996) 
seemed to be writing in this spirit when they stated, "too much of the structure of educational technology in general and instructional design in particular is build upon the sands of relativism, rather than the rock of science” (p. 7). Braden (1996) offered a similar critique. While certainly some instructional technologists have abandoned methods of instructional technology derived from science or engineering, it is incorrect to call them practitioners of Technology III. Practitioners of Technology III use all helpful methods and tools to develop instruction, including those derived from science (e.g. Davies, 1973; Hlynka \& Nelson, 1985). Additionally, it is also incorrect to assume that because practitioners of Technology III adopt other problem-solving approaches besides those of science and engineering, their practice is not rigorous and attentive to detail. Rigor and detail do not belong to science and engineering alone, and all responsible practitioners of Technology III would adopt approaches that help them make the complicated decisions required for good instructional development (see Wilson, 1995). Another possible criticism of Technology III is that it is too eclectic and attempts to draw principles from too many intellectual sources. Slife and Williams (1995) have critiqued the general tendency of some social scientists to adopt eclectic positions. They claimed that "by accepting part of a theory, we also accept all of the assumptions and implications that a theory brings with it” (p. 48). Additionally

If an eclectic theorist claims that sometimes one theory applies and sometimes another, then he or she not only must defend the particular theory that applies in some situation, but requires another, overarching theory to explain why one theory applies here and another applies there. (p. 48)

This is a good warning, and Technology III practitioners would be wise to consider all of the potential consequences of a chosen approach as well as to consider whether their use of a technique is really compatible with other techniques they use to 
solve an instructional problem. Yet, at the same time, one of the strengths of Technology

III appears to be that it does not close itself off from helpful approaches because those approaches do not appear in a certain theory. The Technology III view of theory seems to be similar to the position Wilson (1999) stated

Good ID practice is informed by theory, but not slave to it. Expert designers will keep a theory in mind-or maybe many theories at once-when considering a problem and deciding on a course of action. But the problem is at the center, not the theory. Local conditions dictate a solution . . . in the contextualized, contingent reasoning of professional practice, which cannot be captured by the technical rationality of abstract theories, research, and generalization.

In other words, when practitioners see solving local problems as important as advancing theory, then the methods a theory suggests take on a different status. They become intellectual guides that support the judgment of the professional, rather than rules that bind their actions (e.g. Nelson, Magliaro, \& Sherman, 1988). While certainly some theoretical perspectives are incompatible with others, it does not hold that a method derived from a theory is the exclusive property of only that theory, and so we may possibly combine certain methods with methods from other theoretical perspectives (Sfard, 1998). The key, suggested Slife and Williams (1995), would be for those combining methods from differing theories to have logical, well-thought-out reasons about how and why it is appropriate to use the methods together. As Jonassen (2005) concluded, "human learning, as a sufficiently complex and poorly understood phenomenon, is able to accommodate multiple paradigms and resist any unified theory of instructional design” (p. 92).

Despite these criticisms, there is important evidence to suggest that Technology III does have positive results. The results of Technology III are that instructional technologists view more languages and tools for developing instruction as legitimate, so 
they can better express and understand important characteristics of instructional problems and solutions. This can result in more flexible practice, with instructional technologists better able to meet real-life diversity in student learning needs than they can in Technology I or Technology II. In a sense, they become the reflective practitioner Schön (1987) advocated. Some examples may be illustrative. Wiley and Edwards (2002) described decentralized learning systems which both effectively and efficiently meet real and important needs among participating learners. One of these systems was an Internet forum to assist people learning the Perl programming language. This forum, while not implementing a sequence “of artificially imposed, embedded instructional strategies” (p. 38), nevertheless still provided all forum members the affordances necessary to support their own and other participants' learning in a timely and effective manner. Studying, understanding, and creating decentralized learning systems such as this appear to be a positive result of the Technology III view of expanding the purpose of instructional technology to include the support of all valuable learning no matter where or how it happens, as well as the Technology III view of instruction as more than certain types of preplanned activities developed to lead to predetermined learning outcomes.

As another example, Willis (1995) described a computerized instructional product to help adults learn to read, a program he called LiteraCity. The instructional development process he used to create LiteraCity was similar to Technology III in a number of important ways, including the belief that more than one development path can lead to an acceptable solution, as well as that any relevant sources of data and knowledge are helpful during the instructional development process. For example, Willis described 
how his process helped the instructional development team explore alternative development paths while still helping them maintain a rigorous schedule:

The four components [of the model] are focal points. The ... model is non-linear. ... [and] the ID team (which may be large or small) is expected to actively reflect on and analyze work to date and regularly revise and rework both the material being developed and the models that underlie its development. (p. 14)

In other words, it appears that each phase of the development model functioned in a way similar to a characteristic of Technology III. The process helped the team focus their efforts on critical areas of development, and helped them build the "shared vision" (Bucciarelli, 1994, p. 159) necessary to conduct good development. It also appeared to facilitate their active questioning of the development steps to create a more useful development model for their situation. Willis concluded that LiteraCity did help students learn to read well enough to function in society, not because of the students' performance on a test but because they could actually perform those tasks in a real-world environment. Willis attributed this success in part to their instructional-design process' flexible focus during the product's development.

These products and processes diverge from what is normally thought of as instruction or an instructional development process, yet they have still been effective applications of instructional technology. These examples suggest that Technology III does have the potential to help instructional technologists meet a wide variety of student learning needs. As Davies (1973) said, instructional technologists who practice Technology III are "flexible, able to learn through experience, free to change, and free to respond to new circumstances" (p. 5). The practitioner of Technology III "is not one who follows all of the known rules, not even one who follows all of the known rules well.... [but is someone who] breaks known rules and creates new rules, thus enabling [a type of 
instructional technology] not possible through the application of known, status quo, systematic rules” (Beckwith, 1988, p. 16). And, as Gibbons and McDonald (2005) stated, "in the process [of developing new instruction], the technologist learns, and the standard by which technological solutions is judged continues to evolve.... [It is] a form of research that pushes back the limit of what is possible at the same time it provides solutions for current problems” (p. 7). In other words, instructional technologists are not bound so tightly to the traditions of their practice that they cannot adapt as the circumstances they face change.

In conclusion, because practitioners of Technology III are more flexible and more willing to look for solutions in a wide variety of settings, they do not miss potentially powerful applications of instructional technology because they are not looking only for familiar and comfortable solutions (for a summary of Technology III, see Table 3). As Davies (1991/1981) concluded about this type of practice, "it can . . be relevant and exciting, warm and imaginative. [Instructional technology] should result in a total experience demanding expression, reflection and spontaneity from everyone” (p. 103). And perhaps Beckwith (1988) summed it up with the most imaginatively rich metaphor. Beckwith speculated how other helping professions might improve if they adopted assumptions and behaviors similar to Technology III in their own fields. Rather than struggling with individual problems and solutions in the medical field, Beckwith believed that " health could be realized," in "engineering, ideal living space could be realized," and in "law, peace could be realized" (p. 18). Beckwith hoped that application of Technology III characteristics could transform instructional technology so that 
practitioners could use any available method, along with any available tools, to develop instruction that best characterizes the goals they have for their practice.

Table 3

Comparing Technology I, II, and III

\begin{tabular}{|c|c|c|c|}
\hline Theme & Technology I & Technology II & Technology III \\
\hline $\begin{array}{l}\text { Purpose of } \\
\text { instructional } \\
\text { technology }\end{array}$ & $\begin{array}{l}\text { Making teaching } \\
\text { more efficient and } \\
\text { scalable. }\end{array}$ & $\begin{array}{l}\text { Developing } \\
\text { instruction for } \\
\text { predetermined } \\
\text { outcomes. }\end{array}$ & $\begin{array}{l}\text { Facilitating all } \\
\text { learning. }\end{array}$ \\
\hline $\begin{array}{l}\text { Beliefs about } \\
\text { learning and } \\
\text { learners }\end{array}$ & $\begin{array}{l}\text { Good learning is } \\
\text { efficient; learners are } \\
\text { vessels. }\end{array}$ & $\begin{array}{l}\text { Processes and } \\
\text { strategies control } \\
\text { learning; learning } \\
\text { processes control } \\
\text { learners. }\end{array}$ & $\begin{array}{l}\text { Learners control } \\
\text { learning; learners } \\
\text { are agents. }\end{array}$ \\
\hline $\begin{array}{l}\text { Nature of } \\
\text { technology in } \\
\text { instruction }\end{array}$ & $\begin{array}{l}\text { Physical devices can } \\
\text { solve problems. }\end{array}$ & $\begin{array}{l}\text { Processes and } \\
\text { methods can solve } \\
\text { problems. }\end{array}$ & $\begin{array}{l}\text { Products and } \\
\text { processes are } \\
\text { catalysts. }\end{array}$ \\
\hline Consequences & $\begin{array}{l}\text { Neglect of important } \\
\text { problems and } \\
\text { solutions; inflexible } \\
\text { practice; viewing only } \\
\text { some instructional } \\
\text { types as legitimate. }\end{array}$ & $\begin{array}{l}\text { Languages and } \\
\text { processes used } \\
\text { cannot express all } \\
\text { problems and } \\
\text { solutions; inflexible, } \\
\text { look-alike } \\
\text { instruction. }\end{array}$ & $\begin{array}{l}\text { More languages } \\
\text { and tools are } \\
\text { legitimate; } \\
\text { flexible, reflective } \\
\text { practice. }\end{array}$ \\
\hline
\end{tabular}

Reasons for Technology I, II, or III

While Beckwith (1988) believed that Technology III was an ideal type of practice, he also observed that the field of instructional technology as a whole had yet to consistently adopt beliefs, values, and behaviors aligned with Technology III. Of course, one possible reason might be that some instructional technologists may have always 
believed that Technology I or II lead to an acceptable type of practice. But Beckwith also believed that many people wanted to work in a manner consistent with Technology III, yet environmental factors pulled them away from Technology III into the formulaic practices of Technology I and II. If it is true that Technology I and II represent inflexible traditions of practice, then it may be that Kendall and Wickham's (2001) process of “ordering” (p. 27) sometimes takes place, with instructional technology practice over time becoming more routine, more systematic, and more technical. My purpose in this section is to describe Beckwith’s (1988) possible reasons why instructional technologists fall away from Technology III back towards Technology I or II.

Beckwith’s (1988) first reason was “the trap of compromised integrity” (p. 8). Beckwith described the trap of compromised integrity as instructional technologists abandoning Technology III because the rewards they think will result from Technology I or II distract them. Beckwith specifically predicted two such rewards as the excitement of using a new technology and increased financial gain. While the term "compromised integrity” is somewhat provocative, it does not appear that Beckwith was suggesting any lack of personal integrity on the part of practitioners, but rather was referring to the integrity of their original commitment to Technology III. It is also important to note that Beckwith did not equate the trap of compromised integrity with the Technology III behavior of slowly moving towards an ideal yet also recognizing legitimate constraints that may prevent that ideal's full realization. Compromised integrity occurs only when instructional technologists stop the pursuit of their original goals in favor of alternatives they think will be more rewarding. According to Beckwith, Technology I and II values, 
beliefs, and behaviors result from the trap of compromised integrity because Technology I or II more logically follow from the replacement goals than from the original goals.

Beckwith’s (1988) second reason was "the trap of status quo adherence” (p. 10).

Beckwith described the trap of status quo adherence as instructional technologists adopting Technology I or II because they perceive Technology I or II as more traditional, legitimate, professional, or respected than Technology III. Status quo adherence can also happen when instructional technologists fall back to familiar Technology I or II practices because they have unclear or confused goals about what they are trying to accomplish; using traditional practices might alleviate their insecurity about their lack of direction. Although in some ways the traps of status quo adherence and compromised integrity seem similar, there are differences between the two. In the trap of compromised integrity, instructional technologists abandon the practice of Technology III in pursuit of rewards they think are more important. In the trap of status quo adherence, practitioners move away from Technology III either because they are unsure of what they are trying to accomplish, or because they want to find a practice that they perceive is safer or more valued. As with the trap of compromised integrity, Beckwith also did not use the trap of status quo adherence to describe the Technology III awareness of constraints which prevent the implementation of an ideal solution, but rather he used this trap to describe the "emulation” (p. 11) of approaches practitioners perceived as more respectable.

Beckwith’s (1988) third reason was “the trap of solidification” (p. 13). Beckwith described the trap of solidification as instructional technologists adopting Technology I or II rather than Technology III because they fear they will not be able to sustain their practice unless they make that practice simpler or more routine. As a result, they may 
lose an essential characteristic of their original practice. To clarify, Beckwith was not advocating that instructional technology practice become more expensive or more timeconsuming than necessary. Nor did he appear to oppose routinization that still preserved the essence of a flexible, Technology III approach. The trap of solidification occurs when routinization and simplicity become ends in themselves, rather than means to the end of ultimately becoming more effective (see Januszewski, 2001). Beckwith summarized the central message of the trap of solidification when he stated the motto of this trap as "let's not reinvent the wheel” (p. 14).

Beckwith recognized close connections between the trap of solidification and the traps of compromised integrity and status quo adherence. In fact, he was careful to point out that he separated discussions of these traps for convenience in description and observation. He did not intend his readers to think of the traps as mutually exclusive categories. Yet there does appear to be some difference between each of the traps. I described the difference between the trap of status quo adherence and the trap of compromised integrity earlier. The difference between the trap of solidification and the trap of compromised integrity appears to be that compromised integrity is a misguided search for greater rewards, while solidification connotes the unthinking routinization of an instructional technologist's practices. Perhaps practitioners develop those routines in an attempt to find greater rewards, but also possibly because they face pressures to reduce development costs by reducing the number of decisions they need to make. There also seems to be a difference between the trap of solidification and the trap of status quo adherence. Status quo adherence results from practitioners adopting traditional or respectable practices only because those practices are traditional or respected. 
Solidification may result from copying traditional practices, but may also result from making a practice routine to duplicate that practice more easily. Conclusions from the Review of Literature

This review of literature has suggested that the history of instructional technology has given practitioners many legitimate, yet sometimes conflicting, ways to conduct instructional technology practice. Additionally, this review showed how the foundational assumptions people hold about their work can either help or hinder them from adopting flexible practices, especially if they do not examine their assumptions. I also reviewed the concept of the community of practice, and demonstrated that these communities can either encourage or discourage a flexible approach among instructional technology practitioners. Finally, the review of Technology I, II, and III provided a solid foundation on which to examine real-world examples of how their assumptions may influence instructional technologists. My review of Technology I, II, and III also helped demonstrate that three traps may pull some instructional technologists away from their original goals toward other types of practice that appear more logical or desirable. My purpose in this section is to summarize the major conclusions from the review of literature:

1. Instructional technology is an ill-defined field, with some conflicting ideas about how to carry out acceptable instructional technology practice.

2. The assumptions people hold about their work can influence their attitudes, beliefs, and behaviors about their work, or influence what they believe are acceptable methods for conducting their work. 
3. Unexamined assumptions can lead practitioners to adopt certain practices without considering, or even being aware of, alternatives that might be more appropriate for the circumstances they face.

4. Consistently and rigorously examining one’s assumptions can help lead to the development of prudential knowledge, which can then help instructional technologists continually search for flexible ways of improving their practice so that it better aligns with the most important goals they are trying to achieve.

5. Instructional technologists also work in communities of practice, which give groups of practitioners a sense of shared meaning about their practice as well as a set of tools (physical and intellectual) that they use to carry out their practice.

6. Some communities of practice encourage a flexible, healthy approach to improving the work of the community, while other communities are sometimes trapped in rigid approaches which are detrimental to the work the community is trying to accomplish.

7. A proposed framework to help compare and contrast flexible and inflexible instructional technology practices are the criteria of Technology I, II, and III.

a. Technology I

i. Teaching should be more efficient and scalable.

ii. Good learning is efficient, and learners are vessels who passively receive information. 
iii. Physical technologies have intrinsic power to solve educational problems.

iv. Important problems and solutions can be neglected, and only some types of instruction are legitimate.

b. Technology II

i. Develops instruction only for predetermined outcomes.

ii. The critical requirement controlling learning is that people experience the appropriate processes and strategies.

iii. Process and method technologies have intrinsic power to solve educational problems.

iv. Important problems and solutions are neglected, and instruction tends to be inflexible and one-size-fits-all.

c. Technology III

i. Facilitates all learning.

ii. People are agents in control of their own learning.

iii. Technology can be a catalyst to facilitate good learning, but cannot control learning.

iv. A flexible, reflective practice gives instructional technologists more languages and tools they can use to understand and solve instructional problems.

8. While some instructional technologists may begin with assumptions consistent with Technology I or II, others may fall away from Technology III back into practice of Technology I or II. 
a. The trap of compromised integrity occurs when instructional technologists abandon Technology III because other rewards distract them.

b. The trap of status quo adherence occurs when instructional technologists adopt Technology I or II practices because they perceive Technology I or II to be more traditional, legitimate, professional, or respected than Technology III.

c. The trap of solidification occurs when instructional technologists adopt the rigid practices of Technology I or II because they fear that they will not be able to sustain their practice unless that practice becomes simpler or more routine. 


\section{Chapter 3: Method}

\section{Methodology}

To answer the research questions I proposed in Chapter One, I analyzed the historical development of two networks of instructional technology practice. As I discussed in Chapter Two, the term network of practice describes a loosely connected group of people who over time develop a certain type of practice based on a similar set of philosophies and beliefs. As Brown and Duguid (2000) defined the term, these networks "have practice and knowledge in common” (p. 141), yet members do not necessarily know each other personally and typically communicate through very "explicit” (p. 142) channels, such as journals or professional conferences. Networks of instructional technology practice might include those loose groups of people who develop similar ideas about the practice of instructional technology, as well as how to develop an effective instructional solution. Examples of these networks might include proponents of instructional television, programmed instruction, instructional simulations or games, computer-based instruction, problem-based learning, or cognitive apprenticeship. The two networks I specifically analyzed in this study were programmed instruction and problem-based learning.

To complete this study, I used the techniques of historical data analysis as well as the techniques of qualitative case study. Apart from some techniques of data gathering, the methods of conducting case study research and conducting historical research are very similar (Merriam, 1998). Both methods let researchers engage deeply and meaningfully with specific people or events (Armstrong, 2003; Stake, 1995). Additionally, historians often borrow techniques from other methods of qualitative 
research to better study specific topics (Kaestle, 1992). Combining the case study approach with the approach of historical data analysis helped me write rich descriptions of the events that formed programmed instruction and problem-based learning, as well as to analyze research reports from each type of practice. These rich descriptions will give readers an opportunity to recognize any existing commonalities between a studied technology and their own practice, and so be in a better position to draw their own conclusions as to how the findings of this study relate to how they practice instructional technology (Januszewski, 1996).

\section{Case Selection}

In selecting networks of instructional technology practice to study, I looked for certain defining features that indicated the data I gathered would contribute to answering my research questions (Stake, 1995). The first defining feature was to find identifiable types of instructional technology that early promoters of that technology considered to be revolutionary developments. I also looked for evidence that adopters of the technology felt they belonged to a specific group, or that there existed some cohesiveness that served as a sense of identity to tie participants together in at least a loose network of practice. I looked for examples that had a large literature that would provide the detail necessary to write rich descriptions of the technology. Finally, I looked for examples of instructional technology that in implementation represented a range of outcomes along the spectrum of Technology I, II, and III.

The first example I analyzed was programmed instruction (PI), originally envisioned by B. F. Skinner (e.g. Skinner, 1954). PI stood out as an example based on the highly revolutionary nature of the method as many early instructional technologists 
understood it (e.g. Schramm, 1962). The approach attracted many adherents, who formed a number of professional organizations dedicated to the development of PI. As one example, the original name for the still-active International Society for Performance Improvement was the National Society for Programmed Instruction (International Society for Performance Improvement San Antonio Chapter, n.d.). Developers of PI have written hundreds journal articles and books to advance the theory of PI as a well-defined type of instructional technology practice (Saettler, 1990). However, despite promising high levels of flexibility, as well as instruction that could meet a wide variety of learning goals, critics have often accused developers of PI of creating instruction that was overly mechanical and formulaic (McDonald et al., 2005). Additionally, both Lumsdaine (1964) and Davies (1973) used PI as an example of Technology II in their theoretical writings, which lead to my conclusion that the literature of PI would be especially revealing for the purposes of this study.

The second example I analyzed was problem-based learning (PBL), as originally envisioned by Howard Barrows (e.g. Barrows \& Tamblyn, 1980). PBL developed as an important instructional technology in medical education, with many vocal adherents, and quickly spread to other fields (e.g. Savin-Baden, 2000). But over time, the term problembased began to be given to many other instructional approaches, some of which bore only loose resemblance to the method as originally described (Barrows, 1986). Although PBL was originally promoted as a revolutionary new method of improving education, in recent years it has also been criticized for leading to formulaic practices instead of a flexible approach to understanding and solving educational problems (Barrows, 1997, 2003). Additionally, the fact that no one has yet compared PBL to Technology I, II, and III 
provided a valuable source of data triangulation and verification for the conclusions I drew from the study of PI.

In the interest of complete disclosure, I also considered other networks of instructional technology practice for inclusion in this study. Two of these were computerbased instruction (CBI) and cognitive apprenticeship (CA). While these technologies initially appeared to meet many of the initial criteria for inclusion, as my study progressed it became clear that they actually did not. For example, while the literature of instructional technology contains many examples of cognitive apprenticeship, this literature was not mature enough at the time of this writing to let me describe the history of the approach or to write rich descriptions of the assumptions of those promoting the approach. I found the exactly the opposite situation in the literature of computer-based instruction. The term CBI meant so many different things in so many different literatures that it became apparent that CBI was not a single network but many networks using the term in an inconsistent way. Because of these difficulties, I also excluded computer-based instruction from the study.

\section{Validity and Reliability}

Although many of the methods to ensure the validity and reliability of a quantitative study do not apply to qualitative research (Merriam, 1998), there are generally accepted methods to assure readers that they can rely on the conclusions of a qualitative. Regardless of the research approach they use, when researchers provide evidence of validity and reliability it builds trust in them and the conclusions they draw from their research (Merrick, 1999). In this study, I used the methods of source 
triangulation, rich description, reflective practice, member and peer checks, and source criticism to help ensure the validity and reliability of my findings.

One of the most important methods of validation in historical research is that of source triangulation (Kaestle, 1992). Source triangulation means using multiple data sources to verify the accuracy of the researcher's interpretations. In this study I relied not only on many historical examples within each selected network of instructional technology practice, but also examples from two different networks, to help triangulate my findings. In particular, I looked for and reported conflicting instances and alternative interpretations, to aid readers in making their own interpretation of my conclusions.

Another important method of validation in historical research is the rich descriptions of events the researcher provides (Button, 1979). My study of each instructional technology began with an extended definition of that technology taken primarily from the writings of the originator of the approach. I also provided lengthy summaries of original research, from the perspective of the original researchers. I included this level of detail primarily because, as much as possible, descriptions of events should reflect the views of those who participated in those events. Additionally, in historical research the conclusions readers draw can be just as important as the conclusions the researcher provides (Januszewski, 1996). Providing rich and accurate descriptions of events, often in the context of a story, can help readers determine whether or not the data gathered during the study was sufficient, as well as whether or not a study’s conclusions are appropriate for the data (Stake, 2000).

Another important method of validation in qualitative research is for researchers to report their biases and opinions, and how they believe their biases affect their 
interpretation of the evidence they examine. Guba (1981) called the commitment of researchers to reveal their own biases "practicing reflexivity” (p. 88). As Stake (2004) pointed out, it is not the fact that researchers have biases, but rather when they fail to examine their biases that decreases the reliability of a study. Stiles (1993) added that researchers should reflect on how their biases and opinions changed as the study progressed. In fulfillment of this requirement, both this chapter and the entire study will conclude with comments about my own perspective, and how my study affected my perspective.

Another method to help ensure validity and reliability is to use member and peer checks. The term member check refers to the practice of providing drafts of research reports to members of the group(s) from which the data came. The term peer check refers to the practice of having other researchers critique drafts of the research on an ongoing basis (Guba, 1981). For this study I performed member checks by seeking out (based on interest and availability) critiques from experts in the practice of PI and PBL. Unfortunately, despite reminders sent out after the initial requests, very few of these experts chose to respond. A complete list of those who I approached for a member check, as well as those who responded, is available upon request. Additionally, I performed peer checks by soliciting feedback from other skilled instructional technologists as the study progressed.

In addition to the validation methods I already described, I also used the procedures of source criticism to help ensure the validity of my results. In the methodology of history, source criticism refers first to determining whether or not the primary sources for a historical study are genuine, and then determining whether or not 
those sources are trustworthy (Barzun \& Graff, 2004). Often in historical research there is question as to whether or not the primary sources, or those "original document[s] created contemporaneously with the event under discussion” (R. C. Williams, 2003, p. 58), are genuine, and so historians must spend time and effort judging their authenticity before they examine trustworthiness. However, in this study I was relying on scholarly reports published by academic presses or in academic journals. As a result, there was little reason to doubt that any sources were genuine in the sense that they were authored by the individuals who claimed to have authored them, and that the general circumstances surrounding the report were accurate (i.e. the researchers really conducted the studies they claimed to have conducted). My task, then, was to ensure that the sources I used were trustworthy.

While there are no clear-cut methods to determine the trustworthiness of a source, there are various types of evidence that historians typically look for. Howell and Prevenier (2001) provided a useful list. First, if authors are considered authorities on a topic, their writings on that topic will be considered more trustworthy than the writings of others on the same topic. The originators of both PI and PBL were heavily cited as authorities in each respective chapter, as were others generally considered in the literature to be influential or experts. And, where necessary, other recognized experts were cited along with the comments of a particular researcher, to help establish the researcher's credibility. Another method of determining the trustworthiness of a source is to rely on the reports of eyewitnesses. Readers will notice that I cite large amounts of original research, written from an eyewitness perspective, the following chapters. Additionally, authors that have come to independent agreement with others on similar topics are 
considered more reliable. In this study, I particularly searched for instances of researchers coming to independent agreement, and cited them as commentary throughout the chapter as well as in a dedicated section near the end of each chapter. And finally, if otherwise equal sources disagree with one another, historians will rely on the source(s) that seem to conform most closely to common sense. Readers, then, will sometimes notice appeals to logic as another method to help determine the trustworthiness of my sources.

I also used secondary sources to help validate the conclusions drawn from primary sources. A secondary source is one that "displays primary sources selectively in order to interpret the past” (R. C. Williams, 2003, p. 58). Historians often use secondary sources to help them clarify and verify their conclusions (Storey, 2004), especially in situations in which primary sources are of limited usefulness. For example, participants in an event are often better at answering questions about what happened than why something happened, and so secondary sources may be a better source of information about why an event occurred the way in which it did (Stiles, 1993). When researchers check to ensure their conclusions are consistent with others who have studied the same or similar events, they are following an important method of data triangulation. When using secondary sources, researchers should verify that those sources conform to the same standards of validity and reliability as primary sources. Researchers should also keep in mind the general principle that the more extraordinary the claim being made, the more extraordinary the evidence necessary before that claim can be considered as valid (Barzun \& Graff, 2004; Howell \& Prevenier, 2001). Readers will notice that, wherever possible, I cited secondary sources along with my findings, to demonstrate that my 
conclusions were at least consistent with those of others considered experts in the same area.

Procedure

An initial research plan was developed and approved to serve as the foundation of this study. It is natural in qualitative research that a study will evolve as it progresses (Stake, 1995). Yet it is also assumed that the study will be planned according to generally accepted principles, and that modifications to the study will unfold from the initial plan. While the procedure I describe below does include changes from the originally accepted plan, all changes to the plan were discussed with, and approved by, those advising me on my research. I have described significant changes to the plan in other sections of this chapter. Since my procedures for studying PI and of PBL were so similar, I will describe them together throughout the remainder of this section. Readers should be aware, however, that I conducted my studies of PI and PBL separately. My complete study of PI is in Chapter Four, while my complete study of PBL is in Chapter Five.

My examination of PI and PBL began with the creation of an extended definition of each instructional technology, as originally envisioned by the researcher considered most responsible for the development of that technology. I developed each definition by reviewing primary sources, such as the journal articles or books each researcher wrote, which described PI and PBL's rationale, theory, and overall goals. I used secondary sources when necessary to provide richer descriptions of each technology. However, it is important to note that my initial definition did not extend beyond the theory and goals that the initial researcher described. I recognize that some later features became very important to both PI and PBL. Yet I restricted my initial definitions to the vision of each 
original researcher, to best understand what they were trying to accomplish, and how other researchers and practitioners modified (or did not modify) their technology later. I then compared the definitions of PI and PBL to the criteria for Technology I, II, and III, to determine which level best represented the original goals of each type of instructional technology. I also used Technology I, II, and III to interpret and draw conclusions about the intents, assumptions, beliefs, and behaviors of each original researcher. Additionally, however, I also used the writings of each researcher to refine and more richly describe the criteria for Technology I, II, and III themselves.

Following these definitions, I selected six reports from each of the literatures of PI and PBL to analyze in detail. I purposefully sampled these reports, selected from primary sources describing PI and PBL implementations, to find PI and PBL practices either similar to, or different from, the original definitions of each instructional technology. I also selected each report because of the amount of detail it contained, which helped me write rich and accurate descriptions of each researcher's practice. I compared each report to Technology I, II, and III, both to interpret the researchers' practice as well as to refine my understanding of Technology I, II, and III. Additionally, when a researcher's practice appeared to have veered away from Technology III into Technology I or II, I also compared that study to the traps defined in Chapter Two, both to understand why those instructional technologists did not maintain the level of practice they initially sought to achieve, as well as to refine my understanding of the theoretical reasons Beckwith (1988) advanced.

I used the same criteria to select studies from both the PI and the PBL literature. One report described the actual practice of the original innovator of each instructional 
technology. The second report described the practice of another researcher also considered an exemplar in the practice of that instructional technology. I selected the third report for its less-successful outcomes. The fourth report showed that the researchers intentionally differentiated their approach from that of the original innovators. The last two reports in each chapter displayed unique aspects of the researchers' practice, which indicated their work might reveal uncommon or otherwise interesting insights. The specific reports I analyzed, along with the rationale for analyzing each, are in Chapters Four and Five.

While I concluded that I could describe each report in terms of at least one of the levels of Technology I, II, or III, I did not attempt to generalize that every other implementation of PI or PBL was also an example of that same type of practice. The case study methodology assumes that every case is complex. I expected that events in each network of instructional technology practice would lend insight into the larger issues under study, as well as contain unique events that I could not easily classify or understand in terms of those same issues. As Stake (1995) stated, a "good instrumental case study does not depend on being able to defend the typicality of [the case]" (p. 4). However, to provide readers with some assurance that the issues in each example are relevant to the practice of instructional technology as a whole, I reviewed other literature of both PI and PBL that also described common assumptions, beliefs, and behaviors of real-world practitioners. This review demonstrated that my findings were at least compatible with those of other experts in the field, and that those most familiar with these two types of practice have noticed similar issues to those I considered in this study. Each of these 
analyses is in Chapters Four and Five, for PI and PBL respectively, immediately following the analysis of my six chosen reports.

\section{Study Limitations}

The nature of this study did create some limitations of which readers should be aware. First, the samples were small. I studied only two networks of instructional technology practice, with six reports analyzed in detail for each network. This limited my ability generalize conclusions to other types of instructional technology practice. For this reason, the rich descriptions I provided for PI, PBL, and the twelve studied reports become even more critical, so that readers can better determine for themselves whether or not my conclusions are transferable to their circumstances.

Additionally, I did not randomly select PI, PBL, nor the twelve studied reports. I did this intentionally to find a wide range of interesting issues to examine, yet it does raise the question as to whether or not these particular issues are representative of PI, PBL, or instructional technology practice generally. To help offset this potential limitation, I conducted a literature review of both PI and PBL practice. These literature reviews helped demonstrate that my observations were at least compatible with those of other experts in each technology.

Finally, as a historical study, my research subjects did not have the chance to respond to my interpretations of their reports nor the conclusions I drew from their reports. This does raise the possibility that my own perspectives have biased my interpretation of the data. As mentioned, the member and peer checks I performed on this study helped minimize the effects of this bias, as was my being explicit about some of the perspectives I believe are important and that I think have affected my research. But 
neither of these methods can eliminate bias completely. I encourage readers to rely again on my rich descriptions of PI, PBL, and the twelve reports to provide additional assurance that my interpretations and conclusions are accurate and reasonable.

\section{This Researcher's Perspective}

As mentioned, researchers should be explicit about their own assumptions, so that readers may better judge the trustworthiness of the researcher's findings (Guba, 1981;

Stake, 2004). This final section of the chapter briefly reviews some of my own assumptions, biases, and perspective. A companion section in Chapter Six also discusses how the research I conducted affected my own assumptions and biases.

I became an instructional technologist because I wanted to help people learn. I believe that my personal and professional purpose is to help people learn how to learn. I believe the most important learning helps people understand who they are and what they can become. While I do recognize that interested stakeholders may have important knowledge, skills, or attitudes they want to teach others, I believe that teachers should realize that the students themselves also have important goals and desires which should at least inform the development of instruction. This does not mean that I believe students should necessarily have a veto over instruction they do not like. Rather, I believe other stakeholders' goals should not become ends in themselves. I also believe that all meaningful human relationships, including the teacher-student relationship, are built on foundations of trust, negotiation, and mutual respect.

I believe that powerful learning happens when a person commits to learn, and is willing to sacrifice the time and effort necessary to learn. A talented and committed teacher, or a rich and well-designed instructional environment, can help support the 
student's commitment but cannot replace it. I believe that powerful learning can happen in face-to-face settings or at a distance. Learning can happen while reading a book, watching a film, or using a computer program. I do not believe that one method is inherently better than another. I believe that those who use all instructional approaches should clearly understand their strengths and weaknesses. I also believe that if one elevates one approach over others for all situations, it is probably an indication that the approach has become a distraction away from the ultimate purpose of helping someone learn.

I believe that any instructional method or technology that respects the dignity of the student can be an effective aid to facilitate learning. I believe that our age has developed wonderful and exciting technologies that we can and should use to improve learning. I have successfully developed many instructional technologies that I believe have positively affected students’ learning. However, I personally have difficulty aligning my beliefs or my personal experiences with any particular instructional tool, theory, or paradigm. I believe I have been successful because of the contributions of many in this field, including those whose perspectives are often seen as out-of-date or otherwise not in touch with current trends. I have been personally troubled only when learning power is attributed to the technologies themselves, or when successful theories and technologies are uncritically applied, no matter how current or fashionable they are. I personally have found the most satisfaction as an instructional technologist from pushing the boundary of what I consider possible, and have never felt comfortable recommending an instructional product as the theoretical best I have to offer. I believe that a successful idea belongs to the realm of good ideas, and not to the realm of any particular theory or paradigm. 
In conclusion, I do believe in the themes I described in Chapter Two as typifying Technology III, and I try to exemplify them in my personal practice, though I do respect those who have pioneered technologies in other areas. I also recognize that there are many situations where the ideal practice I describe may not be feasible, and the best an instructional technologist can offer is a solution that outwardly appears very similar to Technology I or II. However, a central message of this study is that the quality of one's practice comes not only from the solution developed, but also by the reasons behind that solution's development. People are only practicing Technology I or II, I believe, if they let their assumptions or their past successes limit or artificially constrain them. I believe that the central attitude of Technology III is to always keep the ideal in mind and work towards it, regardless of external circumstances that may necessarily constrain how close to the ideal one may come. My purpose in completing this study is to encourage others to participate in achieving these ideals, as well as to become better at achieving them myself. 


\section{Chapter 4: Programmed Instruction}

My purpose in this chapter is to analyze programmed instruction (also known as programed instruction, or PI) as a network of instructional technology practice that can be understood using Technology I, II, and III. In previous chapters I described criteria for viewing instructional technology practice as examples of Technology I, Technology II, or Technology III. I also described the value of contrasting real examples against these criteria in order to better understand whether practitioners' assumptions encouraged the flexibility necessary for them to remain focused on the original goals that led to them adopt that practice. In this chapter I will demonstrate that programmed instruction, as originally envisioned, can be accurately described as Technology II. I will also demonstrate that some of those who implemented programmed instruction experienced the predicted results of Technology II, such as inflexible and rigid instruction that could not adequately meet many student learning needs. Additionally, some PI developers appear to have fallen away from their original goals into Technology I practices, and experienced the inflexibility resulting from an over-reliance on the physical devices they used for instructional purposes. Yet some PI practitioners did use the technology in a more flexible way and found uses of PI that helped them work towards all of the learning goals they thought were important for their educational system. Commentary throughout the chapter will contrast the differences between these implementations and draw conclusions about how instructional technologists can use these examples to become appropriately flexible their own professional work. 


\section{Skinner's Programmed Instruction}

Despite the disinterest many have in programmed instruction today, the development of PI was actually a very important event in the history of instructional technology. Jonassen (1991), in fact, called PI "the first true technology of instruction” (p. 6). Some of the early, influential thinkers in instructional technology were closely connected to the development of PI, including Robert Gagné (1965), Robert Glaser (1965), and Arthur A. Lumsdaine (1960/1959). Additionally, many other educators for years had been experimenting with individual ideas that eventually became important characteristics of both PI and instructional technology. Some of these included Sidney Pressey's use of machines to automate parts of the educational process, and Frederic Burk's methods of individualizing and personalizing the pace or sequence of instruction (Saettler, 1990). However, the original vision of programmed instruction, for this chapter, is attributed to the work of psychologist B. F. Skinner. Despite the important work of other researchers, it appears that Skinner was the first to galvanize the concepts of PI into a movement that many saw as a viable alternative to educational methods that had not lived up to their promises of reform (Casas, 1997). As a foundation to further discussion, I begin with an extended definition of Skinner's version of PI.

Outside of education, B. F. Skinner is best remembered as one of the most influential advocates of behavioral psychology. Delprato and Midgley (1992), in fact, called him "the most important [person] in American psychology during the post-World War II period” (p. 1507), which statement they based on a survey of psychologists belonging to the American Psychological Association. Skinner was particularly famous for the principles of operant conditioning. Operant conditioning is an approach to 
psychology founded on the belief that the consequences of an animal's behavior, either positive or negative, influence the likelihood of the animal producing that behavior again in the future (Skinner, 1963). One of Skinner's (1986) detailed discussions of operant conditioning was an example of how one could use conditioning principles to teach a dog to first stand on two legs and then jump into the air. Skinner began by training a dog to accept a camera's flash as a desirable reward. He did this by operating the flash at the same time he fed the hungry dog. In a short time, the dog associated the natural stimulus of food with the artificial stimulus of the flash, and experienced the same satisfaction as being fed whenever the flash was operated. This initial training was an application of another form of conditioning, commonly known as classical conditioning (for more on classical conditioning, see Burton, Moore, \& Magliaro, 2004).

After this, whenever the dog's movements approximated the terminal behavior of jumping, Skinner would operate the flash. The flash acted as a desirable consequence for the dog since it had earlier been associated with the also-desirable consequence of food. The dog began to perform more frequently whatever action immediately preceded the flash in anticipation of receiving that reward again. At first Skinner set off the flash whenever the dog held its head slightly higher than normal. The dog quickly started to stand upright more often, so Skinner then operated the flash whenever the dog lifted its feet. Eventually Skinner's dog was jumping off the ground in anticipation of the flash. During the early and middle years of the twentieth century, Skinner and other psychologists conducted hundreds of similar experiments in which they trained animals to perform very complex tasks, by the selective application or removal of desirable and undesirable consequences (Saettler, 1990). 
During this same period, many American schools were experiencing large amounts of stress, particularly as many teachers and politicians began to believe that schools were not helping America keep its competitive edge in scientific and mathematical subjects. This worry crystallized in 1957 with the launch of the first Soviet satellite, Sputnik. In response, many researchers began the search for new methods of education that were both more effective and more efficient (Casas, 1997; Dick, 1987). The environment was right for the adoption of Skinner's emerging application of operant conditioning to education. Skinner’s personal involvement with educational renewal appears to have begun a few years earlier, when he observed the education of his own daughter (Lockee, Moore, \& Burton, 2004; Skinner, 1989). In 1954, Skinner produced a paper which described his key concerns about education as well as a proposed solution.

This paper, which became foundational to the programmed instruction movement, was titled "The Science of Learning and the Art of Teaching" (Skinner, 1954). In this paper, Skinner described the basic principles of operant conditioning, and how to use operant conditioning to improve human learning. He also described how educators commonly violated the principles of conditioning, and how that negatively influenced students' education. Finally, he described how a mechanical device he called the teaching machine could help educators remain true to the principles of operant conditioning. Over the years, Skinner produced many other works that expanded on these initial ideas (e.g. Skinner, 1958, 1959, 1961, 1968/1963, 1968, 1986). Throughout the remainder of this section, while I will follow the basic format Skinner laid out in his 1954 paper, I will draw on these other works as necessary to richly describe Skinner's version of programmed instruction. 
Human learning, according to Skinner, was based on the same principles of conditioning that he used to change the behavior of any other animal. Skinner (1954) stated, "the species of the organism [being conditioned] has made surprisingly little difference.... Comparable results have been obtained with pigeons, rats, dogs, monkeys, [and] human children” (p. 89). The major principles of operant conditioning that Skinner identified in his 1954 article as being important to learning were the reinforcement of behavior and the shaping of behavior. Skinner's definition of reinforcement was a "particular type of consequence" that was "optimal for producing the changes [in an animal's behavior] called learning” (p. 87). In other words, reinforcement required finding a consequence attractive to an animal, and then using that consequence as a reward when the animal produced the behavior that the trainer considered a desirable learning end. Shaping was the process of reinforcing small, incremental changes in behavior which were anticipatory of a desired terminal behavior. The concept of shaping rested on the assumption that complicated behaviors consisted of an accumulated series of simpler behaviors. Additionally, Skinner believed that in a training sequence there would be more opportunities to reinforce these simpler behaviors than to wait for the rare occasion when a difficult, complex behavior emerged. Skinner, therefore, chose the reinforcement of small behaviors that were components of a larger behavior as the most efficient method of causing an animal to learn. Skinner thought that if the trainer reinforced all of the simpler behaviors over time and in the proper sequence, the animal would ultimately emit the desired complex behavior.

The earlier example of a dog being trained to jump (Skinner, 1986), illustrates the principle of shaping. Initially the dog rarely jumped, but often raised its head or made 
small movements with its feet. Skinner had frequent opportunities to reinforce these smaller behaviors, so the dog started to perform them even more often. Over time he was able to lead the dog from the simple behaviors into ones that were more like the eventual behavior of jumping. As he continued this cyclical process eventually the behavior of jumping consistently emerged. Through the use of shaping and what Skinner (1954) called "schedules of reinforcement” (p. 88), or different patterns of when or how often to apply a reinforcement, Skinner could produce very complex behaviors which could then act as reinforcement for other, even more complex, behaviors. In many cases, training animals using operant conditioning produced very impressive results. Through the use of these processes, Skinner could train animals such as pigeons to behave in ways that gave them appearance of intelligence, such as being able to play games or to mimic dance steps.

Despite the success he had in this training, however, Skinner recognized that waiting for an animal to emit random behaviors which could then be shaped (as in the example of the jumping dog) might not be realistic for all types of learning. This, he thought, was particularly the case when conditioning complex human behavior. In response, Skinner (1968) introduced the use of a stimulus that he called a "prime” (p. 208). Skinner's (1959) definition of what he would eventually come to call the prime was “an available stimulus ... used to evoke the required response” (p. 64) at the very beginning of a conditioning sequence. In other words, to prime was to present a stimulus which would somehow prepare students for the behavior they were to emit. Some examples of priming Skinner $(1959 ; 1968)$ provided included showing students an entire word before asking them to spell it on their own, showing students a dance step before 
asking them to perform it themselves, or having students listen to a song before they tried to sing it alone.

Another principle important to shaping was what Skinner (1968) called “prompting” (p. 214). The principle of prompting was based on the assumption that it would often take more than one behavioral performance for a person or animal to learn to emit the behavior without some kind of assistance. Prompting, then, was the continual use of a prime or "a fragment of a prime” (p. 214) to act as an aid during the learning process, until the subject could emit a behavior alone and without a cue. An example of prompting Skinner provided described a child learning to talk:

In teaching a child to ask for or name an object . . . a parent [first] begins with the full prime: the name of the object is pronounced and the child echoes it. Later, the parent may supply only part of the prime: he may whisper or murmur the name or pronounce only the initial sound. (p. 214)

The second stage, where the parent provided the child with only a portion of the original prime, was an example of prompting. The eventual removal of any prompts, systematically over time, was called “vanishing” (p. 215). Skinner thought that any artificial stimulus could be a prime or a prompt, "provided there are no harmful byproducts and provided the resulting behavior can eventually be taken over by reinforcers the student will encounter in daily life” (p. 155).

When Skinner compared these principles of conditioning to common educational practices, he saw large disparities that he believed negatively affected students’ education. First, even though by Skinner's day schools were moving away from corporeal punishment, Skinner thought that discipline techniques still tended to be based on negative control. Some of the common techniques Skinner (1954) identified included “the teacher’s displeasure,” “criticism or ridicule,” and “low marks” (p. 90). While 
operant conditioning did predict that punishment could lead to behavioral change, Skinner (1968) was very wary of these forms of control because "the student who works mainly to escape aversive stimulation [eventually] discovers other ways of escaping” (p. 97). More plainly, because students do not like punishment they may look for ways to avoid it that they think are easier than conforming to the behaviors their teacher demands.

Skinner directed another criticism towards educational techniques that only provided information to students, and that had little or no effect on the goal of purposefully shaping their behavior. Skinner directed this criticism towards much of the instructional media common in his day. At one time, Skinner (1958) said, "there is a real danger . . . [in using] equipment designed simply to present material. . . . The student is becoming more and more a passive receiver of instruction” (p. 969). At another time, Skinner (1961) stated, "in spite of discouraging evidence to the contrary, it is still supposed that if you tell a student something, he then knows it” (p. 388). And, finally, Skinner (1968) used an analogy to describe what he thought were the results of only presenting information without the intentional application of reinforcers meant to shape students' behavior:

If we throw a lot of children into a pool, some of them will manage to get to the edge and climb out. We may claim we have taught them to swim, although most of them swim badly. ... The method does not teach; it simply selects those who learn without being taught. Selection is always more wasteful than instruction and is especially harmful when it takes place. (pp. 118-119)

Even when teachers did want to condition students’ learning using methods of which Skinner would have approved, he thought that teachers acting alone still faced some significant challenges. Skinner (1954) said

The simple fact is that, as a mere reinforcing mechanism, the teacher is out of date. This would be true even if a single teacher devoted all her time to a single 
child, but her inadequacy is multiplied many-fold when she must serve as a reinforcing device to many children at once. (pp. 94-95)

And, according to Skinner (1958), the problem would only get worse as the need to educate even greater numbers of students increased. The ability to properly apply reinforcements was a major shortcoming of even the most skilled teacher.

This had to do with the conditions under which effective reinforcement took place. As Skinner (1961) said, "by reinforcing only when particular stimuli or classes of stimuli are present, we bring the behavior under the control of the environment” (p. 379, emphasis added). In other words, the best way for the teacher to modify behavior (or learning) was to ensure that reinforcers were only present with the stimuli and behaviors that the teacher wanted to associate in the students. The reinforcer should only apply to whatever small change in behavior was currently the target for shaping. And since the passage of time would almost certainly mean students would have been exposed to other stimuli or performed other behaviors, even "the lapse of only a few seconds between response and reinforcement destroys most of the [learning] effect” (Skinner, 1954, p. 91). Yet Skinner (1954) saw that in the schools reinforcement was commonly applied to “blocks of responses—as in correcting a work sheet or page from a workbook” (p. 91), rather than to small, individual behavior changes. Perhaps even more damaging was the length of time it took for students to receive reinforcement for the proper behavior. Skinner noted that sometimes the lapse of an entire day occurred between students' performance (such as on a test) and their receiving any reinforcement back from the teacher.

Skinner was also discouraged by other common trends he saw among educators. For example, Skinner (1961) criticized those who were primarily concerned with 
improving what he thought were only the logistics of teaching, such as ways to better "group students according to ability,” or efforts to "bring textbooks and other materials up to date” (p. 378). While Skinner recognized these efforts as possibly important, he also believed that they did not address the fundamental learning processes he had identified as being most critical. What was necessary, according to Skinner, was a concentrated effort to find the best way to apply operant conditioning to the schools, and so address the root causes of learning problems.

Skinner’s (1954) answer was to use “mechanical [or] electrical devices” (p. 94) that allowed for very frequent, positive reinforcement, and that broke instructional material down "into a very large number of very small steps” (p 94) to allow for optimal shaping. The fundamental purpose of the device would be to cause "certain forms of behavior ... to be evoked and, through differential reinforcement, brought under the control of specific stimuli” (Skinner, 1958, p. 971). Skinner (1954) described a prototypical device that he thought accomplished precisely this goal:

The device consists of a small box about the size of a small record player. On the top surface is a window through which a question or problem printed on a paper tape may be seen. The child answers the question by moving one or more sliders. . .. The answer appears in square holes punched in the paper upon which the question is printed. When the answer has been set, the child turns a knob. The operation is as simple as adjusting a television set. If the answer is right, the knob turns freely and can be made to ring a bell or provide some other conditioned reinforcement. If the answer is wrong, the knob will not turn.... When the answer is right, a further turn of the knob engages a clutch which moves the next problem into place in the window. (p. 95)

Skinner additionally described the benefits of this device:

Reinforcement for the right answer is immediate. The mere manipulation of the device will probably be reinforcing enough to keep the average pupil at work for a suitable period each day.... Each child may progress at his own rate, completing as many problems as possible within the class period. If forced to be away from school, he may return to pick up where he left off. The gifted child will advance rapidly, but can be kept from getting too far ahead either by being excused from 
[the subject] for a time or by being given special sets of problems which take him into some of the interesting bypaths of [the subject]. (p. 95)

This device, which Skinner called the teaching machine, became an important educational innovation in its own right and led to the set of techniques which later became known as programmed instruction.

These programming techniques emphasized an orderly, detail-oriented procedure to ensure that material developers understood the target learning behaviors and what types of reinforcements were likely to lead to those behaviors. Skinner (1958) summarized the basic process:

The first step is to define the field. A second is to collect technical terms, facts, laws, principles, and cases. These must then be arranged in a plausible development order-linear if possible, branching if necessary. . . The material is distributed among the frames [i.e. chunks of information to be taught] of a program to achieve an arbitrary density. In the final composition of an item, techniques for strengthening asked-for responses and for transferring control from one variable to another are chosen from a list according to a given schedule in order to prevent the establishment of irrelevant verbal tendencies appropriate to a single technique. (p. 974)

Skinner believed that if these basic techniques were followed, the resulting instructional materials would be optimally constructed to keep students' attention on the proper stimuli, evoke from them the behavior currently being shaped, and immediately reinforce the targeted behavior so that students were more likely to emit that behavior again.

Throughout his career, Skinner (e.g. 1961; 1986) was clear that it was the principles of operant conditioning, as implemented through these techniques, that were important to student learning. He was careful to emphasize that the use of a machine not developed according to the proper principles was no guarantee that learning would take place. But Skinner (1954) was also clear that he thought machines played a critical role in the programmed instructional process that other methods of implementation could not 
fully replace. As he stated, the teacher "must have the help of mechanical devices" (p. 95), and "mechanical help is ... demanded by the sheer number of contingencies" (p. 94) required to optimally shape a learning behavior. Skinner (1958) later estimated that a course in spelling may “require 20,000 or 25,000 frames" (p. 972), or individual reinforcements, for students to achieve mastery. Since he thought this was unrealistic for any human teacher, the teaching machine itself assumed the central responsibility of providing that level of reinforcement. Admittedly, Skinner (1986) did see later media used to deliver PI, such as workbooks or other printed materials, as having a legitimate place in education. But even while recognizing that printed PI could be useful in some situations, Skinner did appear to consider the teaching machine, and later the computer, as the ideal way to implement the programmed method.

To enforce the proper implementation of his programming techniques, Skinner encouraged intensive evaluation of PI materials to help ensure they were properly reinforcing and shaping the target behaviors. Skinner (1958) actually thought that PI lent itself very well to rigorous evaluation. Since programmed materials were broken up into such small steps, evaluators could pinpoint with precision exactly what part of the instructional sequence was causing problems for students. Yet Skinner (1968/1963) also encouraged an evaluative approach that sought to improve specific instances of PI, not an agenda that sought to establish the general superiority of PI over other methods of instruction. To Skinner, PI was based on sound, universal principles of learning, whereas nearly all other methods of education were not. For him, that was enough to demonstrate PI’s superiority. He thought the search for evaluative evidence demonstrating PI's superiority over more traditional methods was flawed, "because only specific instances 
[of educational materials] can be tested, and available examples by no means represent all the possibilities” (p. 415). The purpose of evaluation, then, was to make sure any particular teaching machine or other example of PI was as effective as it possibly could be.

Although Skinner saw PI as a very flexible approach to learning, he was often criticized for making education too simple, teaching only rote content and not higherlevel skills, and encouraging students to unhealthily rely on the programmed materials. Skinner (1968) dismissed all of these criticisms as a misunderstanding of the PI method. While many examples of PI did teach simple content such as mathematical facts or spelling (e.g. Skinner, 1954, 1958), Skinner also described how the approach could apply to more complicated subjects such as verbal communication, pattern recognition, music, attention, writing, memorizing, originality, self-control, and ethics (Skinner, 1959, 1961, 1968). Skinner (1968) believed that if someone could analyze a learning outcome and somehow translate it into a set of behaviors to be shaped, they could teach it using PI. Skinner (1968) also thought that the critics who claimed that PI did not teach higher-level skills misunderstood the basic ideas behind the approach. For example, when some critics claimed that programmed materials only taught students to memorize facts and not how to think, Skinner responded that the common educational practice of mixing subjects (such as teaching geography content at the same time as teaching critical reasoning skills), was inappropriate. Skinner believed that these separate content areas should be taught separately, so that both of them could be shaped most efficiently. It was inappropriate, then, to criticize a program designed to teach facts for not also teaching reasoning skills. Other programs should be developed specifically for that purpose. As he 
stated, "programming undertakes to reach one goal at a time. Efficient ways of studying and thinking are separate goals” (p. 87), and should not be taught together. And finally, Skinner (1958) thought that a well-developed program would eventually vanish all prompts and allow the students to perform learned behaviors on their own. If programs did not eventually encourage student self-reliance, it was a failing in that particular program and not in the method itself.

To Skinner, then, PI promised to revolutionize the entire educational system. It first promised to make education much more efficient. Skinner (1958) related one example from Harvard University where students completed a course on behavioral psychology with a median time of $14 \frac{1}{2} 2$ hours. Skinner concluded that, "it is probably because traditional methods are so inefficient that we have been led to suppose that education requires such a prodigious part of a young person's day” (p. 972). At another time, Skinner (1961) said that PI could lead to a general trend of teaching a subject "in half the time with half the effort” (p. 387). In addition to these efficiencies, Skinner (1954) thought PI's potentially greatest contribution was to make the educational system more humane. Teachers would have to use less coercion and punishment to keep their students on task. Students could more easily learn at their own pace, and PI presented new opportunities to learn at home or in other situations where a teacher was not available (Skinner, 1958). Teachers would not only be able to supervise more students, but would also have more time to individually counsel or otherwise "follow the progress of each student and to suggest collateral material which may be of interest” (Skinner, 1961, p. 392). Skinner thought the ultimate goal of education was "the fullest possible development of the human organism” (p. 398), and teaching machines and programmed 
instruction were the best ways to "design ... entirely new educational practices" (p. 397) that would allow teachers and other interested parties to meet this goal. Skinner's Programmed Instruction as an Example of Technology II

Skinner's version of PI can be described as a type of Technology II, which Beckwith (1988) defined as, "the development of methodological, rule-based processes [for] the facilitation of learning” (p. 4). It is not unique to view Skinner's PI as an example of Technology II—in fact both Lumsdaine (1964) and Davies (1973) used Skinner and programmed instruction as the epitome of Technology II in their early explanations of the concept. Skinner did, in fact, appear to explicitly describe his version of PI in terms consistent with Technology II. For example, Skinner (1968) called the programmed approach “a technology of teaching” (p. 255) that gave teachers a set of scientifically based procedures and techniques to help them engineer learning in their students. As an example of Technology II, Skinner's PI reflects some of the assumptions and results predicted in Chapter Two as characteristic of this type of instructional technology. But additionally, Skinner's understanding of PI also leads to some clarifications of how to view the criteria of Technology I, II, and III.

My purpose in this section is to compare the major themes of Skinner's PI to those of Technology II to develop the claim that PI is an example of Technology II assumptions and goals. I also clarify some of the reasons why instructional technologists might adopt goals other than those of Technology III. This discussion will show how the abstract themes of Technology II are observable in the real-world beliefs and behaviors of instructional technologists, as well as provide a concrete, historical example of Technology II which can act as a model for instructional technologists to compare against 
their own beliefs and behaviors. As discussed in Chapter Two, this can help instructional technologists develop a richer prudential knowledge by giving them criteria against which they can more clearly judge what types of behaviors will most closely align with their own foundational assumptions, their beliefs, and the goals they are pursuing. The problem Skinner thought he was solving through PI closely corresponds to the Technology II theme that instructional technologists believe they are trying to develop instruction that effectively and efficiently helps students reach a predetermined instructional outcome. One way to see this is to examine what Skinner specifically thought his purpose was not. For example, Skinner (1958) criticized the goal of only trying to improve the scalability of teaching activities, or of only trying to improve methods of information presentation (both of which align closely with Technology I). In fact, Skinner’s criticisms sound very similar to those in Chapter Two against Technology I. But Skinner (1968/1963) also appeared to criticize Technology III goals, specifically that instructional technologists should try to improve all learning wherever or however it happens. For example, Skinner believed that statements of purpose that described "the teacher [as one who] 'impart[s] knowledge,' 'improve[s] skills,' 'develop[s] rational faculties,' and so on” (p. 410), were imprecise, not measurable, and, ultimately, “irrelevant” (p. 411).

Skinner (1968/1963) also spoke directly about what he viewed his purpose to be. He stated that "the well educated student is distinguished by certain characteristics" (p. 411), and the job of the teacher was to precisely define those characteristics, analyze them in detail, and then teach using methods that resulted in observable and measurable 
learning changes. Skinner (1986) also maintained that successful teachers did not provide overly open or overly realistic experiences for their students in the name of instruction:

Preparing is not the same as living.... Students and teachers tend to move too quickly to the 'living' stage. ... Those who criticize programmed instruction ... . [often do so because they] want to move [students] out of the preparation stage too quickly. (p. 107-108)

Finally, along similar lines, Skinner claimed, "we do not learn by doing, as Aristotle maintained; we learn when what we do has reinforcing consequences. To teach is to arrange such consequences” (p. 107). Presumably, to properly arrange these consequences, one would first have to known and specify them beforehand. All of these statements align with or can be derived from a Technology II sense of purpose.

Recognizing Skinner's sense of purpose as aligning with Technology II leads to a better understanding of the motives of those who adopt Technology II, especially when comparing Technology II beliefs to those of Technology III. Chapter Two described Technology III as being more inclusive and holistic than Technology II. It additionally described how adopters of Technology III believe they have a more complete foundation from which to provide learning assistance to students than is available in either Technology I or II. While my position continues to be that this is the case, I recognize that it is also possible for one to conclude from the descriptions in Chapter Two that those who adopt Technology I or II are not as interested in helping students as are adopters of Technology III. Skinner’s example makes clear that while one may claim that Technology III provides instructional technologists with a richer range of options, one should not claim that adopters of Technology I or II are disinterested in helping students learn. Skinner (1954) was most enthusiastic about PI becoming the foundation of a more humane educational system that did not have to rely on aversive methods of control. And 
he looked forward to PI starting an educational revolution that would result, system wide, in effective methods of learning that had never before been considered. In actuality, Skinner's focus on students and his desire to help them learn should be motivating to instructional technologists even today, whether or not current practitioners agree with how he went about providing that help.

Skinner’s PI, although an example of Technology II, also provides a valuable insight for adopters of Technology III. As I discussed in Chapter Two, a possible criticism of Technology III is that it is not a rigorous approach to instructional development, and that instructional technologists could use the concept of Technology III to adopt an “anything goes” approach to their practice. Skinner’s criticisms of ideas consistent with Technology III seem to be based on similar reasoning. While Skinner (1968/1963) perhaps had an extreme view when he criticized educational outcomes that are not measurable, calling them irrelevant and not valuable, his views are still a helpful warning to adopters of Technology III. Those adopting Technology III should consider how they can determine the value of their work even if they believe there are important learning outcomes that cannot be measured in traditional ways.

There are also parallels between Skinner’s PI and Technology II beliefs about learners and learning. In Technology II, the critical requirement of learning is that people experience the appropriate environmental processes that control the acquisition of the desired learning outcomes. As one example of Skinner's apparent belief of this principle, he once stated that learning "takes place only when the control exercised by [an] available stimulus is transferred to a new stimulus” (1959, p. 64). As another example, he said that "an important condition [for learning] is the relation between behavior and its 
consequences; learning occurs when behavior is 'reinforced'”' (Skinner, 1968/1963, p. 405). This assumption did lead, as Chapter Two explained, to a strong language of control over learners in Skinner's version of PI (e.g. Skinner, 1961, 1968). Skinner (1968) actually thought this was a valuable assumption for instructional technologists to make, "because it encourages a search for causes” (p. 171) of learning that they might not otherwise look for. And, in fact, to Skinner (1971) people were not free to act for themselves apart from environmental conditions. The only options were whether or not the control was provided through positive means (e.g. positive reinforcement or reward) and for benevolent reasons, or if it were provided through negative means (e.g. punishment) and for inhumane reasons. As he stated, "the problem is to free men, not from control, but from certain kinds of control” (p. 41). The benefit of PI, according to Skinner (1968), was that the control PI provided relied on positive reinforcement and was designed to be applied both for the benefit of the individual and of the advancement of the human race.

Additionally, Skinner's beliefs about the nature of technology in instruction were also similar to those found in Technology II. The Technology II assumption about the nature of technology in instruction is that the processes and methods designers use to develop instruction have an inherent power to solve instructional problems. To Skinner this was because the ideal programming process was based on scientific knowledge about behavior shaping that was as reliable as any physical science (see Skinner, 1971). In fact, Skinner’s (e.g. 1958) description of the ideal programming process sounded very similar to the critical aspects of Technology II instructional development processes, as described in Chapter Two. This should not be surprising because, as I have mentioned, PI is widely 
regarded as an important source of ideas in the history of instructional technology. Although Skinner (1968) thought that the programming process was still in its infancy, he was confident that with more experience it could become "much more powerful" (p. 260). Over time, PI could control a wide range of educational outcomes through the development of “standard materials and practices” (p. 255) that could apply to many different instructional situations.

However, although Skinner did accept only certain forms of instruction as legitimate, he did not seem to advocate the same unthinking adherence to process as others predicted would result from Technology II. For example, Skinner (1958) speculated that good programming was “an art” (p. 974) that could not be fully reduced to a checklist of procedural steps. Additionally, Skinner was adamant that programmed materials be evaluated for effectiveness with real students, and he did not accept that a program was sufficient merely because it was developed using the proper process. Skinner's thinking appeared to reflect a theory-based realism. He was convinced that the principles of operant conditioning and programming were valid, and that ultimately all learning arose from the successful application of these procedures and techniques. Yet he also thought that one could not be sure one had implemented those principles correctly before trying a program with the targeted student population. So it appears that Skinner’s PI had not yet solidified into all of the traditions of practice that Chapter Two predicted would occur as a result of Technology II.

Another of Skinner's beliefs about the nature of technology in instruction deserves mention. As I discussed earlier, Skinner thought that some type of mechanical device was critical to let teachers fully implement the proper principles of conditioning. 
Although he was usually careful to give priority to the soft technologies of programming and behavior shaping (which priority leads to Skinner’s PI being classified as Technology II), the teaching machine itself still played a near-irreplaceable role in Skinner's version of PI. In fact, some of Skinner's language sounded similar to that of the Technology I assumption about the nature of technology in instruction. For example, at different times Skinner said both that teachers "must have the help of mechanical devices” (Skinner, 1954, p. 95) to best condition their students, and that the work of successful teaching was so difficult that it "require[d] instrumental aid" (Skinner, 1968, p. 65). This highlights the point that the criteria for Technology I, II, and III, while useful tools for understanding and analyzing the goals and practice of instructional technology, do not fully capture the reality of those goals and practice. Real-life instructional technology, as Skinner’s example illustrates, is much more complex and nuanced than any set of criteria can capture. I encourage readers to use Technology I, II, and III as appropriate to help them develop a richer understanding of how to conduct their practice, without assuming that Technology I, II, and III are absolute descriptions of reality that easily cover all examples (see Wenger, 1998).

Although Skinner did not advocate an unthinking application of PI process, his writings on PI did lead to some of the other types of rigidity predicted in Chapter Two as being associated with Technology II. The most notable was that Skinner's PI neglected important characteristics of instructional problems and solutions that the languages he used to develop instruction did not easily express. Skinner went to great lengths of define all teaching and learning problems in terms consistent with the principles of operant conditioning. Additionally, despite his comment that "not everything we want to teach 
can be programmed" (Skinner, 1986, p. 109), he also often described in great detail how one could create programmed materials for what many considered the most difficult subjects to teach using that method (e.g. Skinner, 1968). Yet the programmed materials resulting from Skinner's, and others', efforts could not adequately address their full range of desired learning goals (McDonald et al., 2005).

One notable example was Skinner's (1968) description of how to program the behaviors associated with creativity. According to Skinner, "the behavior said to show creativity" could be attributed "to manipulable variables" (p. 170). Some of the important variables Skinner identified included: "self-reliance” (p. 174), the ability "to learn how to learn” (p. 176), "the extension of verbal responses to new and unfamiliar stimuli” (p. 178), and "teach[ing] the student to arrange environments which maximize the probability that original responses will occur” (p. 180). Undoubtedly creative people often do exhibit these types of behaviors. Yet Skinner's explanation and justification for reducing creativity to a list of observable behaviors seems convoluted. While perhaps some of his listed behaviors are technically accurate, Skinner seemed to fail at fully capturing what most people would consider a creative person. The question remains, after reading Skinner's operationalized version of creativity, as to whether or not such a trait can be fully reduced to a list of observable behaviors. It does appear, to borrow from Wilson (2005b), that “an intangible part” of creativity was “lost as things [were] documented and codified” (p. 242). In fact, this observation is consistent with some of the classic criticisms of Skinner's work (e.g. Chomsky, 1959). The programming of creativity, along with the many other examples provided in Skinner’s (1968) work, seem 
to exemplify the Technology II tendency of reducing instructional problems and solutions to forms that cannot adequately meet real-life diversity in student learning needs.

Finally, Skinner's understanding of PI also leads to some clarifications of the reasons that instructional technologists might adopt goals consistent with Technology I, II, or III. In Chapter Two I primarily discussed that instructional technologists would be pulled away from Technology III by different reasons that Beckwith (1988) called “traps” (p. 8). But Skinner's development and promotion of programmed instruction raises the very real possibility (only briefly mentioned in Chapter Two) that instructional technologists might choose Technology II (or, presumably, Technology I) because their foundational assumptions are already consistent with its principles. As the quotes from Skinner’s writings should make clear, Skinner deliberately chose Technology II, rather than abandoning Technology III. In fact, he was sometimes critical of assumptions that seemed to align with Technology III (Skinner, 1968/1963). Skinner was undoubtedly committed to the principles of conditioning which were foundational to PI, and so it is not accurate to characterize his adoption of Technology II as becoming distracted by other rewards (the trap of compromised integrity), trying to appear more legitimate or professional (the trap of status quo adherence), or trying to make his work simpler or more routine (the trap of solidification). Overall, Skinner's version of PI not only provides some important clarifications, then, of the themes and results of Technology II, but should also provide a perspective that some instructional technologists may choose Technology I or II because they legitimately think those assumptions, values, beliefs, and behaviors are the best alternatives available for developing instruction. 


\section{Modifications to Programmed Instruction}

Although Skinner (e.g. 1968) recognized that his programming methods could be improved to better implement the principles of conditioning, he was critical of other modifications to PI that ignored or only partially implemented what he considered proper behavioral conditioning, through which neglect he thought PI developers made it more difficult for students to learn. For example, Skinner (1958) thought that teaching machines that used multiple-choice questions rather than requiring students to construct their own responses were harmful because "effective multiple choice material must contain plausible wrong responses, which are out of place in the delicate process of ‘shaping' behavior because they strengthen unwanted forms” (p. 970). Magnifying the problem, according to Skinner (1968/1963), was the tendency some educators had to automate educational tasks using PI without first understanding why those tasks were being automated. Skinner also accused some programmers of encouraging incorrect perceptions as to what programmed instruction was by trying to explain it in the language and terminology of earlier educational methods. It may be a good summary, then, to say that Skinner thought that PI could be improved by bringing it more in line with the principles of behaviorism, but otherwise he considered PI an approach that should remain pure.

My purpose in this section is to describe specific examples of programmed instruction (chosen according to the selection criteria described in Chapter Three), and how each example either conformed to or modified Skinner's original PI. I analyzed each example to discover what types of goals each adopter claimed to be working towards, and what types of practice they actually achieved. The criteria of Technology I, II, and III are 
helpful in making explicit the assumptions foundational to the PI practice in each example. In many cases, these practitioners applied PI in ways that exemplified the rigidity and inflexibility predicted to result from the practices of Technology I and II, regardless of how closely they followed Skinner's PI approach. Yet one case seemed to show how some practitioners modified Skinner's approach to achieve flexible results that seemed to help them better work towards all the goals they had for their educational system. The discussion of each example will help validate that Technology I, II, and III are useful criteria to describe the goals, values, beliefs, and behaviors of real-world instructional technologists. These discussions will also uncover some of the reasons that may prevent instructional technologists from remaining flexible enough to work towards the widest possible range of educational goals they believe are important to pursue. Example one - Skinner's own practice. The first example is Skinner's own practice of programmed instruction, in collaboration with his colleague James Holland (Skinner \& Holland, 1960/1958), reporting use of a teaching machine in a course on behavioral psychology at Harvard University. Skinner and Holland chose PI to help their "students ... analyze and comment upon" the subjects taught in the course, which included "reflexes and Pavlovian conditioning, operant conditioning, discrimination, motivation, emotion, [and] techniques of personal control” (p. 167). Skinner and Holland's example shows that, in practice, they were sometimes more flexible in their PI approach than Skinner was in his theoretical writings on the subject. Yet in many key ways their practice also reflected the assumptions of Technology II, and their example seems to reflect the Technology II consequence of settling on a single solution, then stopping the search for new solutions that might help them better achieve the goals they 
had for their practice. There also appeared in Skinner and Holland signs of the trap of status quo adherence, which resulted in the same narrow view of what made for legitimate instruction that eventually seemed to characterize much of PI practice.

Not surprisingly, Skinner and Holland's (1960/1958) report seemed to reflect many of the beliefs, attitudes, and behaviors of Technology II. It appears they believed their purpose was to develop instruction that only helped students reach certain, predetermined outcomes. For example, they stated that "the programmer must know what verbal behavior the student is to have after completing the course” and then teach only that "sequence of steps ... [that lead] from the initially assumed knowledge up to the specified final repertoire” (pp. 163-164). They also seemed to believe that the critical requirement for learning was that their students experience the appropriate environmental processes that controlled the acquisition of the desired learning outcomes. They stated that "the programmer must not at any time appeal to material not included in the statement [of students’ initial knowledge] or not provided by earlier parts of the program” (p. 164). Otherwise, students would not learn. Skinner and Holland also held that one of the advantages of their program was that it "forced” (p. 165) students to learn technical terms because each of those terms were included as separate frames of the program. And finally, there are also indications that Skinner and Holland believed that the processes and methods they used to develop their program had an inherent power to solve educational problems. Some of the previous quoted provide evidence for this, as well as other statements as arguing that if the programmer understood all of the responses that needed to be conditioned in a program, "a fairly mechanical procedure can be followed” (p. 164) to assure learning. 
Even though Skinner and Holland's (1960/1958) assumptions seemed to align closely with the same assumptions Skinner had championed as he developed the PI approach, in actual practice they seemed to demonstrate more flexibility in their programming than Skinner in theory had allowed for. It appears that their flexibility resulted from unanticipated circumstances that led them to conclude that the ideal practice of PI was not working the way they thought it should. The most notable example of this was Skinner and Holland's advocating that "a slight punishment [be administered to students] for a wrong response” (p. 161), because they saw their students taking a "careless" (p.160) approach to the instruction the teaching machine provided. After the students recorded their response to a frame of instruction, they compared their response to the correct response the machine provided. Students then recorded in the machine whether or not their response was correct or incorrect. After students had responded once to each frame of the program, they went through the program a second time to complete those items they had originally missed. Skinner and Holland found that some of their students, especially those who were "highly motivated" (p. 160) to do well in the course, purposefully recorded wrong answers on their first attempt through the program in order to see the correct response. They then knew the correct response for their second attempt, and so could complete the program with less effort.

By modifying their program to include small punishments, Skinner and Holland (1960/1958) were violating a principle that Skinner advocated for PI developers, that positive reinforcement was the technique of choice to best shape students' behavior. Even after Skinner and Holland's experiment, Skinner (1968) later claimed that punishment in general was a counter-productive technique for behavior shaping. Yet in their practice, 
Skinner and Holland were willing to resort to punishment to extinguish behaviors they saw as an impediment to students’ appropriately learning from the teaching machine. This indicates that Skinner and Holland may have viewed the characteristics making up Skinner’s version of PI as guidelines, and not as absolute rules. It also indicates that they believed that teachers should not apply programming techniques without consideration of the full environment in which the PI was being used. This conclusion seems reasonable given Skinner’s (1958) insistence that programming techniques should not be applied to a given situation without an accompanying evaluation to determine whether or not they were working the way the programmer desired.

Yet despite their willingness to modify some aspects of their PI process to better respond to students' actual behaviors, other indications in Skinner and Holland point to their Technology II assumptions leading them overall to a more inflexible practice. This is most clear in the fact that although Skinner and Holland intensively evaluated their teaching machine with their students, they also never seemed to consider that other approaches besides the teaching machine might better help them achieve their goals. In other words, Skinner and Holland appeared never to consider that the principles of conditioning foundational to PI might need modification based on their experiences; rather they seemed only to think that their specific implementation of those principles was faulty.

For example, during their evaluation Skinner and Holland (1960/1958) discovered that about two thirds of their students felt "anxious" or "pressed for time” (p. 170) as they used the teaching machine, and slightly more than one third "felt they were 'missing many opportunities to reflect on material and consider its implications'” (p. 171). Skinner 
and Holland's conclusion was "that the design of the machine has overemphasized motivation" (p. 170), and their solution was to "redesign [the machine] to produce a somewhat slower pace and lessened pressure” (p. 171). Other alternatives to improving the learning situation never seem to have crossed their minds-for example, that perhaps something about the programmed approach in general led to the result, and they might actually have achieved more desirable results through another instructional method. This observation, that Skinner and Holland considered only certain types of solutions in response to evaluative data, seems to illustrate Gibbons and McDonald's (2005) claim that "having arrived at a set of usable solutions, [the practitioner of Technology II] chooses to stop seeking new solutions and changes from a search for solutions to a service and a craft” (p. 7).

It may seem unfair to criticize Skinner and Holland (1960/1958) for not considering other alternatives at the time, yet the criticism is not a disparagement of their motivations or their talents as instructional developers. Their practice is, in fact, an example of exactly the point that one's assumptions can blind one to unfamiliar, yet potentially useful, alternatives. And it is the stated purpose of this study to help instructional technologists become more aware of how their assumptions can blind them to alternatives, and how to avoid limiting themselves in this way, since these limitations seem to be such a persistent occurrence in the history of the field. Certainly Skinner and Holland's willingness to evaluate their PI technique was commendable, as was their willingness to modify their teaching machine when they observed students’ problems. Yet given the historical demise of programmed instruction, Skinner and Holland may have actually been spending their time perfecting less-helpful techniques that ultimately 
could not facilitate the goals they were trying to achieve. It is interesting to speculate whether or not expanding the possible interpretation of their evaluative findings could have led them to developing new techniques that may have been better at achieving the outcomes they desired. As McDonald et al. (2005) stated

Considering whether or not a certain guideline is being followed because it really is the best choice given the situation, and not simply because it is common practice ... may seem like a burdensome task to some. But the alternative is to risk becoming so entrenched in a certain set of assumptions that those assumptions can no longer be questioned. (p. 90).

Further evidence of this tendency to become "entrenched in a certain set of assumptions” (McDonald et al., 2005, p. 90) is visible in Skinner and Holland's (1960/1958) general description of the programming process they followed to develop their teaching machine. Although their stated goal was to help students “analyze” (p. 167) the material taught in the course, when they actually created their instructional materials they operationalized the skill of analysis as their students eliciting the "verbal behavior. . .. [they need in order to] precisely and extensively ... talk about” (pp. 163-164) course topics. Further specification of their process led to them listing every "term ... procedure ... [and] example” (p. 164) which they wanted students to know, along with every verbal form of each important phrase. For example, they not only selected the word "elicit" as an important term for students to know, but also terms such as "is elicited," and "elicitation" (p. 164). They then followed a "fairly mechanical procedure ... [of] writing frames so that each concept ... was used with each example, in as wide a range or syntactical arrangement as possible” (p. 164). Examples of their finished frames included "a technical word for reward is reinforcement. To reward an organism with food is to it with food,” and, "technically speaking, a thirsty organism can be with 
water” (p. 165). These two frames would supposedly condition in students the two responses of reinforce and reinforced.

Skinner (1959) viewed students’ acquisition of a “verbal repertoire” (p. 66) as the most legitimate evidence that they had also acquired the other important skills of analyzing a subject matter. This was because a verbal response was easier to observe than other types of analysis behavior. As a result, Skinner and Holland (1960/1958) created their program to elicit verbal responses to the neglect of any other potentially important skills helpful in analyzing a subject. Additionally, Skinner and Holland defined the type of verbal behavior in which they were interested as students being able to respond to vocabulary statements arranged in different orders and with different examples, "with rare exceptions, frames [were] statements with words missing, the missing word being supplied by the student” (pp. 164-165). Although Skinner and Holland reported that many of their students thought they learned well from this type of instruction, a significant number also reported that they, in some manner, felt they "were being treated like an experimental organism” (p. 171). Roth (1963) later reported similar reactions, along with very high levels of student boredom, when he evaluated a revised version of Skinner and Holland's program.

These problems may not have arisen because Skinner and Holland taught students using such a method, but because they did it to the complete exclusion of any other method of learning. Garner (1966) commented on this tendency, observed among many developers of PI in addition to Skinner and Holland, as acting "as though all knowledge came through the eyes, and the only responses learners would ever make would be to fill in blanks and write out short phrases” (p. 13). Garner appeared to be suggesting that by 
limiting themselves to such a narrow view of what constituted learning, Skinner and Holland (1960/1958) were also only helping to develop a small sub-set of the skills they wanted their students to acquire.

These tendencies seem to be similar to the trap of status quo adherence. The trap of status quo adherence predicts that instructional technologists can potentially fall away from Technology III because of their desire to find a practice more traditional, legitimate, professional, or respected. Although neither Skinner's PI nor Skinner and Holland's (1960/1958) assumptions seem to predominately align with Technology III, the general statement of status quo adherence does appear to apply to Skinner and Holland's practice. The type of practice they considered legitimate and professional was that practice closely aligned with what Skinner (1954) had earlier called a "scientific technology" (p. 93), so they defined any problem they encountered in the languages and procedures of that technology. It should not be surprising, then, that the solutions they considered legitimate also derived from the languages and procedures of the same technology. Skinner and Holland's example may prove useful for instructional technologists to consider how their practice might become inflexible and unable to facilitate their full range of learning goals, if they look only for familiar solutions that are easily expressed in the languages or theoretical positions that they typically advocate.

Example two - A second PI exemplar. The second example is Meyer (1960), who was considered one of Skinner's most accomplished students, and who in her own right developed influential approaches to programmed instruction (Markle, 1969; Zemke \& Armstrong, 1997). Meyer used PI to teach eighth-grade students the subject of Greek and Latin prefixes used in English words. She additionally used her practice to experiment 
with various types of programmed materials to determine some of the optimal characteristics of PI. Although Meyer modified PI as Skinner promoted it, her practice in this example still seems to have reflected some of the assumptions of Technology II, as well as leading to some Technology II results. In particular, her programmed materials were inflexible, and appear not to have been very adaptable to the diversity in her students’ learning needs. Interestingly, however, Meyer discussed her experience developing and refining the program in a later report (Markle, 1964). In this later work, she advocated a more flexible approach to PI development, indicating that perhaps her experience of trying to implement such a rigid form of instruction helped her modify some of her earlier, Technology II assumptions. Meyer’s change in emphasis is an important confirmation of the ideas, relating to the development of prudential knowledge and how that can help instructional technologists become more flexible in their practice.

Despite having learned the practice of PI from Skinner, Meyer (1960) was willing to modify her practice to improve on the outcomes Skinner achieved. For example, although Skinner (e.g. 1954; 1986) focused most of his attention on the teaching machine, Meyer in this example compared the effectiveness of PI as implemented in a book with PI as implemented in a teaching machine. Also, Skinner (e. g. 1958) thought it was critical to provide immediate confirmation to students of the correctness of their response after they completed each frame, to properly condition and shape their behavior towards the desired end. Meyer, while inclined to accept this as a general rule, also attempted to verify the rule through empirical evidence. To do this, she provided one group of students no information about their performance until after they had completed 
an entire programmed book, and compared their outcomes with students who received information about their performance after each item.

Even considering these and other modifications, Meyer’s (1960) practice seemed to reflect the same type of assumptions about instructional technology as did Skinner's. The most identifiable assumptions relate to her beliefs about learning and learners, and her beliefs about the nature of technology in instruction. Meyer's language as she discussed her students reflected the Technology II assumption of environmental processes being the critical requirement that caused student learning. For example, she discussed how the frames of her program, when well developed, were effective "in controlling [the] writing behavior” (p. 237) of students. She also discussed how one student who was doing poorly in the course "was obviously not under the control of the textual stimulus” (p. 238) the program provided. Meyer's language also indicates she believed the Technology II assumption that the PI strategies and processes she used had an inherent power to solve educational problems and to cause learning. For example, she advocated the technique of "error-free” (p. 235) programming, that a program consisting of such small and simple steps that a student made few or no errors intrinsically had the ability to cause higher levels of student achievement. In other words, she appeared to believe that the perfect program led to error-free results, and that the perfect program could teach all students perfectly.

Another example of Meyer's (1960) beliefs about the nature of technology in instruction was her experiment to compare the effectiveness of different characteristics of PI, such as the difference between a programmed book and a teaching machine, or students who received immediate confirmation of their performance with those who did 
not. Meyer's stated goal in so doing was to develop "a set of 'rules”” (p. 246) that future programmers could use when developing their own programs. As opposed to Skinner (1958), who advocated evaluation to improve a specific program for a specific group of students, Meyer appeared to be trying to define strategies that would be successful in any given situation because of the experimentally verified nature of those strategies themselves.

Meyer’s (1960) practice not only reflected these assumptions of Technology II, it also seemed to lead to some common Technology II results. The clearest illustration of this was the results of Meyer's attempts to make her programmed materials error free. It appears that the simple nature of many frames in Meyer's program encouraged students to complete the program quickly, without careful thought as to the intended learning outcome of the frame (or sequence of frames). An example of a typical frame in Meyer's program was, “the prefix trans- means 'across' or 'over' (from one place to another). A transatlantic flight goes___ the Atlantic Ocean” (p. 237). Students most often answered these types of frames correctly.

However, when students encountered a frame that was of necessity a little more complicated, they often seemed to respond in a superficial way, and perhaps demonstrated the habit of not fully reading each question before responding. For example, a frame Meyer labeled as “complex” (p. 238) read, “a person who has left his native country is an __migrant” (p. 239). The students were to choose one of two prefixes, ex- or dis-, to complete the word. Out of fifty-eight students, "22 students wrote im, and 17 students ... [wrote] em” (p. 239). Both of these prefixes produced common words that students were familiar with, although neither was an option from which 
students were to choose. In another case, which did not produce the same high error rates but was still telling, a frame read, "the opposite of consent is ___ sent” (p. 245). Four of the fifty-eight students responded with the prefix con-, resulting in the same word, when they had been instructed to find its opposite. Ironically, the technique of error-free programming, in the hope of causing deeper and more lasting learning, appeared to lead programmers such as Meyer to develop programs which ultimately required less intellectual effort from students (Markle, 1964), and so sometimes led to less learning (and perhaps even some poor learning habits) than would otherwise have taken place.

This seems to typify the Technology II result of "inadvertently . . . creating 'disabled' learners [by] spoonfeed[ing] them instruction in an effort to achieve homogenous outcomes” (Gordon \& Zemke, 2000, p. 57). As Bernstein, Penner, ClarkeStewart, and Roy (2006) concluded, “large amounts of guidance may produce very good performance during practice, but too much guidance may impair later performance” (p. 231). Meyer (1960) seemed to have discovered this principle when she noted “a large increase in errors" between frames that "highlighted" with "quotation marks or underlining” (p. 246) the correct answer in the body of the frame, and frames that also included the correct answer but did not highlight the answer to make it easier for students to find. This small difference, which Meyer said was one of the important distinctions between a "simple” and a “complex" (p. 245) frame, indicates that her program was not preparing students to learn on their own, and most probably was training them to look for cues within frames which would give them the correct answer. Meyer, in noticing the difference in students' error rate, concluded that the solution was to simplify the frames she defined as complex. This suggests that her method had perhaps blinded her to the 
possibility that the results her students achieved on simple frames were not actually indicators of their learning how to properly use Greek and Latin prefixes.

Interestingly, however, it appears that from this and similar experiences, Meyer (1960) may have learned beliefs and attitudes more similar to those of Technology III. Writing later under the name of Markle (1964), she discussed how her attempts to program had led her to adopt new beliefs about education and programming that appear to be different from some of her beliefs of a few years earlier. For example, in this later report she stated her beliefs about her purpose as to not only teach "the subject to be taught," but also "the values of the culture in which it is taught” (p. 145). Although in her earlier work she did not discuss in detail what she viewed as her purpose, her approach then seemed to suggest that she was most concerned about her students achieving as efficiently as possible the identified set of objectives. Other statements also suggest Markle was becoming more open to unanticipated learning outcomes that unfolded throughout the instructional process, such as her description of ideal teachers as those who are willing to modify their goals based on their students' emerging needs. These statements appear to be indicators that Markle was moving away from the Technology II purpose of only providing preplanned activities for predefined outcomes, to a Technology III purpose of supporting all learning wherever or however it might happen.

Markle’s (1964) later beliefs about the nature of technology in instruction also seemed to contrast with her earlier beliefs. In this later work, she seemed more open to the Technology III idea that there was not one ideal strategy that would meet the needs of all students or all situations. For example, she stated

If [a] tutor has five students to whom [a] subject must be taught, it is highly probable that he will teach it five different ways.... The tactics, the methods of 
getting each student from point to point, will vary from student to student as the tutor discovers the individual's strengths and weaknesses. (p. 146)

Markle also seemed to become more aware of some of the consequences of providing a single, error-free program for all students regardless of other circumstances, "as [a] program is tested on the slowest students for whom it is intended, it rapidly evolves in the direction of slow, easy, unchallenging steps. The weaknesses of each student tested are incorporated into its design” (p. 148).

While Markle (1964) still held that PI had much to offer, her later work encouraged programmers to adopt a reflective practice, and to consider more carefully when and how they applied the techniques she and others developed. This growth in Markle’s assumptions and practice indicates that Technology I, II, or III are not immutable categories. In other words, just because an instructional technologist's practice may at one point reflect one category does not mean that person's practice must always belong to that category. Markle’s willingness to re-examine her own theories and practice based on her experiences seems to typify the process of developing prudential knowledge. In addition, her growth out of assumptions similar to those of Technology II into assumptions similar to those of Technology III indicates that as her prudential knowledge grew she became more dissatisfied with the limits of Technology II, and moved towards a type of practice that offered her more options to flexibly work towards the goals she thought were important to achieve.

Example three - Less successful PI. The third example is Keislar's (1959) report of a teaching machine trial to teach children "understanding” (p. 247) of certain geometric shapes. This study was included for analysis because of its less successful outcomes. Although students’ test scores did improve after they used Keislar’s teaching 
machine, he was very disappointed that students also recorded high error rates while completing the program, and that their final test scores were much lower than he originally predicted. In fact, Keislar himself ultimately concluded that his trial was unsuccessful. Evidence in Keislar's report suggests that his assumptions aligned closely with Technology II, and that he adopted some of the rigid and reductive practices that have been predicted would follow from those assumptions. His assumptions may have not only contributed to the problems Keislar observed, but also influenced the further solutions he proposed, leading him to conclude that even greater rigidity and simplification were necessary to accomplish his goals. Keislar's example provides further evidence that instructional technologists' foundational assumptions predispose them to certain types of practices. It also provides additional evidence that Technology II assumptions and practices tend to limit the types of solutions instructional technologists consider legitimate, and so cut them off from possible solutions which may be more appropriate to help solve the problems they encounter in their practice.

Before specifically examining Keislar’s (1959) report, however, I must make a note about how I chose his study as a less successful example. Unfortunately, no good method exists for determining how an individual PI report compares to others in terms of procedure, student outcomes, or other results. Current techniques to investigate these matters, such as the meta-analysis, had not been developed during the period when many researchers were originally investigating PI. The studies from the era that did examine the effectiveness of PI (e.g. Schramm, 1964b) did not do so in a systematic manner, and Kulik, Cohen, and Ebeling (1980) described them as unreliable for anything other than general descriptions of each study because of the "crude techniques” (p. 53) they 
employed. More current studies which have retrospectively looked back on PI also do not provide adequate information. For example, some (e.g. Kulik et al., 1980; Nash, Muczyk, \& Vettori, 1971), while employing more sophisticated statistical techniques, do not provide adequate information to identify the procedures or results of individual studies. Others (e.g. Lockee et al., 2004; McDonald et al., 2005) provide descriptions of individual studies without attempting to evaluate them against any type of standard criteria.

As a result, to find a less successful example of PI I reviewed available surveys of the literature and noted those studies that were singled out on measures that might in some way indicate the quality of the original researcher's practice. I then read each of these studies, looking for whether or not the original investigators provided enough detail in their reports to let me compare their assumptions or practice to Technology I, II, or III. Most, unfortunately, did not. But Lockee et al. (2004) mentioned Keislar’s (1959) study as a PI report that found less consistency among student outcomes than did other researchers. This indicated that perhaps Keislar had implemented PI differently than others had, and also that his implementation might have been of a lower quality than others because of the general finding that PI often resulted in very consistent student outcomes (Lockee et al., 2004). Further examination of Keislar's report confirmed that it would be insightful as an example of less-successful PI.

Keislar (1959) adopted the teaching machine to develop in his students an “understanding,” of “the concepts of squares, rectangles, length, and width” (p. 247). Keislar defined the skill of understanding as "the ability to answer a variety of questions different from those encountered during training but belonging to the same general class; 
the broader this class is, the greater is the understanding” (p. 247). Each frame of Keislar's program contained a short statement explaining or illustrating a mathematical principle or concept, as well as a question about the information in the frame. Also included in each frame were up to five multiple-choice options from which students selected their response. If students chose the correct answer, they moved on to the next question. If students chose an incorrect answer, a red light flashed to inform them to try again. Students did not move on to the next question until they had selected the correct response. Before the trial began students completed a pretest, with a posttest following within one day of their completing the program. While analysis of the test results showed that all but one of the students had learned at least some of the material, Keislar said that students "learned far less than what had been expected” (p. 257). Specifically, he was disappointed that students made frequent mistakes while completing the program (as I will discuss later, Keislar had attempted to make the program error free), and that the error pattern in the posttest indicated that students had not learned as deeply as Keislar predicted they would.

In implementing his program and carrying out this trial, Keislar (1959) seemed to align with the assumptions of Technology II. This is most clear in his description of how he used Skinner's principles of programming. Keislar specifically mentioned error-free programming, vanishing prompts, and developing a large number of verbal behaviors as techniques he adopted from Skinner. His description of how he used these processes and techniques indicate that he believed the Technology II theme that the critical requirement for people to learn was for them to experience the appropriate environmental processes that controlled the acquisition of learning. His report also indicates that he accepted the 
Technology II theme that those processes and techniques had an intrinsic power to solve educational problems.

As an example of his alignment with both of these themes, Keislar (1959) stated, “in this study it was assumed that if a pupil selected the wrong alternative to an item he did so either because he was improperly selected for the program or because of inadequate prior learning in the program itself” (p. 248). Keislar seemed to be saying that he believed if students had the assumed prior knowledge when they began the program, they would only select wrong answers because the program itself was somehow deficient. Keislar also predicted that if his program was properly constructed, student learning from each frame would be “practically assured” (p. 248). As another example of his beliefs about technology in instruction, Keislar also described how specific items in his program developed in his students certain verbal behaviors which "function[ed] to extend the pupil's learning to entirely new items,” and that would allow them to understand "why . . . you multiply in one case and divide in the other” (p. 150). Stated another way, Keislar appeared to be saying that each component of his program was necessary for students to acquire certain verbal responses, which in turn were necessary for them to achieve understanding of the mathematical concepts. Although it is possible that Keislar believed that other educational methods might help students achieve the same outcomes, the general tone of his report does suggest that he believed that students must experience some instructional intervention to learn these mathematical concepts, as well as that his approach was the optimal method for students to do so.

Keislar’s (1959) report also indicates that his Technology II assumptions led him into some of the rigid and reductive practices that result from those assumptions. One of 
these was the Technology II tendency to apply instructional techniques without understanding whether or not those techniques are appropriate for the situation (see Davies, 1984). Although Keislar's stated goal was to help his students understand mathematical concepts, he did not appear to consider whether or not the actual techniques he used to program were the most appropriate to facilitate this outcome. Rather, he appeared to have adopted his techniques because they were viewed as the legitimate way that one went about creating programmed instructional materials.

The clearest case of this was in his adoption of error-free programming. Keislar (1959) tried to create "a minimum difficulty level for the items” (p. 248) in his program. To do this, he simplified the content to the point that he thought students would be most likely to always answer the item correctly. In some cases, he colored certain parts of a frame to draw students' attention to the correct response, and in others he labeled a diagram with the correct response students were to select in the accompanying question. As was discussed in Meyer's (1960) example, evidence suggests that these types of programs required less intellectual effort from students, and so may have actually worked against Keislar's broad goal of developing in his students the "understanding” (p. 247) of the concepts. It appears, in fact, that this did take place. Keislar reported the mean number of errors his students recorded as they completed the program was 54 (out of 120 frames), much higher than his goal of error free. Keislar also stated that on the posttest, "most [students] missed several items which were similar to those presented in the program” (pp. 250-251), which indicates that students did not develop understanding as he defined it, which was for students to answer questions different from, but similar to, those they had studied. 
This evidence leads to the conclusion that the PI technique may not have been appropriate for Keislar's (1959) goal. Yet when Keislar discovered this evidence himself, he actually concluded that it was his use of PI techniques that was inadequate, and that the solution was to make each frame and the program as a whole simpler. Keislar concluded that his program "was ... far more difficult than intended” (p. 252) and therefore should be simplified for students to be able to achieve the outcomes he expected. Yet in the twelve sample frames that Keislar provided in his article (which were $10 \%$ of his complete program), the longest frame consisted of thirty-six words. Despite this, Keislar concluded that "the steps in many if not most cases could be smaller” (p. 252). Keislar also concluded that the reading level of the program was too difficult, and should be simplified in spite of the already short frame length, sentence length, and lack of a specialized vocabulary. This response seems similar to the Technology II reaction, as Tennyson (2000) mentioned, to “offer the same solution process regardless of the conditions of the given learning problem or need” (p. 232). In other words, in reaction to the problems he encountered, Keislar looked back to the same narrow set of techniques that may have led him to create the problems to begin with. Keislar's example, then, seems to provide another valuable piece of evidence that the assumptions and practices of Technology II can lead to instructional technologists limiting their options, and cutting themselves off from possible solutions which may be more appropriate to help them solve the educational problems they encounter.

Example four - Intrinsic PI. The fourth example (Crowder, 1963) is valuable because of its intentional differences to Skinner’s version of PI. Crowder’s program, “A Theorem in Number Theory” (p. 89), was an example of what he called “intrinsic 
programming” (p. 84). It appears that some of Crowder’s beliefs approached the criteria for Technology III. Yet Crowder’s example also illustrates the trap of solidification, visible in others' reaction to his program. Those to whom Crowder presented his program showed resistance because Crowder rejected the idea that the most important consideration was to create a simple and routine process for PI development. Crowder's example also demonstrates the difficulty instructional technologists might have in explaining their practices or assumptions to those who hold different practices and assumptions. An important lesson from Crowder's example is that because of this difficulty, instructional technologists might be more successful in disseminating the ideal of a Technology III approach if they were not only aware of their own assumptions but also the assumptions of those with whom they work. If this were the case, instructional technologists might be able to more easily explain to others the rationale for specific instructional solutions, and the value of using flexible methods to help facilitate all the educational goals they believe are important to work towards.

Crowder’s (1963) report described a program Crowder developed using his method of "intrinsic programming” (p. 84). Intrinsic programming historically was the major alternative to Skinner’s version of PI (Saettler, 1990). Although he developed his approach independent of Skinner or even from much of the then-current psychological research, Crowder was aware of Skinner's work and intentionally contrasted his approach with Skinner's (e.g. Crowder, 1964). There were a number of significant differences between intrinsic programming, also known as “branching” (Crowder, 1963, p. 85) programming, and Skinner's version. One of the most significant was the idea the name of branching PI implied. Skinner (1958) championed linear programs in which students 
completed each frame in the same order, and suggested programmers use branching techniques only as a last resort. Crowder, on the other hand, advocated programs which did not have a pre-determined order, and where the frames students saw depended on their response to the previous frame. To make the number of branches somewhat manageable for a programmer to develop, Crowder also popularized the use of multiplechoice questions in PI, rather than having students construct their own response as Skinner advocated. As a final example, Skinner opposed student errors on the principle that errors reinforced incorrect behaviors. Crowder recognized that when students made an error it was an opportunity for the programmer to correct a misconception, or provide some other type of remediation, so that students had all the assistance they needed to properly learn the material. To other programmers from the era, these differences were not insignificant. In fact, it was not uncommon to hear different types of PI described as either “Skinner programs” or “Crowder programs” (Hoth, 1964/1961, p. 195).

Crowder’s (1963) reasons for developing his program with the intrinsic approach indicate that some of his assumptions about learning and learners, and about the nature of technology in instruction, approached the criteria for Technology III. For example, in contrast to other PI research, Crowder believed that learning occurred when "the material presented to each student is continuously and directly controlled by [the student]” (p. 86). In other words, rather than the program controlling the students and their learning, the students controlled both the program and their own learning. This corresponds well to the Technology III theme that learners are agents with the ability to control their own learning as well as the purposes that drive their learning. Additionally, although Crowder seemed somewhat confused about how technology influenced instruction, some of his 
statements indicate that he thought there was more to the effectiveness of an instructional technology than either the physical devices or the processes and methods programmers used to develop that instruction. The clearest example of this was in his encouragement that programmers should consider the broader context, the students' abilities, and other factors when implementing an instructional method or strategy. He also believed that it was a "gross oversimplification” (p. 88) to postulate a simple cause-and-effect relationship between an instructional technology and student success. This indicates that he may have sympathized with the Technology III theme that the products and processes of instructional technology can facilitate the creation of good learning experiences, but those experiences cannot be fully reduced to, nor controlled by, the technology.

In addition to these indications of Technology III assumptions and beliefs, Crowder's (1963) report also shows signs of the trap of solidification. The trap of solidification occurs when instructional technologists adopt the rigid practices of Technology I or II because they fear they will not be able to sustain their practice unless they make that practice simpler or more routine. The trap of solidification is apparent not in Crowder's practice personally, but in the reaction of others to whom Crowder demonstrated his program. These reactions were recorded in the transcript of a questionand-answer session that accompanied Crowder's report. Many of them indicate that Crowder's audience had adopted a solidified practice. For example, at one point Crowder stated, “people are frequently disappointed . . . because [intrinsic programming] doesn’t appear to offer any very firm set of rules whereby you can produce effective materials” (p;. 104). Questioners seemed critical of this stance and responded that they would prefer well-defined processes for program development. One questioner stated that Crowder 
made “programming skills sound so superficial” (p. 105), while another was concerned that if there were not easy-to-follow PI development rules, the job of the programmer would become too difficult.

Crowder’s (1963) reaction to these responses demonstrates the difficulty instructional technologists might have in explaining their practices or assumptions to those who have different practices and assumptions. Crowder not only seemed to have difficulty explaining the rationale of his program in ways that his audience could understand, but as the questioning continued he appeared to spend less effort in explaining his practice to questioners. Some of his responses seemed slightly antagonistic, as if he were intentionally trying to provoke his audience so that they would give more thought to their own purpose and goals. For example, in response to one series of questions that Crowder seemed particularly displeased with, he finally responded with one characteristic that he thought all programmed instruction should include. It was "that [the programmer] have something to say” (p. 104). In contrast, Crowder described a common alternative as to include meaningless material only "on the grounds that it might do [the student] some good” (p.114).

One conclusion that can be drawn from this example is that part of the communication problem between Crowder (1963) and his audience may have been due to the differing assumptions they brought to the situation. Because Crowder's audience had such different assumptions about the nature of their practice, it appears they were blind to the possibilities Crowder presented to them. When one adopts certain traditions, such as Crowder's audience apparently adopting the tradition of routine and rule-based practice, those traditions can predispose them to see unfamiliar solutions in terms of the solutions 
with which they are familiar. The solution to this problem includes making explicit the assumptions underlying, and implications leading from, those traditions so that one can determine how well they align with the type of practice one wants to develop. Since Crowder was not only innovating a more flexible approach but trying to explain his innovation to others, another important lesson may be that instructional technologists should not only make explicit their own assumptions about instruction and instructional technology, but also those of others with whom they are working. If this were the case, instructional technologists might be able to more easily explain to others the rationale for specific instructional solutions, potentially leading to better understanding and dissemination of beliefs and behaviors consistent with Technology III (which it appears Crowder was not able to do). This conclusion seems consistent with innovation researchers such as Rogers (2003), who encouraged innovators to have a rich understanding of why those with whom they are sharing an innovation believe and act the way they do, both to better understand why they are resistant to the innovation and to potentially understand whether or not the innovation is even appropriate for those with whom the innovator shares it.

Example five - Televised PI. The fifth example, Estarellas (1966), is notable because of Estarellas’ attempt to develop a programmed instructional course to teach Spanish using the medium of television. Estarellas was one of a number of researchers who investigated how to combine the techniques of PI with those of instructional television (e.g. Dick, 1964; Gropper, 1964). Although some of Estarellas’ assumptions appeared similar to those of Technology II, others seemed to align better with Technology I. Despite showing tendencies towards both sets of assumptions, however, 
Estarellas’ practice itself actually seems most similar to that of Technology I. Evidence suggests that because Estarellas gave priority to assumptions that aligned with Technology I, he fell into a rigid practice that abandoned some of the goals he originally stated were of importance. Estarellas’ example demonstrates that Technology I does describe at least some types of real-world instructional technology practice, as well as provides important insights about the beliefs and attitudes of those practicing at this level. Instructional technologists, then, can use Estarellas' example to better understand whether or not Technology I aligns with their own assumptions, attitudes, and beliefs, as well as whether or not it can help them achieve a practice which will best help them accomplish their goals.

Before specifically examining Estarellas’ (1966) example, however, a note must be made about how his study was chosen for analysis. Combining the programmed approach with other instructional approaches, such as television, was a noticeable trend in the literature of PI (e.g. Gropper, 1964). To find a representative study from this literature, I conducted an ERIC search on the terms programmed instruction and programed instruction. I scanned the abstracts of the resulting articles for those that also included the word television. Most of these studies did not contain enough information to make any judgments about the researcher's practice. Estarellas’ study was the first I analyzed from this subset that included enough information to draw conclusions about how well his assumptions, beliefs, and practices might have aligned with Technology I, II, or III. Based on this review, I chose his report to represent one of the two studies in this chapter that presented a unique viewpoint on PI research. 
Estarellas’ (1966) Spanish course, geared towards beginning college students, was specifically designed to combine the techniques of PI with those of instructional television. Estarellas investigated this combination because he believed that PI was "the solution to [the] problem" of "overcrowded classrooms and language teaching materials based on dull drills” (p. 1). Yet PI alone, according to Estarellas, needed to be presented through a medium that would "give the student a more realistic learning situation in which the very process of language could be related to the purpose of language” (p. 2). Estarellas here appeared to mean that common implementations of PI did not show language being used in realistic situations, which he thought would inhibit student learning. Television was a good medium for PI, Estarellas thought, because of its ability to combine visuals with audio stimuli. To create his program, Estarellas took a photograph of each frame of a Spanish language program and added audio segments (along with some video segments) of people saying phrases in Spanish to which students were to respond. Students were given a book in which to write their responses to most of the frames; additionally, they were to speak some responses when the program prompted them to do so. The program had pauses built into it to give students time to respond to each frame. Estarellas created more than one version of his program, with pauses of different lengths, to give students the option to proceed quicker or more slowly through the program based on their personal preferences.

Examining Estarellas’ (1966) report reveals assumptions, attitudes, and beliefs that seem to align both with Technology II as well as Technology I. This perhaps should not be surprising, given his stated desire to combine PI with instructional television. As I have discussed throughout this chapter, PI often typified Technology II tendencies, while 
Lumsdaine (1964), when initially describing Technology I and II, used instructional television as an epitome for the practices of Technology I. As an example of Estarellas’ conflicting beliefs, at one point he indicated that the two features on which "the success of a program ... depends” were "the materials," and "the medium or machine used to communicate these materials to the students” (p. 2). Estarellas here appeared to give equal weight to both of these factors, seemingly accepting both Technology II and Technology I beliefs about the nature of technology in instruction (respectively that processes and techniques, as well as physical devices, used for instructional purposes have an inherent power to solve educational problems).

Others of Estarellas' (1966) beliefs, however, seem to more closely align only with Technology I. For example, as he discussed the need he saw to make language instruction more "realistic" (p. 2), it appears that he equated seeing or hearing life-like situations with realistic instruction. However, Estarellas most often required students to respond to an instructional stimulus by writing a response as they would in nearly all other programmed materials. Some researchers in PI (e.g. Garner, 1966) criticized the belief many programmers had that writing responses was a universally appropriate method of learning. So despite the realism of the visual or audio stimuli, the responses students made in Estarellas’ program were typical of other programs, and most often not authentic. Yet Estarellas seemed not to consider this, and more closely aligned with the Technology I theme that only presenting students with an appropriate stimulus was sufficient to cause learning, without regard to what students did in response to that stimulus. Finally, there was a strong statement in Estarellas’ report that the primary problem he was trying to solve was how to make language instruction more scalable and 
efficient. In this drive for efficiency, Estarellas demonstrated willingness, as I will discuss further, to compromise what he saw as effective instructional practices. This corresponds with the Technology I theme that the most important problem instructional technologists are trying to solve is how to make instruction a more efficient activity, to the exclusion of searching for other alternatives that might be more appropriate for the full context in which they are working.

Despite showing tendencies towards the assumptions of both Technology II and Technology I, Estarellas' (1966) actual PI practice itself seems to most closely align with that of Technology I. Estarellas appeared to give priority in his program to the physical device of television. He believed that television had "unique” (p. 3) properties that made it ideal for PI. He also stated that there were "tremendous possibilities that TV offers as a self-instructional machine, and . . . thanks to this medium, the days of total selfinstruction are nearer” (p. 13). Although Estarellas occasionally mentioned programming strategies he considered essential to the approach, he also consistently favored the device of television over those programming strategies. For example, although he mentioned that it was very difficult to let students pace their own instruction using the television, as well as difficult to require them to make a response, Estarellas was willing to sacrifice these features of the PI approach in favor of continuing to use the television.

Estarellas’ (1966) modification of PI to make it more similar to conventional instructional television appears similar to the rigid, Technology I result that views only certain types of instruction as legitimate. Estarellas' practice seemed to reflect his abandonment of some principles he initially believed were important in favor of using the television. Some of these have already been mentioned, such as the goals of self-pacing 
and required response that Estarellas was willing to abandon in favor of the televised medium. Another telling example was that Estarellas initially described developing instruction better than the "dull drills" (p. 1), which he thought were typical of other language instruction, as an important goal. Yet it appears that the only step he took to avoid this was to include visuals and audio in some frames. The example frames that he included in his report were all similar to those that described at other points of this chapter, and that have been criticized in the research for being "slow, easy, [and] unchallenging” (Markle, 1964, p. 148; see also McDonald et al., 2005). Even those sections of his program where he used video to prompt responses, which he called the most authentic and realistic that he could provide, were actually structured beyond the point of realism, with Spanish conversations broken up into short phrases across many frames. It appears that Estarellas defined "realism” only as the quality of the visuals and audio, and not the realism or authenticity of the situation in which students would use the knowledge they learned. This is another example of how he aligned with the Technology I belief that presenting information to students in a realistic way was sufficient to cause learning.

It is important to note that another possible interpretation of Estarellas’ (1966) practice is that he was making incremental improvements towards an ultimate ideal, or that he was making difficult compromises because of constraints he faced in the design situation. Both of these approaches would align more closely with Technology III, rather than Technology I. However, there does not appear to be evidence in his report that this was the case. Estarellas was very enthusiastic about television, and it appears that this enthusiasm that was the guiding principle for most of his implementation decisions. From 
the beginning he seemed to assume that because of television's intrinsic properties it would be an effective medium for PI. Because of this presupposition that seems clear from the examples I have provided from his report, it is a reasonable conclusion that Estarellas aligned more closely with the Technology I tendency to define instructional technology in terms of the physical devices used, rather than the Technology III tendency to move incrementally towards a goal by any means available.

Estarellas' (1966) example demonstrates that Technology I does describe some real types of instructional technology practice. Additionally, as with some of the Technology II examples analyzed to this point of the chapter, Estarellas’ report can help instructional technologists understand how the abstract concepts of Technology I might occur in real instructional technology practice. One interesting insight is that although Estarellas seemed to align with more than one type of foundational assumption, some of his assumptions were of greater importance to him than others. This may account for the confusion Estarellas sometimes seemed to show as he was discussing his program or related matters, such as his beliefs about what type of technology had the power to solve educational problems. He may actually have held some contradictory beliefs regarding whether or not the programmed materials or the medium of television that were the critical factor. The literature I reviewed in Chapter Two would suggest that Estarellas had probably not examined these assumptions or their implications, leaving him in a state where he may not have been aware of any contradictions in his thinking. Yet some of Estarellas' assumptions did take precedence in his practice, and it appears that it was his enthusiasm for television that drove many of the decisions he made about his PI implementation. 
Overall, Estarellas’ example can provide instructional technologists with a greater understanding of whether or not Technology I aligns with their own assumptions, attitudes, and beliefs, and whether it is a type of practice which will best help them accomplish their goals. For instructional technologists who do hold many different beliefs about technology and its role in instruction, Estarellas' example can show them how easily their enthusiasm for hardware technologies might distract them from other principles they consider important. Estarellas probably did not set out to abandon features of PI that he sincerely believed in. He most likely would have affirmed his commitment to PI if he were questioned at the time that he wrote his report. Yet something still appears to have been lost when he translated his beliefs into a tangible practice. Ultimately, he viewed only those PI practices which he could implemented through television as important. Instructional technologists can use Estarellas’ example, then, as a reminder to not abandon what they consider important in their enthusiasm for a new technology (hard or soft) which they may be interested in using.

Example six - PI in a larger system. The sixth example, Schramm (1964a), was part of a compilation of PI case studies that the editors of the volume intended to encourage a richer use of the approach than they thought was common (Edling et al., 1964). Some of the assumptions of those involved at Denver actually appear similar to Technology III, especially their beliefs about the nature of technology in instruction. Schramm recorded in great detail how the Denver public school system implemented PI, and his report indicates that Technology III assumptions positively influenced the personnel at Denver. Denver's personnel slowly investigated the types of situations in which PI might be beneficial, carefully evaluated each implementation of PI, and over 
time became better at involving all interested parties in the implementation process. As a result, despite some unsuccessful results when they began, the personnel at Denver ultimately felt that they found the most appropriate uses of PI for the educational goals they pursued in the entire system. Schramm’s report is a useful example that can help instructional technologists better understand how their beliefs, values, and behaviors can help them remain flexible in their adoption of an instructional technology, and so be better able to use those technologies in the pursuit of goals which they consider important.

Schramm (1964a) reported that the Denver public school system investigated PI over a three-and-a-half year period. Initially, they directed their effort towards creating their own programs. As commercially prepared programs became available, they also tested some of those. Yet they found that commercial programs did not target their specific goals and sometimes were not of the quality they desired, so they re-focused their effort back on developing their own programs. Initially, Schramm stated that most of Denver's implementation efforts were unsuccessful. It took much more time and effort than they anticipated to develop programs that met their standards of quality. In fact, in one case they simply ran out of time and released a program to teachers before they thought it was ready. In early evaluations, while some students seem to learn very well through PI, others who were already experiencing difficulty performed very poorly. This was discouraging to many at Denver because "they had . . expected the program to narrow the difference between the faster and slower students-in the belief that everybody, at his own rate, would learn most of what the program had to teach” (p. 33). Additionally, the central administration forced Denver’s initial PI materials on teachers . 
Teachers felt unprepared to use the programs, and there were high levels of variability between teachers in terms of success.

Yet Schramm (1964a) believed that over time Denver learned from their previous efforts and slowly began to find more successful places for PI in their curriculum. One important change they made based on evaluative data was to include teachers more in the preparation process, including having teachers develop their own small programs or complete a program themselves in the role of a student. Schramm reported that this made a tremendous difference in teachers' abilities to know when and how they might use a program as a successful tool. Another change at Denver was to use small programs for specific topics, and to use those programs in combination with other methods and techniques for instruction. This countered a general trend of developing programs for course-length topics, and to use those programs as the exclusive instructional method for teaching that topic. Schramm believed that this was an effective approach, because teachers could better pick programs for very targeted situations and use those programs in conjunction with other helpful instructional techniques, in "combinations [that were] best for given students and given situations” (p. 39).

Another notable change Schramm (1964a) reported was that personnel at Denver became more willing to modify the techniques of programming to better meet the student learning needs they observed. If teachers had an outcome that they did not think they could easily implement through strict application of PI strategy, rather than redefining their outcome (as they thought PI experts would have probably encouraged them to do) they chose another strategy. This led to those at Denver colloquially calling their PI “teachers’ programs, rather than psychologists’ programs” (p. 38). This example also 
appears to reflect a broader shift in the teachers' and administrators' expectations about PI itself. In addition to changing beliefs about how to develop effective programs, they also increased the amount of time they allocated to developing good programs. Additionally, they lowered their expectations about the types of changes PI would bring to their system. In other words, rather than believing that PI was a panacea that would solve all their educational problems, they began to view PI as one tool among many, that in some cases was a good choice but in others was detrimental to the student learning experience. Finally, those at Denver also adopted a very flexible approach to trying out programs (as well as other methods of instruction). They were willing to change or abandon their programs when they thought it was necessary, but were also willing to advocate for PI's use when evidence showed that it could be advantageous.

Examining Schramm’s (1964a) report seems to indicate that some of the assumptions of those at Denver actually aligned with Technology III. This is in contrast to the other PI research in this chapter, which was more similar to either Technology I or II. The most notable of the Denver personnel's assumptions was their apparent beliefs about technology in instruction, which sounded similar to the Technology III theme that the products and processes of instructional technology can facilitate the creation of good learning experiences, but those experiences cannot be fully reduced to, nor controlled by, the technology. Much of the evidence for their alignment with this theme has just been reviewed, regarding matters such as their use of PI in combination with other methods, or their pragmatic use of programming strategies. One final statement also seems to support the conclusion that the Denver personnel aligned with Technology III assumptions about technology in instruction, which is that Schramm observed that "the effort [at Denver 
was] to find the job a program can best do, under the guidance of a teacher who is responsible for combining the learning experiences at her disposal” (p. 39). An additional Technology III theme in Schramm's report is the theme that learners are agents with the ability to control their own learning as well as the purposes that drive their learning. Those at Denver appeared to align with this theme when they noticed that those students who had a better attitude towards PI seemed to learn more from using it. Schramm also stated that the Denver personnel thought it was best for students to be "involve[d] actively” (p. 40) in what happened to them in the classroom.

Schramm's (1964a) report is a useful example that can help instructional technologists better understand how Technology III beliefs, values, and behaviors can help them remain flexible in their adoption of an instructional technology, and so be better able to use those technologies in the pursuit of goals which they consider important. PI developers at Denver did not rigidly adopt programming practices that they thought were ineffective for the situation, which corresponded to Technology III themes about the nature of technology in instruction. Yet it is also important to note that they did not outright reject programming practices and techniques, either, but used those techniques whenever they saw evidence that those techniques would have a positive benefit. Additionally, they provided their personnel with formal training opportunities in PI technique as well as eventually dedicating some teachers exclusively to PI development, so that those teachers could best hone their craft. This sounds similar to the description of prudential knowledge provided in Chapter Two, which stated that instructional technologists should develop a practice that is well-grounded in the best theory the field of instructional technology has to offer, but is also continually pushing 
them to greater flexibility by reflection on their personal experience. It additionally illustrates how practitioners of Technology III look for helpful techniques wherever they may be found, and do not cut themselves off from potentially helpful sources because of a bias against that source.

Another example in Schramm’s (1964a) report of how Technology III practices helped Denver's personnel achieve a wider range of possible goals was their constant evaluation of PI results and practices, as well as a determination to act on whatever evaluative data they found. Schramm stated that "the Denver people agree with the increasingly held belief that a school cannot be certain of a program without testing it on students” (p. 37). Although an often-repeated step of many instructional development processes, evaluation historically has been a stage that practitioners often ignore (Seawright \& Williams, 2006; Smith \& Ragan, 2005). Yet Technology III would encourage instructional technologists to take evaluative data seriously, because of the view that the products or process used cannot determine the effectiveness of an instructional technology, only the results. In the Denver experience, Schramm reported that evaluation did improve their ability to achieve a wider variety of instructional goals. Schramm reported that the Denver personnel seemed surprised by some of their findings, such as the finding that they achieved the greatest learning outcomes by using PI as a part of a greater systemic whole, rather than as the only instructional method to help facilitate learning. Yet because they discovered this principle and were willing to implement their finding, their PI practice was more effective than many other implementations. As Wenger (2000) observed, communities of practice can become rigid if they do not build into their communities the values and practices that will help them avoid becoming 
unhealthily “oriented to their own focus” (p. 233). The example of Denver suggests that evaluation is at least one way that instructional technologists can build into their communities some values and practices that will help them avoid this rigidity.

Representativeness of these studies. Although it is difficult to determine how representative these six studies are of PI practice in general, the body of PI literature suggests that the issues these adopters encountered were at least common enough to warrant consideration of my findings. Perhaps the most significant challenge in judging how representative these six studies are is that, as Lockee et al. (2004) concluded, "the research conducted and published in [the] era of . . . programmed instruction use is generally poor” (p. 552; see also Nash et al., 1971). Most often, it is difficult to judge how closely any particular PI implementation conformed to Skinner’s version of the approach because researchers rarely reported enough information about their PI to compare it to Skinner’s. In fact, most studies lacked sufficient information to make any judgments at all about the quality of the researcher's practice.

Yet a number of authors from the era, including Skinner himself, saw significant differences in how practitioners implemented PI (e.g. Garner, 1966; Markle, 1967; Skinner, 1968/1963). Some have also concluded that as PI became more popular it also became even more rigid and inflexible than Skinner used it in his own practice (McDonald et al., 2005). Those who have discussed the rigidity of PI also sometimes provided reasons why, in their opinion, the approach was too inflexible. Many of these reasons sound similar to the traps of compromised integrity, status quo adherence, and solidification. Although I proposed these three traps as aids to understand why those with Technology III assumptions sometimes limited themselves to Technology I and II, these 
traps also appear to be useful aids to classify different types of rigidity adopters of PI experienced, even when those programmers did not originally hold Technology III assumptions.

The first trap, compromised integrity, describes instructional technologists abandoning some of their goals in favor of other priorities they think will be more rewarding. Some observers noted that this behavior was a factor in the practice of some PI developers. For example, Skinner (1968/1963) directed heavy criticism towards those who thought that "education [was] big business" (p. 404), and who were more interested in making money from PI than using it to improve education. As a result, according to Skinner, they developed poor programs that "were not well built or designed" (p. 404), but that could still make money. Foster (1983) concurred, seeing more of an emphasis on selling PI than on developing effective programs (see also Sherwin, 1972). Lawson (1969) described another type of compromised integrity, noting a tendency among programmers to put "too much emphasis ... on gadgetry” (p. 93). This Technology I emphasis led programmers to abandon their efforts to improve PI because of their excitement about perfecting the physical technology. Garner (1966) also described the "halo of glamour surrounding this new technology,” with PI developers "pursu[ing] goals blindly, [and] reject[ing] elements of the old that might be salvaged” (p. 50), which ultimately resulted in an ineffective practice. And Schramm (1962) combined the hardware focus Lawson and Garner described with the business interests Skinner and Foster decried, stating that PI "shows signs of hardening, partly under commercial pressure, into a fixed and mechanical technology” (p. 37). 
The trap of status quo adherence occurs when instructional technologists abandon some of their goals in favor of practices perceived to be more traditional, legitimate, respected, or professional. Some observers discussed how practitioners implemented PI in ways that look like status quo adherence. The most notable example in PI was the historical trend in the era to view instructional methods derived from scientifically verified behavioral psychology as the most legitimate. Klaus (1964), for example, was an advocate for empirically verified principles of programming and believed that he was representing many others who would accept as legitimate only those practices which had been tested experimentally. Yet Blyth (1964/1962) was one who recognized that rigidity could result from an inappropriate adherence to behavioral principles, because that adherence limited the legitimate types of instructional solutions without fully investigating whether or not other solutions had anything to offer. In addition, Cook (1997) criticized some PI developers for inappropriately appealing to behavioral psychology as justification for programming practices that actually had little to do with the principles of behaviorism. Yet because their justification legitimized those practices, programmers often unthinkingly applied the practices, which often led to rigid results.

The trap of solidification happens when instructional technologists lose a critical characteristic of their original practice as they attempt to make their practice simpler or more routine. Many commentators observed behaviors similar to this trap in the literature of PI. Mechner (1977), for example, described how his own employees often resisted proposed PI innovations, which he thought would help them better achieve their instructional goals, because the new practices threatened the routines they had developed over time. McDonald et al. (2005) documented the general trend among PI developers to 
try to make complicated ideas simpler, leading to the unintended outcome of "be[ing] more concerned with the outward form of their materials than with the learning outcomes” (p. 89). Post (1972) described a similar trend, noticing that programmers were trapped in "needlessly narrow theory" (p. 14) that he thought led to overly simplistic rules for PI production. For example, Pipe (1966) described how some programmers would take a textbook, break it up into frames of one or two sentences each, and provide it to students as a program. And Gilbert (1996) believed that many programmers thought they could define a small number of rules for PI which they could then procedurally follow to develop an acceptable program for any situation.

Yet it appears that despite many poor examples, PI may not have been a universally rigid instructional technology. Many researchers described a theory of the ideal PI practitioner as one who carefully examined whether or not PI was an appropriate choice for an instructional situation, and who used the approach in conjunction with other approaches to make a small, but positive, change in an educational system (Corrigan, 1964; Gotkin \& McSweeney, 1967). This seems to be a good description of how the Denver implementation was conducted (Schramm, 1964a). Other observers of PI also commented on how other practitioners from the era were sometimes able to use PI in uncommon ways, and were able to avoid the Technology II inflexibility that appeared to characterize so many implementations. For example, also similar to the Denver approach, some teachers would use small programs for targeted, specific instructional goals; use PI as one instructional approach among many; and would intervene if the program was not facilitating learning as they or their students desired (e.g. Dutton \& Riggs, 1969; Edling, 1964). 


\section{Conclusions from Programmed Instruction}

My review in this chapter of Skinner's version of PI, and of six analyzed examples of PI, has provided some valuable insights about Technology I, II and III. The analysis in this chapter also uncovered some reasons why instructional technologists sometimes adopt the rigid assumptions and practices of Technology I or II, as well as some of the results that may follow from adopting Technology I or II practices. Finally, I described how some instructional technologists have been able to avoid the pitfalls of Technology I or II and find ways to implement even inflexible instructional technologies in a way that better helped them work towards goals they considered important. My purpose in this section is to summarize the major conclusions from the analysis completed in this chapter:

1. Skinner’s programmed instruction represented Technology II; Skinner's PI principles aligned closely with the major themes of Technology II.

2. The results of Skinner's PI indicate that his approach was rigid and inflexible, although Skinner did not promote the same unthinking application of PI process as did others.

3. Practitioners of Technology II do not necessarily have bad motives, nor are they necessarily uninterested in helping students learn. Yet their foundational assumptions can distract them from these motives and lead them to an approach that is more focused on other rewards.

4. Those practicing Technology III should consider how they can determine the value of their practice even if they believe there are valuable learning outcomes that cannot be measured in traditional ways. 
5. Some instructional technologists may adopt Technology I or II not because they fell away from Technology III, but because they think Technology I or II are the best alternatives available for developing good instruction.

6. Of the six reports I analyzed in this chapter, four of them typified Technology II, one typified Technology I, and one appeared to approach Technology III. This indicates that all three levels of Technology I, II, and III can provide real-world examples against which instructional technologists can compare their own practice to see if that type of practice is likely to lead to the types of outcomes they desire.

7. Technology II can lead to inflexible practice when instructional technologists look only for familiar solutions they can easily express in the languages or theoretical positions that they typically advocate.

8. Technology II can lead to overly simple instructional solutions that may not prepare students to perform outside of the original learning context.

9. Technology I, II, or III are not immutable categories to which one will always belong; one’s assumptions and practice may change and grow based on experience.

10. Instructional technologists with Technology II assumptions sometimes apply instructional techniques without understanding whether or not those techniques are appropriate for the situation. 
11. Instructional technologists who work with others may benefit from not only examining their own assumptions, but also from understanding those of others with whom they work.

12. Instructional technologists sometimes hold conflicting attitudes and beliefs about instructional technology (for example, beliefs characteristic of both Technology I and II). Yet some of these assumptions may be more likely than others to influence their practice, and left unexamined may lead to undesirable practices.

13. Practitioners can use even traditionally inflexible technologies in Technology III ways. The technology itself is less critical than the attitudes, beliefs, and behaviors of the people and communities using the technology. 


\section{Chapter 5: Problem-Based Learning}

My purpose in this chapter is to analyze problem-based learning (PBL) as a network of instructional technology practice with characteristics compatible with Technology I, II, and III. In previous chapters, I described criteria for viewing instructional technology practice as examples of Technology I, Technology II, or Technology III. I also described the value of contrasting real examples against these criteria to better understand whether practitioners' assumptions encouraged the flexibility necessary for them to remain focused on the original goals that led to them adopting that practice. I have also described some potential traps that can lead instructional technologists who have Technology III goals away into the practice of Technology I or II. In this chapter, I will demonstrate that problem-based learning, as originally envisioned, can be described as Technology III. I will also demonstrate that some adopters of problem-based learning have not been able to fully achieve the goals they originally stated were important to their practice. This appears to have been due, in part, to the three traps described earlier. Yet other PBL practitioners seem to have been able to avoid these traps and remain true in their practice to the goals they originally set out to achieve. Commentary throughout the chapter will contrast the observed differences between these implementations, and draw conclusions about how instructional technologists can use these examples to become appropriately flexible their own professional work.

\section{Barrows’ Problem-Based Learning}

The idea of using problems as an instructional device is not unique to PBL, and in fact some authors have attributed the beginning of problem-based learning to the 
influence of such thinkers as John Dewey, Edward Thorndike, Jerome Bruner, or even Socrates (e.g. Berkson, 1993; Birch, 1986; Januszewski, 1999). However, this chapter attributes the original version of problem-based learning as a distinct educational approach to the work of Howard Barrows and his colleagues in the medical field. Barrows appears to have been the first to consistently use the term problem-based learning to describe an identifiable, disciplined educational approach. Additionally, Barrows appears to have originated some of the most thorough descriptions of how PBL differed from other educational approaches, and how to develop and follow a PBL curriculum. I begin with an extended definition of Barrows’ PBL. Although Barrows recorded his version of PBL in a number of reports, there are a few that are more often cited or more detailed than others (Barrows, 1983, 1985, 1988, 1994, 1996; Barrows \& Tamblyn, 1980; Neufeld \& Barrows, 1978/1974). Throughout the first section of this chapter, unless otherwise noted, my definition of PBL is based on these works. In the 1960s, Howard Barrows, a neurologist, became concerned with what he viewed as serious problems in medical education as commonly conducted. For example, he noticed that many of the students he evaluated at the later stages of medical school retained little of the basic anatomical and scientific information from courses they had completed earlier in their education. This was particularly troubling to Barrows because he had taught many of those students himself, and knew that they had performed very well on the exams which concluded his courses. Another of Barrows' concerns was his observation that many medical students did not act interested in the early stages of their education, where they spent most of their time listening to lectures or completing other classroom-based activities. Yet those same students became very enthusiastic and more 
motivated as they began the practical, clinical portions of their educational programs.

Finally, Barrows also began to feel that many faculty and students in medical education over-emphasized memorizing factual information. He thought that this approach not only left too little time for the pursuit of other educational goals, but also could be detrimental because it could lead students to develop habits (such as cramming for exams) that discouraged life-long learning and problem-solving skills.

Barrows ultimately concluded that the traditional medical school, whatever it was originally designed to accomplish, no longer helped students achieve the overarching goal of medical education, which he defined as, "to produce doctors capable of managing the health problems of those who seek their services, in a competent and humane manner” (Barrows, 1985, p. 3). Barrows and Tamblyn (1980) provided an extended analogy to highlight the importance of this goal, and how they thought traditional schooling detracted from its achievement:

Imagine that you are about to enter a commercial aircraft and that you are told that the pilot has just graduated from a commercial aviation school. To reassure you about this new graduate's competence in the field of aviation, you are told of the important sciences basic to aviation that he has been taught, including physics of flight, geophysics, aircraft design, meteorology, navigation, aircraft engine design and function, hazards in flight, airport design, and so on. To further reassure you of his ability to fly this aircraft you are told that he was given a whole battery of multiple-choice questions and that he had received high marks. He was even given problems on paper, to determine what he would do if an engine failed or a wing was damaged; he handled them very well. It seems doubtful that you would be reassured, despite his scholarship in aviation science, unless you were told that he had proved his proficiency in actual flight maneuvers. Your real concern would relate to his ability to take off, his competency to fly, his ability to get you safely to your destination, and to land. You would hope he could competently handle any unsuspected, real-life problems or emergencies that might develop during your flight. (pp. 6-7)

The solution, according to Barrows, was problem-based learning. There has not always been agreement in the literature about how Barrows actually designed the first 
PBL curriculum. In one report, Barrows (1983) claimed that PBL was "based on principles from educational psychology ... [and] studies carried out ... on the problemsolving or clinical reasoning process used by expert physicians” (p. 3078). Yet on another occasion, he stated that neither "educational psychology or cognitive science” (Evensen \& Hmelo, 2000, p. vii) led to the development of PBL. It may have been that, while Barrows and his associates were familiar with well-known educational theories, they did not use those theories as an explicit guide in the development of PBL. Rather, it appears that each feature of Barrows' PBL approach was a logical solution to the problems in medical education as he defined them, and only later did he make a direct appeal to educational theory in an attempt to lend authority to what he was already doing. This view finds some support in Neufeld and Barrows (1978/1974), who stated that "none of these ideas [that make up PBL] is entirely novel in education," but rather it was "the combination of these ideas into a single and unified approach” (p. 314), tailor-made for the problems in medical education, that led to the approach's success.

Barrows and his associates experimented with some of the ideas of PBL throughout the 1960s, but they discovered that it was too difficult to significantly change the cultures of existing medical schools for the faculty to fully accept and implement their innovative ideas. The newly created McMaster University in Canada offered Barrows the opportunity to implement a PBL curriculum according to his ideal principles. McMaster University also offered Barrows the opportunity to collaborate with other like-minded individuals who had the same goals for medical education, which further helped to refine the problem-based approach. 
Beyond the general goal of better preparing doctors, Barrows also stated more specific objectives for problem-based learning that he intended to serve as guiding principles for the design of PBL curricula. However, he was careful to avoid specifying any of his objectives as the definitive list. He preferred to lay out general guidelines with the explicit assumption that the education of doctors could not be reduced to a single list, no matter how detailed, and that adopters of PBL may appropriately specify other objectives consistent with the general goals he provided. For this reason, it may be more appropriate to call Barrows' approach a "philosophy” (Neufeld \& Barrows, 1978/1974, p. 313) of instruction rather than a method (although many, including Barrows, have also called PBL a method). While he at times expressed the objectives of PBL in different ways, there is a consistency among his stated objectives that indicates Barrows had a clearly defined vision of what PBL could accomplish. The following PBL objectives, from Barrows (1994), are some of his more detailed, and provide a thorough overview of the vision he had for this type medical education:

1. The acquisition of an extensive knowledge base that is:

a. Integrated from multiple discipline/subject areas

b. Retained in long term memory

c. Structured for application to patient problems

d. Recalled in association with patient problem cues that occur in clinical contexts

e. Enmeshed with the clinical reasoning process used in clinical practice

2. The development of clinical reasoning skills.... 
3. The development of independent, self-directed learning skills....

4. The development of effective skills in history taking, physical examination, patient education, communication and interpersonal skills.

5. The development of an internal motivation to:
a. Learn
b. Question
c. Understand.

6. An early immersion into the culture and values of medicine as a profession to become aware of such things as:

a. The ambiguities of practice and the limits of knowledge

b. The fact that experts can hold differing opinions

c. The responsibilities and obligations of the physician in caring for individual patients and communities of patients

d. The moral and ethical dilemmas of medicine

e. The complexities of health care delivery and the financial burdens and inequities involved.

7. The development of an ability to work effectively in a team setting by:
a. Working collaboratively
b. Assisting peers in their learning
c. Learning from peers
d. Accepting and giving constructive feedback. (pp. 32-34)

Barrows viewed a curriculum based around students solving real problems as both an effective and efficient way to achieve these goals. Yet he was also very specific about 
when and how problems were an effective instructional tool. As he titled one report, "problem-based learning is more than just learning around problems" (Barrows, 1997, p. 4). Barrows felt that the use of problems as an instructional technique ranged along a continuum on such dimensions as the centrality of the problem to the learning goals, or how well the problem simulated situations encountered in real-world medical practice. For example, students could listen to a lecture on a medical topic, then be given a problem based on the lecture for such purposes as illustrating how well they could apply that topic or testing how well they had understood the information in the lecture. While recognizing some possible benefits to this use of problems, Barrows also felt this type of practice was far beneath the PBL's potential for improving education.

One critical quality of how problems were used in Barrows' PBL approach was that they were given to students at the beginning of a learning unit with no preparation, and that all course learning activities for that unit were based around solving the problem or problems. The importance of this sequence to Barrows' PBL is critical. Some critics said that giving students a problem first was "fooling around, allowing the students to express their naïve ideas, [and wasting their time by] allowing them to wander around without the facts” (Barrows, 1985, p. 15). Barrows replied by referring back to his full list of objectives for PBL, and stated that only focusing on the information-transmission part of learning was ignoring too many of the outcomes necessary for doctors after their graduation. Also, he believed that since doctors often received little or no preparation for problems they encountered in actual medical practice, it was better to help them learn how to handle common situations in an environment in which they could receive guidance from trained faculty members. 
For similar reasons, Barrows insisted that problems exhibit other qualities that mimicked those found in actual medical practice. For example, he thought that the initial information students received about a problem should be similar to what they would encounter in real conditions, and not embedded with hints they would normally discover only after researching the problem. Additionally, students were expected to deal with the consequences of their proposed solutions to problems. If they proposed a solution that actually made the problem worse, they were expected to return to their research and attempt to find a new solution for their mistake. Additionally, Barrows thought PBL problems should not have a predetermined sequence which students must follow to arrive at a solution; neither did he think there should be a predetermined solution to the problem that all students were expected to find. Students were evaluated based on their application of problem-solving skills and how well their proposed solution would improve the health situation of an individual if the student were engaged in real medical practice.

The use of problems in Barrows’ PBL curriculum replaced all traditional coursework or other educational activities. In fact, topics were not divided into discrete courses of study at all. Since problems-in-practice required solutions drawn from multiple subject areas, students were expected to learn whatever information they needed, in whatever order they needed it, to completely solve the problem. Barrows also wanted students to revisit information from the same subject areas again and again to solve new problems, both to reinforce what they had earlier learned as well as to learn how the same information applied to different contexts. There was not necessarily a sequential order in which problems were presented to students, either. Barrows (1985) stated, “I do not believe that the sequence of problems is important. There seems to be little evidence that 
there is a logical first problem in any discipline or area” (p. 80). He also noted that there may even be advantages to presenting problems to different groups of students in various orders. For example, in situations where learning resources were limited, one student group could be solving Problem A which required a certain set of learning resources, while another student group was solving Problem B which required a different set of resources.

One last quality of the problems in Barrows’ original vision of PBL deserves mention. Barrows preferred that problems be, as much as possible, based on real patients and real cases physicians encountered in their actual practice. There were a number of reasons for this. The first was a strikingly practical one. As Barrows (1985) put it, "fictitious, hypothetical, or combined cases become nightmares to construct as there is no reference against which all details can be determined or verified” (p. 17). In other words, it was more difficult to make up realistic problems than to just use real problems. But there were other important reasons for using real problems beyond the efficiency of problem generation. Real problems were nearly always more similar to what the students would encounter once they left school and began their medical practice than were fictitious problems. And, additionally, by avoiding fictional problems Barrows could also check whether or not the information necessary to solve a problem was really something that medical students needed to know. As Barrows (1996) stated, "if a [real] patient problem cannot be found, the relevance of that content area for medical student learning can be questioned” (p. 9). In this way, Barrows could avoid asking students to spend time on irrelevant material because it had been traditionally included in information-based courses or curricula. 
In Barrows’ PBL, students worked in small groups to solve assigned problems. Each group was free to organize however group members thought would help them best understand, research, and solve the problem. Interestingly, many students initially found this to be difficult because their educational experience to that point had encouraged them to compete, and not cooperate, with each other. In general, student groups were expected to spend their initial learning time specifying with each other what parts of the problem they understood and what was still unknown. They then together developed a plan for each member of the group to conduct independent research or other learning tasks to help them contribute to an eventual solution to the problem. Many resources were available to students as they conducted their research-for example, reports on the topic in the library or faculty experts on the topic within the medical school.

After each group member completed their assignment (the group also controlled the deadlines for each assignment), students regrouped to apply their newly discovered information to a solution for the problem under study. Barrows (1998) was careful to specify that each student was to not summarize their research into a report or other "minilecture” (p. 632) that presented the information de-contextualized from the problem. Rather, "students [should] apply the new information they have acquired to the patient problem by discussing how that information causes the hypotheses they were considering to change” (p. 632). In other words, students were to show other group members how their understanding of the problem and possible solutions changed because of what they learned. After each problem-solving activity, students also evaluated with each other their problem-solving processes both individually and as a group, how they could improve 
their processes for future problems, and how they could incorporate their new knowledge with knowledge they had learned previously.

According to Barrows, a curriculum based around problems, and the intensive group work accompanying such a curriculum, required students to exhibit a high degree of self-motivation and self-regulation. Helping medical students learn how to direct their own learning was just as important a goal to Barrows as was the information they learned or the problem-solving skills they employed. Neufeld and Barrows (1978/1974) summarized both the type of self-direction they expected of medical students, and their reason for doing so, when they stated, "if physicians are to be life-long learners ... they must. ... [be] encouraged, with appropriate guidance, to define [their] own learning goals, to select appropriate experiences to achieve these goals, and to be responsible for assessing [their] own learning progress” (p. 314). Additionally, Barrows (1983) believed that "learning is most effective when students are able to freely reveal what they know and believe” (p. 3078), and not as effective when an instructor heavily controlled their thinking or actions. Do not assumed, however, that Barrows felt students in a PBL curriculum were not accountable for institutionally imposed learning goals. He did establish learning goals for students in PBL curricula (as discussed earlier), as well as conduct evaluations of student performance against those goals. Yet even in evaluation of student progress Barrows felt that the students themselves had the responsibility to direct their own self-evaluations to monitor their progress, as much as the institution had responsibility to evaluate students’ performance from its standpoint.

This is not to say that faculty members did not have an important role in Barrows' version of PBL. For example, each student learning group had a faculty advisor, most 
often referred to in the PBL literature as a tutor. Barrows gave the tutor broad

responsibilities within the learning group. Neufeld and Barrows (1978/1974) stated that a tutor

Must understand the general goals and methods of the programme. He must be skilled in managing small-group interaction. While a participating member of the group he must help the group become gradually more responsible for its own activity and more mature as a learning resource. He must co-ordinate effective and meaningful evaluation. He should himself be an example of self-directed learning and problem solving. (pp. 317-318)

Barrows felt strongly that the tutor was a resource for the student group more than a director of the group. He felt it was inappropriate for tutors to adopt strategies that would lead students to correct answers without the students engaging in rigorous problemsolving activities. The tutor's role was to advise and to encourage the group to question their own knowledge, processes, and activities, even in situations where the tutor felt the students were already working well towards a solution.

Faculty members beyond the tutor also had an important role in Barrows’ PBL. Since no individual tutor could have all of the information, resources, or skills necessary to help each learning group solve all of the problems they encountered, Barrows felt it was more important for tutors to be skilled as group facilitators than to be experts in any specific subject areas (although he did recognize the desirability of having tutors who could play both roles). As a result, for most subject-matter concerns students were referred to other faculty members at the school, who were experts in that area. Barrows felt that, overall, faculty members' time requirements were less intensive in a PBL situation than in a more conventional curriculum, even though they were expected to engage more deeply with smaller learning groups than in the conventional situation. This was primarily because students were expected to take so much more of the responsibility 
for learning management, as well as because faculty members had fewer administrative responsibilities (such as preparing lecture materials).

Although Barrows did not call his problem-based learning approach a technology, it can be considered a process technology according to definitions such as Gibbons (2003), who defined technology as a human-produced process or product created to solve an observed problem. Additionally, Barrows described certain hard technologies that could support the implementation of his PBL principles. Yet even in the development of these technologies Barrows remained true to the underlying principles that the technologies were meant to facilitate, and did not lose sight of his ultimate purpose in the development or use of any specific technology. Two examples illustrate the role that technology played in Barrows’ PBL curricula.

The first example was what Barrows and Tamblyn (1980) referred to as the “portable patient problem pack,” or “P4” (p. 164) for short. Each P4 set was a simulated patient, consisting of a deck of cards which presented in a standardized format a patient problem, information about actions students might choose to address the causes of the problem, and information about the outcomes of those actions. As students began with the initial problem card, they were also given a number of alternative actions which they could choose and which referred them to another card. The new card presented students with additional information, questions they should ask themselves to help ensure their understanding of the situation, and new actions from which to choose their next move. Students could stop at any time to conduct research or learning activities relevant to the problem, after which they returned to the P4 set to make a choice and continue with the problem. To prevent students from using clues from the cards themselves to solve the 
problem, each P4 set included large numbers of both relevant and irrelevant information and actions, as well as each P4 set within a larger sequence using the same standardized set of action cards. As students or a student group completed a problem, the instructors used cards they chose and the order in which they chose them to assess both the content the students had learned as well as the process they followed to come to a solution.

As a technology, the P4 set followed very standardized conventions regarding the type of information on each card, the way the card presented information, and even the color of the cards which represented certain types of learning actions. Although Barrows did not go into great detail in describing how he developed P4 sets, it can be inferred from the number of cards in a set and the amount of detail on each card that a standardized development process must have been followed to prevent the production of cards from becoming unmanageable. Yet P4 sets were also very flexible in implementation. Barrows and Tamblyn (1980) described many possible uses of a P4 set that did not require any modification to the cards (or, presumably, the process used to develop the cards), "by individual students, pairs of students, groups of students, and classes.... [and for a variety of] educational objectives of either the faculty or students involved” (pp. 167-168). Barrows clearly seemed to view P4 sets as a helpful tool for tutors to create problems for students to study, as well as to facilitate student learning from the problems in a PBL unit. Yet the evidence also points to him believing that there was nothing immutable about either the form of the cards or the process of developing the cards. He encouraged tutors and students to use P4 sets as they were helpful, but did not claim they would not be able to achieve any essential outcomes of PBL if they did not use the sets. 
A second example of technology facilitating Barrows' PBL was the use of audiovisual media such as photographs, $\mathrm{x}$-rays, videotapes, or audiotapes to provide students with as realistic information about a problem as possible. However, Barrows did not accept the use of instructional media uncritically. He was concerned that media only be used if the media presentation was the same (or very similar) to the way in which a doctor would receive that information about a patient in real medical practice. Barrows and Tamblyn (1980) provided some examples, such as

Abstract concepts, introductory and background information, static images, and lectures should not be presented on videotape. Small print and detailed diagrams should not go on slides. A patient should not be described in print. (p. 177)

Another benefit of using media technology, according to Barrows, was that audio-visual displays could potentially make PBL a more efficient experience for both students and their tutors, for example by providing multiple copies of patient problems or by allowing for portability of learning materials. However, Barrows did not think it was acceptable to use instructional media if it was too time-consuming, or if it distracted too much from the overall reality of the problem situation.

Overall, Barrows was very enthusiastic about the results his version of PBL achieved. In terms of the content knowledge students learned in a PBL curriculum, Barrows (1996; 1998) interpreted evaluation reports to show that medical students performed about the same as students taught using other educational approaches. But Barrows (1996; 2003) also criticized common methods of assessment used to compare students in PBL curricula with those taught through other curricula. He thought standard assessments were not valid measurement tools for the unique outcomes of PBL, given that they were created to test students' achievement of other educational objectives. For example, a PBL curriculum could not guarantee that students would learn a certain fact 
that might be an answer on a certification exam, because Barrows was willing to sacrifice externally imposed standards of information transmission for the more encompassing goal of student self-direction. As Barrows (1996) stated, “a major advantage of PBL is that the students, responsible for their own learning and engaged in self-directed learning and stimulated by the problem, may pursue areas of study far beyond the fondest dreams of the course designer” (p. 9).

In fact, for the objectives more unique to PBL, such as students becoming more independent learners or being better able to solve problems, Barrows considered the PBL approach very successful (although he did recognize that it could be difficult for some students to adjust to). For example, after using the approach for over two decades, Barrows (1998) felt confident enough to report that students in PBL curricula "perform more effectively with patients and are very enthusiastic about their curriculum," "are more involved in deep, as opposed to superficial, learning,” and “[record] better performance during clinical clerkships” (pp. 632-633) than did students not using PBL. And finally, Barrows (2003) concluded that

Problem-based learning has now been around long enough for a number of comparative curricular evaluations to be carried out showing that students learn as much science, perform better clinically, and continue to educate themselves more effectively in the years after graduation. (p. 255)

In the final assessment, Barrows recommended PBL as a legitimate and very effective alternative for helping students flexibly learn all of the attitudes, skills, and behaviors they needed far better than they did through traditional curricula.

\section{Barrows’ Problem-Based Learning as an Example of Technology III}

Barrows founded his version of PBL on assumptions that resemble Technology III. According to Beckwith (1988), Technology III is "the creation of unified and 
dynamic wholes (from previously separated components) to effect the transformation of learning” (p. 4). Barrows’ descriptions of PBL indicate he was attempting to approach this ideal. For example, Barrows was very committed to a broad range of learning goals beyond those traditional instruction facilitated. And he was especially concerned when faculty members gave priority to factors, such as cost effectiveness, to the point of abandoning goals that seemed to be more aligned with his broader, systemic, view of education. For example, Barrows (1994) once said, "whenever [educational] efficiency is mentioned as a concern by faculty ... it usually refers solely to efficiency in the acquisition of information” (p. 86), and not to efficiency in achieving other goals such "immersion into the culture and values of medicine” (p. 33).

Yet one can also see in Barrows' descriptions of PBL an emphasis on the principles of the approach more than on any particular implementation, and that he was willing to modify the surface characteristics of PBL as necessary to best meet his goals. For example, Barrows (1994) described some modifications to PBL as acceptable when there were overwhelmingly positive reasons to do so, such as allowing for a guest lecture by a visiting faculty member recognized as an expert in a certain area, or allowing tutors to require the use of a certain unique resource (such as a special laboratory) in some PBL sequences if there were a compelling reason to make sure that every student had some experience in using that resource.

My purpose in this section is to compare major themes in Barrows' PBL to those of Technology III, to develop the claim that PBL is an example of Technology III assumptions and goals. As an example of Technology III, Barrow's PBL also reflects some of the results predicted to be characteristic of this type of instructional technology. 
This discussion will show how the abstract themes of Technology III are apparent in the real-world beliefs and behaviors of instructional technologists, as well as provide a concrete, historical example of Technology III which can act as a model for instructional technologists to compare against their own beliefs and behaviors. This comparison can help instructional technologists develop a richer prudential knowledge by giving them criteria against which they can more clearly judge what types of behaviors most closely align with their own foundational assumptions and beliefs, and the goals they are pursuing.

The problem that Barrows thought he was solving with PBL corresponds very closely to the Technology III theme that instructional technologists believe they are trying to facilitate learning wherever or however that learning may happen. For example, Neufeld and Barrows (1978/1974) stated that "the overall emphasis [in PBL] is on the learner and the facilitation of learning rather than on teaching” (p. 324). As another example, Barrows (1983) was very critical of teaching practices common in medical education—such as tests on information that was de-contextualized from the medical practice in which that information was used-that overwhelmed students and encouraged them to focus on tasks that would not help them learn the full practice of medicine. As he reported one student's summary of medical school, "I have so much to remember, I have no time to learn” (p. 3077). The discussion of Technology III in Chapter Two predicted that having a Technology III sense of purpose would help instructional technologists avoid performing routine tasks only because they were familiar, especially when those tasks were not helpful for the problem situation. A corollary to the Technology III theme of facilitating the widest possible range of learning is that instruction should be designed 
for more than only teaching a predetermined set of facts or skills, but rather should help students develop their potential as self-directed learners and as human beings even if everything they learn cannot be predicted beforehand. Barrows seemed to exemplify these assumptions, and his PBL writings demonstrate that Technology III assumptions can translate into practical approaches that do not reduce the essential qualities of the original ideas.

As one example of how these assumptions affected Barrows’ PBL, it is remarkable how committed Barrows was to questioning any teaching activity if he did not believe that activity was contributing to the widest possible range of student learning. It is very clear that Barrows was not concerned with following tradition, and much more concerned that teaching environments and activities have a demonstrated positive influence on learning. This approach to the selection of learning activities has always been an ideal in instructional technology, even if instructional technologists have not always lived up to it (Merrill, 1997, Nov/Dec). Yet Barrows’ reports show he took this ideal seriously. Over the course of his career, he questioned the value of traditional practices such as lectures (1983), standardized tests (Barrows \& Tamblyn, 1980), the Socratic method of discussion (1998), curriculum being divided into discrete courses by subject matter, and the idea that faculty should choose information to teach based on their interest or because of its traditional inclusion in the curriculum (1996). Barrows remained completely committed to activities that he thought best facilitated learning, even though he had to completely redefine the role of the faculty member, the curriculum, and the student to improve learning as he understood it. 
Yet Barrows did not solidify his own concept of PBL to the detriment of this ultimate goal of student learning. Barrows avoided the extreme of being so committed to his carefully designed system that he was not open to change where it was obviously necessary. For example, even though Barrows was in principle very negative towards activities such as lectures, he did imagine situations in which they might be helpful in achieving his overall educational goals, such as when a recognized expert on an important topic visited a PBL group (Barrows, 1994). Perhaps the most important result of Technology III, which this example from Barrows illustrates, is that Technology III promotes an appropriate level of flexibility so that practitioners can continually evaluate and adjust outward features of an instructional approach to better align with changing environmental circumstances.

As another example, early in his promotion of PBL, Barrows (1988) tried to find tutors for student groups who were not experts in the content areas central to the problem under study. This was to discourage tutors from reverting back to learning activities that set them up as the source of information for students, as well as to discourage students from pressuring their tutor into just giving them the correct answer. However, Barrows (1996) ultimately realized that the more fundamental goal he was trying to achieve was to have tutors who could appropriately facilitate a student group's activities. And rather than attempting to justify the non-specialist as the only appropriate type of tutor, Barrows began describing the role of the tutor in terms more consistent with his fundamental purpose. He also recognized that both specialist and non-specialist tutors had advantages and disadvantages in achieving this purpose, and in fact ultimately changed his original position to advocate that often the specialist tutor had many advantages over the non- 
specialist. Ultimately, although Barrows remained true to his vision, he also recognized that implementing that vision required research, evaluation, practical experience, and plenty of time (Barrows, 2003).

There are also parallels between Barrows' version of PBL and the Technology III theme of learners being agents with the ability to control their own learning. Barrows’ attitude towards learners exemplifies a balance between two possible extremes. On the one hand, he rejected the belief that students will not learn anything unless a teacher controlled them. On the other hand, he rejected the belief that student self-direction meant requiring learners to do everything for themselves in an instructional situation, regardless of their readiness. Neufeld and Barrows (1978/1974) summarized their view of the student role in PBL by stating

The student is assumed to be a responsible and motivated adult. He is encouraged, with appropriate guidance, to define his own learning goals, to select appropriate experiences to achieve these goals, and to be responsible for assessing his own learning progress. (p. 314)

In other words, students were assumed to be self-evaluators, and had the ability, or with appropriate assistance could develop the ability, to determine whether or not they had learned and what corrective steps to take to improve their learning. Barrows (1985) also resisted the notion that it was "more effective, efficient, and easier ... just to give the students the knowledge they need” (p. 15). He believed that taking this approach was at best shortsighted and at worst dangerous. Barrows believed if a medical school ignored the complete development of medical students, even though that might imply their education was not always efficient, the school was negatively affecting both students' ability to give future care to their patients and their satisfaction with what they hoped to achieve from their medical education (Barrows, 1994, 1996). 
Barrows (1994) recognized that a criticism of this approach was that students were not always ready for self-directed learning, and so needed teachers to make at least some learning decisions for them. A related criticism might be that medical students are usually very mature physically, mentally, and emotionally, and so even if they can be self-directed learners it is not realistic to assume that less-mature students in other educational situations can also be self-directed. His response to this criticism is helpful for instructional technologists. While he did not directly address the issue of physical maturity, he did seem to question whether or not even medical students are always mentally or emotionally prepared for self-directed learning. Barrows (1983) noted that when students initially struggle with PBL, it was often because they had never learned how to take responsibility for their own education (see also Barrows, 1996; Neufeld \& Barrows, 1978/1974). However, he also noted that students "learn . . . by continual practice and critique to become effective in self-directed learning” (p. 3079).

Additionally, Barrows (1998) stated, "student-centered education requires faith that, when given responsibility for their own learning, students will do it well. When sincerely applied, this faith is rarely shaken," so "the teacher must avoid doing anything in PBL that will make students dependent on him or her for what they should learn and what they should know” (p. 630). The lesson for the practice of Technology III seems to be that it may be useful to distinguish between teacher direction and teacher control of learning. Teacher direction may be helpful and necessary at early stages of the learning process, especially if students are not used to taking control of their own learning, but long-term teacher control is not appropriate. The ultimate goal must always be to have 
students eventually direct their own learning, rather than relying on a teacher or any others to direct it for them (e.g. Barrows, 1985).

Barrows’ willingness to modify the process used to implement PBL principles also shows that he acted in harmony with the third theme of Technology III, that the products and processes of instructional technology can facilitate the creation of good learning experiences, but those experiences cannot be fully reduced to, nor controlled by, the technology. Evidence for Barrows' (1994) belief in this theme include his willingness to allow for lectures in certain types of PBL situations. Barrows' justification was that it may sometimes be more harmful to the overall student learning experience to stay true to the outward characteristics of a PBL curriculum (in other words, the product or process technologies), because so doing would mean one was not true to the ultimate goals or ideals of that curriculum. Barrows willingness to be true to principles more than technologies is reminiscent (by counter-example) of Brown and Duguid’s (1996) belief that a technique can become an unhealthy tradition if that technique becomes disconnected from the reasons that originally led to its development.

PBL also provides some counter-evidence for the criticism that adopters of Technology III do not believe in rigorous or detail-oriented work. In actuality, rigor and attention to detail characterize all of Barrows' descriptions of the technologies he used to implement PBL. For example, the amount of detail-oriented effort required to create “several hundred 3” X 5” cards in a variety of colors, a collection of 3” X 5” photographs, printed instructions, and evaluation materials” (Barrows \& Tamblyn, 1980, p. 165) for a single PBL problem must have been staggering. What is even more impressive is the level of discipline necessary to ensure those cards all contributed to the 
important learning goals of PBL, as Barrows seems to have done. Barrows (1986) described a proper implementation of PBL as difficult primarily because "complex problem simulations.... take time and effort to prepare” (p. 485). Barrows also criticized simpler implementations of PBL that he felt were not true to the fundamental principles, but that were cheaper and quicker to develop. Barrows' example suggests that Technology III does take time and hard work, and in fact it is likely that Technology III is more time and labor intensive than the alternatives. Barrows' example also suggests that it is practical for instructional technologists to take the time they need to ensure that their efforts are contributing to appropriate solutions for problem situations.

Barrows’ PBL also helps to illustrate the Technology III result of instructional technologists being flexible enough to discern a wide range of instructional problems, and develop a wide range of instructional solutions. Because of this flexibility, Barrows could more effectively meet student needs than if he adopted either Technology I or II. Many uses of technology appear in Barrows' descriptions of PBL, both media usage (e.g. Barrows \& Tamblyn, 1980) and process, method, and strategy (e.g. Barrows, 1988). These technologies did have a place in Barrows' PBL to potentially facilitate student learning. However, it is also clear that Barrows gave priority to the principles that led him to select a specific technology. He seemed comfortable switching between many different types of PBL techniques as necessary to build a complete learning system customized for each student. By participating in Barrows' PBL system, students were not only able to reach their own learning goals, but they could also learn how to evaluate for themselves what were important learning goals and how to begin achieving them. These and other beliefs enculturated students into a type of practice very important for them to become 
functioning members of the medical profession (Barrows, 1994). With no formal exposure to the ideas of Technology III, and even with no formal training as an instructional technologist, Barrows could create a complex, yet very elegant, approach to instructional technology that exemplifies the important themes and outcomes of Technology III.

\section{Modifications to Problem-Based Learning}

Even though problem-based learning started a minor revolution in medical education, and has been adopted by many other disciplines, a number of researchers (including Barrows himself) have criticized how the approach has evolved (e.g. Barrows, 1986, 1997, 1998; Herreid, 2003; Margetson, 1998; Maudsley, 1999). One of the most common criticisms has been that the term problem-based learning is used to describe a wide variety of instructional methods, many of which ignore or abandon those features which Barrows felt made PBL an effective learning approach. Barrows (1986) even went so far as to create a "taxonomy of problem-based learning methods" (p. 481), that classified PBL implementations by how well they adhered to what he considered some of the most critical principles underlying the approach. Yet Barrows did not insist that PBL remain a static, unchanging instructional method; after all, even Barrows (e.g. 1994) suggested modifications to PBL to improve specific implementations or because evaluation or additional experience helped him find better ways to achieve his vision for medical education. But he was insistent that adopters not make changes that compromised the effectiveness of the approach, especially when they were unaware of the consequences those changes were likely to have (Barrows, 1986). 
My purpose in this section is to describe specific examples of problem-based learning (chosen according to the selection criteria described in Chapter Three), and how each example either conformed to or modified Barrows’ original PBL. I analyzed each example to discover what types of goals each adopter claimed to work towards, and what types of practice they actually achieved. I then applied the criteria of Technology I, II, and III to help make explicit the assumptions foundational to the practice of those adopting PBL in each example. Some practitioners appear to have held assumptions consistent with Technology III, and maintained this type of practice throughout their PBL implementation. Yet others were pulled away from their original, Technology III, goals into narrower and more rigid types of practice by the traps of compromised integrity, status quo adherence, and solidification. The discussion of each example will help validate that Technology I, II, and III are useful criteria to help describe the goals, values, beliefs, and behaviors of real-world instructional technologists. These discussions will also uncover some of the reasons that may prevent instructional technologists from remaining flexible enough to work towards the widest possible range of educational goals they believe are important to pursue.

Example one - Barrows' own practice. The first example is Barrows' own practice of problem-based learning, in collaboration with his colleague Donna Mitchell (Barrows \& Mitchell, 1975), reporting two years of a ten-week PBL implementation at McMaster University. Barrows and Mitchell chose PBL to help their students gain experience with a wide range of skills which they believed were necessary to educate fully competent doctors. This example is notable because in it one can find evidence that Barrows and Mitchell avoided the traps of status quo adherence and solidification. There 
is also strong correlation between Barrows and Mitchell's Technology III assumptions about their practice and their ability to solve the implementation problems they encountered during their practice while remaining true to their original goals. Barrows and Mitchell appear to have used their beliefs about their purpose, the nature of learners, and the nature of technology as applied to instruction, to help them make decisions about their PBL implementation that did not compromise their larger goals, yet were still responsive to the changing circumstances they faced.

Barrows and Mitchell (1975) selected PBL as an instructional approach because they envisioned a broader range of student learning outcomes than they thought was possible to accomplish through traditional medical education. This is not too surprising, since Barrows originated the PBL approach specifically for this reason. One statement from Barrows and Mitchell should serve to validate the goal they set for themselves:

Research ... suggested that the usual educational approaches in medical school actually inhibited the development of problem-solving skills which are central to the performance of the physician.... The educational approach described here is aimed at developing problem-solving skills by capitalizing on the educational advantages of problem-based learning. (p. 223)

Barrows and Mitchell (1975) also appear to have remained flexible in their PBL approach, and continually improved their practice through the innovation of new instructional solutions when they encountered problems in their work. Their continual improvement points to Barrows and Mitchell avoiding the trap of status quo adherence, which can happen when instructional technologists stop pursuing their original goals in exchange for practices they perceive to be more traditional, legitimate, professional, or respected. Perhaps the most informative example of their avoidance of this trap was Barrows and Mitchell's response to problems their students faced in taking full responsibility for their own learning. In the first year of implementation, students worked 
on problems individually, with the small groups mainly helping assess each student's performance. Half-way through the first year, Barrows and Mitchell evaluated their PBL process and discovered that students reported feeling very overwhelmed with the amount of work in the curriculum, and their performance indicated they were having a difficult time focusing their efforts on productive learning tasks. In response, Barrows and Mitchell restructured the groups so students worked together in ways more consistent with Barrows' later descriptions of PBL, such as group members choosing problems on which to work, defining learning needs, and evaluating the learning process as a group.

When confronted with evidence that their students were overwhelmed by selfdirected learning, it would have been a simple solution for Barrows and Mitchell (1975) to shift responsibility away from the students and give it to the teachers. In fact, as I will discuss in later examples, other instructional technologists implementing PBL have chosen this solution. This solution is appealing because it is a familiar pattern that most teachers are comfortable with, it is relatively simple, and it can help teachers maintain order in situations in which they feel they are losing control (see Goodlad, 1984). Yet choosing a familiar solution for such reasons is not the same as choosing a solution because it is the best instructional strategy for the situation, and is an indication of status quo adherence.

By definition, if Barrows and Mitchell (1975) had a clear sense of purpose this would indicate one reason they avoided the trap of status quo adherence, since status quo adherence can happen when instructional technologists have confused or unclear goals about what they are trying to accomplish. One can infer Barrows and Mitchell's sense of purpose from their initial statement (quoted above) that they were trying to help students 
achieve a broader range of learning outcomes than was often the case in medical education. Other indicators of purpose include Barrows and Mitchell stating their desire for students to develop skills of self-directed learning, and stating that the curriculum should be more relevant, allowing students to pursue their own learning goals. These are indicators of a Technology III sense of purpose, or that Barrows and Mitchell viewed their purpose as facilitating all learning even if it could not be fully predicted beforehand. With this strong Technology III purpose in their minds, it appears reasonable to conclude that Barrows and Mitchell would have been very hesitant to adopt practices they thought would compromise that purpose, even in favor of more traditional practices. Barrows and Mitchell's statement that "no one can guarantee a good education by what is taught" (p. 228), and that they thought learning in the traditional classroom was not necessarily synonymous with learning how to become a doctor, helps strengthen this conclusion.

Yet it also appears that Barrows and Mitchell (1975) avoided the trap of status quo adherence because of their strong Technology III belief about learners being able to control (or learning how to control) their own learning. This view of learners is one of the most foundational principles in Barrows' descriptions of PBL (e.g. Neufeld \& Barrows, 1978/1974). Specific evidence in Barrows and Mitchell's report regarding their belief about learners is evident in the many significant and critical learning choices they required students to make throughout the PBL unit, such as on what parts of the problem students should focus their learning attention, and what learning resources would be most beneficial to help students learn what they wanted to learn. When faced with the problem of students feeling overwhelmed with PBL, Barrows and Mitchell (1975) chose to find a solution that preserved as much student self-direction as possible while still providing 
students with necessary help in self-directed learning. Although it cannot be causally demonstrated that Barrows and Mitchell developed their solution because they had a Technology III understanding of learners, in this example the more familiar solution of giving control back to the teacher would have conflicted at least somewhat with Barrows' view (and the Technology III view) that students are capable of directing their own learning. It is interesting to consider the possibility that Barrows and Mitchell's creative solution was born in part from their desire to meet an observed learning need and to avoid violating their principles about learner control.

This is not to suggest that Barrows and Mitchell's (1975) solution was always appropriate, or that giving more responsibility to teachers is always a bad idea. Yet it does suggest the value of instructional technologists using their beliefs (such as about their purpose or the role technology plays in learning) as guiding principles when making instructional development decisions. In so doing, they can help ensure that they do not lose the essence of what they are trying to accomplish because they unknowingly sacrifice it in pursuit of a more familiar solution that may not align with the fundamental goal they are trying to achieve. Additionally, Barrows and Mitchell's example suggests that viewing instructional problems from the perspective of their principles (in their case, principles consistent with the criteria for Technology III) can help instructional technologists define design constraints in ways that reveal more situationally appropriate solutions (see Alexander, 1964). Both of these approaches to their practice can help instructional technologists avoid the trap of status quo adherence.

In addition to avoiding status quo adherence, Barrows and Mitchell (1975) also appear to have avoided the trap of solidification. The trap of solidification occurs when 
instructional technologists routinize or otherwise oversimplify their practice because they feel that is the only way to sustain their practice. In other words, they chose an instructional technology not because it is the best fit for a situation but because their practice has "solidified" around the use of that technology. Perhaps the best indicator that Barrows and Mitchell (1975) avoided the trap of solidification was Barrows' ultimate abandonment of the central technology he used in this example, which tool they referred to as the "problem box" (p. 223). The problem box was a complete set of potential learning resources that Barrows and Mitchell provided for each problem in their curriculum. Problem boxes included copies of journal articles, textbooks, relevant media, and contact information for faculty experts who could provide information about the problem to students. In other words, the problem was completely self-contained, and students could solve the problem without using any resource outside of the problem box.

Barrows and Mitchell (1975) concluded in this study that the problem box was a very effective technology to implement PBL. Students felt the problem boxes helped them improve their problem-solving skills, and assessment data confirmed that this was the case. Yet shortly after Barrows and Mitchell’s report, Barrows and Tamblyn (1980) specifically criticized the problem box, primarily because they came to believe that while problem boxes facilitated certain PBL learning goals, they actually detracted from others. As Barrows and Tamblyn concluded

It was realized that the inclusion of references [in the problem box] took away the opportunity for the student to gain the appropriate skills of finding his [sic] own references. ... This principal educational objective for medical students was being ignored! (p. 179) 
In other words, Barrows and Tamblyn reasoned that problem boxes actually detracted from their overarching objective of helping medical students learn the skills of selfdirected learning.

It would have been very simple for Barrows to lose sight of this goal because of his earlier success with the problem box. Yet Barrows and Tamblyn’s (1980) evaluation of the problem box went beyond determining whether or not it improved student performance on some PBL learning goals, to consider how its use affected the entire PBL environment. Barrows was willing to abandon what all reports indicated was a successful technology when he considered other evidence that presented a more rich view of all of the consequences resulting from problem boxes. This indicated that Barrows was paying careful attention to the reasons he used the technology, and so could move away from the technology when it became clear that it was not performing the function he wanted it to perform.

Additionally, it appears that Barrows and Mitchell’s (1975) Technology III understanding about the nature of technology as it applies to instruction also helped them avoid the trap of solidification. This understanding - that the products and processes of technology can facilitate the creation of good learning experiences, but those experiences cannot be fully reduced to, nor controlled by, the technology-helped Barrows and Mitchell avoid solidification by focusing their implementation efforts on the underlying reasons for adopting a technology and not on the technology itself. This was even the case when their technology proved to be very successful. As with Barrows and Mitchell's avoidance of the trap of status quo adherence, their example indicates the value that strong commitment to a principle can have for instructional technologists to avoid 
solidifying their practice into a rigid approach that does not help them accomplish the goal they originally set out to achieve. It also helps confirm the value of instructional technologists remaining responsive in their use of technology, and being willing to continually evaluate their technology as they continue to gain experience or as their circumstances otherwise change, even when (or perhaps especially if) they find technology to be a successful tool to help facilitate student learning.

Example two - A second PBL exemplar. The second example is Bridges and Hallinger (1996), who pioneered the use of PBL in the preparation of educational administrators (Engvig, 1997). Bridges and Hallinger adopted PBL to accomplish goals similar to those Barrows described. Yet they also adapted certain features of PBL because they felt a strict duplication of Barrows approach was not an appropriate fit for their environment. As they modified PBL, Bridges and Hallinger demonstrated a commitment to beliefs, values, and behaviors consistent with Technology III. Their commitment to Technology III helped them modify their implementation to account for the differences they observed in their situation, without narrowing their focus and inadvertently losing any of the characteristics of PBL they considered important. This demonstrates that Bridges and Hallinger avoided the trap of solidification. Paradoxically, Bridges and Hallinger's modifications helped them remain more true to the ultimate goals of PBL than if they had not modified the approach, because not changing the details of Barrows’ PBL would have hindered them from facilitating the full range of learning outcomes they felt were necessary for students to learn educational leadership. This example is an important source of data triangulation for the conclusion that Technology III beliefs and 
values can help instructional technologists remain focused on their most important goals, and so be flexible enough in their practice as to better achieve those goals.

Bridges and Hallinger (1996) seemed to have a very broad goal in mind when they chose to adopt problem-based learning. For example, they described their primary reason for adopting PBL as to create an environment where students could learn not only information but also the skills of problem solving, communication, and diplomacy. They also described more vague goals that they nevertheless considered critical to the full development of educational leaders. Some of these more abstract goals included students “getting results through others,” and “dealing with the emotional aspects of leadership” (p. 54). Yet as they began to implement PBL, they quickly made modifications to the general approach as Barrows had described it. An example of a PBL modification was the inclusion in each PBL unit of some unscheduled interruptions while students were studying. These interruptions, unrelated to the problem they studied, were still realistic interruptions that a school administrator could expect to encounter in practice. For example, in one unit Bridges and Hallinger sent an actor playing the role of a student with a discipline problem. Later in the same unit, they sent another actor playing the role of an angry parent. Students were expected to both appropriately handle the interruption and find a way to get back on track with the task in which they were engaged, as they would have to do in their real work as an administrator. Bridges and Hallinger reasoned that an important part of effective problem-solving was learning how to handle unexpected distractions without losing focus on their ultimate objective, and so to best prepare their students they thought they should provide practice in this skill during their PBL curriculum. 
Another modification Bridges and Hallinger (1996) introduced was to situate problems in the context of students creating and implementing a product such as a report, memo, or work plan, that a school administrator in practice would create if faced with that problem. In other words, students not only had to address a realistic problem that school leaders faced in practice, they also had to find a practical way to execute their solution. Bridges and Hallinger stated that Implementation forces [students] to struggle with a range of political, cultural, organizational, and human issues inherent in putting action plans into effect. ... Students also confront the realistic possibility that their solution may not work. If things go poorly, they learn how to deal constructively with frustration and disappointment. If things go well, the students' level of confidence in their ability increases. (p. 58)

Bridges and Hallinger justified this modification with a similar reason to that of their other modifications. They believed that seeing plans through to completion was an important part of an effective administrator's work, and so a problem-based learning experience should allow students to experience this aspect of real practice.

The reasons Bridges and Hallinger (1996) reported for their modifications to PBL suggest that they had a clear understanding of the educational problem they were trying to solve. It also suggests that their purpose corresponded closely to the Technology III purpose of facilitating all learning, even if all learning cannot be predicted beforehand. Bridges and Hallinger specifically stated they modified PBL to make it less predicable for students and more “ambiguous” (p. 56), since handling ambiguity was an important part of preparing students for educational leadership. A number of other indicators in their report also point to how Bridges and Hallinger viewed their purpose. Early in the report they described what they considered to be failings of traditional leadership programs. Representative phrases include "most programs view their purpose as 
imparting knowledge," "students learn about leadership in the abstract," and "the education students receive occurs within a classroom setting that bears little resemblance to the context in which leaders perform their roles” (pp. 53-54). Additionally, Bridges and Hallinger advocated student customization of the curriculum to target their unique learning needs, as well as encouraged future adopters of their approach to be willing to tolerate the uncertainty that sometimes comes with allowing students to learn in an environment that evolves as students gain experience.

Another modification suggests that Bridges and Hallinger (1996) also believed the Technology III theme that learners are capable of controlling their own learning. Bridges and Hallinger structured small-group learning very similar to Barrows, and perhaps even went further than Barrows in allowing for student self-control over their own learning. Students in Bridges and Hallinger's implementation were given full responsibility over every aspect of their group from the first day of the curriculum. Bridges and Hallinger also defined the role of the instructor as one who helps create a learning culture that expects and rewards self-direction. Students were accountable for practically every other aspect of the PBL unit, including leading and facilitating groups, planning how to get work done in the group, and determining the role each student would play in the group. This modification was very closely tied to Bridges and Hallinger's sense of purpose, since they stated they adjusted PBL in this way to give students more practice acting as they would once they had entered their professions. Yet this modification also required Bridges and Hallinger to have confidence in their students' ability to make good learning decisions when leading and working in their groups. Additionally, Bridges and Hallinger 
reported that they trusted their students to make other significant learning decisions, such as curriculum customizations to target their own learning needs.

Bridges and Hallinger's (1996) modifications did not oversimplify the practice of PBL or make it more routine in ways that lost some of the essential goals they were trying to achieve. This indicates they avoided the trap of solidification. It perhaps would have been easy for Bridges and Hallinger to adopt Barrows’ techniques without modification, both because of the many reported successes of Barrows’ version (e.g. Vernon \& Blake, 1993) as well as because it could have taken less time or required less effort to implement without changes. In spite of these possibilities, they stated that they intentionally changed Barrows’ version in order to give greater “opportunity [to their] students to learn and practice skills essential to getting results through people” (p. 57). Bridges and Hallinger seemed to think that a static implementation of Barrows' approach would have narrowed the range of learning outcomes their students might have experienced. In this case, more fidelity to the outward features of Barrows’ PBL would have resulted in less fidelity to the underlying PBL vision. Bridges and Hallinger did not indicate that they thought Barrows' approach was wrong; rather, they thought that in their environment strict conformity to Barrows' approach was not the best way to facilitate learning. From this example, it does appear that Technology III can help instructional technologists make decisions about their practice that allow them to flexibly modify an instructional approach to better match that approach to the goals they are trying to accomplish. This evidence also helps confirm the conclusion from Barrows and Mitchell's (1975) practice of PBL that a strong commitment to ideals consistent with 
Technology III can help instructional technologists avoid being pulled into a rigid practice that does not help them achieve their goals.

Example three - Less successful PBL. The third example is Kaufman et al.’s (1989) report of their ten-year PBL trial at the University of New Mexico School of Medicine. Two often-cited meta-analyses (Albanese \& Mitchell, 1993; Vernon \& Blake, 1993) referred to Kaufman et al. as an example of PBL that was less successful than other examples on at least one measure of PBL effectiveness. Kaufman et al.'s initial vision was to facilitate a broad range of learning outcomes with their students. There is evidence in their study that the traps of compromised integrity and status quo adherence pulled some of the participating faculty members away from their ideal practice. There is additional evidence that these faculty members' beliefs and values may have slowed the rate of PBL adoption at New Mexico, and contributed to the lower rates of success Albanese and Mitchell, and Vernon and Blake reported. Yet Kaufman et al. also demonstrated that a small number of instructional technologists with Technology III beliefs can act as “opinion leaders” (Rogers, 2003, p. 27) to help larger organizations overcome the traps that lead to a Technology I or II practice by consistently demonstrating the benefits the organization can accrue through practice that meets the criteria for Technology III. An additional factor in Kaufman et al. also appears to have been that those faculty members with a Technology III belief about the nature of technology as it applies to instruction did not force change so quickly that they left other unprepared or uncommitted faculty members behind.

Kaufman et al. (1989) chose PBL "to equip [their] graduates with skills in selfdirected, lifelong learning, and to attract students to careers in primary care in rural and 
other underserved areas” (p. 285). Yet Kaufman et al.'s report supports the view that, at least initially, both compromised integrity and status quo adherence trapped their practice. The trap of compromised integrity occurs when instructional technologists intentionally abandon Technology III practice in pursuit of other, incompatible rewards. The best indicator of compromised integrity was Kaufman et al.'s statement that some faculty members gave more priority to "research and clinical service than [to] teaching" (p. 293). As a result, they were not interested in implementing PBL, nor were they all committed to the underlying goals Kaufman et al. mentioned as leading to the adoption of PBL. It also appears that some faculty members at New Mexico fell into the trap of status quo adherence. In fact, Kaufmann et al. actually used this phrase to describe some participants' practice, stating that some faculty members' "comfort with the status quo (the familiar, the efficient)” (p. 293) led them to reject the PBL approach. Kaufmann et al. also described other faculty members who rejected PBL, who may have been uncomfortable with change because of their "fear of loss of control" (p. 293), which also reflects practice trapped in status-quo adherence.

These faculty members who demonstrated the traps of compromised integrity and status quo adherence also seemed to have held a Technology II sense of purposebelieving that the problem they were solving was how to best teach students how to achieve a predetermined and narrow set of instructional objectives. The primary indicator of this in Kaufman et al. (1989) was the criticism of some within the School of Medicine that the PBL curricula did not follow the traditional sequence of teaching students basic science facts before asking them to perform in realistic medical situations. Kaufman et al. hinted that this criticism resulted from faculty members believing that the traditional 
approach was the only way to ensure that students learned the proper science, and that learning a fixed body of scientific facts was a critical prerequisite for students to achieve before they started working with a patient. This corresponds closely to the Technology II belief that instructional technologists are solving the problem of how to best teach a set of predetermined objectives.

Kaufman et al. (1989) additionally reported that these faculty members also had beliefs about learners which seemed to closely align with Technology II. The Technology II belief is that learners must respond appropriately to instructional activities so that those activities can cause them to experience learning. For example, one faculty member, who Kaufman et al. stated was representative of the feelings of "many" at the school, worried, “if students, rather than faculty, control their own learning, won't students graduate with great gaps in their knowledge?” (p. 293) An assumption underlying this comment is that if teachers controlled the instruction, then students would learn everything they were supposed to learn, presumably because teachers would follow a curriculum that they thought would provide all of the necessary knowledge and activities to cause student learning.

During the early years of Kaufman et al.’s (1989) implementation, they reported data that seemed to indicate that their students were not fully achieving the full range of educational goals that New Mexico had originally set out to achieve. The best indicator of this was the lower results of PBL students, compared to a control group, on some indicators that had traditionally shown an advantage for PBL students. One example was students’ performance in a clinical clerkship during their third year of medical school. Students from PBL curricula often score high on measures of clinical performance 
(Vernon \& Blake, 1993), yet Kaufman et al. reported that their students scored lower than did a comparison group during early years of the New Mexico implementation. In addition to any other factors that can affect the early success of an implementation, Rogers (2003) reported that potential adopters who are unconvinced of an innovation's benefits can sabotage implementation efforts and slow down the rate of progress. Although Kaufman et al. (1989) did not directly state that this took place at New Mexico, they did hint that some faculty members who had shown the tendencies of compromised integrity and status quo adherence had "resisted” (p. 293) using PBL, and that may have contributed to the problems New Mexico encountered early on. However, Rogers also predicted that as “opinion leaders” (p. 27) or “champions” (p. 414) for an innovation demonstrate the innovation's benefits, reluctant adopters can be convinced to adopt the innovation themselves.

At New Mexico, faculty members who appeared to have a Technology III practice did advocate for PBL and successfully helped many of the reluctant faculty members move beyond their initial resistance. That some faculty members at New Mexico had adopted Technology III is evident in Kaufman et al.’s (1989) contrasts between the beliefs and values of the resistant faculty members and a second group of faculty who seemed to have a more flexible approach to their practice. Some of the differences between the two groups concerned the educational problems faculty members felt they were solving. Whereas the first group seemed to hold narrower, Technology II beliefs about their purpose, Kaufman et al. reported that other faculty members and administrators had beliefs about their purpose more similar to Technology III. They described these participants' beliefs in the effectiveness of unstructured learning 
environments in leading to valuable and significant learning, even if they could not predict everything that the students learned in advance. Other evidence of their Technology III sense of purpose can be seen in Kaufman et al.'s negative comments about the previous, structured curriculum, and their apparent belief that an emphasis on traditional classroom instruction hindered the learning and performance of medical students along the full range of goals important for them to pursue in their education.

Other beliefs that differed among the groups at New Mexico had to do with their beliefs about the nature of learners. Whereas some faculty members in Kaufman et al. (1989) seemed to have a Technology II belief about learners, others advocated more of a Technology III approach. These faculty members reported wanting "to help students learn to take responsibility for the pace, scope, and assessment of their own education” (p. 285). They additionally reported that in all of the PBL activities provided at New Mexico, "it [was] the responsibility of each student to learn. The faculty's role [was] to guide, probe, and support the students' initiatives" (p. 286). Also, they gave "students ... substantial free time [in the curriculum] to enable them truly to assume responsibility for their own learning” (p. 287).

Over time some of the Technology II faculty members at New Mexico converted to PBL under the influence of the faculty members practicing Technology III. Kaufman et al. (1989) attributed this in part to the long-term persistence of the second group, who introduced a PBL approach first in an experimental track that ran parallel to a mainstream track, and who over time slowly transferred successful techniques from the experimental track to the other. Just as important, Kaufman et al. stated that some of the Technology II faculty members who were reluctant to fully implement PBL were given an opportunity 
to try it first in the experimental curriculum, and so become convinced of its benefit not by debate but by personal experience. To convince faculty members who may have been trapped by compromised integrity, Kaufman et al. also described changes in the administrative culture to provide hesitant faculty members more "rewards . . . [such as] educational grants and ... research” (p. 294) related to PBL.

Later years at New Mexico showed much higher rates of success than did earlier years, including improvements on the measures of clinical performance discussed earlier. This indicates that the PBL implementers at New Mexico did begin to achieve more of the goals they considered important. It is interesting to speculate that the higher levels of success were due in part to more faculty members becoming converted to the PBL approach as well as the underlying goals New Mexico was trying to achieve through the approach. I must mentioned that Kaufman et al. (1989) did not report that the discussed differences in student performance, either positive or negative, were statistically significant. However, they also did not control for factors such as the faculty member's commitment to PBL, which this analysis suggests would be important to include into a study of PBL effectiveness. As a result, this interpretation, while interesting, must be considered tentative.

Despite the tentative nature of this analysis, however, Kaufman et al. (1989) does provide some interesting points of triangulation with the findings discussed earlier in this section. A conclusion of earlier examples suggested the value of instructional technologists having strong commitments to Technology III to help them maintain a flexible practice. Kaufman et al. extends that value to instructional technologists with Technology III ideals being able to influence the practice of others with whom they work. 
Kaufman et al. contains examples such as the New Mexico administrators modifying the faculty reward structure to encourage faculty members to change the motivation and goals for their practice.

Yet it may also be that practitioners of Technology III can influence the culture of the communities of practice in which they are working even without administrative change, and so move the practice of that community in the direction they want it to go. Along these lines, Tripp (1994) called for strong models of flexible practice to encourage other instructional technologists to adopt a similar type of practice. Kaufman et al. (1989) provides an example of this encouragement, since they reported that some of their PBL faculty did act as models of PBL practice for others who were less enthusiastic. Kaufman et al.'s descriptions of how they converted reluctant faculty members also sounds similar to the ideas of legitimate peripheral participation, in that they let newcomers to PBL practice authentically experience it firsthand before trying to move them into more central roles in the community of PBL practitioners. Strong Technology III practitioners in a community of practice, then, may be able to help create a sense of joint enterprise in the community that recognizes the validity of new practices, and helps create a new, shared repertoire (i.e. new reward structures) to encourage those new practices.

Finally, the general description of New Mexico slowly adopting PBL innovations over time, as more and more faculty members were prepared for it, suggests that those leading the PBL implementation also had Technology III beliefs about the nature of technology as it applies to instruction, especially the bias towards making incremental improvements as the situational constraints in their environment allowed for it. Yet, at the same time, Kaufman et al. (1989) seemed to maintain a strong vision of what purpose 
they were working towards even though they were open to changes in how to achieve their purpose as time went along. In fact, Kaufman et al.’s reporting of how they strategically carried out their PBL trial is reminiscent of Beckwith's (1988) metaphor of Technology III as directing a film or Davies’ (1978) metaphor of Technology III as playing a game of chess. Rogers (2003) also discussed the danger of opinion leaders moving so quickly that they scare away potential adopters who are unprepared for an innovation. Kaufman et al. suggests that this is also true for the practice of instructional technology, as instructional technologists already practicing Technology III try to help others avoid the traps pulling them away from this type of practice.

Example four - Hybrid PBL. Although all of the studies I have analyzed this far have somehow modified Barrows' version of PBL, the fourth example (D. C. Clark, 2001) was selected specifically on the criterion of a PBL study that intentionally changed Barrows’ approach. Clark reported a fundamental ideal of his PBL implementation was to reduce the "curricular overcrowding” (p. 34) at the University of British Columbia Faculty of Dentistry. Yet Clark’s study provides evidence that instructional technologists who already favor Technology II beliefs and values can fall into the trap of status quo adherence when they encounter stressful situations that lead them to retrench into practice that they viewed as safer or more legitimate. Although Clark reported that this implementation did not achieve the goals they set out to accomplish, his report still provides the fruitful speculation that communities of practice facing stress may avoid being pulled into either Technology I or II by finding ways to resolve the "tension” (p. 39) that in Clark's situation led to more inflexible results than otherwise might have existed. 
Clark (2001) described how some in the Faculty of Dentistry at the University of British Columbia, although reluctant adopters of PBL, saw PBL as an opportunity to reduce the perceived “overcrowding” (p. 34) resulting from the large amounts of factual material taught to students in the early years of their dental education. In response, according to Clark, the faculty adopted what he called "hybrid PBL" (p. 35) in order to reduce the amount of material they taught while still providing students with a valuable education (Clark did not specify exactly what he meant by the term hybrid, other than it was somehow different from the classic PBL approach). Yet Clark’s report also seemed to describe how faculty members fell into the trap of status quo adherence as their PBL implementation progressed. Their practice remained closely aligned with those activities and techniques which they had traditionally viewed as respected and legitimate. Clark’s conclusion about the implementation best illustrated this situation. It appeared as though the faculty in Dentistry could not implement most of the changes they planned to make. Clark stated that after nearly three years of implementation

Our new . . . curriculum is [still] overcrowded. No one is willing to give up any of his or her scheduled hours. . . . The rationale is that more [time in the classroom] is better. Although curriculum time was supposed to be organized into a hybrid PBL format, we have not given students the necessary independent study time and there are more lectures than we prescribed. To a large extent, we repackaged much of the old teaching and added one PBL module each week with a little independent study time. To date, we have not enough [PBL] cases to fill the new third year. We suspect that fourth year will be short of cases, too. The rest will be lectures. (p. 37)

So despite years of effort on the part of PBL innovators, the PBL curriculum at the University of British Columbia looked much like the traditional dental curriculum with which they began.

Clark’s (2001) report indicates that the implementation may have suffered from status quo adherence in part because of Technology II beliefs that members of the faculty 
already held. The Faculty of Dentistry did not choose to move to PBL because they thought it was the best alternative for their students. Rather, faculty members felt that circumstances forced them into adopting PBL because the Faculty of Medicine at the same university had already decided to transition to PBL, and Dentistry relied on Medicine to teach some of the subjects in their curriculum. When they heard of the impending change, some members of the faculty in Dentistry had an immediately negative reaction. Some of their reactions included the feeling "that there would be a loss of teaching time for their subject” (p. 36) and statements about learners such as "students wouldn't learn the material unless it was given to them," or "students [cannot] make good decisions about what and how to learn” (p. 38). These statements reflect Technology II assumptions about the problem faculty members thought they were trying to solve, as well as about the nature of learners.

Yet beyond these initial indications of faculty members' tendency to believe that traditional educational methods were the most legitimate, the circumstances surrounding their implementation encouraged further retrenchment among the faculty into status quo adherence. In addition to having the PBL curriculum forced upon them, a new Dean of Dentistry was appointed at approximately the same time, a Dean who not only asked the faculty to implement more curricular changes than they had initially planned but also attempted to reorganize the departments within the Faculty of Dentistry. Budget cuts at the University of British Columbia also put faculty members under stress. All of these unsettling factors discouraged a spirit of innovation in the Faculty of Dentistry, and led them to push for types of practice with which they were already most familiar. As Clark (2001) concluded, the "faculty did what they thought they needed to do. They negotiated 
for the hours they needed with little consideration of the PBL. In the end, faculty had the time they wanted to teach the way they always had” (p. 38). Much to Clark’s disappointment, despite the initial excitement among administrators about PBL, when the faculty resisted making changes the administration retreated from their initial position of PBL advocacy and did not force any changes on them.

When reflecting on his experience of trying to implement PBL, Clark (2001) refused to place full blame on either university administrators or the faculty. Yet he also recognized that both groups had contributed to the rigid, traditional, and less-than-hopedfor practice that resulted from their efforts. Significant organizational stress is sometimes unavoidable, yet Clark had hoped that all of the participants in the Faculty of Dentistry would have showed more commitment to their PBL goals and implementation despite the unfavorable conditions in which they worked. For example, Clark cited research suggesting that administrators such as college deans can facilitate the process of PBL adoption (Abrahamson, 1998), and reasoned that perhaps if the dean had been more willing to enforce PBL compliance among the faculty the implementation would have been more successful. Yet Clark also recognized the futility of relying solely on administrative effort when faculty members were already unwilling to change. As he reflected, "if faculty do not want [PBL] to work, would they find a way to sabotage it anyway? Would senior administrators find it easier and more acceptable to make tough decisions if more work has first been put into developing . . f faculty?” (p. 39) As discussed in the communities of practice literature, reviewed in Chapter Two, communities work best when their practice evolves internally, not when its culture is externally imposed (Wenger \& Snyder, 2000). 
So while Clark (2001) could not find a solution for the University of British Columbia, it is possible to compare his experience to that of Kaufman et al. (1989). It is true that Clark reported many environmental factors that probably diminished his likelihood of success, and some of these reasons probably had nothing to do with Technology I, II, and III practices. However, in addition to any other reasons, there were indicators of some faculty's Technology II tendencies becoming more likely to affect their behaviors because of the trap of status quo adherence. It is also interesting to speculate what would have happened at British Columbia if Clark had been able to help the community of practice's joint enterprise and shared repertoire evolve, as did Kaufman et al. While I can state nothing definitively, it does provide a point of triangulation to show that Clark's experience was missing some of the factors found in Kaufman et al.'s experience, and that Clark remained trapped in status quo adherence whereas Kaufman et al. were eventually able to pull out of status quo adherence into a practice more representative of Technology III.

Example five - Philosophical opposition to PBL. Maudsley (1999) cited the fifth example, Abdulrazzaq and Qayed (1991), as an interesting example of a PBL curriculum that slowly evolved away from both PBL practices and PBL goals towards a more traditional approach. Abdulrazzaq and Qayed began at the United Arab Emirates University Faculty of Medicine with a broad vision of facilitating a wide range of learning among their medical students. However, their example is also a practice that fell into the trap of status quo adherence, and it appears that their status quo adherence was connected to Technology II practices and beliefs among other participating faculty. However, unlike the previous example of Kaufman et al. (1989), those with Technology 
II beliefs in Abdulrazzaq and Qayed's case seem to have held their beliefs more strongly than did faculty members who held Technology III beliefs. In Kaufman et al., faculty members practicing Technology III acted as opinion leaders, encouraging others to adopt PBL practice. However, in Abdulrazzaq and Qayed, it appears to have worked in the other direction. Faculty members who adopted a rigid practice disseminated that approach throughout the organization after those with a strong commitment both to PBL and to students achieving a broad range of learning outcomes left the school. From this, one can deduce that a few individuals' commitment to Technology III, no matter how strong, is not enough to continue that type of practice. Those promoting Technology III must also find ways of promoting the culture of that ideal among other community members, to help them develop identities consistent with Technology III and its associated values, beliefs, and behaviors.

Abdulrazzaq and Qayed (1991) described a PBL practice that initially seemed closely aligned with the practice of Technology III. A notable piece of evidence is that the founding faculty members in the Faculty of Medicine at the UAE University advocated a belief that PBL would help their students take control over their own learning. Abdulrazzaq and Qayed described the specific desire of the founding faculty members in the Faculty of Medicine to create a curriculum based around the "philosophy ... [of] 'self-learning' by students, a community-oriented programme, [and] problembased learning," and their search for the first outside faculty members focused on finding others who were willing to use PBL as the foundation to help students accomplish these goals. 
However, Abdulrazzaq and Qayed's (1991) reported that, over time, their implementation at the UAE University changed from a clear example of problem-based learning with a broad range of learning goals to a curriculum resembling more traditional approaches with a narrower range of goals. For example, despite presumably receiving satisfactory answers throughout the hiring process, Abdulrazzaq and Qayed discovered that out of the initial eighteen new hires, half of them had concerns about PBL, with four stating that they were "not impressed" with PBL and another five being "openly hostile" towards the approach. As the initial founders of the Faculty of Medicine left the university and this newer group began to exert more influence over the curriculum, Abdulrazzaq and Qayed reported that

The curriculum has been deviating markedly from the original principles and philosophies adopted by the Faculty. The relative frequency of the use of problem-based teaching is decreasing and the Faculty is slowly but surely veering towards the classical didactic teaching that was anathema to the original group of people involved in planning strategies and Faculty philosophy.

The example of these faculty members in Abdulrazzaq and Qayed (1991) show them falling into the trap of status quo adherence. Some of the evidence they reported includes not only the previous statement that practice at the UAE University reverted back "towards the classical" model of medical education, but also that this came from the faculty members' "preconceived rigid ideas of how a course should be taught." Both of these indicators point to the faculty members at the UAE University believing that traditional practices of medical education were more legitimate than PBL. Additionally, when Abdulrazzaq and Qayed questioned the new faculty members about how well they understood the philosophy of the UAE Faculty of Medicine, nearly half were confused about the school's philosophy in some way. Confusion about goals is another indicator of status quo adherence. 
In addition, there is evidence in Abdulrazzaq and Qayed (1991) to suggest that these faculty members held Technology II beliefs, and that over time these beliefs potentially narrowed the range of learning goals the students at the UAE University accomplished. This is visible in some of the comments that faculty members reported to Abdulrazzaq and Qayed about their purpose as teachers, and about learners. Representative comments included "the teacher was one who gave information,” and students learn by “memorisation,” or by “sitting in peace and quiet.” Abdulrazzaq and Qayed did not discuss student outcomes at the school either before or after their move away from PBL, but it is reasonable to assume that if the faculty members were teaching in a traditional manner, and if some of them felt that the focus of education should be on “information” and "memorisation," then it was less likely that they were helping students achieve the broad range of outcomes such as to become self-directed learners. And unfortunately, it does not appear that anyone undertook an evaluative effort at the UAE University to determine which practice (PBL or traditional) was more helpful for students, with the faculty and administration instead making decisions on the basis of how closely an approach resembled “classical” medical education.

Whereas Kaufman et al. (1989) described practitioners of Technology III at New Mexico as opinion leaders to help convert faculty members to a more flexible approach, Abdulrazzaq and Qayed (1991) described a contrasting experience. Abdulrazzaq and Qayed reported that after the founding faculty members of the Faculty of Medicine left the university, others "who [were] convinced of the advantage of the PBL method have done very little to orientate, inform and induct new members into the system.” It also appears that those faculty members advocating a rigid practice assumed leadership 
positions at the school, and Abdulrazzaq and Qayed feared that "these same individuals are now taking part in the recruitment of others and the prediction is that the views held by these individuals would be propagated and would affect the new recruits.” In other words, when interviewing potential new faculty members, "little weight would be placed on ... [their] opinion [of] PBL as a viable educational method.” And, presumably, little weight would be placed on their opinion of the full range of learning goals that the founders of the Faculty of Medicine described.

Additionally, whereas in Kaufman et al. (1989) those with a Technology III approach created a culture among the faculty that facilitated the adoption of PBL, along with acceptance of the goals which led to PBL's adoption, it does not appear that the faculty created such a culture at the UAE University. As a result, faculty members seemed to return to the type of practice with which they were most familiar. The initial leaders in Abdulrazzaq and Qayed (1991) may have forced PBL upon the faculty through the strength of their personal commitment to the goals which led to them adopting PBL, but without building into their organizational culture a level of group commitment to ensure PBL’s continuance. As another contrast with Kaufman et al., a critical aspect of the eventual success of New Mexico’s PBL was faculty members seeing good models of PBL as well experiencing it personally before fully deciding to adopt or reject it. On the other hand, Abdulrazzaq and Qayed reported that many of the faculty members who came to the UAE University did not have any experience with PBL before they arrived, and there did not seem to be any way once they arrived for faculty members to have the same or similar experience with trying PBL as Kaufman et al. reported. 
The contrasts between Abdulrazzaq and Qayed's (1991) and Kaufman et al.'s (1989) reports underscores the importance of instructional technologists developing a strong culture in their communities of practice to encourage a commitment to the goals of the community. Since no one at the UAE University was willing to advocate for PBL after the founders of the Faculty of Medicine left, the practice of PBL slowly died away. Those practicing Technology II seemed to have held their beliefs more strongly than those practicing Technology III, and as a result status quo adherence became the most logical approach for the faculty to follow. One can infer from this example that even once a new practice is introduced, it those who desire to see its continuance must nurture it, or it risks being discarded by others who have not adopted the same ideals as their primary motivators. As Torff (1999) concluded, people will practice in a manner consistent with the culture from which they take their primary identity. As a result, instructional technologists who wish to encourage an ideal Technology III practice would be wise to promote a strong culture in their communities around that ideal to help others begin thinking in terms of the same identity the ideal promotes. This, rather than solely trying to rely on the strength of a few peoples' commitment to Technology III practice, can make change more sustainable.

Example six - Solidifying PBL. Berkson (1993) cited the sixth example, Heestand, Templeton, and Adams (1989), as an interesting example of a medical school that began with the stated goal of fully implementing Barrows’ vision of PBL, yet over time evolved away from a pure implementation towards a more structured and routine one. While some of the changes to PBL Heestand et al. reported seemed to reflect Technology III beliefs about the nature of technology as it applies to instruction, other changes seemed to better 
represent Technology II practices resulting from the trap of solidification. This example illustrates the difficulty instructional technologists sometimes face in determining when a less-than-ideal practice might be an appropriate response to a legitimate constraint, and when it might be part of a solidified Technology II approach resulting from assumptions and values that discourage flexible practice. Contrasts between Heestand et al.’s report and Barrows and Mitchell's (1975), provide more evidence for the conclusion that instructional technologists’ practice in part reflects their primary assumptions, and that a strong commitment to Technology III can help instructional technologists avoid solidifying into a rigid approach that leads to their losing the essence of the goals they originally tried to accomplish.

Heestand et al. (1989) reported that Mercer University School of Medicine was founded on the goal of educating "physicians who strive for excellence ... with refined skills to solve problems and manage information, and [who have a] commitment to lifelong learning” (pp. 157-158). Although initially trying to adopt as much of Barrow’s version of PBL as possible, the school very quickly began to move away from pure PBL and to make the curriculum more structured and routine. An early change was to introduce some lectures into the curriculum, which they called "scheduled optional resource sessions” (p. 161), to facilitate faculty-student contact on certain subjects for which there were few faculty experts. They introduced other changes to raise student scores on medical certification exams. Some of these included providing students with specific objectives on which to focus their study (along with suggested study resources for each objective), and distributing commercially available exam preparation materials. A final set of changes gave students a basic "knowledge base” (p. 164) that some faculty 
felt students were missing, as well as decreasing faculty workload in managing small student groups. Some of these changes included workshops on conducting a physical exam and lectures on community health problems.

Interpreting why Heestand et al. (1989) modified their PBL curriculum over time is difficult. Some of the changes Heestand et al. reported seem to show them deciding that some of the principles of PBL were not the best fit for Mercer's situation, and so implementers began to move away from practices based on those principles. Or, perhaps, the reported changes may have reflected that Heestand et al. adopted the Technology III practice of working towards an ideal, yet were willing to modify their practice as necessary to work with and within environmental constraints they faced. For example, in one instance early in Mercer's history, Heestand et al. provided students with commercially developed exam preparation materials. Mercer students had performed poorly enough on medical certification exams to result in Mercer's accrediting agency putting them on probation. Potentially, these exam-preparation materials could have discouraged students from fully achieving the goal of self-directed, lifelong learning because they would not have to expend as much effort searching out important information on their own. This is similar to Barrows and Tamblyn's (1980) reason for discouraging the use of learning techniques such as the problem box.

Although Heestand et al. were dissatisfied that they felt compelled to compromise their approach to raise test scores, they also recognized that unless scores improve, they might lose their accreditation. Perhaps they reasoned it would be of little comfort that they remained true to their vision of PBL if they could not graduate any of their students as certified physicians. So even though they recognized that performance on the exams 
was not necessarily the best predictor of who would become a good doctor, they adopted raising test scores as an important, but secondary, goal. Heestand et al. later concluded that students eventually stopped using these extra materials because they had developed much more confidence in the PBL curriculum, and began to believe that they could learn on their own without the additional help. Although Heestand et al. did not mention it, another possibility is that the faculty at Mercer became better at facilitating learning with PBL, as well. In either case, as the need for the modification went away, Heestand et al. reverted back towards greater fidelity in their PBL practice, including facilitating the full range of goals (such as self-directed learning) in which they were originally interested.

On the other hand, other modifications in Heestand et al. (1989) seemed to better represent the trap of solidification. The trap of solidification is not looking for obvious and rational time-saving techniques that do not adversely affect the ultimate goal pursued by an instructional technologist. The trap of solidification occurs when instructional technologists adopt practices that make their work simpler or more routine, and as a result lose essential characteristics of their original goals. One example of solidification in Heestand et al.'s report was an instance where the Mercer faculty reorganized a number of PBL units so those units facilitated the acquisition of factual knowledgespecifically, how to conduct a physical exam—rather than the skill of independent problem-solving. Students were, in fact, not learning how to conduct a physical exam, but it may have been that this was a convenient excuse for the faculty to make changes to a curriculum they thought had become too expensive. Heestand et al. reported that the faculty were facing pressures to lower costs, and that "the program coordinators discovered that in order to emphasize skills, values, and attitudes more faculty 
development is needed than that required to concentrate upon knowledge” (p. 164). So even though developing skills was Mercer’s stated institutional goal, faculty members chose a practice that emphasized knowledge acquisition rather than the skills they originally stated were of importance.

Other examples of solidification appear in Heestand et al.’s (1989) report. One example was the replacement of PBL units with lectures because the PBL units were “cumbersome and inefficient in conveying the knowledge students needed for their projects ... and [certification exams]” (p. 166). Another was a decrease in the amount of freedom students had to choose their own learning goals to make the curriculum more predictable. And finally, the faculty at Mercer developer a handbook, called the "Study Unit Index," that included "the major topics pertinent to the cases, the relevant objectives, and the major resources” (p. 162) the faculty felt were useful for studying each problem. Heestand et al. concluded that each of these practices, which could potentially discourage students from reaching the broadest range of PBL goals the Mercer faculty originally hoped for, were attempts to be "more structured and [to provide] more guidance to the students," because of “the faculty’s uneasiness about the [PBL] program” (p. 162). Heestand et al.’s (1989) report, then, presents examples of both Technology III practice and Technology II practice resulting from the trap of solidification. In the former case, faculty members seemed to view their PBL modifications as a response to unavoidable constraints. But in the second case, while faculty members may have justified their modifications as a response to situational constraints, closer analysis shows that the modifications resulted from a lack of acceptance of all of the implications resulting from a flexible, PBL practice, as well as a perceived need to move towards 
more structured curriculum. The trap of solidification did not encourage faculty members to remain focused on the full range of goals they originally tried to accomplish. In this regard it may be helpful to compare Heestand et al.'s report to that of Barrows and Mitchell (1975), when they avoided the trap of status quo adherence. When Barrows and Mitchell's evaluation showed that students were struggling with the PBL approach, they chose a solution that let them meet the legitimate need while still adhering to their principles of learner control. When faculty members in Heestand et al.'s report faced a similar situation, they chose to use it as evidence that they needed to eliminate certain aspects of PBL that they were already inclined to oppose, which resulted in the curriculum becoming less flexible overall and less able to accomplish the full range of goals in which they were originally interested.

This provides additional evidence for the conclusion that strong commitment to Technology III can help one avoid the trap of solidification. While recognizing that there were some external problems which may have been difficult for them to avoid, Heestand et al.’s (1989) report does suggest that at least some of Mercer's outcomes resulted from faculty members’ primary assumptions about instruction and learning, as did the outcomes of Barrows and Mitchell (1975). Barrows and Mitchell’s Technology III assumptions encouraged them to adopt a flexible practice that continually looked for new ways to meet the full range of students’ needs. Mercer faculty members’ Technology II assumptions - in at least some cases_encouraged a less flexible curriculum that addressed a narrower range of concerns, even though they originally stated their intent to create a curriculum to facilitate a much wider range of student learning goals. 
Unfortunately, as Mercer's faculty solidified their practice they also eliminated some of the flexibility they needed to facilitate all of those goals.

As Wenger (2000) observed, solidified practice can trap communities of practice if they do not build in to their communities the values and practices that will help them avoid being unhealthily “oriented to their own focus” (p. 233). The contrasting examples of Heestand et al. (1989) and Barrows and Mitchell (1975) illustrate some of those values and practices. Barrows and Mitchell's assumptions can orient instructional technologists' practice and help them use guiding principles to make flexible decisions about how to achieve the goals for any particular situation. On the other hand, assumptions like those of Heestand et al.'s may result in instructional technologists’ focusing on shorter-term goals and potentially losing sight of the full range of goals they want to pursue, as their narrow focus solidifies into a narrow practice.

Representativeness of these studies. Although it is difficult to determine how representative these six studies are of PBL practice in general, the body of PBL literature suggests that the issues these adopters encountered are common enough to warrant consideration of my findings. Perhaps the most significant challenge in judging how representative these studies are is that very few adopters of PBL have reported enough detail about their PBL approach to allow cross-study comparison (Engvig, 1997). It then becomes difficult to judge how closely any particular implementation conformed to Barrows' PBL, or why adopters choose to either use or not use specific characteristics of his approach. Yet a number of authors have observed significant differences in PBL implementations as the approach has spread (e.g. Barrows, 1986; Charlin, Mann, \& Hansen, 1998; Harden \& Davis, 1998; Herreid, 2003; Margetson, 1998; Maudsley, 
1999). Many of those observing PBL have also commented on reasons why PBL adopters modify their practice, and some of these reasons align with the traps of compromised integrity, status quo adherence, or solidification. Additionally, other modifications show a PBL adopter avoiding these traps and implementing PBL in a way consistent with the Technology III ideal of remaining flexible and reflective in order to better accomplish all the goals they set for their practice.

The first trap, compromised integrity, connotes instructional technologists abandoning their Technology III values in pursuit of other priorities they think will be more rewarding. Some commentators in the PBL literature have seen indications that this trap happens frequently enough to warrant attention. Savin-Baden (2000) described certain "organizational structures that impinge on problem-based learning” (p. 141), two of which included, "the business ethic of the university ... affecting the overall quality of the courses," and "the institutional emphasis on procuring funds and research monies rather than valu[ing] quality learning” (p. 143). Glew (2003) concurred with this view, with his observation that a number of faculty trying to implement PBL face "pressure to secure extramural grants” (p. 55) that take so much time away from teaching that it is difficult for them to adequately prepare a full PBL approach. And Schwartz, Steward, and Webb’s (2001) volume of PBL case studies provided a number of examples of PBL implementations afflicted with compromised integrity, including Schor's (2001) analysis of a PBL implementation that suffered because of the pressure on faculty members to spend less time with students and more time at the university hospital seeing billable patients. 
The trap of status quo adherence occurs when instructional technologists abandon Technology III in favor of practice they perceive to be more traditional, legitimate, respectable, or professional. A large number of PBL commentators have discussed PBL modifications that come from status quo adherence. Ward and Lee (2002), in their review of the PBL literature, described how difficult it could be for teachers to abandon the traditional roles in which they were trained and in which they had years of experience. Abrandt Dahlgren and Dahlgren (2002) concluded that

Since PBL [is] a flexible way of organizing teaching and learning, there are possibilities for different academic cultures to shape PBL according to their own needs and traditions and to their inherent perspective of learning. Thus, the implementation of PBL does not necessarily mean a new way of thinking about teaching or learning. (p. 125)

Chen, Cowdroy, Kingsland, and Ostwald (1994) concurred with this assessment, stating that some who promote PBL feel "obligated to couch discussion about their proposals and experiences in terms related to more traditional educational approaches,” or "us[e] Problem-Based Learning as jargon to re-define existing educational approaches” (p. 9). Chen et al. thought that as a result, over time PBL could begin to look more and more like those traditional teaching approaches with which educators are already familiar (see also Savin-Baden, 2000). And both Herreid (2003) and Kovalik (1999) reported personal observations and literature that pointed to a general trend of teachers modifying PBL so that it more closely resembled traditional educational practices, such as lectures or an emphasis on teaching factual information.

The trap of solidification happens when instructional technologists make their practice more routine, and as a result lose a critical characteristic of their Technology III practice. This trap also finds general support in the PBL literature. Wilkerson and Gijselaers (1996), in their collection of PBL case studies, described "curricular structures 
that are too rigid” to fully implement PBL as one of the "common problems” (p. 102) the contributors to their book faced. Maudsley (1999), after reviewing a number of different types of PBL implementations, warned against a tendency towards "oversimplifying the essence of PBL to convince potential detractors” (p. 182). Cowdroy (1994) described a “dogma of Problem-Based Learning” that is “in danger of . . . slipping back into mediocrity” (p. 45) because it is too structured or rigid. And Chen et al. (1994) warned against "those who have ... embraced Problem-Based Learning ... and who now attempt to limit the field of Problem-Based Learning by narrow definition” (p. 9), not allowing for new and potentially helpful innovations as a healthy adaptation of the PBL approach.

Yet the PBL literature also contains reports of others whose practice appears to have avoided these three traps. For example, Stinson and Milter (1996) described their philosophy as “continuing the search for better ways to assist students with learning. We believe this search will never end. When we begin to feel we are doing it right, it will be time to get out of the business” (p. 41). Margetson (1998) described what sounds like the Technology III approach of making incremental improvements while remaining focused on her most important goals: "transition cases [i.e. cases of PBL that only implement some PBL features] may be valuable, but, if so, they should be valued as transitions, not as something they are not.” While it is unknown how often these more flexible approaches to PBL practice occur, in contrast to those attitudes typifying the traps of compromised integrity, status quo adherence, and solidification, it appears clear that all of these approaches are valid and accurate descriptions of PBL practice as it actually happens. This lends weight to the conclusion that the traps, as well as Technology I, II, 
and III, are useful ways to approach and understand the practice of problem-based learning.

\section{Conclusions from Problem-Based Learning}

My review in this chapter of Barrows' vision of PBL, as well as the analysis of the six examples, have provided some valuable insights about Technology II and III, why some instructional technologists abandon aspects of their ideal practice in favor of Technology II, and how some instructional technologists have been able to stay true in practice to the goals they originally set out to achieve. My purpose in this section is to summarize the major conclusions drawn from this chapter:

1. Barrows' vision of problem-based learning fits Technology III criteria; the principles Barrows espoused align closely with the major themes of Technology III.

2. The results of Barrows' PBL indicate that his approach was flexible enough to allow for unique instructional solutions, leading to a wide range of learning outcomes.

3. Barrows' PBL indicates that Technology III is a realistic goal for instructional technologists to work towards; people have achieved Technology III in real-world instructional development.

4. Technology III does not necessarily imply that an instructional method is perfect; nor does it imply that instructional technologists should not try to improve a successful approach.

5. Technology I, II, and III can be used to describe the assumptions of realworld PBL practitioners. 
6. Of the six reports in this chapter, four contained evidence for the traps of compromised integrity, status quo adherence, or solidification. Reasons for these traps included:

a. Compromised integrity: Focusing more on research than on teaching (one study).

b. Status quo adherence: Comfort with the status quo; fear of change; lack of trust in an innovative, Technology III practice; organizational stress; a sense of personal identity that in part depends upon the traditional practice (three studies).

c. Solidification: Unease with unpredictability, overreaction to problems that occurred during an implementation, pressure to reduce costs, pressure to conform to external expectations (one study).

7. Technology III is strongly evaluative, encouraging instructional technologists to continually monitor their activities and results in search of improvements that help them better accomplish their ideal practice.

8. Instructional technologists can use the principles of Technology III to help them redefine problem constraints in ways that reveal more situationally appropriate solutions than the initially evident solutions.

9. Instructional technologists can rely on Technology III values and beliefs to avoid solidifying an initially successful solution into a rigid practice, when additional evaluation may suggest to them a need for a change. 
10. Technology III can help instructional technologists make decisions that allow them to flexibly modify an instructional approach to better match that approach to the goals they are trying to accomplish.

11. Instructional technologists practicing Technology III can act as opinion leaders to help change a culture and, over time, convert others to a Technology III practice.

12. A forced Technology III practice that does not have the support of those who must implement that practice may not be sustainable beyond the application of whatever force led to the practice originally.

13. It is sometimes difficult to distinguish between the Technology III approach of slowly making incremental improvements in a less-than-ideal situation and the trap of solidification which encourages practices to become more routinized over time. 


\section{Chapter 6: Discussion and Conclusion}

In previous chapters, I analyzed Technology I, II, and III, using the examples of programmed instruction and problem-based learning. I analyzed what could limit instructional technologists to only Technology I or II, especially when they originally intended to pursue other goals in their work. I also analyzed what could help instructional technologists avoid so limiting themselves, and achieve the level of Technology III in their work. I will summarize my findings and conclusions from these earlier chapters below. Additionally, I will make specific recommendations to help instructional technologists best implement the conclusions from my findings. I will also discuss directions for future research. Finally, I conclude this study with a statement of encouragement directed towards instructional technologists, recommending Technology III to them as a legitimate means to help them flexibly develop instruction that characterizes the goals they feel are most important to pursue in their practice.

\section{Summary of Findings}

In Chapter One, I proposed the purposes of this study were to (a) describe Technology I, II, and III, and whether or not the criteria for each is evident in the practice of real-world instructional technologists; (b) to discover what influences instructional technologists to adopt Technology I, Technology II, or Technology III; and (c) to recommend how instructional technologists can use the criteria of Technology I, II, and III to avoid any traps that might get in the way of the types of practice they desire. I also restated these purposes as four research questions, answers to which I used to organize and summarize my findings. In this section, I answer the first three of these questions. I will answer the fourth question in a later section. Additionally, what follows is only a 
summary of my findings. Please see Chapters Four and Five for richer descriptions of the information I present below.

My first question was “Do the criteria for Technology I, II, and III accurately describe the goals and practice of real-world instructional technologists?” The historical case studies in Chapters Four and Five provided valuable data to help answer this question. First, the criteria of Technology II and III accurately described Skinner’s goals for PI and Barrows’ goals for PBL, respectively. Additionally, all of the Technology I, II, and III criteria described the twelve case study reports, representing real-world practice of both PI and PBL. Both of these findings, which I summarize in more detail below, lead to my affirmative response that Technology I, II, and III can indeed describe the goals and practices of real-world instructional technologists.

Skinner's and Barrows' theoretical writings helped demonstrate that Technology I, II, and III can describe the goals instructional technologists held. For example, Skinner believed that his programming techniques did have the power to predict and control learning. This shows that Skinner's goals for PI were consistent with Technology II. As another example, Barrows’ believed that no teaching activity, even an activity he may have invented, was as important as the underlying goals he was trying to accomplish through the development of PBL. This shows that Barrows' goals for PBL were consistent with Technology III. Additionally, analyzing Skinner’s PI and Barrows’ PBL from the perspectives of Technology II and Technology III revealed new insights about the goals of instructional technologists. For example, in Chapter Five, I observed that viewing Barrows’ PBL from the perspective of Technology III shows that one can distinguish when the surface characteristics of a technology may have become 
disconnected from the original goals that led to the development of that technology. This is an important observation because of the claim that it is difficult to predict the consequences of a behavior if that behavior has become disconnected from the context which originally led to its development (see Brown \& Duguid, 1996). Please see Chapters Four and Five for complete descriptions of how PI and PBL are examples of Technology II and Technology III, as well as additional insights that come from using the criteria of Technology II and III to understand each approach.

The twelve reports I analyzed in depth (six each from PI and PBL) help demonstrate that Technology I, II, and III can also describe the practices, in addition to the goals, of real-world instructional technologists. The criteria for Technology I, II, and III were all necessary to completely analyze these twelve reports. As with the goals of instructional technologists, using Technology I, II, and III also helped me analyze these reports in ways that revealed uncommon insights about instructional technology practice. For example, I observed in many reports that there was a correlation between practitioners holding limiting assumptions about their practice and those practitioners actually achieving limited results. This observation helps confirm the assertion in Chapter One that instructional technologists should become aware of their fundamental assumptions, to determine whether their assumptions and beliefs are helping them achieve their desired goals in their practice. Again, Chapters Four and Five include complete descriptions of how my twelve reports are examples of Technology I, II, and III, as well as additional insights that come from using the criteria of Technology I, II, and III to understand each report. 
My findings also led me to confirm my original definitions of Technology I, II, and III. As I originally stated, and emphasized at many points throughout the study, Technology I and II are not just the use of instructional products or processes, per se. Rather, they are the presupposition that only adopting a technology product or process will lead to the results one desires, without any further analysis or investigation. My study supports this view of Technology I and II. For example, Clark’s (2001) study of how PBL failed at the University of British Columbia helps confirm that even though one may adopt a powerful instructional technology, the simple adoption of that technology may not necessarily lead to the results one is hoping for. However, use of Technology I or II should be limited to analyze instructional technologists' beliefs about their purpose, learning, learners, and the nature of technology in instruction. One cannot necessarily judge the underlying motives, or desires to add value to an educational situation, of those who adopt a Technology I or II approach. As was evident from Skinner's writings on PI, adopters of Technology I or II may be very sincere in their commitment to help other people, even though others may disagree with their methods of providing that help.

Conversely, I originally defined Technology III as an approach that does not put the measure of quality only in the adoption of a technology, but rather monitors the consequences that technology has with students or with the broader system. The example of the PI implementation at Denver (Schramm, 1964a) helps confirm this definition of Technology III. Schramm described how Denver's personnel were willing to invest in the PI approach, but did not uncritically adopt PI for all learning goals they considered important for their students to achieve. Those at Denver were flexible in their development of PI, and as a result seemed to be better able to find those situations in 
which PI was an appropriate fit to help facilitate some of their system's educational goals. However, instructional technologists must remember that they cannot claim their Technology III practice needs no further improvement. Neither is Technology III an excuse to adopt an "anything goes” approach to one’s practice. In fact, either of these beliefs would suggest that one is not actually a practitioner of Technology III. As Barrows' eventual rejection of the problem box illustrated, continual evaluation and selfcorrection are implicit in the concept of Technology III (Barrows \& Mitchell, 1975; Barrows \& Tamblyn, 1980). Practitioners should rigorously evaluate even successful technologies to determine how well the actual use of the technology contributes to the full range of goals instructional technologists may have for their practice.

My second question was "Does anything lead instructional technologists to limit themselves to only Technology I or Technology II?” I found that some instructional technologists began with goals consistent with Technology III, yet fell away from into the practices of Technology I or II. Chapter Two discussed Beckwith’s (1988) three traps as one way of organizing reasons why practitioners might be pulled away from Technology III into Technology I or II. The trap of compromised integrity is when instructional technologists reject Technology III because other rewards distract them. The trap of status quo adherence is when instructional technologists adopt practices they perceive as more traditional, legitimate, professional, or respectable than Technology III. And the trap of solidification is when instructional technologists adopt more inflexible practices as they attempt to make their work simpler or more routine. I observed all three of these traps during the course of this study. However, other practitioners seemed to adopt Technology I or II because they legitimately believed that those approaches were the best 
ways to accomplish their goals as instructional technologists. Table 4 shows my summary

of each of these reasons. Richer descriptions of each reason follow the table.

Table 4

What Limits Instructional Technologists to Technology I or II

Reason Definition Indicators

Compromised integrity Rejecting Technology III in (Distracted focus) pursuit of other rewards.
Other interests (i.e. research); excitement for new technologies; primary concern for financial rewards.

Status quo adherence Searching for practices that are legitimate, professional, respectable, or traditional. legitimate; comfort with the
Equating the scientific with the status quo; fear of change; lack of trust in Technology III practices; organizational stress; personal identity that depends on traditional practices. $\begin{array}{ll}\text { Solidification } & \begin{array}{l}\text { Losing Technology III in the } \\ \text { pursuit of routinization. }\end{array}\end{array}$

Unease with unpredictability; overreaction to problems; fear of difficulty; pressure to reduce costs or conform to external expectations.

\begin{tabular}{lll} 
Deliberately chosen & $\begin{array}{l}\text { Believing Technology I or II } \\
\text { are the best alternatives for } \\
\text { developing instruction. }\end{array}$ & $\begin{array}{l}\text { Explicit selection of Technology } \\
\text { I or II assumptions and } \\
\text { practices. }\end{array}$ \\
\hline
\end{tabular}

While I did observe the trap of compromised integrity during the course of this study, I found it in only one of the twelve reports I analyzed in detail (Kaufman et al., 1989). Particularly, Kaufmann et al.'s report suggested that some faculty members at New Mexico were not willing to invest time in adopting a flexible, Technology III approach because they were more interested in pursuing their personal research agendas. 
However, my broader searches of the PI and PBL literature found other researchers who expressed concerns similar to the trap of compromised integrity. One indicator of compromised integrity was Lawson's (1969) observation that some developers of PI put “too much emphasis ... on gadgetry” (p. 93), and so spent more effort on perfecting PI tools rather than on the underlying theory of when or how to best use PI. Another indicator was Savin-Baden’s (2000) description that sometimes PBL implementations suffered when "the business ethic of [a] university . . . affect[ed] the overall quality of the courses," or when "the institutional emphasis on procuring funds and research monies [was more important] than .. . quality learning” (p. 143). However, because the specific term "compromised integrity" connotes a lack of honor on the part of those who fall into the trap, and because of my finding that one should not use Technology I, II, and III to judge the motives of instructional technologists, I propose an alternative name for the trap of compromised integrity: the trap of distracted focus.

The most common trap in this study was the trap of status quo adherence, which I observed in four of the twelve reports (Abdulrazzaq \& Qayed, 1991; D. C. Clark, 2001; Kaufman et al., 1989; Skinner \& Holland, 1960/1958). Specific indicators for this trap, which pulled instructional technologists away from Technology III, included: (a) the belief that some theories of instruction were more scientific and therefore more legitimate than others; (b) comfort with the status quo; (c) fear of change; (d) lack of trust in Technology III practices; (e) organizational stress; and (f) having a sense of personal identity that in part depended on traditional practices. Additionally, my broader searches of the PI and PBL literature found other researchers who expressed concerns similar to the trap of status quo adherence. One indicator of status quo adherence was Klaus’ (1964) 
belief that PI practices that had not been tested experimentally were illegitimate, and therefore should not be thought of as potentially helpful. Another indicator was Chen et al.'s (1994) observation of PBL practitioners who used "Problem-Based Learning as jargon to re-define existing educational approaches” (p. 9), and so lost a critical characteristic of what made PBL unique.

I observed the trap of solidification in two of the reports I analyzed, Crowder (1963) and Heestand et al. (1989). Specific indicators for this trap, which pulled instructional technologists away from Technology III, included: (a) discomfort with unpredictability (unpredictability can often happen in Technology III practice); (b) overreacting to problems during practice, (c) fear that practice will become too difficult without high levels of routinization; and (d) pressure to conform to external expectations that encourage solidification. Additionally, my broader searches of the PI and PBL literature found other researchers who expressed concerns similar to the trap of solidification. Many researchers have viewed PI in particular as a solidified type of instructional technology practice. One indicator of solidification in PI was McDonald et al.’s (2005) observation of the general trend among PI developers to try make their complicated ideas simpler, leading to the unintended outcome of "be[ing] more concerned with the outward form of their materials than with the learning outcomes” (p. 89). Another indicator was Maudsley's (1999) warning against a tendency in PBL practice towards "oversimplifying the essence of PBL to convince potential detractors" (p. 182) of the merits of the approach.

Finally, I also observed that some instructional technologists do not fall away from Technology III, but intentionally choose Technology I or II as the best ways to 
develop instruction and to help students. The best example I found of someone intentionally choosing Technology I or II was B. F. Skinner, in his development of the programmed instructional approach. Skinner, by design, crafted an instructional technology that reflected assumptions very consistent with Technology II. Yet Skinner was also undoubtedly committed to helping others, even though many people today disagree with the methods he used to provide that help. Although it continues to be my position that Technology III offers the richest set of assumptions about how to develop instruction, Skinner's example is an important reminder that reasonable people may view things differently. Understanding this should help promoters of Technology III avoid making unwarranted assumptions about the motives of other instructional technologists, as well as act in ways more respectful of their peers. Because some practitioners have made a deliberate choice about the type of practice they wish to pursue, I describe this reason as deliberately chosen Technology I or II.

My third question was "Does anything help instructional technologists avoid limiting themselves to only Technology I or II, and sustain practices consistent with Technology III?” Answers to this question can help instructional technologists compare and contrast attitudes, beliefs, and behaviors that can lead to rigidity with those that can lead to greater flexibility. Three general findings emerged from my study regarding how some instructional technologists have been able to avoid limiting themselves to only Technology I or II: (a) legitimate evaluation of one’s practice; (b) using Technology III beliefs or values as guiding principles to make decisions about one's work; and (c) relying on opinion leaders who can help disseminate Technology III beliefs, values, or 
behaviors among other practitioners. My findings are summarized in Table 5. Richer descriptions of each finding follow.

Table 5

Methods to Sustain Technology III

\begin{tabular}{ll}
\hline \multicolumn{1}{c}{ Method } & \multicolumn{1}{c}{ How it helps } \\
\hline Legitimate evaluation & $\begin{array}{l}\text { Legitimate evaluation helps practitioners better align } \\
\text { technology use with the goals they have for their } \\
\text { practice. }\end{array}$ \\
$\begin{array}{l}\text { Guiding principles about } \\
\text { practice }\end{array}$ & $\begin{array}{l}\text { Strong Technology III beliefs and values help } \\
\text { practitioners view constraints in creative ways, so they } \\
\text { can solve problems without abandoning important } \\
\text { characteristics of their practice. }\end{array}$ \\
Opinion leaders & $\begin{array}{l}\text { Good opinion leaders can help alter the culture of } \\
\text { communities of practice, leading to Technology III } \\
\text { becoming a more legitimate alternative. }\end{array}$ \\
\hline
\end{tabular}

As some adopters of PI and PBL continually and legitimately evaluated their own practice, they avoided limiting themselves to only Technology I or II. In particular, Barrows seemed to exemplify the value of legitimate evaluation, as his eventual abandonment of the problem box shows. Barrows was not content with initial evaluations that indicated the problem box was a successful technology. While it would have been simple for Barrows to solidify his use of the problem box because of his initial success, he continued to evaluate his practice and ultimately concluded that there were better technologies to help facilitate the full range of goals he envisioned students achieving (Barrows \& Mitchell, 1975; Barrows \& Tamblyn, 1980). The example of the Denver school system also exemplified the use of legitimate evaluation (Schramm, 1964a). 
Through their willingness to evaluate PI, as well as their willingness to act on their evaluative findings, Denver’s personnel found ways to avoid PI rigidity, and to better achieve some of their instructional goals, than they had before their evaluations.

The evaluations the personnel at Denver conducted (Schramm, 1964a) seemed to be broader than simply judging the effectiveness of their final products. Their evaluative efforts also considered the processes by which they developed the products, as well as the context in which they would use the products. As Chapter Four discussed, Denver's PI developers evaluated the programming processes they used when those processes did not lead to the results they hoped for. This led them to create modified PI processes they thought were more practical for the types of outcomes important to them. Those at Denver also evaluated the context in which they were using PI, leading to the finding that their PI was more effective when they combined the technique with other educational techniques, rather than when it was the only instructional method they used. It is probable that they would not have discovered these insights if their evaluative efforts focused only on the effectiveness of the final product alone. This suggests, then, that practitioners should conduct the legitimate evaluation Technology III requires in all phases of an instructional development process (see Stufflebeam, 2001).

These reports of legitimate evaluation contrasted with other reports of technology adopters who seemed to use evaluative findings to justify whatever course they were already pursuing, even if that course was not aligned with goals they originally stated were of importance. Both Keislar (1959) and Heestand et al. (1989) seemed to typify this type of evaluation. While Keislar did evaluate his PI materials, he seemed to use his evaluative data to reinforce his preconceived ideas about the importance of simple and 
error-free programs, despite indications that error-free programs did not help his students achieve the results Keislar stated were of value. And some faculty members in Heestand et al. appeared to use evaluative data about their PBL implementation to reinforce existing notions about student self-direction and the structure of a curriculum, despite the desire of others at Mercer to work towards goals consistent with the PBL approach. As I mentioned in Chapter Four, this leads to the conclusion that although practitioners often include evaluation as an important stage of an ideal instructional development processes, taking evaluation seriously is a rarer occurrence. Those who do use evaluative data seriously have an important tool to help them avoid limiting themselves to only Technology I or II, and to continually find better uses of instructional technology that are consistent with the full range of goals they have for their practice.

Other adopters of PI and PBL seemed to rely on their Technology III beliefs and values as guiding principles to help them avoid limiting themselves to only Technology I or II. Recognizing that some practitioners have strong guiding principles for their work is more than simply restating that there is a connection between one's assumptions and one’s practice. Rather, this finding aligns with Ely’s (1970) encouragement that instructional technologists should develop a strong personal philosophy about how to carry out a type of practice they consider important. This finding also recognizes that some practitioners have been so committed to one or more ideals for their practice that those ideals have helped them be creative about potentially legitimate constraints they faced in their work. In other words, even in situations where a reasonable person could have concluded that constraints justify deviation from one's ideal practice, some 
practitioners have been able to find ways to both legitimately respond to the constraint and remain true to what they were originally trying to accomplish.

Barrows and Mitchell (1975) is perhaps the best report to demonstrate the value of practitioners having guiding principles for their work. Barrows and Mitchell were so strongly committed to the ideal of student self-direction that even when students struggled with the amount of control they had, Barrows and Mitchell refused to give control of the curriculum back to the teachers. Their solution, of restructuring student groups so members of each group could better support one another, creatively redefined the problem. Rather than setting up a dichotomy between teacher control and student control, Barrows and Mitchell said that the best solution was for students to help each other. The way they viewed the constraint depended in part on the assumptions they brought to the situation, especially their assumptions of the nature of learning and of learners. In saying that the principle of student self-direction was important enough to implement regardless of any problems they encountered, Barrows and Mitchell demonstrated that one can remain true to one’s important goals, without necessarily ignoring that there may sometimes be difficult circumstances where some type of intervention is necessary.

The final finding that seemed to help some adopters of PI and PBL avoid limiting themselves to only Technology I or II was to rely on opinion leaders who were already practicing Technology III, and who were skilled at helping others alter their Technology I or II beliefs. The most effective opinion leaders I observed did more than simply promote Technology III alternatives to their colleagues. As evident in reports such as Abdulrazzaq and Qayed (1991), Clark (2001), and Crowder (1963), only communicating Technology 
III alternatives is likely to be insufficient when working with others who already have deeply held Technology I or II beliefs. In fact, this approach alone may generate more resistance than would otherwise exist. The most effective opinion leaders I observed were in Kaufmann et al.'s (1989) PBL report, where some faculty members seemed to take an approach more consistent with the general literature on innovation diffusion (e.g. Rogers, 2003). Opinion leaders in Kaufmann et al. not only advocated for a wide range of goals in their PBL implementation, but altered the culture of their community of practice so that other community members would also value those goals. Additionally, they helped resistant faculty members test PBL in a safe way before fully committing to adopting the approach themselves. In a sense, Kaufmann et al.'s opinion leaders helped PBL at New Mexico become part a legitimate part of the mutual engagement, joint enterprise, and shared repertoire of their community (see Wenger, 1998). And over time, more and more of the reluctant faculty members decided on their own to adopt PBL practices, as well as the goals of PBL practitioners, both of which were more consistent with Technology III.

\section{Unexpected Findings}

In addition to these findings that directly answered my research questions, other elements I observed were more surprising. One unexpected finding was that some researchers seemed to hold contradictory beliefs about instructional technology, or about their goals for their practice. This led to me describing their reports using more than one level of Technology I, II, or III. When I began this study, I assumed that applying the criteria would be simpler, and that examples would clearly fall into one or another category. While this was sometimes the case, other researchers were more difficult to classify—for example Estarellas' (1966) televised PI and Heestand et al.'s (1989) PBL 
implementation at Mercer University. This should not have been surprising, given that researchers have concluded that people often belong to multiple communities with contradictory cultures (e.g. Hodges, 1998; Levine \& Moreland, 1991; Wardle, 2004), which can also lead to them adopting contradictory goals, beliefs and behaviors. Yet it is still a finding worth making explicit, in the interest of helping readers understand how to best use the criteria for Technology I, II, and III. Users of these criteria should understand that while Technology I, II, and III are a useful perspective, they cannot fully capture the richness of practice that exists in the real world. There may be examples of instructional technology practice that are difficult to classify using only one level of Technology I, II, and III, so I urge readers not to oversimplify those examples by trying to force them into only one category.

It was also surprising that not every researcher I studied experienced the full range of rigidity predicted as following from Technology I or II. Certainly in some cases this may have been due to a lack of evidence in the published reports. Yet other reports raised the possibility that there may be some variability even within the broader categories of Technology I or II. For example, although Skinner's PI did lead to some of the rigid beliefs and behaviors that were predicted to follow from Technology II, his approach did not typify other Technology II results. Perhaps the best indicator that Skinner avoided some Technology II results was that he did not believe that only adhering to a proper procedure was sufficient to determine the quality of PI materials. Rather, he advocated critical and rigorous evaluation to help ensure that PI processes and procedures had been used correctly for the situation. This leads to the conclusion that users of Technology I, II, and III criteria should not assume that every example of 
Technology I, II, or III necessarily also experiences all the predicted results. Another interesting speculation, is that perhaps Skinner understood nuances about his own approach that others did not adopt, opting instead for the easier-to-implement formulas that seemed to characterize much of PI practice (Gilbert, 1996; McDonald et al., 2005).

Another unexpected finding was that I was able to classify only one report as an example of Technology I (Estarellas, 1966). While having even one example supports the conclusion that Technology I is at least a possible type of practice, given some of the rhetoric among researchers, I expected Technology I to be more prevalent. For instance, some researchers specifically claimed that behaviors consistent with Technology I were widespread among practitioners of PI (e.g. Lawson, 1969; Schramm, 1962), while other researchers believed that behaviors consistent with Technology I have been generally common in the field (e.g. Davies, 1973; du Boulay, 2000; Saettler, 1990; Solomon, 2000). It is possible that my sampling procedures simply missed most of the available examples of Technology I. Or, Technology I may not have been as common in real-world practice as many researchers have believed. A third possibility is that, because many respected researchers in instructional technology have considered practices consistent with Technology I to be illegitimate (e.g. Gilbert, 1960; Lumsdaine, 1964; Reigeluth, 2001), those with Technology I beliefs simply have not joined the same communities of practice from which I drew reports to study. Without further evidence, it is not possible to say which alternative, or another alternative, is most likely.

And finally, it was actually surprising that I found as many examples of Technology III as I did among instructional technology practitioners. Researchers such as Beckwith (1988) seemed very pessimistic that instructional technologists in general were 
capable of avoiding the traps that pull them away from Technology III. Yet in many of the reports I studied, practitioners infused their work with the flexibility and vision necessary to help them avoid limiting their practice to narrow and rigid outcomes (e.g. Bridges \& Hallinger, 1996; Schramm, 1964a). They also seemed to be the type of practitioner who was interested in more than merely completing the specific project on which they were working, but rather was also interested in disseminating their findings to others. They blended the best qualities of the practitioner with the best qualities of the researcher to develop instructional technologies that could solve local problems and be examples for others to emulate. In other words, they were the opinion leaders whom I discussed earlier as being an important way to sustain a Technology III type of practice. This finding is encouraging. It helps demonstrate that real-world instructional technologists are capable of avoiding the influences that can limit their practice, as well as suggesting that historically they may have done so more often than researchers have realized. This finding also led me to speculate that studying Technology I, II, and III can do more than help convince practitioners of the value of Technology III. Studying these criteria may also help existing Technology III practitioners better understand their own work, and so help them become opinion leaders who can help other instructional technologists also adopt the goals, beliefs, and behaviors of Technology III.

\section{Recommendations}

These findings lead to answers to my fourth question, “can instructional technologists use this knowledge to help them avoid rigid practices, and more consistently work in flexible ways that are appropriate to help them achieve the goals they have for their work?” In a sense, this question is the centerpiece of my study, 
because of its potential to improve the practical, day-to-day work of the instructional technologist. In this section, I will describe practices that my findings imply, as well as attitudes instructional technologists could adopt to fully benefit from my findings.

I recommend that instructional technologists be more aware of the criteria of Technology I, II, and III, and consider at what level their own personal beliefs, goals, research, and practice are located. While the specific labels they use may not be as important as actually adopting beliefs, values, and behaviors consistent with a flexible practice, the terminology of Technology I, II, and III are a convenient way to think and talk about how to avoid rigidity in their work. The same is true for the influences that can limit instructional technologists to either Technology I or II. I recommend that instructional technologists become more aware of these influences, and whether or not the results of their practice are consistent with all the goals they are aiming to achieve. Additionally, instructional technologists should remember that their adoption of any level of Technology I, II, and III is not unchangeable. As their prudential knowledge grows, practitioners can adopt new beliefs, values, and behaviors that may be more appropriate for achieving the outcomes they desire.

I also recommend that instructional technologists adopt those practices that have helped other practitioners avoid limiting themselves to only Technology I or II. First, I encourage instructional technologists to legitimately and critically evaluate their own practice, and to take seriously the evaluative data they discover. While this is a helpful practice in all circumstances, instructional technologists have the example of Barrows and Mitchell's (1975) continued evaluation of the seemingly successful problem box. Barrows and Mitchell used evaluative data to help them avoid solidifying on a 
technology that had led to past success but was not appropriate to help facilitate the full range of learning outcomes they desired. I also recommend that instructional technologists avoid using evaluation to reinforce their preconceived notions about instructional technology, as in the examples of Keislar (1959) and Heestand et al. (1989). Rather, I recommend that instructional technologists be open to whatever alternatives the evaluative data suggest, even if they would prefer the data support other conclusions. I recommend that instructional technologists also adopt Technology III guiding principles to help them better respond to the constraints they may face in their work. As this study demonstrated, guiding principles about instructional technology can help practitioners more creatively develop instruction that is aligned with what they hope to accomplish in their practice, yet is still an appropriate fit for the challenges or problems they face. These guiding principles can also help them avoid modifying an instructional technology in ways that lead to rigid or reductive results. However, practitioners must be careful not to solidify their guiding principles into rigid and dogmatic rules, or view them as the only legitimate methods for instructional technology improvement. By their nature, guiding principles should allow for the adoption of a wide variety of practices and strategies. The benefit of guiding principles comes as they help one remain flexible, so that one may respond to complex challenges in a principled and well-thought-out way. Instructional technologists should use their guiding principles to help them be more reflective on their practice and on the constraints of the environments in which they work. They should not translate their guiding principles into the same inflexible practices that this study critiqued. 
To instructional technologists who can sustain a Technology III approach, I recommend that they act as opinion leaders to other practitioners, promoting the benefits of a rich and flexible practice. I encourage instructional technologists to demonstrate through their Technology III practices that instructional technology can be both rigorous and flexible at the same time, and that Technology III can help practitioners find better ways to work towards all of the results they desire. Opinion leaders should help resistant practitioners consider whether or not their use of a technology is limiting the likelihood of their achieving a result they consider important. Opinion leaders should also let those who are resistant experience for themselves the benefits of a Technology III approach. Where possible, opinion leaders should build into their organizations reward systems that encourage practitioners to be more thoughtful about their practice, and to consider alternatives beyond those which may be the most fashionable. Additionally, I recommend that opinion leaders discuss the characteristics of Technology III in their published work, as another method to legitimize flexible, Technology III alternatives. And opinion leaders who are part of instructional development teams must question decisions that seem to spring from Technology I or II reasoning, as well as develop the ability to respond with a Technology III option, and communicate the differences between the alternative approaches.

And finally, I recommend that all instructional technologists adopt the central message of Technology III, which is to use all methods available to work towards the full range of goals they consider important for their practice. As I stated previously in this section, observation and evaluation of one's own practice is one important method, as are the guiding principles that describe what one values about instructional technology. But I 
should also mention, as Schramm's (1964a) report indicated, that good instructional theory does have a place in helping inform and guide the work of the instructional technologist, as well as theory derived from similar fields about the nature of human beings, learning, teaching, and design. As Gibbons and McDonald (2005) concluded about Technology III

Those with a Technology III view assume that instruction can be improved through many means. It refuses to solidify its position simply because one successful solution has been found. It does not try to make the successful solution fit all problems, but it continues its search for new solutions, new principles, [and] new designs. In the process, the technologist learns, and the standard by which technological solutions [are] judged continues to evolve. ... [It is] a form of research that pushes back the limit of what is possible at the same time it provides solutions for current problems. (p. 7)

I hope that instructional technologists will be reflective and creative as they develop new instructional technologies, or as they use existing technologies to create well-designed instruction that helps facilitate all the learning goals they want their students to achieve.

\section{Directions for Future Research}

My findings also suggested other research topics. The following are only some of the research questions this study raised:

1. My study relied on historical evidence to find indicators of Technology I, II, and III. Would an observational study of current instructional technology practice yield similar results?

2. My findings suggested that there was a difference in work quality between certain opinion leaders who blended the roles of researcher and practitioner, and other practitioners who focused only on projects on which they are working. Would a specific study of this issue confirm my observation? 
3. More examples of Technology III appeared in PBL than in PI. Would a broader survey of instructional technology reveal if certain types of practice were more likely than others to be Technology III?

4. I found only one example of Technology I. Is Technology I actually more common than this study indicated? Or is Technology I not as common as some researchers have believed? What is the relative distribution of Technology I, II, and III?

5. My review of literature suggested that a person's education might lead them to adopt rigid or inflexible practices, or to abandon practices they originally thought were important. Yet my findings do not allow me to draw conclusions about the validity of this observation. Does the education (or, perhaps, lack of education) of instructional technologists contribute to their either adopting or not adopting Technology III?

6. I concluded that good instructional theory was also important to help instructional technologists practice in the most flexible ways possible. Are there any methods of research more likely than others to produce knowledge or theories helpful to the practice of Technology III?

7. My review of literature suggested that some practices of classroom teachers were similar to those of instructional technologists, including that constraints might trap them and limit the results they could achieve. Would a study of Technology I, II, and III among practicing teachers produce results similar to this study? 
8. This study did not directly examine the role of the student during instruction. Are there equivalents among the assumptions and behaviors of students for Technology I, II, and III? How do the assumptions and behaviors of students affect an instructional technologist's practice of Technology I, II, or III?

9. A central message of Technology III is that there are always new ways for instructional technologists to work towards the goals they consider important for their practice. Does this imply that there might be assumptions and practices one could classify as Technology IV?

\section{Conclusion}

In Chapter Three, I stated that researchers should be explicit about their own perspectives, so that readers have more of the information they need to determine for themselves to what extent they should trust a research report. In the interest of full disclosure, I am providing some comments about how this study affected me as part of this conclusion, to help increase readers' confidence in my findings. I gained more respect for instructional technology practitioners as I studied in detail some of the difficult circumstances they have faced in their practice. Although I recognize that at times my criticism of Technology I and II have been harsh, I have also gained empathy for those practitioners who have been limited to Technology I and II, especially in cases where they may not have known that there were viable alternatives. As I put myself in the place of those who had to make choices in the face of difficult constraints, I asked myself if I would have chosen differently, even with my commitment to the values of Technology III. I believe the empathy I have developed will serve me well as I work with 
practitioners of Technology I and II. I recognize the good they are trying to accomplish, although I will continue to encourage them to consider whether or not their use of a technology is limiting the likelihood of them achieving results they consider important.

Despite this increased empathy, this study did not lessen my commitment to the values, goals, and practices of Technology III. As the study progressed, I became more convinced that even though the tools and processes of instructional technology can be extremely helpful, the very adoption of successful technologies opens one up to the danger of solidifying one's practice around using them. However, I do not go so far as to advocate abandoning instructional technology, product, or process. As I carried out this study, I was impressed by the wide variety of creative technologies that committed researchers and practitioners have developed to help facilitate better learning. I believe that these tools and strategies, when properly applied, do have a positive effect on students' ability to succeed as learners. And I believe that the findings of this study have the potential to help instructional technologists better capitalize on the strengths of their technologies to achieve the widest possible range of goals in their work.

I present this study to researchers as part of the growing body of knowledge concerning the connection between foundational assumptions and actual practice, as well as the body of knowledge concerning how to develop effective instructional technology. I also present it to practitioners, to help them find the most flexible ways of accomplishing the type of practice they desire. I conclude with a final encouragement to all instructional technologists to look for powerful instructional technologies wherever they may be found, and to not close themselves off from potentially helpful approaches because they are unfamiliar or unfashionable. While certainly all instructional technologists should be 
concerned with developing the most rigorous and effective practice possible, I encourage them to not replace their original goals with the pursuit of rigor or with technological improvement as an end in itself. And I encourage them to define their purpose as instructional technologists broadly, and to be willing to look for solutions in a wide variety of settings beyond only those that are familiar and comfortable. In other words, I encourage instructional technologists to adopt Technology III, with all its assumptions, as a legitimate means to help them develop instructional technology that is flexible and that best characterizes the goals they have for their practice. 


\section{References}

Abdulrazzaq, Y. M., \& Qayed, K. I. (1991). A study of the attitudes of the foundation staff of a new medical faculty to problem-based learning. Medical Teacher, 13(4), 281-288.

Abrahamson, S. (1998). Obstacles to establishing problem-based learning. Journal of Dental Education, 62, 656-659.

Abrandt Dahlgren, M., \& Dahlgren, L. O. (2002). Portraits of PBL: Students' experiences of the characteristics of problem-based learning in physiotherapy, computer engineering and psychology. Instructional Science, 30, 111-127.

Albanese, M. A., \& Mitchell, S. (1993). Problem-based learning: A review of literature on its outcomes and implementation issues. Academic Medicine, 68(1), 52-81.

Alexander, C. (1964). Notes on the synthesis of form. Cambridge, MA: Harvard University Press.

Alvesson, M. (2002). Understanding organizational culture. London: SAGE Publications Ltd.

Armstrong, D. (2003). Historical voices: Philosophical idealism and the methodology of 'voice' in the history of education. History of Education, 32(3), 201-217.

Atkinson, R. C., \& Wilson, H. A. (1969). Computer-assisted instruction. In R. C. Atkinson \& H. A. Wilson (Eds.), Computer-assisted instruction: A book of readings (pp. 3-13). New York: Academic Press.

Baek, E. O. (2002). A study of dynamic design dualities in a web-supported community of practice for teachers. Unpublished Dissertation, Indiana University, Bloomington.

Banathy, B. H. (1987). Instructional systems design. In R. M. Gagné (Ed.), Instructional technology: Foundations (pp. 85-112). Hillsdale, NJ: L. Erlbaum Associates.

Banathy, B. H., \& Jenlink, P. M. (2004). Systems inquiry and its application in education. In D. H. Jonassen (Ed.), Handbook of research on educational communications and technology (2nd ed., pp. 37-58). Mahwah, N.J.: Lawrence Erlbaum. 
Barab, S. A., \& Duffy, T. M. (2000). From practice fields to communities of practice. In D. H. Jonassen \& S. Land (Eds.), Theoretical foundations of learning environments. Mahwah, NJ: Lawrence Erlbaum Associates.

Barab, S. A., MaKinster, J. G., \& Scheckler, R. (2004). Designing system dualities: Characterizing an online professional development community. In S. A. Barab, R. Kling \& J. H. Gray (Eds.), Designing for virtual communities in the service of learning (pp. 53-90). New York: Cambridge University Press.

Barab, S. A., \& Plucker, J. A. (2002). Smart people or smart contexts? Cognition, ability, and talent development in an age of situated approaches to knowing and learning. Educational Psychologist, 37(3), 165-182.

Barrows, H. S. (1983). Problem-based, self-directed learning. Journal of the American Medical Association, 250(2), 3077-3080.

Barrows, H. S. (1985). How to design a problem-based curriculum for the preclinical years. New York: Springer Publishing Company.

Barrows, H. S. (1986). A taxonomy of problem-based learning methods. Medical Education, 20, 481-486.

Barrows, H. S. (1988). The tutorial process. Springfield, IL: Southern Illinois University School of Medicine.

Barrows, H. S. (1994). Practice-based learning: Problem-based learning applied to medical education. Springfield, IL: Southern Illinois University School of Medicine.

Barrows, H. S. (1996). Problem-based learning in medicine and beyond: A brief overview. In L. Wilkerson \& W. H. Gijselaers (Eds.), Bringing problem-based learning to higher education: Theory and practice (Vol. 68, pp. 3-12). San Francisco: Jossey-Bass Publishers.

Barrows, H. S. (1997). Problem-based learning is more than just learning based around problems. The Problem Log, 2(2), 4-5.

Barrows, H. S. (1998). The essentials of problem-based learning. Journal of Dental Education, 62(9), 630-633. 
Barrows, H. S. (2003). Response to "The problem with problem-based medical education: Promises not kept" By R. H. Glew. Biochemistry and Molecular Biology Education, 31(4), 255-256.

Barrows, H. S., \& Mitchell, D. L. M. (1975). An innovative course in undergraduate neuroscience: Experiment in problem-based learning with 'problem boxes'. British Journal of Medical Education, 9, 223-230.

Barrows, H. S., \& Tamblyn, R. M. (1980). Problem-based learning: An approach to medical education. New York: Springer Pub. Co.

Barzun, J., \& Graff, H. F. (2004). The modern researcher (6th ed.). Belmont, CA: Wadsworth/Thomson Learning.

Beaudoin, M. (1990). The instructor's changing role in distance education. The American Journal of Distance Education, 4(2), 21-29.

Beckwith, D. (1988). The future of educational technology. Canadian Journal of Educational Communication, 17(1), 3-20.

Beckwith, D. (1989). Fashioning the future educational technology: An invitation. Canadian Journal of Educational Communication, 18(2), 127-131.

Berkson, L. (1993). Problem-based learning: Have the expectations been met? Academic Medicine, 68(10), 579-588.

Bernstein, D. A., Penner, L. A., Clarke-Stewart, A., \& Roy, E. J. (2006). Psychology (7th ed.). Boston: Houghton Mifflin.

Bertalanffy, L. V. (1968). General system theory: Foundations, development, applications. New York: George Braziller, Inc.

Birch, W. (1986). Towards a model for problem-based learning. Studies in Higher Education, 11(1), 73-82.

Blyth, J. W. (1960). Teaching machines and human beings. In A. A. Lumsdaine \& R. Glaser (Eds.), Teaching machines and programmed learning: A source book (pp. 
401-415). Washington, DC: National Education Association of the United States. (Reprinted from The Educational Record, April 1960)

Blyth, J. W. (1964). Behaviorism is not enough. In A. de Grazia \& D. A. Sohn (Eds.), Programs, teachers, and machines (pp. 99-103). New York: Bantam Books. (Reprinted from The American Behavioral Scientist, 6(3), 1962)

Braden, R. A. (1984). A place in space: ID's universe. In R. K. Bass \& C. R. Dills (Eds.), Instructional development: The state of the art (Vol. 2, pp. 29-39). Dubuque, IA: Kendall/Hunt Publishing.

Braden, R. A. (1996). The case for linear instructional design and development: A commentary on models, challenges, and myths. Educational Technology, 36(2), $5-23$.

Bransford, J. D., Brown, A. L., \& Cocking, R. R. (2000). How people learn: Brain, mind, experience, and school (Expanded ed.). Washington, DC: National Academy Press.

Bridges, E. M., \& Hallinger, P. (1996). Problem-based learning in leadership education. In L. Wilkerson \& W. H. Gijselaers (Eds.), Bringing problem-based learning to higher education: Theory and practice (Vol. 68, pp. 53-61). San Francisco: Jossey-Bass Publishers.

Brown, J. S., Collins, A., \& Duguid, P. (1989). Situated cognition and the culture of learning. Educational Researcher, 18(1), 32-42.

Brown, J. S., \& Duguid, P. (1991). Organizational learning and communities-of-practice: Toward a unified view of working, learning, and innovation. Organization Science, 2(1), 40-57.

Brown, J. S., \& Duguid, P. (1996). Stolen knowledge. In H. McLellan (Ed.), Situated learning perspectives (pp. 47-56). Englewood Cliffs, NJ: Educational Technology Publications.

Brown, J. S., \& Duguid, P. (2000). The social life of information. Boston, MA: Harvard Business School Publishing. 
Brown, J. S., \& Duguid, P. (2001). Knowledge and organization: A social-practice perspective. Organization Science, 12(2), 198-213.

Bruning, R. H., Schraw, G. J., \& Ronning, R. R. (1999). Cognitive psychology and instruction (3rd ed.). Upper Saddle River, NJ: Prentice Hall, Inc.

Bucciarelli, L. L. (1994). Designing engineers. Cambridge, MA: MIT Press.

Bucholtz, M., \& Hall, K. (2004). Language and identity. In A. Duranti (Ed.), A companion to linguistic anthropology (pp. 369-394). Malden, MA: Blackwell Publishing Ltd.

Burgess-Limerick, R., Abernethy, B., \& Limerick, B. (1994). Identification of underlying assumptions is an integral part of research: An example from motor control. Theory \& Psychology, 4(1), 139-146.

Burroughs, R., Schwartz, T. A., \& Hendricks-Lee, M. (2000). Communities of practice and discourse communities: Negotiating boundaries in NBPTS certification. Teachers College Record, 102(2), 344-374.

Burton, J. K., Moore, D. M., \& Magliaro, S. G. (2004). Behaviorism and instructional technology. In D. H. Jonassen (Ed.), Handbook of research on educational communications and technology (2nd ed., pp. 3-36). Mahwah, N.J.: Lawrence Erlbaum.

Button, H. W. (1979). Creating more useable pasts: History in the study of education. Educational Researcher, 8(5), 3-9.

Casas, M. (1997). The history surrounding the use of Skinnerian teaching machines and programmed instruction (1960-1970). Unpublished Dissertation, Harvard University, Boston.

Charlin, B., Mann, K. V., \& Hansen, P. (1998). The many faces of problem-based learning: A framework for understanding and comparison. Medical Teacher, 20(4), 323-330.

Chen, S. E., Cowdroy, R. M., Kingsland, A., \& Ostwald, M. (1994). Reflections on problem based learning. In S. E. Chen, R. M. Cowdroy, A. Kingsland \& M. 
Ostwald (Eds.), Reflections on problem based learning (pp. 7-13). Sydney, Australia: Australian Problem Based Learning Network.

Chomsky, N. (1959). A review of B. F. Skinner's verbal behavior. Language, 35(1), 2658.

Churchman, C. W. (1996). On the design of educational systems. In D. P. Ely \& T. Plomp (Eds.), Classic writings on instructional technology (pp. 39-46). Englewood, CO: Libraries Unlimited. (Reprinted from Audiovisual Instruction, 10(5), 361-365, 1965)

Clark, D. C. (2001). Lost in the mêlée. In P. Schwartz, M. Stewart \& G. Webb (Eds.), Problem-based learning: Case studies, experience and practice (pp. 34-39). Sterling, VA: Stylus Publishing Inc.

Clark, R. E. (1994a). Media and method. Educational Technology Research and Development, 42(3), 7-10.

Clark, R. E. (1994b). Media will never influence learning. Educational Technology Research and Development, 42(2), 21-30.

Cook, D. A. (1997). Behavioral analysis as a basis for instructional design. In C. R. Dills \& A. J. Romiszowski (Eds.), Instructional development paradigms (pp. 215-244). Englewood Cliffs, NJ: Educational Technology Publications.

Cook, S. D. N., \& Yanow, D. (1993). Culture and organizational learning. Journal of Management Inquiry, 2(4), 373-390.

Corey, S. M. (1971). The nature of instruction. In M. D. Merrill (Ed.), Instructional design: Readings (pp. 5-17). Englewood Cliffs, NJ: Prentice-Hall. (Reprinted from Programed Instruction: NSSE 66th Yearbook, Part II, pp. 5-27, 1967, Chicago: University of Chicago Press)

Corrigan, R. E. (1964). Programmed instruction as a systems approach to education. In G. D. Ofiesh \& W. C. Meierhenry (Eds.), Trends in programmed instruction (pp. 36-45). Washington, DC: Department of Audiovisual Instruction, National Education Association of the United States. 
Cowdroy, R. M. (1994). Concepts, constructs and insights: The essence of problem-based learning. In S. E. Chen, R. M. Cowdroy, A. Kingsland \& M. Ostwald (Eds.), Reflections on problem based learning (pp. 45-56). Sydney, Australia: Australian Problem Based Learning Network.

Crowder, N. A. (1963). Intrinsic programing: Facts, fallacies, and future. In R. T. Filep (Ed.), Prospectives in programing (pp. 84-115). New York: The Macmillan Company.

Crowder, N. A. (1964). Programmed instruction compared with automated instruction. In G. D. Ofiesh \& W. C. Meierhenry (Eds.), Trends in programmed instruction (pp. 28-30). Washington, DC: Department of Audiovisual Instruction, National Education Association of the United States.

Danziger, K. (1985). The methodological imperative in psychology. Philosophy of the Social Sciences, 15, 1-13.

Davies, I. K. (1973). Competency based learning: Technology, management, and design. New York: McGraw-Hill.

Davies, I. K. (1978). Educational technology: Archetypes, paradigms, and models. In J. Hartley \& I. K. Davies (Eds.), Contributions to an educational technology (Vol. 2, pp. 9-24). New York: Crane, Russak \& Company, Inc.

Davies, I. K. (1984). Instructional development: Themata, archetypes, paradigms and models. In R. K. Bass \& C. R. Dills (Eds.), Instructional development: The state of the art (Vol. 2, pp. 8-17). Dubuque, IA: Kendall/Hunt Publishing.

Davies, I. K. (1989). Total educational technology (TET): Challenging current limits. Canadian Journal of Educational Communication, 18(2), 132-136.

Davies, I. K. (1991). Instructional development as an art. In D. Hlynka \& J. C. Belland (Eds.), Paradigms regained: The uses of illuminative, semiotic and post-modern criticism as modes of inquiry in educational technology (pp. 93-106). Englewood Cliffs, NJ: Educational Technology Publications. (Reprinted from Performance \& Instruction, 20(7), 1981)

Davies, I. K. (1997). Paradigms and conceptual ISD systems. In C. R. Dills \& A. J. Romiszowski (Eds.), Instructional development paradigms (pp. 31-44). Englewood Cliffs, NJ: Educational Technology Publications. 
De Vaney, A., \& Butler, R. P. (1996). Voices of the founders: Early discourse in educational technology. In D. H. Jonassen (Ed.), Handbook of research for educational communications and technology (pp. 3-45). New York: Simon \& Schuster Macmillan.

Delprato, D. J., \& Midgley, D. D. (1992). Some fundamentals of B. F. Skinner's behaviorism. American Psychologist, 47(11), 1507-1520.

Di Vista, F. J. (1987). The cognitive movement and education. In J. A. Glover \& R. R. Ronning (Eds.), Historical foundations of educational psychology (pp. 203-233). New York: Plenum Press.

Dick, W. (1964). Programmed instruction over closed circuit television. In G. D. Ofiesh \& W. C. Meierhenry (Eds.), Trends in programmed instruction (pp. 251-253). Washington, DC: Department of Audiovisual Instruction, National Education Association of the United States.

Dick, W. (1987). A history of instructional design and its impact on educational psychology. In J. A. Glover \& R. R. Ronning (Eds.), Historical foundations of educational psychology (pp. 183-202). New York: Plenum Press.

Dijkstra, S. (2005). Cognition and instructional design for problem-based learning. In J. M. Spector, C. Ohrazda, A. Van Schaack \& D. A. Wiley (Eds.), Innovations in instructional technology: Essays in honor of M. David Merrill (pp. 187-206). Mahwah, NJ: Lawrence Erlbaum Associates.

du Boulay, B. (2000). Can we learn from ITSs? In G. Gauthier, C. Frasson \& K. VanLehn (Eds.), Intelligent tutoring systems: 5th international conference, ITS 2000, Montrâeal, Canada, June 19-23, 2000: Proceedings (pp. 9-17). New York: Springer.

Dutton, W. H., \& Riggs, C. W. (1969). Programmed instruction on graphs with implications for curriculum improvements. California Journal of Educational Research, 20(1), 8-15.

Edling, J. V. (1964). Programed instruction in a "Continuous progress" School—Provo, Utah. In J. V. Edling, A. W. Foshay, J. R. Ginther, J. Herbert, W. Schramm \& H. Thelen (Eds.), Four case studies of programed instruction (pp. 65-94). New York: Fund for the Advancement of Education. 
Edling, J. V., Foshay, A. W., Ginther, J. R., Herbert, J., Schramm, W., \& Thelen, H. (Eds.). (1964). Four case studies of programed instruction. New York: Fund for the Advancement of Education.

Ely, D. P. (1970). Toward a philosophy of instructional technology. Journal of Educational Technology, 1, 81-94.

Engvig, M. B. (1997). Professors' adoption and implementation of problem-based learning. Unpublished Thesis (Ph. D.), Stanford University, School of Education.

Ennis, R. H. (1982). Identifying implicit assumptions. Synthese, 51, 61-86.

Estarellas, J. (1966, April). Programmed TV instruction in a foreign language. Paper presented at the Fourth Annual Instructional Television Conference of the National Association of Educational Broadcasters, Santa Barbara, CA.

Evensen, D. H., \& Hmelo, C. E. (Eds.). (2000). Problem-based learning: A research perspective on learning interactions. Mahwah, NJ: Lawrence Erlbaum Associates.

Fairclough, N. (2003). Analysing discourse: Textual analysis for social research. New York: Routledge.

Finn, J. D. (1960a). Automation and education: Technology and the instructional process. Audiovisual Communication Review, 8(1), 5-26.

Finn, J. D. (1960b). Technology and the instructional process. In A. A. Lumsdaine \& R. Glaser (Eds.), Teaching machines and programmed learning: A source book (pp. 382-394). Washington, DC: National Education Association of the United States. (Reprinted from Audio-Visual Communication Review, 8(1), 1960)

Finn, J. D. (1963). Technological development: Its meaning for education in the 1970s. In R. T. Filep (Ed.), Prospectives in programing (pp. 193-204). New York: The Macmillan Company.

Foster, C. (1983). An analysis of the rise and fall of programmed instruction: Implications for computer-assisted instruction. Journal of Special Education Technology, 6(1), 5-14. 
Fuhrer, U. (1993). Behavior setting analysis of situated learning: The case of newcomers. In S. Chaiklin \& J. Lave (Eds.), Understanding practice: Perspectives on activity and context (pp. 179-211). New York: Cambridge University Press.

Gagné, R. M. (1965). The analysis of instructional objectives for the design of instruction. In R. Glaser (Ed.), Teaching machines and programmed learning II: Data and directions (pp. 21-65). Washington, DC: National Education Association of the United States.

Garner, W. L. (1966). Programed instruction. New York: The Center for Applied Research in Education, Inc.

Gee, J. P. (1996). Social linguistics and literacies: Ideology in discourse (2nd ed.). Bristol, PA: Taylor \& Francis Inc.

Gee, J. P. (2003). What video games have to teach us about learning and literacy. New York: Palgrave Macmillan.

Gee, J. P. (2005). An introduction to discourse analysis: Theory and method (2nd ed.). New York: Routledge.

Gentry, C. G. (1995). Educational technology: A question of meaning. In G. J. Anglin (Ed.), Instructional technology: Past, present, and future (pp. 1-10). Englewood, CO: Libraries Unlimited, Inc. (Reprinted from Educational media and technology yearbook, 1987, Littleton, CO: Libraries Unlimited)

Gentry, C. G., \& Csete, J. (1995). Educational technology in the 1990s. In G. J. Anglin (Ed.), Instructional technology: Past, present, and future (pp. 20-33). Englewood, CO: Libraries Unlimited, Inc.

Gerard, R. W. (1969). Shaping the mind: Computers in education. In R. C. Atkinson \& H. A. Wilson (Eds.), Computer-assisted instruction: A book of readings (pp. 1539). New York: Academic Press.

Gibbons, A. S. (2001). Model-centered instruction. Journal of Structural Learning and Intelligent Systems, 14, 511-540.

Gibbons, A. S. (2003a). The practice of instructional technology: Science and technology. Educational Technology, 43(5), 11-16. 
Gibbons, A. S. (2003b). What and how do designers design? A theory of design structure. TechTrends, 47(5), 22-27.

Gibbons, A. S., \& Brewer, E. K. (2005). Elementary principles of design languages and design notation systems for instructional design. In J. M. Spector, C. Ohrazda, A. Van Schaack \& D. A. Wiley (Eds.), Innovations in instructional technology: Essays in honor of M. David Merrill (pp. 111-130). Mahwah, NJ: Lawrence Erlbaum Associates.

Gibbons, A. S., \& Fairweather, P. G. (2000). Computer-based instruction. In S. Tobias \& J. D. Fletcher (Eds.), Training and retraining: A handbook for business, industry, government, and the military. New York: Macmillan Library Reference.

Gibbons, A. S., \& McDonald, J. K. (2005). Technological gravity. Paper presented at the Global Chinese Conference on Computers in Education 2005 (GCCCE 2005), Laie, HI.

Gibbons, A. S., Nelson, J., \& Richards, R. (2000). The nature and origin of instructional objects. In D. A. Wiley (Ed.), The instructional use of learning objects.

Bloomington, IN: Association for Educational Communications and Technology.

Gilbert, T. F. (1960). On the relevance of laboratory investigation of learning to selfinstructional programming. In A. A. Lumsdaine \& R. Glaser (Eds.), Teaching machines and programmed learning: A source book (pp. 475-485). Washington, DC: National Education Association of the United States.

Gilbert, T. F. (1996). Human competence: Engineering worthy performance. Silver Spring, MD: International Society for Performance Improvement.

Glaser, R. (1970). The education of individuals. In V. M. Howes (Ed.), Individualization of instruction: A teaching strategy (pp. 128-135). New York: Macmillan.

Glaser, R. (1977). Adaptive education: Individual diversity and learning. New York: Holt, Rinehart and Winston.

Glaser, R. (Ed.). (1965). Teaching machines and programmed learning II: Data and directions. Washington, DC: National Education Association of the United States. 
Glew, R. H. (2003). The problem with problem-based medical education: Promises not kept. Biochemistry and Molecular Biology Education, 31(1), 52-56.

Goldstone, R. L. (2006). The complex systems see-change in education. The Journal of the Learning Sciences, 15(1), 35-43.

Goodlad, J. I. (1984). A place called school: Prospects for the future. New York: McGraw-Hill Book Company.

Gordon, J., \& Zemke, R. (2000). The attack on ISD. Training, 37(4), 42-53.

Gotkin, L. G., \& McSweeney, J. (1967). Learning from teaching machines. In P. C. Lange (Ed.), Programed instruction: The sixty-sixth yearbook of the National Society for the Study of Education, part II (pp. 255-283). Chicago: The University of Chicago Press.

Gropper, G. L. (1964). What should be programmed for television? In G. D. Ofiesh \& W. C. Meierhenry (Eds.), Trends in programmed instruction (pp. 263-266). Washington, DC: Department of Audiovisual Instruction, National Education Association of the United States.

Guba, E. G. (1981). Criteria for assessing the trustworthiness of naturalistic inquiries. Educational Communication and Technology Journal, 29(2), 75-91.

Gustafson, K. L., \& Branch, R. M. (1997). Revisioning models of instructional development. Educational Technology Research and Development, 45(3), 73-89.

Häkkinen, P. (2002). Challenges for design of computer-based learning environments. British Journal of Educational Technology, 33(4), 461-469.

Hamblin, A. C. (1974). Evaluation and control of training. London: McGraw-Hill.

Hara, N. (2000). Social construction of knowledge in professional communities of practice. Unpublished Dissertation, Indiana University, Bloomington.

Harden, R. M., \& Davis, M. H. (1998). The continuum of problem-based learning. Medical Teacher, 20(4), 317-322. 
Heestand, D. E., Templeton, B. B., \& Adams, B. D. (1989). Responding to perceived needs of the twenty-first century: A case study in curriculum design. Medical Teacher, 11(2), 157-167.

Heinich, R. (1995). The proper study of instructional technology. In G. J. Anglin (Ed.), Instructional technology: Past, present, and future (pp. 61-83). Englewood, CO: Libraries Unlimited, Inc. (Reprinted from Educational Communications and Technology Journal, 33(1), 1984)

Herreid, C. F. (2003). The death of problem-based learning? Journal of College Science Teaching, 32(3), 364-366.

Hill, J. R., Wiley, D. A., Nelson, L. M., \& Han, S. (2004). Exploring research on internetbased learning: From infrastructure to interactions. In D. H. Jonassen (Ed.), Handbook of research on educational communications and technology (2nd ed., pp. 433-460). Mahwah, N.J.: Lawrence Erlbaum.

Hlynka, D., \& Nelson, B. (1985). Educational technology as metaphor. Programmed Learning and Educational Technology, 22(1), 7-15.

Hmelo-Silver, C. E., \& Azevedo, R. (2006). Understanding complex systems: Some core challenges. The Journal of the Learning Sciences, 15(1), 53-61.

Hoadley, C. M. (2004). Learning and design: Why the learning sciences and instructional systems need each other. Educational Technology, 44(3), 6-12.

Hoban, C. F. (1996). A systems approach to audio-visual communications: The Okoboji 1956 keynote address. In D. P. Ely \& T. Plomp (Eds.), Classic writings on instructional technology (pp. 57-64). Englewood, CO: Libraries Unlimited. (Reprinted from Okoboji: A 20 year review of leadership 1955-1974, Cochran, L. W. (Ed.), 1977, Kendall/Hunt: Dubuque, IA)

Hockings, C. (2004). Practising what we preach? Contradictions between pedagogy and practice in the move to problem-based learning. In M. Savin-Baden \& K. Wilkie (Eds.), Challenging research in problem-based learning (pp. 69-80). New York: Open University Press.

Hodges, D. C. (1998). Participation as dis-identification with/in a community of practice. Mind, Culture, and Activity, 5(4), 272-290. 
Horvath, J. A. (1999). Tacit knowledge in the professions. In R. J. Sternberg \& J. A. Horvath (Eds.), Tacit knowledge in professional practice (pp. ix-xiii). Mahwah, NJ: Lawrence Erlbaum Associates.

Hoth, W. E. (1964). From Skinner to Crowder to chance: A primer on teaching machines. In A. de Grazia \& D. A. Sohn (Eds.), Programs, teachers, and machines (pp. 193197). New York: Bantam Books. (Reprinted from the English Journal, September 1961)

Hough, J. (1973). Instruction. In J. R. Frymier (Ed.), A school for tomorrow (pp. 129167). Berkeley, CA: McCutchan Pub. Corp.

Howell, M., \& Prevenier, W. (2001). From reliable sources: An introduction to historical methods. Ithaca, NY: Cornell University Press.

Hug, W. E., \& King, J. E. (1984). Educational interpretations of general systems theory. In R. K. Bass \& C. R. Dills (Eds.), Instructional development: The state of the art (Vol. 2, pp. 18-28). Dubuque, IA: Kendall/Hunt Publishing.

Hung, D. W. L. (1999). Activity, apprenticeship, and epistemological appropriation: Implications from the writings of Michael Polanyi. Educational Psychologist, 34(4), 193-205.

Hutchins, E. (1996). Learning to navigate. In S. Chaiklin \& J. Lave (Eds.), Understanding practice: Perspectives on activity and context (pp. 35-63). New York: Cambridge University Press.

Inouye, D. K., Merrill, P. F., \& Swan, R. H. (2005). Help: Toward a new ethics-centered paradigm for instructional design and technology [Electronic Version]. IDT Record. Retrieved August 26, 2006 from http://www.indiana.edu/ idt/articles/documents/Inouye_print_version.pdf.

International Society for Performance Improvement San Antonio Chapter. (n.d.). The history of ISPI. Retrieved August 26, 2006, from http://www.icodap.org/ispi/ispihist.htm

Jacobson, M. J., \& Wilensky, U. (2006). Complex systems in education: Scientific and educational importance and implications for the learning sciences. The Journal of the Learning Sciences, 15(1), 11-34. 
Januszewski, A. (1996). History in educational technology. Paper presented at the annual meeting of the Association for Educational Communications and Technology, Indianapolis, IN.

Januszewski, A. (1999). Problem-based learning: A historical analysis. Paper presented at the annual meeting of the Association for Educational Communications and Technology, Houston, TX.

Januszewski, A. (2001). Educational technology: The development of a concept. Englewood, CO: Libraries Unlimited, Inc.

Januszewski, A., \& Koetting, J. R. (1998). Debunking the conspiracy theory: Understanding ideology in explanations in historical studies of educational technology. TechTrends, 43(1), 33-36.

Johnson, C. M. (2001). A survey of current research on online communities of practice. The Internet and Higher Education, 4(1), 45-60.

Jonassen, D. H. (1991). Objectivism versus constructivism: Do we need a new philosophical paradigm? Educational Technology, Research and Development, 39(3), 5-14.

Jonassen, D. H. (1994). Technology as cognitive tools: Learners as designers. Retrieved August 26, 2006, from http://itech1.coe.uga.edu/itforum/paper1/paper1.html

Jonassen, D. H. (2005). Problem solving: The enterprise. In J. M. Spector, C. Ohrazda, A. Van Schaack \& D. A. Wiley (Eds.), Innovations in instructional technology: Essays in honor of M. David Merrill (pp. 91-110). Mahwah, NJ: Lawrence Erlbaum Associates.

Jonassen, D. H., Hennon, R. J., Ondrusek, A., Samouilova, M., Spaulding, K. L., Yueh, H. P., et al. (1997). Certainty, determinism, and predictability in theories of instructional design: Lessons from science. Educational Technology, 37(1), 2734.

Kaestle, C. F. (1992). Standards of evidence in historical research: How do we know when we know? History of Education Quarterly, 32(3), 361-366. 
Kaufman, A., Mennin, S., Waterman, R., Duban, S., Hansbarger, C., Silverblatt, H., et al. (1989). The New Mexico experiment: Educational innovation and institutional change. Academic Medicine, 64, 285-294.

Kays, E. J. (2003). Architecture and instructional design: A conceptual model for elearning. Unpublished Dissertation (PhD), Capella University, School of Education.

Keating, E., \& Egbert, M. (2004). Conversation as a cultural activity. In A. Duranti (Ed.), A companion to linguistic anthropology (pp. 169-196). Malden, MA: Blackwell Publishing Ltd.

Keislar, E. R. (1959). The development of understanding in arithmetic by a teaching machine. Journal of Educational Psychology, 50(6), 247-253.

Kendall, G., \& Wickham, G. (2001). Understanding culture: Cultural studies, order, ordering. London: SAGE Publishing, Ltd.

Kirby, J. A., Hoadley, C. M., \& Carr-Chellman, A. A. (2005). Instructional systems design and the learning sciences: A citation analysis. Educational Technology Research and Development, 53(1), 37-48.

Kirschner, S. R. (2005). Toward critical openness. In B. D. Slife, J. S. Reber \& F. C. Richardson (Eds.), Critical thinking about psychology: Hidden assumptions and plausible alternatives (pp. 267-277). Washington, DC: American Psychological Association.

Klaus, D. J. (1964). Programming the impossible. In G. D. Ofiesh \& W. C. Meierhenry (Eds.), Trends in programmed instruction (pp. 19-23). Washington, DC: Department of Audiovisual Instruction, National Education Association of the United States.

Koetting, J. R., \& Malisa, M. (2004). Philosophy, research, and education. In D. H. Jonassen (Ed.), Handbook of research on educational communications and technology (2nd ed., pp. 1009-1020). Mahwah, N.J.: Lawrence Erlbaum.

Kovalik, C. L. (1999). Technology integration and problem-based learning: Implications for teaching and learning. Unpublished Thesis (Ph. D.), Kent State University, School of Education. 
Kozma, R. B. (1994). Will media influence learning? Reframing the debate. Educational Technology Research and Development, 42(2), 7-20.

Kulik, J. A., Cohen, P. A., \& Ebeling, B. J. (1980). Effectiveness of programmed instruction in higher education: A meta-analysis of findings. Educational Evaluation and Policy Analysis, 2(6), 51-64.

Lave, J. (1991). Situated learning in communities of practice. In L. B. Resnick, J. M. Levine \& S. Teasley (Eds.), Perspectives on socially shared cognition (pp. 6382). Washington, DC: American Psychological Association.

Lave, J., \& Wenger, E. (1991). Situated learning: Legitimate peripheral participation. New York: Cambridge University Press.

Lawson, D. R. (1969). Who thought of it first? A review of historical references to programmed instruction. Educational Technology, 9(5), 93-96.

Lee, I. S. (2002). Educational technology and systems science: Looking back and looking ahead. Paper presented at the 46th Annual Meeting of the International Society for the Systems Sciences, Shanghai, P. R. China.

Lesser, E. L., \& Storck, J. (2001). Communities of practice and organizational performance. IBM Systems Journal, 40(4), 831-841.

Levine, J. M., \& Moreland, R. L. (1991). Culture and socialization in work groups. In L. B. Resnick, J. M. Levine \& S. Teasley (Eds.), Perspectives on socially shared cognition (pp. 257-279). Washington, DC: American Psychological Association.

Lian, A. (2000). Knowledge transfer and technology in education: Toward a complete learning environment. Educational Technology \& Society, 3(3), 13-22.

Lockee, B., Moore, D. M., \& Burton, J. (2004). Foundations of programmed instruction. In D. H. Jonassen (Ed.), Handbook of research on educational communications and technology (2nd ed., pp. 545-569). Mahwah, N.J.: Lawrence Erlbaum.

Lumsdaine, A. A. (1960). Teaching machines: An introductory overview. In A. A. Lumsdaine \& R. Glaser (Eds.), Teaching machines and programmed learning: A source book (pp. 5-22). Washington, DC: National Education Association of the 
United States. (Reprinted from Audio-Visual Communication Review, Summer 1959)

Lumsdaine, A. A. (1964). Educational technology, programed learning, and instructional science. In E. R. Hilgard (Ed.), Theories of learning and instruction: The sixtythird yearbook of the National Society for the Study of Education (pp. 371-401). Chicago: The National Society for the Study of Education.

Lysaught, J. P., \& Williams, C. M. (1963). A guide to programmed instruction. New York: Wiley.

Margetson, D. (1998). What counts as problem-based learning? Education in Health: Change in Learning and Practice, 11(2), 193-201.

Markle, S. M. (1964). Individualizing programed instruction: The programer's part. In A. de Grazia \& D. A. Sohn (Eds.), Programs, teachers, and machines (pp. 145-158). New York: Bantam Books.

Markle, S. M. (1967). Empirical testing of programs. In P. C. Lange (Ed.), Programed instruction: The sixty-sixth yearbook of the National Society for the Study of Education, part II (pp. 104-138). Chicago: The University of Chicago Press.

Markle, S. M. (1969). Good frames and bad: A grammar of frame writing (2nd ed.). New York: John Wiley \& Sons, Inc.

Maudsley, G. (1999). Do we all mean the same thing by "Problem-based learning"? A review of the concepts and a formulation of the ground rules. Academic Medicine, 74(2), 178-185.

McDonald, J. K., Yanchar, S. C., \& Osguthorpe, R. T. (2005). Learning from programmed instruction: Examining implications for modern instructional technology. Educational Technology Research and Development, 53(2), 84-98.

McIsaac, M. S., \& Gunawardena, C. N. (1996). Distance education. In D. H. Jonassen (Ed.), Handbook of research for educational communications and technology (pp. 403-437). New York: Simon \& Schuster Macmillan. 
Mechner, F. (1977). A new approach to programmed instruction. Retrieved August 26, 2006, from http://mechnerfoundation.org/pdf_downloads/programmed_instruction.pdf

Merriam, S. B. (1998). Qualitative research and case study applications in education. San Francisco: Jossey-Bass Publishers.

Merrick, E. (1999). An exploration of quality in qualitative research: Are "Reliability" And "Validity" Relevant? In M. Kopala \& L. A. Suzuki (Eds.), Using qualitative methods in psychology (pp. 25-36). Thousand Oaks, CA: SAGE Publications, Inc.

Merrill, M. D. (1997, Nov/Dec). Instructional strategies that teach. CBT Solutions, 1-11.

Merrill, M. D. (Ed.). (1971). Instructional design: Readings. Englewood Cliffs, NJ: Prentice-Hall.

Merrill, M. D., Drake, L., Lacy, M. J., Pratt, J. A., \& The $\mathrm{ID}_{2}$ Research Group at Utah State University. (1996). Reclaiming instructional design. Educational Technology, 36(5), 5-7.

Merrill, M. D., \& Twitchell, D. (1994). Instructional design theory. Englewood Cliffs, NJ: Educational Technology Publications.

Merrill, M. D., \& Wilson, B. G. (2007). The future of instructional design (point/counterpoint). In R. A. Reiser \& J. V. Dempsey (Eds.), Trends and issues in instructional design and technology (2nd ed.). Upper Saddle River, NJ: Pearson Education, Inc.

Meyer, S. R. (1960). Report on the initial test of a junior high-school vocabulary program. In A. A. Lumsdaine \& R. Glaser (Eds.), Teaching machines and programmed learning: A source book (pp. 229-246). Washington, DC: National Education Association of the United States.

Minstrell, J. (1999). Expertise in teaching. In R. J. Sternberg \& J. A. Horvath (Eds.), Tacit knowledge in professional practice (pp. 215-230). Mahwah, NJ: Lawrence Erlbaum Associates.

Mitchell, P. D. (1989). The future of educational technology is past. Canadian Journal of Educational Communication, 18(1), 3-27. 
Mitzel, H. E. (1974). The impending instructional revolution. In M. Mohan \& R. E. Hull (Eds.), Individualized instruction and learning (pp. 67-83). Chicago: Nelson-Hall Co. (Reprinted from Phi Delta Kappan, 1970)

Molenda, M. (1997). Historical and philosophical foundations of instructional design: A North American view. In R. D. Tennyson, F. Schott, N. M. Seel \& S. Dijkstra (Eds.), Instructional design: International perspectives (Vol. 1: Theory, Research, and Models). Mahwah, NJ: Lawrence Erlbaum Associates.

Molenda, M. (2003). In search of the elusive ADDIE model. Performance Improvement, 42(5), 34-36.

Morgan, M. (2004). Speech community. In A. Duranti (Ed.), A companion to linguistic anthropology (pp. 3-22). Malden, MA: Blackwell Publishing Ltd.

Morgan, R. M. (1978). Educational technology: Adolescence to adulthood. Educational Communication and Technology Journal, 26(2), 142-152.

Morrell, E. (2003). Legitimate peripheral participation as professional development: Lessons from a summer research seminar. Teacher Education Quarterly, 30(2), 89-99.

Nash, A. N., Muczyk, J. P., \& Vettori, F. L. (1971). The relative practical effectiveness of programmed instruction. Personnel Psychology, 24(3), 397-418.

Nelson, W. A., Magliaro, S., \& Sherman, T. M. (1988). The intellectual content of instructional design. Journal of Instructional Development, 11(1), 29-35.

Neufeld, V., \& Barrows, H. S. (1978). The 'McMaster philosophy': An approach to medical education. In J. Hartley \& I. K. Davies (Eds.), Contributions to an educational technology (Vol. 2, pp. 313-324). New York: Crane, Russak \& Company, Inc. (Reprinted from the Journal of Medical Education, 49(11), 10401050, 1974)

Nichols, R. G. (1991). Toward a conscience: Negative aspects of educational technology. In D. Hlynka \& J. C. Belland (Eds.), Paradigms regained: The uses of illuminative, semiotic and post-modern criticism as modes of inquiry in educational technology (pp. 121-137). Englewood Cliffs, NJ: Educational Technology Publications. (Reprinted from Journal of Visual/Verbal Learning, $7(1), 1987)$ 
Osguthorpe, R. T., \& Osguthorpe, R. D. (2002). Re-examining the foundations of instructional design: Toward a conscience of craft. Paper presented at the annual meeting of the Association for Educational Communications and Technology, Dallas, TX.

Osguthorpe, R. T., Osguthorpe, R. D., Jacob, W. J., \& Davies, R. (2003). The moral dimensions of instructional design. Educational Technology, 43(2), 19-23.

Osguthorpe, R. T., \& Zhou, L. (1989). Instructional science: What is it and where did it come from? Educational Technology, 29(6), 7-17.

Pask, G. (1960). Adaptive teaching with adaptive machines. In A. A. Lumsdaine \& R. Glaser (Eds.), Teaching machines and programmed learning: A source book (pp. 349-366). Washington, DC: National Education Association of the United States.

Pfeffer, J., \& Sutton, R. I. (2000). The knowing-doing gap: How smart companies turn knowledge into action. Boston, MA: Harvard Business School Press.

Pipe, P. (1966). Practical programming. New York: Holt, Rinehart, and Winston, Inc.

Pogner, K. H. (2005). Discourse communities and communities of practice: On the social context of text and knowledge production in the workplace. Paper presented at the 21st EGOS Colloquium, Berlin, Germany.

Polanyi, M. (1962). Personal knowledge: Towards a post-critical philosophy (Corrected ed.). Chicago: University of Chicago Press.

Post, D. (1972). Up the programmer: How to stop PI from boring learners and strangling results. Educational Technology, 12(8), 14-17.

Reber, A. S. (1989). Implicit learning and tacit knowledge. Journal of Experimental Psychology: General, 118(3), 219-235.

Reeves, T. C. (1995). Questioning the questions of instructional technology research. Retrieved August 26, 2006, from http://itech1.coe.uga.edu/itforum/paper5/paper5b.html 
Reeves, T. C., Herrington, J., \& Oliver, R. (2004). A development research agenda for online collaborative learning. Educational Technology Research and Development, 52(4), 53-65.

Reigeluth, C. M. (1997). Instructional theory, practitioner needs, and new directions: Some reflections. Educational Technology, 37(1), 42-47.

Reigeluth, C. M. (2001). What every AECT member needs to know about systemic change: The beginning of a dialogue. TechTrends, 46(1), 12-15.

Reiser, R. A. (1987). Instructional technology: A history. In R. M. Gagné (Ed.), Instructional technology: Foundations (pp. 11-48). Hillsdale, NJ: L. Erlbaum Associates.

Reiser, R. A. (2001a). A history of instructional design and technology: Part I: A history of instructional media. Educational Technology Research and Development, 49(1), 53-64.

Reiser, R. A. (2001b). A history of instructional design and technology: Part II: A history of instructional design. Educational Technology Research and Development, 49(2), 57-67.

Reiser, R. A., \& Ely, D. P. (1997). The field of educational technology as reflected through its definitions. Educational Technology Research and Development, 45(3), 63-72.

Rogers, E. M. (2003). Diffusion of innovations (5th ed.). New York: Free Press.

Romiszowski, A. J. (1981). Designing instructional systems: Decision making in course planning and curriculum design. New York: Nichols Publishing.

Romiszowski, A. J. (1996). Systems approach to design and development. In T. Plomp \& D. P. Ely (Eds.), International encyclopedia of educational technology (2nd ed., pp. 37-43). New York: Pergamon.

Roschelle, J. (1992). What should collaborative technology be? A perspective from Dewey and situated learning. Sigcue Outlook, 21(3), 39-42. 
Rosenberg, M. J., Coscarelli, W. C., \& Hutchinson, C. S. (1999). The origins and evolution of the field. In H. D. Stolovitch \& E. J. Keeps (Eds.), Handbook of human performance technology: Improving individual and organizational performance worldwide (2nd ed., pp. 24-46). San Francisco: Jossey-Bass.

Ross, J., \& Schulz, R. (1999). Can computer-aided instruction accommodate all learners equally? British Journal of Educational Technology, 30(1), 5-24.

Roth, R. H. (1963). Student reactions to programed learning. Phi Delta Kappan, 44, 278281.

Rowland, G. (1993). Designing and instructional design. Educational Technology Research and Development, 41(1), 79-91.

Saettler, L. P. (1990). The evolution of American educational technology. Englewood, CO: Libraries Unlimited.

Salomon, G. (2002). Technology and pedagogy: Why don't we see the promised revolution? Educational Technology, 42(2), 71-75.

Savin-Baden, M. (2000). Problem-based learning in higher education: Untold stories. Philadelphia: Open University Press.

Schlager, M. S., \& Fusco, J. (2004). Teacher professional development, technology, and communities of practice: Are we putting the cart before the horse? In S. A. Barab, R. Kling \& J. H. Gray (Eds.), Designing for virtual communities in the service of learning (pp. 120-153). New York: Cambridge University Press.

Schön, D. A. (1987). Educating the reflective practitioner: Toward a new design for teaching and learning in the professions. San Francisco: Jossey-Bass.

Schor, N. F. (2001). No money where your mouth is. In P. Schwartz, M. Stewart \& G. Webb (Eds.), Problem-based learning: Case studies, experience and practice (pp. 20-26). Sterling, VA: Stylus Publishing Inc.

Schramm, W. (1962). Programed instruction: Today and tomorrow: The Fund for the Advancement of Education. 
Schramm, W. (1964a). Programed instruction in Denver. In J. V. Edling, A. W. Foshay, J. R. Ginther, J. Herbert, W. Schramm \& H. Thelen (Eds.), Four case studies of programed instruction (pp. 29-40). New York: Fund for the Advancement of Education.

Schramm, W. (1964b). The research on programed instruction: An annotated bibliography (No. OE-31034). Washington, DC: U.S. Department of Health, Education, and Welfare, Office of Education.

Schuller, C. F. (1986). Some historical perspectives on the instructional technology field. Journal of Instructional Development, 8(3), 3-6.

Schwartz, P., Stewart, M., \& Webb, G. (Eds.). (2001). Problem-based learning: Case studies, experience and practice. Sterling, VA: Stylus Publishing Inc.

Schwen, T. M., \& Hara, N. (2004). Community of practice: A metaphor for online design? In S. A. Barab, R. Kling \& J. H. Gray (Eds.), Designing for virtual communities in the service of learning (pp. 154-178). New York: Cambridge University Press.

Schwen, T. M., Leitzman, D., F., Misanchuk, E. R., Foshay, W. R., \& Heitland, K. M. (1984). Instructional development: The social implications of technical interventions. In R. K. Bass \& C. R. Dills (Eds.), Instructional development: The state of the art (Vol. 2, pp. 40-50). Dubuque, IA: Kendall/Hunt Publishing.

Schwier, R. A., Campbell, K., \& Kenny, R. (2004). Instructional designers' observations about identity, communities of practice and change agency [Electronic Version]. Australasian Journal of Educational Technology, 69-100. Retrieved August 26, 2006 from http://www.ascilite.org.au/ajet/ajet20/schwier.html.

Seawright, L. L., \& Williams, D. D. (2006, November). Implications of evaluation in instructional design. Paper presented at the Evaluation 2006 conference, Portland, OR.

Sfard, A. (1998). On two metaphors for learning and the dangers of choosing just one. Educational Researcher, 27(2), 4-13.

Sherwin, M. R. (1972). A comparison of criteria utilized by companies publishing elementary programmed reading materials and educators' opinions of the proper 
criteria. Unpublished Thesis (Ph. D.), Brigham Young University, Department of Elementary Curriculum and Instruction.

Shrock, S. A. (1995). A brief history of instructional development. In G. J. Anglin (Ed.), Instructional technology: Past, present, and future (pp. 11-19). Englewood, CO: Libraries Unlimited, Inc.

Silber, K. H. (1972). The learning system. Audiovisual Instruction, 17(7), 10-27.

Sims, R. (2006). Beyond instructional design: Making learning design a reality. Journal of Learning Design, 1(2), 1-8.

Skinner, B. F. (1954). The science of learning and the art of teaching. Harvard Educational Review, 24(1), 86-97.

Skinner, B. F. (1958). Teaching machines. Science, 128, 969-977.

Skinner, B. F. (1959). The programming of verbal knowledge. In E. Galanter (Ed.), Automatic teaching: The state of the art (pp. 63-68). New York: John Wiley \& Sons, Inc.

Skinner, B. F. (1961). Why we need teaching machines. Harvard Educational Review, 31(4), 377-398.

Skinner, B. F. (1963). Operant behavior. American Psychologist, 18, 503-515.

Skinner, B. F. (1968). Reflections on a decade of teaching machines. In R. A. Weisgerber (Ed.), Instructional process and media innovation (pp. 404-417). Chicago: Rand McNally \& Company. (Reprinted from the Teachers College Record, November 1963)

Skinner, B. F. (1968). The technology of teaching. New York: Meredith Corporation.

Skinner, B. F. (1971). Beyond freedom and dignity. New York: Alfred A. Knopf.

Skinner, B. F. (1986, October). Programmed instruction revisited. Phi Delta Kappan, 68, 103-110. 
Skinner, B. F. (1989). Recent issues in the analysis of behavior. Columbus, OH: Merrill Publishing Company.

Skinner, B. F., \& Holland, J. G. (1960). The use of teaching machines in college instruction. In A. A. Lumsdaine \& R. Glaser (Eds.), Teaching machines and programmed learning: A source book (pp. 159-172). Washington, DC: National Education Association of the United States. (Reprinted from Science, October 1958)

Slife, B. D. (1998). Raising the consciousness of researchers: Hidden assumptions in the behavioral sciences. Adapted Physical Activity Quarterly, 15(3), 208-221.

Slife, B. D., \& Williams, R. N. (1995). What's behind the research: Discovering hidden assumptions in the behavioral sciences. Thousand Oaks, CA: SAGE Publications, Inc.

Slife, B. D., Yanchar, S. C., \& Reber, J. S. (2005). Thinking critically about critical thinking. In B. D. Slife, J. S. Reber \& F. C. Richardson (Eds.), Critical thinking about psychology: Hidden assumptions and plausible alternatives (pp. 3-14). Washington, DC: American Psychological Association.

Smith, P. L., \& Ragan, T. J. (2005). Instructional design (3rd ed.). Hoboken, NJ: John Wiley \& Sons, Inc.

Snelbecker, G. E. (1999). Some thoughts about theories, perfection, and instruction. In C. M. Reigeluth (Ed.), Instructional-design theories and models: A new paradigm of instructional theory (Vol. 2, pp. 31-47). Mahwah, NJ: Lawrence Erlbaum Associates, Publishers.

Solomon, D. L. (2000). Philosophical inquiry in instructional technology: The forgotten pathway to learning. Paper presented at the annual meeting of the Association for Educational Communications and Technology, Long Beach, CA.

Spector, J. M. (2000). Towards a philosophy of instruction. Educational Technology \& Society, 3(3), 522-525.

Spector, J. M. (2001). A philosophy of instructional design for the 21st century? Journal of Structural Learning and Intelligent Systems, 14, 307-318. 
Spiro, R. J., Collins, B. P., Thota, J. J., \& Feltovich, P. L. (2003). Cognitive flexibility theory: Hypermedia for complex learning, adaptive knowledge application, and experience acceleration. Educational Technology, 43(5), 5-10.

Stake, R. E. (1995). The art of case study research. Thousand Oaks, CA: Sage Publications.

Stake, R. E. (2000). Case studies. In N. K. Denzin \& Y. S. Lincoln (Eds.), The handbook of qualitative research (2nd ed., pp. 435-454). Thousand Oaks, CA: Sage Publications.

Stake, R. E. (2004). Standards-based \& responsive evaluation. Thousand Oaks, CA: Sage Publications, Inc.

Stamps, D. (1997). Communities of practice: Learning is social. Training is irrelevant? Training, 34(2), 34-42.

Sternberg, R. J. (1999). What do we know about tacit knowledge? Making the tacit explicit. In R. J. Sternberg \& J. A. Horvath (Eds.), Tacit knowledge in professional practice (pp. 231-236). Mahwah, NJ: Lawrence Erlbaum Associates.

Sternberg, R. J., Wagner, R. K., Williams, W. M., \& Horvath, J. A. (1995). Testing common sense. American Psychologist, 50(11), 912-927.

Stiles, W. B. (1993). Quality control in qualitative research. Clinical Psychology Review, 13, 593-618.

Stinson, J. E., \& Milter, R. G. (1996). Problem-based learning in business education: Curriculum design and implementation issues. In L. Wilkerson \& W. H. Gijselaers (Eds.), Bringing problem-based learning to higher education: Theory and practice (Vol. 68, pp. 33-42). San Francisco: Jossey-Bass Publishers.

Storey, W. K. (2004). Writing history: A guide for students (2nd ed.). New York: Oxford University Press.

Stufflebeam, D. L. (2001). Evaluation models. San Francisco: Jossey-Bass Publishers. 
Suppes, P. (1969). Personalizing education through computers. In R. C. Atkinson \& H. A. Wilson (Eds.), Computer-assisted instruction: A book of readings (pp. 41-47). New York: Academic Press. (Reprinted from Phi Delta Kappan, 49(8), 420-423, 1968)

Surowiecki, J. (2004). The wisdom of crowds: Why the many are smarter than the few and how collective wisdom shapes business, economies, societies and nations. New York: Doubleday.

Swales, J. M. (1990). Genre analysis: English in academic and research settings. New York: Cambridge University Press.

Teigland, R. (2003). Knowledge networking: Structure and performance in networks of practice. Unpublished Dissertation, Stockholm School of Economics, Stockholm, Sweden.

Tennyson, R. D. (1994). The Big Wrench vs. Integrated approaches: The great media debate. Educational Technology Research and Development, 42(3), 15-28.

Tennyson, R. D. (1997). A system dynamics approach to instructional systems development. In R. D. Tennyson, F. Schott, N. M. Seel \& S. Dijkstra (Eds.), Instructional design: International perspectives (Vol. 1: Theory, Research, and Models, pp. 413-426). Mahwah, NJ: Lawrence Erlbaum and Associates.

Tennyson, R. D. (2000). Fourth generation instructional systems development: A problem solving approach. Journal of Structural Learning and Intelligent Systems, 14(3), 229-252.

Tennyson, R. D. (2005). Learning theories and instructional design: A historical perspective of the linking model. In J. M. Spector, C. Ohrazda, A. Van Schaack \& D. A. Wiley (Eds.), Innovations in instructional technology: Essays in honor of M. David Merrill (pp. 219-236). Mahwah, NJ: Lawrence Erlbaum Associates.

Torff, B. (1999). Tacit knowledge in teaching: Folk pedagogy. In R. J. Sternberg \& J. A. Horvath (Eds.), Tacit knowledge in professional practice (pp. 195-214). Mahwah, NJ: Lawrence Erlbaum Associates.

Torkelson, G. M. (1989). The future of educational technology is past-a reaction. Canadian Journal of Educational Communication, 18(2), 146-148. 
Torkelson, G. M. (1998). A history of AECT from a personal perspective. TechTrends, 43(1), 47-50.

Trimby, M. J., \& Gentry, C. G. (1984). State of ID systems approach models. In R. K. Bass \& C. R. Dills (Eds.), Instructional development: The state of the art (Vol. 2, pp. 80-93). Dubuque, IA: Kendall/Hunt Publishing.

Tripp, S. D. (1994). How should instructional designers be educated? Performance Improvement Quarterly, 7(3), 116-126.

Tyler, R. W. (1975). Have educational reforms since 1950 created quality education? Viewpoints, 51(2), 35-57.

Vernon, D. T. A., \& Blake, R. L. (1993). Does problem-based learning work? A metaanalysis of evaluative research. Academic Medicine, 68(7), 550-563.

Ward, J. D., \& Lee, C. L. (2002). A review of problem-based learning. Journal of Family and Consumer Sciences Education, 20(1), 16-26.

Wardle, E. (2004). Identity, authority, and learning to write in new workplaces [Electronic Version]. Enculturation. Retrieved August 26, 2006 from http://enculturation.gmu.edu/5_2/wardle.html.

Wasko, M., Faraj, S., \& Teigland, R. (2004). Collective action and knowledge contribution in electronic networks of practice. Journal of the Association for Information Systems, 5(11-12), 493-513.

Weimer, P. (1960). A proposed "Automatic" Teaching device. In A. A. Lumsdaine \& R. Glaser (Eds.), Teaching machines and programmed learning: A source book (pp. 311-317). Washington, DC: National Education Association of the United States. (Reprinted from the IRE Transactions on Education, E-1(2), June 1958)

Wenger, E. (1998). Communities of practice: Learning, meaning, and identity. New York: Cambridge University Press.

Wenger, E. (2000). Communities of practice and social learning systems. Organization, 7(2), 225-246. 
Wenger, E., \& Snyder, W. M. (2000). Communities of practice: The organizational frontier. Harvard Business Review, 78(1), 139-145.

Wiley, D. A. (2003). The coming collision between automated instruction and social constructivism. In C. M. Gynn \& S. R. Acker (Eds.), Learning objects: Contexts and connections (pp. 17-28). Columbus, OH: The Ohio State University.

Wiley, D. A., \& Edwards, E. K. (2002). Online self-organizing social systems: The decentralized future of online learning. The Quarterly Review of Distance Education, 3(1), 33-46.

Wilkerson, L., \& Gijselaers, W. H. (1996). Concluding comments. In L. Wilkerson \& W. H. Gijselaers (Eds.), Bringing problem-based learning to higher education: Theory and practice (Vol. 68, pp. 101-104). San Francisco: Jossey-Bass Publishers.

Williams, R. C. (2003). The historian's toolbox: A student's guide to the theory and craft of history. Armonk, NY: M. E. Sharpe, Inc.

Williams, R. N. (2005). The language and methods of science: Common assumptions and uncommon conclusions. In B. D. Slife, J. S. Reber \& F. C. Richardson (Eds.), Critical thinking about psychology: Hidden assumptions and plausible alternatives (pp. 235-249). Washington, DC: American Psychological Association.

Willis, J. (1995). A recursive, reflective instructional design model based on constructivist-interpretivist theory. Educational Technology, 35(6), 5-23.

Wilson, B. G. (1995). Metaphors for instruction: Why we talk about learning environments. Educational Technology, 35(5), 25-30.

Wilson, B. G. (1997). The postmodern paradigm. In C. R. Dills \& A. J. Romiszowski (Eds.), Instructional development paradigms (pp. 297-309). Englewood Cliffs, NJ: Educational Technology Publications.

Wilson, B. G. (1999). The dangers of theory-based design. Retrieved August 26, 2006, from http://itech1.coe.uga.edu/itforum/paper31/disc31.html 
Wilson, B. G. (2004). Designing e-Learning environments for flexible activity and instruction. Educational Technology Research and Development, 52(4), 77-84.

Wilson, B. G. (2005a). Broadening our foundation for instructional design: Four pillars of practice. Educational Technology, 45(2), 10-15.

Wilson, B. G. (2005b). Foundations for instructional design: Reclaiming the conversation. In J. M. Spector, C. Ohrazda, A. Van Schaack \& D. A. Wiley (Eds.), Innovations in instructional technology: Essays in honor of M. David Merrill (pp. 237-252). Mahwah, NJ: Lawrence Erlbaum Associates.

Wilson, B. G., \& Ryder, M. (1998). Distributed learning communities: An alternative to designed instructional systems. Retrieved August 26, 2006, from http://carbon.cudenver.edu/ bwilson/dlc.html

Winn, W. D. (1986). Trends and future directions in educational technology research from a North American perspective. Programmed Learning and Educational Technology, 23(4), 346-355.

Winn, W. D. (1988). The theoretical foundations of educational technology and future directions for the field. Paper presented at the annual meeting of the Association for Educational Communications and Technology, New Orleans, LA.

Winn, W. D. (1989). Revitalizing educational technology: A response to Mitchell. Canadian Journal of Educational Communication, 18(2), 149-152.

Winn, W. D. (1997). Advantages of a theory-based curriculum in instructional technology. Educational Technology, 37(1), 34-41.

Winn, W. D. (2004). Cognitive perspectives in psychology. In D. H. Jonassen (Ed.), Handbook of research on educational communications and technology (2nd ed., pp. 79-112). Mahwah, N.J.: Lawrence Erlbaum.

Yanchar, S. C., \& Hill, J. R. (2003). What is psychology about? Toward an explicit ontology. Journal of Humanistic Psychology, 43(1), 11-32.

Yanchar, S. C., \& Slife, B. D. (2004). Teaching critical thinking by examining assumptions. Teaching of Psychology, 31(2), 85-90. 
Yeaman, A. R. J. (1994). Deconstructing modern educational technology. Educational Technology, 34(2), 15-24.

Zemke, R., \& Armstrong, J. (1997). Training classics: Timeless rules for good instruction. Training, 34(9), 55-60.

Zemke, R., \& Rossett, A. (2002). A hard look at ISD. Training, 39(2), $26-34$. 